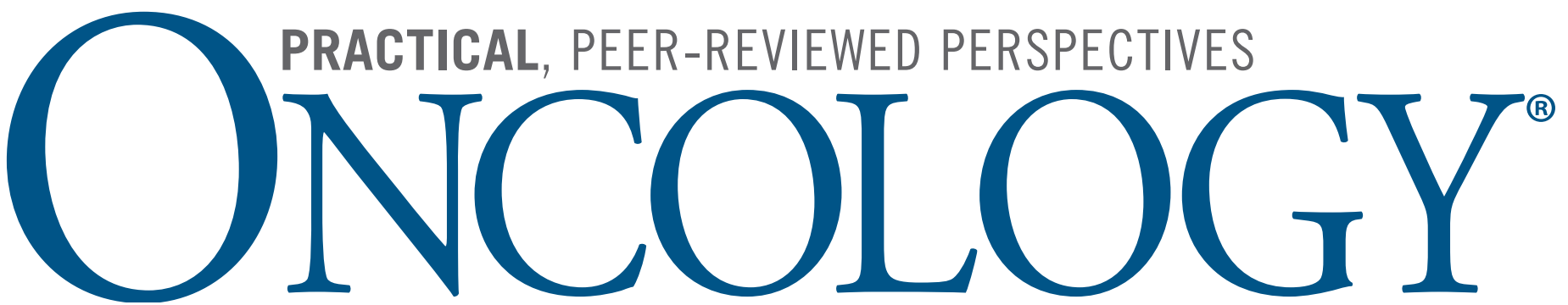

NOVEMBER 2021 | Vol 35 • No 11

\title{
PROSTATE CANCER
}

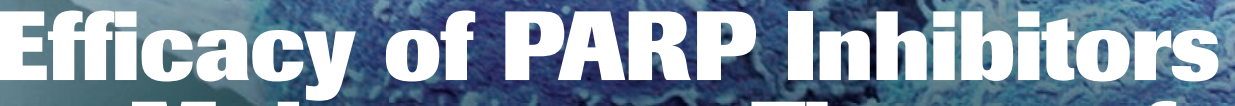

as Maintenance Therapy for

Metastatio Castratond esistants

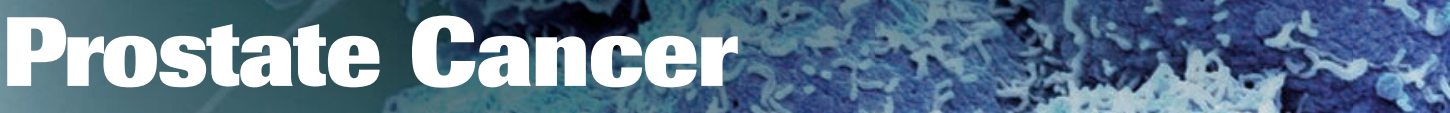

A Meta-Analysis of Randomized

Controlled Trials

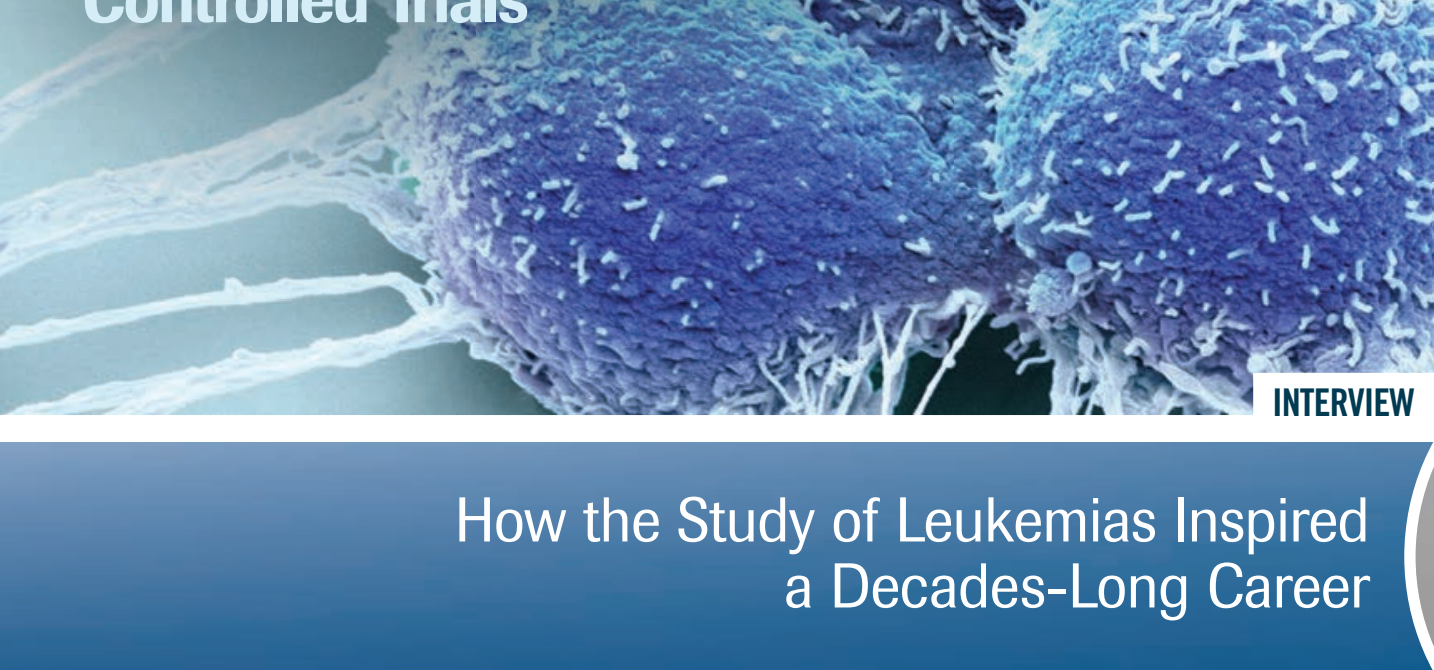

Central Nervous System Cancers A Rare

JORGE E. CORTES, MD

Case of Glioblastoma With Extensive

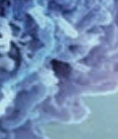

\section{Liver Metastases}

Cervical Cancer Treatment of Locally

Advanced Cervical Cancer With

Kidney Failure and Comorbidities

Gastrointestinal Cancers Abstracts From the

18th Annual Meeting of the International

Society of Gastrointestinal Oncology 


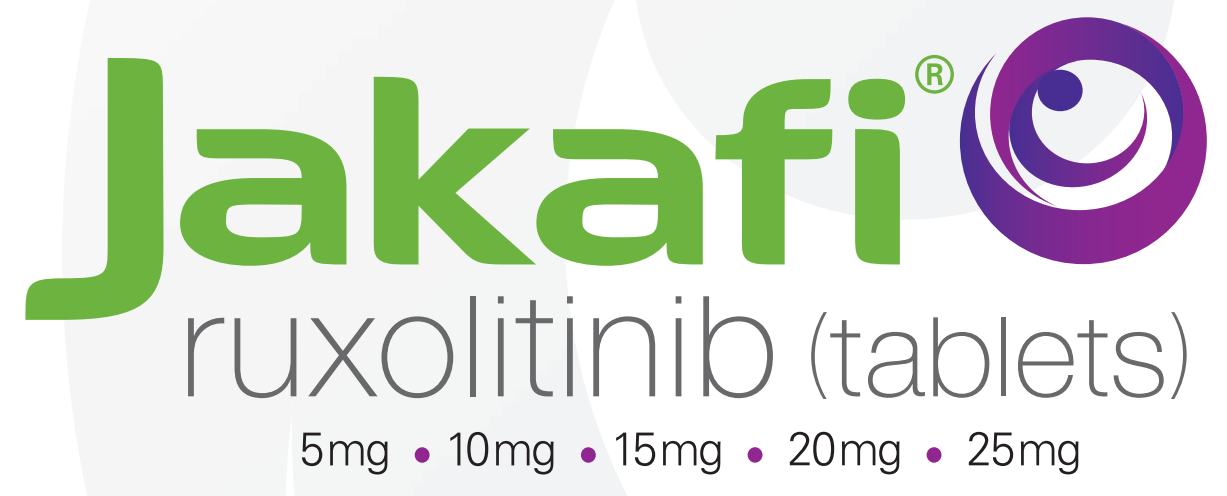

NOW APPROVED for Chronic Graft-Versus-Host Disease after failure of one or two lines of systemic therapy in adult and pediatric patients 12 years and older ${ }^{1}$

Scan code to visit hcp.jakafi.com to learn more 


\section{Indications and Usage}

Jakafi $^{\circledast}$ (ruxolitinib) is indicated for treatment of chronic graft-versus-host disease (cGVHD) after failure of one or two lines of systemic therapy in adult and pediatric patients 12 years and older.

\section{Important Safety Information}

- Treatment with Jakafi ${ }^{\circledast}$ (ruxolitinib) can cause thrombocytopenia, anemia and neutropenia, which are each dose-related effects. Perform a pre-treatment complete blood count (CBC) and monitor CBCs every 2 to 4 weeks until doses are stabilized, and then as clinically indicated

- Manage thrombocytopenia by reducing the dose or temporarily interrupting Jakafi. Platelet transfusions may be necessary

- Patients developing anemia may require blood transfusions and/or dose modifications of Jakafi

Severe neutropenia (ANC $<0.5 \times 10^{9} / \mathrm{L}$ ) was generally reversible by withholding Jakafi until recovery

- Serious bacterial, mycobacterial, fungal and viral infections have occurred. Delay starting Jakafi until active serious infections have resolved. Observe patients receiving Jakafi for signs and symptoms of infection and manage promptly. Use active surveillance and prophylactic antibiotics according to clinical guidelines

- Tuberculosis (TB) infection has been reported. Observe patients taking Jakafi for signs and symptoms of active TB and manage promptly. Prior to initiating Jakafi, evaluate patients for TB risk factors and test those at higher risk for latent infection. Consult a physician with expertise in the treatment of TB before starting Jakafi in patients with evidence of active or latent TB. Continuation of Jakafi during treatment of active TB should be based on the overall risk-benefit determination

Progressive multifocal leukoencephalopathy (PML) has occurred with Jakafi treatment. If PML is suspected, stop Jakafi and evaluate

- Advise patients about early signs and symptoms of herpes zoster and to seek early treatment

Increases in hepatitis B viral load with or without associated elevations in alanine aminotransferase and aspartate aminotransferase have been reported in patients with chronic hepatitis B virus (HBV) infections. Monitor and treat patients with chronic HBV infection according to clinical guidelines

- When discontinuing Jakafi, myeloproliferative neoplasm-related symptoms may return within one week. After discontinuation, some patients with myelofibrosis have experienced fever, respiratory distress, hypotension, DIC, or multi-organ failure. If any of these occur after discontinuation or while tapering Jakafi, evaluate and treat any intercurrent illness and consider restarting or increasing the dose of Jakafi. Instruct patients not to interrupt or discontinue Jakafi without consulting their physician. When discontinuing or interrupting Jakafi for reasons other than thrombocytopenia or neutropenia, consider gradual tapering rather than abrupt discontinuation

- Non-melanoma skin cancers (NMSC) including basal cell, squamous cell, and Merkel cell carcinoma have occurred. Perform periodic skin examinations

- Treatment with Jakafi has been associated with increases in total cholesterol, low-density lipoprotein cholesterol, and triglycerides. Assess lipid parameters 8-12 weeks after initiating Jakafi. Monitor and treat according to clinical guidelines for the management of hyperlipidemia

Another JAK-inhibitor has increased the risk of major adverse cardiovascular events (MACE), including cardiovascular death, myocardial infarction, and stroke (compared to those treated with tumor TNF blockers) in patients with rheumatoid arthritis, a condition for which Jakafi is not indicated. Consider the benefits and risks for the individual patient prior to initiating or continuing therapy with Jakafi particularly in patients who are current or past smokers and patients with other cardiovascular risk factors. Patients should be informed about the symptoms of serious cardiovascular events and the steps to take if they occur

- Another JAK-inhibitor has increased the risk of thrombosis, including deep venous thrombosis (DVT), pulmonary embolism (PE), and arterial thrombosis (compared to those treated with TNF blockers) in patients with rheumatoid arthritis, a condition for which Jakafi is not indicated. In patients with myelofibrosis (MF) and polycythemia vera (PV) treated with Jakafi in clinical trials, the rates of thromboembolic events were similar in Jakafi and control treated patients. Patients with symptoms of thrombosis should be promptly evaluated and treated appropriately

- Another JAK-inhibitor has increased the risk of lymphoma and other malignancies excluding NMSC (compared to those treated with TNF blockers) in patients with rheumatoid arthritis, a condition for which Jakafi is not indicated. Patients who are current or past smokers are at additional increased risk. Consider the benefits and risks for the individual patient prior to initiating or continuing therapy with Jakafi, particularly in patients with a known secondary malignancy (other than a successfully treated NMSC), patients who develop a malignancy, and patients who are current or past smokers

- In myelofibrosis and polycythemia vera, the most common nonhematologic adverse reactions (incidence $\geq 15 \%$ ) were bruising, dizziness, headache, and diarrhea. In acute graft-versus-host disease, the most common nonhematologic adverse reactions (incidence $>50 \%$ ) were infections (pathogen not specified) and edema. In chronic graft-versus-host disease, the most common nonhematologic adverse reactions (incidence $\geq 20 \%$ ) were infections (pathogen not specified) and viral infections

- Avoid concomitant use with fluconazole doses greater than $200 \mathrm{mg}$. Dose modifications may be required when administering Jakafi with fluconazole doses of $200 \mathrm{mg}$ or less, or with strong CYP3A4 inhibitors, or in patients with renal or hepatic impairment. Patients should be closely monitored and the dose titrated based on safety and efficacy

- Use of Jakafi during pregnancy is not recommended and should only be used if the potential benefit justifies the potential risk to the fetus. Women taking Jakafi should not breastfeed during treatment and for 2 weeks after the final dose

\section{Please see Brief Summary of Full Prescribing Information for Jakafi on the following pages.}

Reference: 1. Jakafi [package insert]. Wilmington, DE: Incyte Corporation. 


\section{Jakafio \\ uxolitinib (tablets)}

BRIEF SUMMARY: For Full Prescribing Information, see package insert.

INDICATIONS AND USAGE Myelofibrosis Jakafi is indicated for treatment of intermediate or high-risk myelofibrosis (MF), including primary MF, post-polycythemia vera MF and post-essential thrombocythemia MF in adults. Polycythemia Vera Jakafi is indicated for treatment of polycythemia vera (PV) in adults who have had an inadequate response to or are intolerant of hydroxyurea. Acute Graft-Versus-Host Disease Jakafi is indicated for treatment of steroidrefractory acute graft-versus-host disease (aGVHD) in adult and pediatric patients 12 years and older. Chronic GraftVersus-Host Disease Jakafi is indicated for treatment of chronic graft-versus-host disease (cGVHD) after failure of one or two lines of systemic therapy in adult and pediatric patients 12 years and older.

\section{CONTRAINDICATIONS None.}

\section{WARNINGS AND PRECAUTIONS Thrombocytopenia,}

Anemia and Neutropenia Treatment with Jakafi can cause thrombocytopenia, anemia and neutropenia. [see Adverse Reactions (6.1) in Full Prescribing Information]. Manage thrombocytopenia by reducing the dose or temporarily interrupting Jakafi. Platelet transfusions may be necessary [see Dosage and Administration (2) in Full Prescribing Information]. Patients developing anemia may require blood transfusions and/or dose modifications of Jakafi. Severe neutropenia (ANC less than $0.5 \times 10^{9} / \mathrm{L}$ ) was generally reversible by withholding Jakafi until recovery. Perform a pre-treatment complete blood count (CBC) and monitor CBCs every 2 to 4 weeks until doses are stabilized, and then as clinically indicated [see Dosage and Administration (2) in Full Prescribing Information]. Risk of Infection Serious bacterial, mycobacterial, fungal and viral infections have occurred [see Adverse Reactions (6.1) in Full Prescribing Information]. Delay starting therapy with Jakafi until active serious infections have resolved. Observe patients receiving Jakafi for signs and symptoms of infection and manage promptly. Use active surveillance and prophylactic antibiotics according to clinical guidelines. Tuberculosis Tuberculosis infection has been reported in patients receiving Jakafi. Observe patients receiving Jakafi for signs and symptoms of active tuberculosis and manage promptly. Prior to initiating Jakafi, patients should be evaluated for tuberculosis risk factors, and those at higher risk should be tested for latent infection. Risk factors include, but are not limited to, prior residence in or travel to countries with a high prevalence of tuberculosis, close contact with a person with active tuberculosis, and a history of active or latent tuberculosis where an adequate course of treatment cannot be confirmed. For patients with evidence of active or latent tuberculosis, consult a physician with expertise in the treatment of tuberculosis before starting Jakafi. The decision to continue Jakafi during treatment of active tuberculosis should be based on the overall risk-benefit determination. Progressive Multifocal

Leukoencephalopathy Progressive multifocal

leukoencephalopathy (PML) has occurred with Jakafi treatment. If PML is suspected, stop Jakafi and evaluate. Herpes Zoster Advise patients about early signs and symptoms of herpes zoster and to seek treatment as early as possible if suspected. Hepatitis $B$ Hepatitis B viral load (HBV-DNA titer) increases, with or without associated elevations in alanine aminotransferase and aspartate aminotransferase, have been reported in patients with chronic HBV infections taking Jakafi. The effect of Jakafi on viral replication in patients with chronic HBV infection is unknown. Patients with chronic HBV infection should be treated and monitored according to clinical guidelines. Symptom Exacerbation Following Interruption or Discontinuation of Treatment with Jakafi Following discontinuation of Jakafi, symptoms from myeloproliferative neoplasms may return to pretreatment levels over a period of approximately one week. Some patients with MF have experienced one or more of the following adverse events after discontinuing Jakafi: fever, respiratory distress, hypotension, DIC, or multi-organ failure. If one or more of these occur after discontinuation of, or while tapering the dose of Jakafi, evaluate for and treat any intercurrent illness and consider restarting or increasing the dose of Jakafi. Instruct patients not to interrupt or discontinue Jakafi therapy without consulting their physician. When discontinuing or interrupting therapy with Jakafi for reasons other than thrombocytopenia or neutropenia [see Dosage and Administration (2.7) in Full Prescribing Information], consider tapering the dose of Jakafi gradually rather than discontinuing abruptly. Non-Melanoma Skin Cancer (NMSC) Non-melanoma skin cancers including basal cell, squamous cell, and Merkel cell carcinoma have occurred in patients treated with Jakafi. Perform periodic skin examinations. Lipid Elevations Treatment with Jakafi has been associated with increases in lipid parameters including total cholesterol, low-density lipoprotein (LDL) cholesterol, and triglycerides [see Adverse Reactions (6.1) in Full Prescribing Information]. The effect of these lipid parameter elevations on cardiovascular morbidity and mortality has not been determined in patients treated with Jakafi. Assess lipid parameters approximately 8-12 weeks following initiation of Jakafi therapy. Monitor and treat according to clinical guidelines for the management of hyperlipidemia. Major Adverse Cardiovascular Events (MACE) Another JAK-inhibitor has increased the risk of MACE, including cardiovascular death, myocardia infarction, and stroke (compared to those treated with TNF blockers) in patients with rheumatoid arthritis, a condition for which Jakafi is not indicated. Consider the benefits and risks for the individual patient prior to initiating or continuing therapy with Jakafi particularly in patients who are current or past smokers and patients with other cardiovascular risk factors. Patients should be informed about the symptoms of serious cardiovascular events and the steps to take if they occur. Thrombosis Another JAK-inhibitor has increased the risk of thrombosis, including deep venous thrombosis (DVT), pulmonary embolism (PE), and arterial thrombosis (compared to those treated with TNF blockers) in patients with rheumatoid arthritis, a condition for which Jakafi is not indicated. In patients with MF and PV treated with Jakafi in clinical trials, the rates of thromboembolic events were similar in Jakafi and control treated patients. Patients with symptoms of thrombosis should be promptly evaluated and treated appropriately. Secondary Malignancies Another JAK-inhibitor has increased the risk of lymphoma and other malignancies excluding NMSC (compared to those treated with TNF blockers) in patients with rheumatoid arthritis, a condition for which Jakafi is not indicated. Patients who are current or past smokers are at additional increased risk. Consider the benefits and risks for the individual patient prior to initiating or continuing therapy with Jakafi, particularly in patients with a known secondary malignancy (other than a successfully treated NMSC), patients who develop a malignancy, and patients who are current or past smokers. ADVERSE REACTIONS The following clinically significant adverse reactions are discussed in greater detail in other sections of the labeling: • Thrombocytopenia, Anemia and Neutropenia [see Warnings and Precautions (5.1) in Full Prescribing Information] • Risk of Infection [see Warnings and Precautions (5.2) in Full Prescribing Information] • Symptom Exacerbation Following Interruption or Discontinuation of Treatment with Jakafi [see Warnings and Precautions (5.3) in Full Prescribing Information ] - Non-Melanoma Skin Cancer [see Warnings and Precautions (5.4) in Full Prescribing Information] - Lipid Elevations [see Warnings and Precautions (5.5) in Full Prescribing Information] - Major Adverse Cardiovascular Events (MACE) [see Warnings and Precautions (5.6) in Full Prescribing Information] • Thrombosis [see Warnings and Precautions (5.7) in Full Prescribing Information] - Secondary Malignancies [see Warnings and Precautions (5.8) in Full Prescribing Information]. Clinical Trials Experience Because clinical trials are conducted under widely varying conditions, adverse reaction rates observed in the clinical trials of a drug cannot be directly compared to rates in the clinical trials of another drug and may not reflect the rates observed in practice.
Myelofibrosis The safety of Jakafi was assessed in 617 patients in six clinical studies with a median duration of follow-up of 10.9 months, including 301 patients with MF in two Phase 3 studies. In these two Phase 3 studies, patients had a median duration of exposure to Jakafi of 9.5 months (range 0.5 to 17 months), with $89 \%$ of patients treated for more than 6 months and $25 \%$ treated for more than 12 months. One hundred and eleven (111) patients started treatment at $15 \mathrm{mg}$ twice daily and 190 patients started at $20 \mathrm{mg}$ twice daily. In patients starting treatment with $15 \mathrm{mg}$ twice daily (pretreatment platelet counts of 100 to $200 \times 10^{9} / \mathrm{L}$ ) and $20 \mathrm{mg}$ twice daily (pretreatment platelet counts greater than $200 \times 10^{9} / \mathrm{L}$ ), $65 \%$ and $25 \%$ of patients, respectively, required a dose reduction below the starting dose within the first 8 weeks of therapy. In a double-blind, randomized, placebocontrolled study of Jakafi, among the 155 patients treated with Jakafi, the most frequent adverse reactions were thrombocytopenia and anemia [see Table 2].

Thrombocytopenia, anemia and neutropenia are dose-related effects. The three most frequent nonhematologic adverse reactions were bruising, dizziness and headache [see Table 1]. Discontinuation for adverse events, regardless of causality, was observed in $11 \%$ of patients treated with Jakafi and $11 \%$ of patients treated with placebo. Table 1 presents the most common nonhematologic adverse reactions occurring in patients who received Jakafi in the double-blind, placebo-controlled study during randomized treatment.

Table 1: Myelofibrosis: Nonhematologic Adverse Reactions Occurring in Patients on Jakafi in the Double-blind, Placebo-controlled Study During Randomized Treatment

\begin{tabular}{|c|c|c|c|c|c|c|}
\hline & \multicolumn{3}{|c|}{$\begin{array}{c}\text { Jakafi } \\
(\mathrm{N}=155)\end{array}$} & \multicolumn{3}{|c|}{$\begin{array}{l}\text { Placebo } \\
(\mathrm{N}=151)\end{array}$} \\
\hline $\begin{array}{l}\text { Adverse } \\
\text { Reactions }\end{array}$ & $\begin{array}{c}\text { All } \\
\text { Grades } \\
(\%) \\
\end{array}$ & $\begin{array}{c}\text { Grade } \\
3 \\
(\%)\end{array}$ & $\begin{array}{c}\text { Grade } \\
4 \\
(\%)\end{array}$ & $\begin{array}{c}\text { All } \\
\text { Grades } \\
(\%)\end{array}$ & $\begin{array}{c}\text { Grade } \\
3 \\
(\%)\end{array}$ & $\begin{array}{c}\text { Grade } \\
4 \\
(\%)\end{array}$ \\
\hline Bruising $^{b}$ & 23 & $<1$ & 0 & 15 & 0 & 0 \\
\hline Dizziness $^{c}$ & 18 & $<1$ & 0 & 7 & 0 & 0 \\
\hline Headache & 15 & 0 & 0 & 5 & 0 & 0 \\
\hline $\begin{array}{l}\text { Urinary Tract } \\
\text { Infections }^{d}\end{array}$ & 9 & 0 & 0 & 5 & $<1$ & $<1$ \\
\hline Weight Gaine & 7 & $<1$ & 0 & 1 & $<1$ & 0 \\
\hline Flatulence & 5 & 0 & 0 & $<1$ & 0 & 0 \\
\hline Herpes Zoster ${ }^{\dagger}$ & 2 & 0 & 0 & $<1$ & 0 & 0 \\
\hline
\end{tabular}

National Cancer Institute Common Terminology Criteria for Adverse Events (CTCAE), version 3.0

includes contusion, ecchymosis, hematoma, injection site hematoma, periorbital hematoma, vessel puncture site hematoma, increased tendency to bruise, petechiae, purpura

includes dizziness, postural dizziness, vertigo, balance disorder, Meniere's Disease, labyrinthitis

includes urinary tract infection, cystitis, urosepsis, urinary tract infection bacterial, kidney infection, pyuria, bacteria urine, bacteria urine identified, nitrite urine present

includes weight increased, abnormal weight gain

includes herpes zoster and post-herpetic neuralgia

Description of Selected Adverse Reactions: Anemia

In the two Phase 3 clinical studies, median time to onset of first CTCAE Grade 2 or higher anemia was approximately 6 weeks. One patient $(<1 \%)$ discontinued treatment because of anemia. In patients receiving Jakafi mean decreases in hemoglobin reached a nadir of approximately 1.5 to $2.0 \mathrm{~g} / \mathrm{dL}$ below baseline after 8 to 12 weeks of therapy and then gradually recovered to reach a new steady state that was approximately $1.0 \mathrm{~g} / \mathrm{dL}$ below baseline. This pattern was observed in patients regardless of whether they had received transfusions during therapy. In the randomized, placebo-controlled study, $60 \%$ of patients treated with Jakafi and $38 \%$ of patients receiving placebo received red blood cell transfusions during randomized treatment. Among transfused patients, the median number of units transfused per month was 1.2 in patients treated with Jakafi and 1.7 in placebo treated patients. Thrombocytopenia In the two Phase 3 clinical studies, in patients who developed Grade 3 or 4 thrombocytopenia, the median time to onset was approximately 8 weeks. Thrombocytopenia was generally reversible with dose reduction or dose interruption. The median time to recovery of platelet counts above $50 \times 10^{9} / \mathrm{L}$ was 14 days. Platelet transfusions were administered to $5 \%$ of patients receiving Jakafi and to $4 \%$ of patients receiving control regimens. Discontinuation 
of treatment because of thrombocytopenia occurred in $<1 \%$ of patients receiving Jakafi and $<1 \%$ of patients receiving control regimens. Patients with a platelet count of $100 \times 10^{9} / \mathrm{L}$ to $200 \times 10^{\%} / \mathrm{L}$ before starting Jakafi had a higher frequency of Grade 3 or 4 thrombocytopenia compared to patients with a platelet count greater than $200 \times 10^{9} / \mathrm{L}(17 \%$ versus $7 \%$ ). Neutropenia In the two Phase 3 clinical studies, $1 \%$ of patients reduced or stopped Jakafi because of neutropenia. Table 2 provides the frequency and severity of clinical hematology abnormalities reported for patients receiving treatment with Jakafi or placebo in the placebo-controlled study.

Table 2: Myelofibrosis: Worst Hematology Laboratory Abnormalities in the Placebo-Controlled Study ${ }^{a}$

\begin{tabular}{|c|c|c|c|c|c|c|}
\hline & \multicolumn{3}{|c|}{$\begin{array}{c}\text { Jakafi } \\
\text { (N=155) }\end{array}$} & \multicolumn{3}{|c|}{$\begin{array}{l}\text { Placebo } \\
(\mathrm{N}=151)\end{array}$} \\
\hline $\begin{array}{l}\text { Laboratory } \\
\text { Parameter }\end{array}$ & $\begin{array}{c}\text { All } \\
\text { Grades } \\
(\%)\end{array}$ & $\begin{array}{c}\text { Grade } \\
3 \\
(\%)\end{array}$ & $\begin{array}{c}\text { Grade } \\
4 \\
(\%)\end{array}$ & $\begin{array}{c}\text { All } \\
\text { Grades } \\
\text { (\%) }\end{array}$ & $\begin{array}{c}\text { Grade } \\
3 \\
(\%)\end{array}$ & $\begin{array}{c}\text { Grad } \\
4 \\
(\%)\end{array}$ \\
\hline Thrombocytopenia & 70 & 9 & 4 & 31 & 1 & 0 \\
\hline Anemia & 96 & 34 & 11 & 87 & 16 & 3 \\
\hline Neutropenia & 19 & 5 & 2 & 4 & $<1$ & 1 \\
\hline
\end{tabular}

a Presented values are worst Grade values regardless of baseline National Cancer Institute Common Terminology Criteria for Adverse Events, version 3.0

\section{Additional Data from the Placebo-Controlled Study}

- $25 \%$ of patients treated with Jakafi and $7 \%$ of patients treated with placebo developed newly occurring or worsening Grade 1 abnormalities in alanine transaminase (ALT). The incidence of greater than or equal to Grade 2 elevations was $2 \%$ for Jakafi with $1 \%$ Grade 3 and no Grade 4 ALT elevations. $\bullet 17 \%$ of patients treated with Jakafi and $6 \%$ of patients treated with placebo developed newly occurring or worsening Grade 1 abnormalities in aspartate transaminase (AST). The incidence of Grade 2 AST elevations was $<1 \%$ for Jakafi with no Grade 3 or 4 AST elevations. $\bullet 17 \%$ of patients treated with Jakafi and $<1 \%$ of patients treated with placebo developed newly occurring or worsening Grade 1 elevations in cholesterol. The incidence of Grade 2 cholesterol elevations was $<1 \%$ for Jakafi with no Grade 3 or 4 cholesterol elevations. Polycythemia Vera In a randomized, open-label, active-controlled study, 110 patients with PV resistant to or intolerant of hydroxyurea received Jakafi and 111 patients received best available therapy [see Clinical Studies (14.2) in Full Prescribing Information]. The most frequent adverse reaction was anemia. Discontinuation for adverse events, regardless of causality, was observed in $4 \%$ of patients treated with Jakafi. Table 3 presents the most frequent nonhematologic adverse reactions occurring up to Week 32 .

Table 3: Polycythemia Vera: Nonhematologic Adverse Reactions 0ccurring in $\geq 5 \%$ of Patients on Jakafi in the Open-Label, Active-controlled Study up to Week 32 of Randomized Treatment

\begin{tabular}{|c|c|c|c|c|}
\hline \multirow[b]{2}{*}{ Adverse Reactions } & \multicolumn{2}{|c|}{$\begin{array}{c}\text { Jakafi } \\
(\mathrm{N}=110)\end{array}$} & \multicolumn{2}{|c|}{$\begin{array}{c}\text { Best Available } \\
\text { Therapy ( } \mathrm{N}=111)\end{array}$} \\
\hline & $\begin{array}{c}\text { All } \\
\text { Grades }^{\mathrm{a}} \\
(\%)\end{array}$ & $\begin{array}{c}\text { Grade } \\
3-4 \\
(\%)\end{array}$ & $\begin{array}{c}\text { All } \\
\text { Grades } \\
(\%)\end{array}$ & $\begin{array}{c}\text { Grade } \\
3-4 \\
(\%)\end{array}$ \\
\hline Diarrhea & 15 & 0 & 7 & $<1$ \\
\hline Dizziness $^{b}$ & 15 & 0 & 13 & 0 \\
\hline Dyspneac $^{c}$ & 13 & 3 & 4 & 0 \\
\hline Muscle Spasms & 12 & $<1$ & 5 & 0 \\
\hline Constipation & 8 & 0 & 3 & 0 \\
\hline Herpes Zoster ${ }^{d}$ & 6 & $<1$ & 0 & 0 \\
\hline Nausea & 6 & 0 & 4 & 0 \\
\hline Weight Gaine & 6 & 0 & $<1$ & 0 \\
\hline Urinary Tract Infections ${ }^{f}$ & 6 & 0 & 3 & 0 \\
\hline Hypertension & 5 & $<1$ & 3 & $<1$ \\
\hline
\end{tabular}

a National Cancer Institute Common Terminology Criteria for Adverse Events (CTCAE), version 3.0

includes dizziness and vertigo

includes dyspnea and dyspnea exertiona

includes herpes zoster and post-herpetic neuralgia

includes weight increased and abnormal weight gain

' includes urinary tract infection and cystitis

Clinically relevant laboratory abnormalities are shown in Table 4.
Table 4: Polycythemia Vera: Selected Laboratory Abnormalities in the Open-Label, Activecontrolled Study up to Week 32 of Randomized Treatment ${ }^{\mathrm{a}}$

\begin{tabular}{|c|c|c|c|c|c|c|}
\hline \multirow[b]{3}{*}{$\begin{array}{l}\text { Laboratory } \\
\text { Parameter }\end{array}$} & \multicolumn{3}{|c|}{$\begin{array}{c}\text { Jakafi } \\
(\mathrm{N}=110)\end{array}$} & \multicolumn{3}{|c|}{$\begin{array}{l}\text { Best Available } \\
\text { Therapy ( } \mathrm{N}=111)\end{array}$} \\
\hline & All & Grade & Grade & All & Grade & Grade \\
\hline & $\begin{array}{c}\text { Grades }^{b} \\
(\%)\end{array}$ & $\begin{array}{c}3 \\
(\%)\end{array}$ & $\begin{array}{c}4 \\
(\%)\end{array}$ & $\begin{array}{c}\text { Grades } \\
(\%)\end{array}$ & $\begin{array}{c}3 \\
(\%)\end{array}$ & $\begin{array}{c}4 \\
(\%)\end{array}$ \\
\hline \multicolumn{7}{|l|}{ Hematology } \\
\hline Anemia & 72 & $<1$ & $<1$ & 58 & 0 & 0 \\
\hline Thrombocytopenia & 27 & 5 & $<1$ & 24 & 3 & $<1$ \\
\hline Neutropenia & 3 & 0 & $<1$ & 10 & $<1$ & 0 \\
\hline
\end{tabular}

Chemistry

\begin{tabular}{|l|c|c|c|c|c|c|}
\hline Hypercholesterolemia & 35 & 0 & 0 & 8 & 0 & 0 \\
\hline
\end{tabular}

\begin{tabular}{|l|c|c|c|c|c|c|}
\hline Elevated ALT & 25 & $<1$ & 0 & 16 & 0 & 0 \\
\hline
\end{tabular}

\begin{tabular}{|l|c|c|c|c|c|c|}
\hline Elevated AST & 23 & 0 & 0 & 23 & $<1$ & 0 \\
\hline
\end{tabular}

\begin{tabular}{|l|l|l|l|l|l|l|}
\hline Hypertriglyceridemia & 15 & 0 & 0 & 13 & 0 & 0 \\
\hline
\end{tabular}

a Presented values are worst Grade values regardless of baseline

${ }^{6}$ National Cancer Institute Common Terminology Criteria for Adverse Events, version 3.0

Acute Graft-Versus-Host Disease In a single-arm,

open-label study, 71 adults (ages 18-73 years) were treated with Jakafi for aGVHD failing treatment with steroids with or without other immunosuppressive drugs [see Clinical Studies (14.3) in Full Prescribing Information]. The median duration of treatment with Jakafi was 46 days (range, 4-382 days). There were no fatal adverse reactions to Jakafi. An adverse reaction resulting in treatment discontinuation occurred in $31 \%$ of patients. The most common adverse reaction leading to treatment discontinuation was infection (10\%). Table 5 shows the adverse reactions other than laboratory abnormalities.

Table 5: Acute Graft-Versus-Host Disease: Nonhematologic Adverse Reactions Occurring in $\geq 15 \%$ of Patients in the Open-Label, SingleCohort Study

\begin{tabular}{|c|c|c|}
\hline & \multicolumn{2}{|c|}{ Jakafi ( $N=71)$} \\
\hline Adverse Reactions ${ }^{a}$ & All Grades $^{b}(\%)$ & Grade 3-4 (\%) \\
\hline $\begin{array}{l}\text { Infections (pathogen } \\
\text { not specified) }\end{array}$ & 55 & 41 \\
\hline Edema & 51 & 13 \\
\hline Hemorrhage & 49 & 20 \\
\hline Fatigue & 37 & 14 \\
\hline Bacterial infections & 32 & 28 \\
\hline Dyspnea & 32 & 7 \\
\hline Viral infections & 31 & 14 \\
\hline Thrombosis & 25 & 11 \\
\hline Diarrhea & 24 & 7 \\
\hline Rash & 23 & 3 \\
\hline Headache & 21 & 4 \\
\hline Hypertension & 20 & 13 \\
\hline Dizziness & 16 & 0 \\
\hline
\end{tabular}

a Selected laboratory abnormalities are listed in Table 6 below ${ }^{-}$National Cancer Institute Common Terminology Criteria for Adverse Events (CTCAE), version 4.03

Selected laboratory abnormalities during treatment with Jakafi are shown in Table 6.

Table 6: Acute Graft-Versus-Host Disease: Selected Laboratory Abnormalities Worsening from Baseline in the Open-Label, Single Cohort Study

\begin{tabular}{|c|c|c|}
\hline & \multicolumn{2}{|c|}{ Jakafi (N=71) } \\
\hline & Worst grade d & uring treatment \\
\hline aboratory Parameter & All Grades ${ }^{a}(\%)$ & Grade 3-4 (\%) \\
\hline
\end{tabular}

Hematology

Anemia

\begin{tabular}{|l|l|l|}
\hline Thrombocytopenia & 75 & 45 \\
\hline
\end{tabular}

Neutropenia

Chemistry

Elevated ALT

Elevated AST

Hypertriglyceridemia

National Cancer Institute Common Terminology Criteria for Adverse Events, version 4.03

Chronic Graft-Versus-Host Disease In a Phase 3, randomized, open-label, multi-center study, 165 patients were treated with Jakafi and 158 patients were treated with best available therapy for cGVHD failing treatment with steroids with or without other immunosuppressive drugs [see Clinical Studies (14.4) in full Prescribing Information]; sixty-five patients crossed over from best available therapy to treatment with Jakafi, for a total of 230 patients treated with Jakafi. The median duration of exposure to Jakafi for the study was 49.7 weeks (range, 0.7 to 144.9 weeks) in the Jakafi arm. One hundred and nine (47\%) patients were on Jakafi for at least 1 year. There were five fatal adverse reactions to Jakafi, including 1 from toxic epidermal necrolysis and 4 from neutropenia, anemia and/or thrombocytopenia. An adverse reaction resulting in treatment discontinuation occurred in 18\% of patients treated with Jakafi. An adverse reaction resulting in dose modification occurred in $27 \%$, and an adverse reaction resulting in treatment interruption occurred in $23 \%$. The most common hematologic adverse reactions (incidence $>35 \%$ ) are anemia and thrombocytopenia. The most common nonhematologic adverse reactions (incidence $\geq 20 \%$ ) are infections (pathogen not specified) and viral infection. Table 7 presents the most frequent nonlaboratory adverse reactions occurring up to Cycle 7 Day 1 of randomized treatment.

Table 7: Chronic Graft-Versus-Host Disease: All-Grade ( $\geq 10 \%$ ) and Grades 3-5 ( $\geq 3 \%$ ) Nonlaboratory Adverse Reactions Occurring in Patients in the Open-Label, Active-controlled Study up to Cycle 7 Day 1 of Randomized Treatment

\begin{tabular}{|c|c|c|c|c|}
\hline & \multicolumn{2}{|c|}{$\begin{array}{c}\text { Jakafi } \\
(\mathrm{N}=165)\end{array}$} & \multicolumn{2}{|c|}{$\begin{array}{c}\text { Best Available } \\
\text { Therapy }(\mathrm{N}=158)\end{array}$} \\
\hline Adverse Reactions ${ }^{b}$ & $\begin{array}{c}\text { All } \\
\text { Grades }^{a} \\
(\%)\end{array}$ & $\begin{array}{c}\text { Grade } \\
\geq 3 \\
(\%)\end{array}$ & $\begin{array}{c}\text { All } \\
\text { Grades } \\
(\%)\end{array}$ & $\begin{array}{c}\text { Grade } \\
\geq 3 \\
(\%)\end{array}$ \\
\hline
\end{tabular}

\section{Infections and infestations}

Infections (pathogen

not specified)

Viral infections

Musculoskeletal and connective tissue disorders

\begin{tabular}{|c|c|c|c|c|}
\hline Musculoskeletal pain & 18 & 1 & 13 & 0 \\
\hline
\end{tabular}

General disorders and administration site conditions

Pyrexia

Fatigue

Edema

Vascular disorders

Hypertension

Hemorrhage

Respiratory, thoracic and mediastinal disorders

\begin{tabular}{|l|c|c|c|c|}
\hline Cough & 13 & 0 & 8 & 0 \\
\hline Dyspnea & 11 & 1 & 8 & 1 \\
\hline
\end{tabular}

Gastrointestinal disorders

Nausea

Diarrhea

12

\begin{tabular}{l|l|l|}
\hline & 0 & 13 \\
\hline
\end{tabular}
(CTCAE), version 4.03

b Grouped terms that are composites of applicable adverse reaction terms. Clinically relevant laboratory abnormalities are shown in Table 8.

Table 8: Chronic Graft-Versus-Host Disease: Selected Laboratory Abnormalities in the Open-Label, Active-controlled Study up to Cycle 7 Day 1 of Randomized Treatment ${ }^{\mathrm{a}}$

\begin{tabular}{|l|c|c|c|c|}
\hline & \multicolumn{2}{|c|}{$\begin{array}{c}\text { Jakafi } \\
\text { (N=165) }\end{array}$} & \multicolumn{2}{c|}{$\begin{array}{c}\text { Best Available } \\
\text { Therapy (N=158) }\end{array}$} \\
\hline & All & Grade & All & Grade \\
Laboratory Test & Grades $^{\mathrm{b}}$ & $\geq 3$ & Grades $^{\prime}$ & $\geq 3$ \\
$(\%)$ & $(\%)$ & $(\%)$ & $(\%)$ \\
\hline
\end{tabular}

Hematology

\begin{tabular}{|l|c|c|c|c|}
\hline Anemia & 82 & 13 & 75 & 8 \\
\hline Thrombocytopenia & 27 & 12 & 23 & 9 \\
\hline Neutropenia & 58 & 20 & 54 & 17 \\
\hline
\end{tabular}

Neutropenia

Chemistry

Hypercholesterolemia

Elevated AST

Elevated ALT

Gamma

glutamyltransferase

increased

\section{Creatinine increased}

Elevated lipase

Elevated amylase

\begin{tabular}{l|c|c|c|}
\hline 88 & 10 & 85 & 8
\end{tabular}

a Presented values are worst Grade values regardless of baseline

${ }^{b}$ National Cancer Institute Common Terminology Criteria for Adverse Events, version 4.03 
DRUG INTERACTIONS Fluconazole Concomitant use of Jakafi with fluconazole increases ruxolitinib exposure [see Clinical Pharmacology (12.3) in Full Prescribing Information], which may increase the risk of exposurerelated adverse reactions. Avoid concomitant use of Jakafi with fluconazole doses of greater than $200 \mathrm{mg}$ daily. Reduce the Jakafi dosage when used concomitantly with fluconazole doses of less than or equal to $200 \mathrm{mg}$ [see Dosage and Administration (2.5) in Full Prescribing Information]. Strong CYP3A4 Inhibitors Concomitant use of Jakafi with strong CYP3A4 inhibitors increases ruxolitinib exposure [see Clinical Pharmacology (12.3) in Full Prescribing Information], which may increase the risk of exposure-related adverse reactions. Reduce the Jakafi dosage when used concomitantly with strong CYP3A4 inhibitors except in patients with aGVHD or cGVHD [see Dosage and Administration (2.5) in Full Prescribing Information]. Strong CYP3A4 Inducers Concomitant use of Jakafi with strong CYP3A4 inducers may decrease ruxolitinib exposure [see Clinical Pharmacology (12.3) in Full Prescribing Information], which may reduce efficacy of Jakafi. Monitor patients frequently and adjust the Jakafi dose based on safety and efficacy [see Clinical Pharmacology (12.3) in Full Prescribing Information]. USE IN SPECIFIC POPULATIONS Pregnancy: Risk Summary When pregnant rats and rabbits were administered ruxolitinib during the period of organogenesis adverse developmental outcomes occurred at doses associated with maternal toxicity (see Data). There are no studies with the use of Jakafi in pregnant women to inform drug-associated risks. The background risk of major birth defects and miscarriage for the indicated populations is unknown. Adverse outcomes in pregnancy occur regardless of the health of the mother or the use of medications. The background risk in the U.S. general population of major birth defects is $2 \%$ to $4 \%$ and miscarriage is $15 \%$ to $20 \%$ of clinically recognized pregnancies. Data: Animal Data Ruxolitinib was administered orally to pregnant rats or rabbits during the period of organogenesis, at doses of 15,30 or $60 \mathrm{mg} / \mathrm{kg} /$ day in rats and 10,30 or $60 \mathrm{mg} / \mathrm{kg} /$ day in rabbits. There were no treatment-related malformations. Adverse developmental outcomes, such as decreases of approximately $9 \%$ in fetal weights were noted in rats at the highest and maternally toxic dose of $60 \mathrm{mg} / \mathrm{kg} / \mathrm{day}$. This dose results in an exposure (AUC) that is approximately 2 times the clinical exposure at the maximum recommended dose of $25 \mathrm{mg}$ twice daily. In rabbits, lower fetal weights of approximately $8 \%$ and increased late resorptions were noted at the highest and maternally toxic dose of $60 \mathrm{mg} / \mathrm{kg} /$ day. This dose is approximately $7 \%$ the clinical exposure at the maximum recommended dose. In a pre- and post-natal development study in rats, pregnant animals were dosed with ruxolitinib from implantation through lactation at doses up to $30 \mathrm{mg} / \mathrm{kg} /$ day. There were no drug-related adverse findings in pups for fertility indices or for maternal or embryofetal survival, growth and development parameters at the highest dose evaluated (34\% the clinical exposure at the maximum recommended dose of $25 \mathrm{mg}$ twice daily). Lactation: Risk Summary No data are available regarding the presence of ruxolitinib in human milk, the effects on the breast fed child, or the effects on milk production. Ruxolitinib and/or its metabolites were present in the milk of lactating rats (see Data). Because many drugs are present in human milk and because of the potential for thrombocytopenia and anemia shown for Jakafi in human studies, discontinue breastfeeding during treatment with Jakafi and for two weeks after the final dose. Data: Animal Data Lactating rats were administered a single dose of $\left[{ }^{14} \mathrm{C}\right]$-labeled ruxolitinib $(30 \mathrm{mg} / \mathrm{kg})$ on postnatal Day 10, after which plasma and milk samples were collected for up to 24 hours. The AUC for total radioactivity in milk was approximately 13 -fold the maternal plasma AUC. Additional analysis showed the presence of ruxolitinib and several of its metabolites in milk, all at levels higher than those in maternal plasma. Pediatric Use The safety and effectiveness of Jakafi for treatment of myelofibrosis or polycythemia vera in pediatric patients have not been established. The safety and effectiveness of Jakafi for treatment of steroid-refractory aGVHD has been established for treatment of children 12 years and older. Use of Jakafi in pediatric patients with steroid-refractory aGVHD is supported by evidence from adequate and well-controlled trials of Jakafi in adults [see Clinical Studies (14.3) in Full Prescribing Information] and additional pharmacokinetic and safety data in pediatric patients. The safety and effectiveness of Jakafi for treatment of steroid-refractory aGVHD has not been established in pediatric patients younger than 12 years old. The safety and effectiveness of Jakafi for treatment of CGVHD after failure of one or two lines of systemic therapy has been established for treatment of children 12 years and older. Use of Jakafi in pediatric patients with cGVHD after failure of one or two lines of systemic therapy is supported by evidence from adequate and well-controlled trials of Jakafi in adults and adolescents [see Clinical Studies $(14.3,14.4)$ in Full Prescribing Information] and additional pharmacokinetic and safety data in pediatric patients. The safety and effectiveness of Jakafi for treatment of CGVHD has not been established in pediatric patients younger than 12 years old. Jakafi was evaluated in a single-arm, dose-escalation study (NCT01164163) in 27 pediatric patients with relapsed or refractory solid tumors (Cohort $A$ ) and 20 with leukemias or myeloproliferative neoplasms (Cohort B). The patients had a median age of 14 years (range, 2 to 21 years) and included 18 children (age 2 to $<12$ years), and 14 adolescents (age 12 to $<17$ years). The dose levels tested were $15,21,29,39$, or $50 \mathrm{mg} / \mathrm{m}^{2}$ twice daily in 28-day cycles with up to 6 patients per dose group. Overall, 38 (81\%) patients were treated with no more than a single cycle of Jakafi, while 3, 1, 2, and 3 patients received 2, 3, 4, and 5 or more cycles, respectively. A protocol-defined maximal tolerated dose was not observed, but since few patients were treated for multiple cycles, tolerability with continued use was not assessed adequately to establish a recommended Phase 2 dose higher than the recommended dose for adults. The safety profile in children was similar to that seen in adults. Juvenile Animal Toxicity Data Administration of ruxolitinib to juvenile rats resulted in effects on growth and bone measures. When administered starting at postnatal day 7 (the equivalent of a human newborn) at doses of 1.5 to $75 \mathrm{mg} / \mathrm{kg} /$ day, evidence of fractures occurred at doses $\geq 30 \mathrm{mg} / \mathrm{kg} /$ day, and effects on body weight and other bone measures [e.g., bone mineral content, peripheral quantitative computed tomography, and $\mathrm{x}$-ray analysis] occurred at doses $\geq 5 \mathrm{mg} / \mathrm{kg} /$ day. When administered starting at postnatal day 21 (the equivalent of a human 2-3 years of age) at doses of 5 to $60 \mathrm{mg} / \mathrm{kg} /$ day, effects on body weight and bone occurred at doses $\geq 15 \mathrm{mg} / \mathrm{kg} /$ day, which were considered adverse at $60 \mathrm{mg} / \mathrm{kg} /$ day. Males were more severely affected than females in all age groups, and effects were generally more severe when administration was initiated earlier in the postnatal period. These findings were observed at exposures that are at least $27 \%$ the clinical exposure at the maximum recommended dose of $25 \mathrm{mg}$ twice daily. Geriatric Use Of the total number of patients with MF in clinical studies with Jakafi, $52 \%$ were 65 years and older, while $15 \%$ were 75 years and older. No overall differences in safety or effectiveness of Jakafi were observed between these patients and younger patients. Clinical studies of Jakafi in patients with aGVHD did not include sufficient numbers of subjects age 65 and over to determine whether they respond differently from younger subjects. Of the total number of patients with CGVHD treated with Jakafi in clinical trials, $11 \%$ were 65 years and older. No overall differences in safety or effectiveness of Jakafi were observed between these patients and younger patients. Renal Impairment Total exposure of ruxolitinib and its active metabolites increased with moderate (CLcr 30 to $59 \mathrm{~mL} / \mathrm{min}$ ) and severe (CLcr 15 to $29 \mathrm{~mL} / \mathrm{min}$ ) renal impairment, and ESRD (CLcr less than $15 \mathrm{~mL} / \mathrm{min}$ ) on dialysis [see Clinical Pharmacology (12.3) in Full Prescribing Information]. Modify Jakafi dosage as recommended [see Dosage and Administration (2.6) in full Prescribing Information]. Hepatic Impairment Exposure of ruxolitinib increased with mild (Child-Pugh A), moderate (Child-Pugh B) and severe (Child-Pugh C) hepatic impairment [see Clinical Pharmacology (12.3) in full Prescribing Information].
Reduce Jakafi dosage as recommended in patients with MF or PV with hepatic impairment [see Dosage and Administration (2.6) in full Prescribing Information]. Reduce Jakafi dosage as recommended for patients with Stage 4 liver aGVHD. Monitor blood counts more frequently for toxicity and modify the Jakafi dosage for adverse reactions if they occur for patients with Score 3 liver CGVHD [see Dosage and Administration (2.6) and Clinical Pharmacology (12.3) in full Prescribing Information]. OVERDOSAGE There is no known antidote for overdoses with Jakafi. Single doses up to $200 \mathrm{mg}$ have been given with acceptable acute tolerability. Higher than recommended repeat doses are associated with increased myelosuppression including leukopenia, anemia and thrombocytopenia. Appropriate supportive treatment should be given. Hemodialysis is not expected to enhance the elimination of Jakafi.

Jakafi is a registered trademark of Incyte. U.S. Patent Nos. 7598257; 8415362; 8722693; 8822481; 8829013; 9079912; 9814722; 10016429 (C) 2011-2021 Incyte Corporation. Revised: September 2021 PLR-JAK-00054 


\section{IN THIS ISSUE}

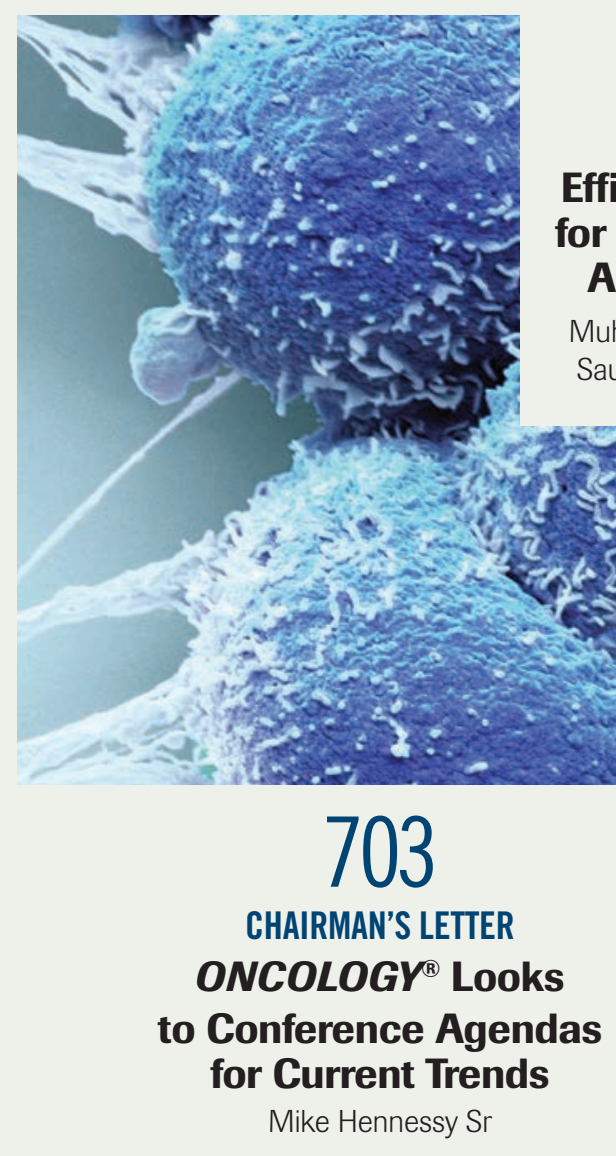

708

PROSTATE CANCER: ORIGINAL RESEARCH

Efficacy of PARP Inhibitors as Maintenance Therapy for Metastatic Castration-Resistant Prostate Cancer: A Meta-Analysis of Randomized Controlled Trials

Muhammad Rafay Khan Niazi, MD; Abdullah Jahangir, MD; Syeda Sahra, MD; Saud Bin Abdul Sattar, MD; Divya Asti, MD; and Alexander Bershadskiy, MD

\section{cancernetwork.com}

Visit CancerNetwork.com, home of the journal ONCOLOGY ${ }^{\circledR}$ and a web destination for oncologists seeking expert peer perspectives, podcasts, and other clinically practical features.

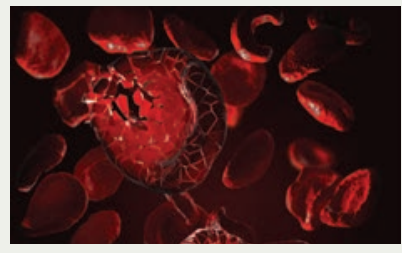

\section{VIDEO}

Luciano Costa, MD, PhD, Discusses Lessons Learned From the COVID-19 Pandemic in the Treatment of Myeloma

CancerNetwork.com/ IMW21_Costa

\author{
NEWS \\ Oncology Peer Review \\ On-The-Go: Plasma \\ Glutamine as a Prognostic \\ Biomarker in Localized \\ Prostate Cancer \\ CancerNetwork.com/ \\ podcast_11.21
}

LETTER TO THE READERS

LEADing the Way: Leadership, Empowerment, and Development Conference

Julie M. Vose, MD, MBA 
HEMATOLOGIC MALIGNANCIES:

INTERVIEW

706 How the Study of

Leukemias Inspired a

Decades-Long Career

CENTRAL NERVOUS SYSTEM CANCER:

CASE STUDY

733 A Rare Case

of Glioblastoma

With Extensive Liver

Metastases

Ghulam Ghous, MD; Douglas

Miller, MD; Donald Doll, MD;

and Tolga Tuncer, MD

CERVICAL CANCER:

CLINICAL QUANDARIES

\section{Treatment of}

Locally Advanced

Cervical Cancer

With Kidney Failure and Comorbidities

Eder A. Arango Bravo, MD;

Tatiana Galicia Carmona, MD;

Denisse Castro-Eguiluz, PhD;

Dolores Gallardo-Rincón, MD;

Emilio Conde Flores, MD; and

Lucely del Carmen Cetina-Pérez

MD, MSc
GASTROINTESTINAL CANCERS:

MEETING ABSTRACTS

752 Abstracts From

the 18th Annual

Meeting of the

International Society

of Gastrointestinal

Oncology

MEDICAL INSURANCE:

MEDICAL ECONOMICS ${ }^{\circledR}$

758 Physicians

Consider Needs of

Underinsured Patients

LUNG CANCER: PRODUCT PROFILE

759 Expert

Commentary on

the Product Profile

of Tepotinib

RAPID REPORTER

764 ONCOLOGY

Recap of

Presentations From

the 2021 European

Society for Medical Oncology Congress
PROSTATE CANCER:

BETWEEN THE LINES

768 Experts Detail

Potential of

${ }^{18}$ F-fluciclovine

PET/CT to Guide

Prostate Cancer

Decision-Making

HEAD AND NECK CANCER:

BETWEEN THE LINES

770 Experts Examine

Tipifarnib to Treat

HNSCC With HRAS

Mutations

SKIN CANCER:

CONTINUING MEDICAL EDUCATION

772 Exploring

Emerging Immunotherapies in Melanoma

Omid Hamid, MD

Published in affiliation with

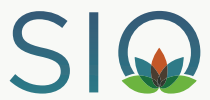

Integrative Oncology
$\mathrm{PER}=$

gotoper.com

CHECK OUT CONTINUING EDUCATION ACTIVITIES from out partners at Physicians' Education Resource $^{\circledR}\left(\mathrm{PER}^{\circledR}\right)$, LLC. We've picked this one especially for our ONCOLOGY ${ }^{\circledR}$ readers.

Go to: https://bit.ly/3bGWNAI

ONCOLOGY (ISSN 0890-9091) is published monthly by MultiMedia Healthcare LLC, 2 Clarke Drive, Suite 100 Cranbury, NN 08512. Annual subscription rates: US, \$237 and Canada, \$261; students and nurses, $\$ 96$; international, $\$ 296$. Single copies: $\$ 20$ each. Institutional US, $\$ 299$; Canada, $\$ 329$; international, $\$ 375$. Periodicals postage paid at Trenton, $\mathrm{N}$ and at additional mailing offices. POSTMASTER: Please send address changes to Oncology PO Box 457, Cranbury N 08512-0457, USA. Publications Mail Agreement No 40612608. Return Undeliverable Canadian Addresses to: IMEX Global Solutions, PO Box 25542 London ON N6C 6B2. Canadian G.S.T number: R-124213133RT001. Printed in U.S.A.

For address changes, please notify the Circulation Department by visiting www.surveymonkey.com/s/ subscriptions, or by mail to ONCOLOGY. ( 2021 MJH Life Sciences, PO Box 457, Cranbury N 08512-0457. Send old address, new address and attach a copy of mail label, if possible. 
AIM-HN

KURA KO-TIP-007

\section{FONCOLOG}

Now enrolling patients with HRAS-mutant HNSCC for AIM-HN

\section{A FARNESYLTRANSFERASE INHIBITOR STUDY}

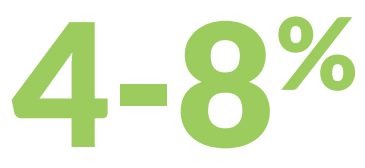

\section{OF PATIENTS WITH HNSCC HAVE HRAS MUTATIONS.}

HRAS mutations can be detected by most commercially available NGS panels. ${ }^{1,2}$

There are currently no FDA-approved therapies that target HRAS-mutant head and neck squamous cell carcinoma (HNSCC). ${ }^{1}$

\section{$\rightarrow$ ABOUT TIPIFARNIB $1,3,4$}

Tipifarnib is an oral investigational drug candidate for HRAS-mutant HNSCC. In preclinical models, tipifarnib blocks the activity of an enzyme called farnesyltransferase. It is the only farnesyltransferase inhibitor under investigation for HRAS-dependent HNSCC.

\section{$\rightarrow$ ABOUT AIM-HN}

AIM-HN is a pivotal, registration-directed study designed to evaluate the efficacy and tolerability of tipifarnib in HRAS-mutant HNSCC.

\section{KEY INCLUSION CRITERIA}

- At least 18 years of age.

- Histologically confirmed head and neck cancer (oral cavity, pharynx, larynx, sinonasal, nasopharyngeal, or unknown primary) of squamous histology not amenable to local therapy with curative intent.

- Documented treatment failure from most recent prior therapy (eg, tumor progression, clinical deterioration, or recurrence), and from at least one prior platinum-containing regimen, in any treatment setting. The most recent prior and platinum-based therapy may be the same regimen.

- Known tumor missense HRAS mutation.

- Measurable disease by Response Evaluation Criteria in Solid Tumors (RECIST) v1.1.

- Eastern Cooperative Oncology Group (ECOG) performance status of 0-1.

- Acceptable organ function.

\section{KEY EXCLUSION CRITERIA}

- Histologically confirmed salivary gland, thyroid, (primary) cutaneous squamous, or nonsquamous histologies (eg, mucosal melanoma).

- Concomitant disease or condition that could interfere with the conduct of the study or that would, in the opinion of the investigator, pose an unacceptable risk to the subject in this study.

$\rightarrow$ PRIMARY OUTCOME

- Objective response rate

\section{$\rightarrow$ KEY SECONDARY OUTCOMES}

- Duration of response

- Time to response

- Overall survival

- Progression-free survival

For your patients who are positive for HRAS mutation(s), AIM-HN may be right for them. Learn more about AIM-HN trial enrollment at kuraoncology.com/clinical-trials-aim. ClinicalTrials.gov identifier: $\underline{\text { NCT03719690 }}$

REFERENCES: 1. Malone E, Siu LL. Precision medicine in head and neck cancer: myth or reality? Clin Med Insights Oncol.

2018;12:1179554918779581. doi:10.1177/1179554918779581 2. The Cancer Genome Atlas Network. Comprehensive genomic characterization of head and neck squamous cell carcinomas. Nature. 2015;517(7536):576-582. 3. Gilardi M, Wang Z, Proietto M, et al. Tipifarnib as a precision therapy for HRAS-mutant head and neck squamous cell carcinomas. Mol Cancer Ther. 2020;19(9):1784-1796. 4. Kura Oncology (29 May 2020). Kura Oncology Reports Overall Survival Data from Phase 2 Trial of Tipifarnib in HRAS Mutant Head and Neck Squamous Cell Carcinoma [Press Release]. Retrieved from https://www.globenewswire.com/news-release/2020/05/29/2040900/0/en/Kura-Oncology-Reports-OverallSurvival-Data-from-Phase-2-Trial-of-Tipifarnib-in-HRAS-Mutant-Head-and-Neck-Squamous-Cell-Carcinoma.html 


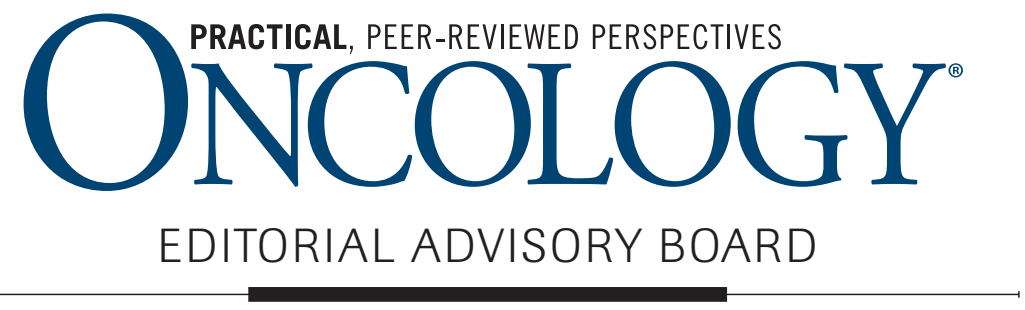

MISSION

ONCOLOGY ${ }^{\circledR}$ and its website, CancerNetwork.com, provide oncologists with the practical, timely, clinical information they need to deliver the highest level of care to their patients. Expert authors and peer review ensure the quality of ONCOLOGY ${ }^{\circledR}$ and CancerNetwork.com's articles and features. Focused discussions capture key clinical take-aways for application in today's time-constrained practice environment.

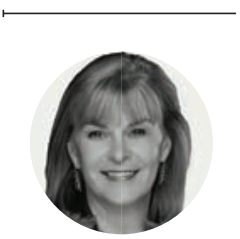

Julie M. Vose, MD, MBA Omaha, NE

\section{EDITORS-IN-CHIEF}

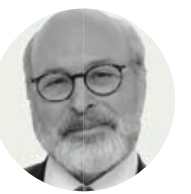

Howard S. Hochster, MD New Brunswick, NJ

\section{EDITORIAL BOARD}

\section{TUMOR CHAIRS}

\section{BREAST CANCER}

Sara A. Hurvitz, MD, Los Angeles, CA

GENITOURINARY CANCER

Robert A. Figlin, MD, Los Angeles, CA
GASTROINTESTINAL CANCER

Tanios S. Bekaii-Saab, MD, Phoenix, AZ

HEAD AND NECK CANCER

Eric J. Sherman, MD, New York, NY
HEMATOLOGIC MALIGNANCIES

C. Ola Landgren, MD, PhD, Miami, FL

THORACIC MALIGNANCIES

Hossein Borghaei, DO, MS, Philadelphia, PA

\section{BOARD MEMBERS}

BREAST CANCER

William J. Gradishar, MD, FACP, Chicago, IL

Tari King, MD, Boston, MA

Vered Stearns, MD, Baltimore, MD

Melinda L. Telli, MD, Palo Alto, CA

CANCER SURVIVORSHIP

Matthew J. Matasar, MD, MS, New York, NY

COLORECTAL/GASTROINTESTINAL CANCER

Edward Chu, MD, Pittsburgh, PA

Mehmet Sitki Copur, MD, FACP, Omaha, NE

Daniel Haller, MD, Philadelphia, PA

John L. Marshall, MD, Washington, DC

Shubham Pant, MD, Houston, TX

Matthew B. Yurgelun, MD, Boston, MA

GENITOURINARY CANCER

L. Michael Glodé, MD, FACP, Denver, CO

Paul Mathew, MD, Boston, MA

Elisabeth Heath, MD, FACP, Detroit, MI

Bobby Liaw, MD, New York, NY

GYNECOLOGIC ONCOLOGY

Mario M. Leitao Jr, MD, New York, NY

HEAD AND NECK CANCER

Apar K. Ganti, MD, MS, FACP, Omaha, NE
HEALTH ECONOMICS

Nora Janjan, MD, MPSA, MBA, Dallas, TX

HEMATOLOGIC MALIGNANCIES

Danielle M. Brander, MD, Durham, NC

Christopher R. Flowers, MD, Houston, TX

Steven T. Rosen, MD, Duarte, CA

Naval G. Daver, MD, Houston, TX

Ehab L. Atallah, MD, Milwaukee, WI

INFECTIOUS DISEASE

Genovefa Papanicolaou, MD, New York, NY

INTEGRATIVE ONCOLOGY

Ting Bao, MD, New York, NY

Linda Carlson, PhD, RPsych, Calgary, Alberta, Canada

LUNG CANCER

David S. Ettinger, MD, Baltimore, MD

James L. Mulshine, MD, Chicago, IL

Edward S. Kim, MD, Duarte, CA

Jennifer W. Carlisle, MD, Atlanta, GA

MELANOMA

Richard D. Carvajal, MD, New York, NY Jason Luke, MD, FACP, Pittsburgh, PA

\section{NEURO-ONCOLOGY}

David A. Reardon, MD, Boston, MA Stuart A. Grossman, MD, Baltimore, MD Nicole A. Shonka, MD, Omaha, NE

PEDIATRIC ONCOLOGY

David G. Poplack, MD, Houston, TX Richard A. Drachtman, MD, New Brunswick, NJ PROSTATE CANCER

Tomasz M. Beer, MD, Portland, OR

E. David Crawford, MD, Denver, CO Judd W. Moul, MD, FACS, Durham, NC

PSYCHO-ONCOLOGY

Daniel C. McFarland, DO, New York, NY Michelle Riba, MD, Ann Arbor, MI

\section{RADIATION ONCOLOGY}

Louis Potters, MD, FACR, Hempstead, NY James B. Yu, MD, MHS, New Haven, CT

SARCOMA

Kenneth Cardona, MD, FACS, Atlanta, GA

SUPPORTIVE AND PALLIATIVE CARE

Thomas J. Smith, MD, FACP, Baltimore, MD N. Simon Tchekmedyian, MD, Long Beach, CA

SURGICAL ONCOLOGY

Burton L. Eisenberg, MD, Newport Beach, CA

\section{INTERESTED IN SUBMITTING TO ONCOLOGY?}

Please contact Managing Editor Audrey Sternberg at ASternberg@mjhlifesciences.com for submission guidelines. 
NOVEMBER 2021 • VOL. 35 • NO. 5

\section{EDITORIAL}

KRISTIE L. KAHL Vice President, Content

AUDREY STERNBERG Managing Editor

HAYLEY VIRGIL Senior Editor

MATTHEW FOWLER, ARIANA PELOSCI Assistant Editors

JENNIFER POTASH Copy Chief

PAUL SILVERMAN Copy Supervisor

MARIE-LOUISE BEST, KELLY KING Senior Copy Editors CHENEY BALTZ, GEORGINA CARSON, KIRSTY MACKAY, RON PANAROTII, YASMEEN QAHWASH Copy Editors

\section{DESIGN \& PRODUCTION}

ROBERT MCGARR Creative Director

KRISTEN MORABITO Art Director

MAIA THAGARD Senior Graphic Designer

JONATHAN SEVERN Circulation Director

KEYONNA GRAHAM Production Director

\section{PUBLISHING \& SALES}

BRIAN HAUG Executive Vice President 609-325-4780•bhaug@mmhgroup.com MICHELLE JANIN Director of Sales

732-429-4316•mjanin@mmhgroup.com

PATRIC PASTORE National Accounts Manager 609-955-1694 • ppastore@mjhlifesciences.com

KRISTEN KOEDERITZ National Accounts Associate KKoederitz@mihlifesciences.com

\section{CORPORATE}

MIKE HENNESSY JR President \& CEO

JACK LEPPING Vice Chairman

NEIL GLASSER, CPA/CFE Chief Financial Officer

JOE PETROZIELLO Executive Vice President, Global Medical Affairs and Corporate Development SILAS INMAN Senior Vice President, Content MICHAEL BALL Senior Vice President Operations

SHARI LUNDENBERG Vice President, Human Resources \& Administration

CHRIS HENNESSY Vice President, Mergers \& Acquisitions

JEFF BROWN Executive Creative Director

Creative Services

\section{SUBSCRIPTIONS}

888-527-7008

\section{CHAIRMAN \& FOUNDER} MIKE HENNESSY SR

\section{ONCOLOGY ${ }^{\circledR}$ Looks to Conference Agendas for Current Trends}

As we approach the last few weeks of 2021, the oncology community is abuzz with news about major medical conferences and research breakthroughs presented therein. What's also evident when looking at conference agendas is just how much has changed in the treatment of cancer, with presentations dominated by topics related to extending health care to underserved populations and managing care with consideration to the COVID-19 pandemic.

Scheduled for presentation at the Society for Immunotherapy of Cancer's 36th Annual Meeting, taking place from November 10 through 14, are sessions covering topics related to COVID-19's impact on immunology and immunobiology and what the pandemic means to the conduct of clinical trials. Leaders in the field, such as Jeffrey Weber, MD, PhD, of NYU Langone Medical Center, will provide their expertise in this area.

At the upcoming American Society for Hematology Annual Meeting and Exposition, awards will include honoring Deepika Darbari, MD, of Children's National Hospital and the George Washington University School of Medicine and Health Sciences, for her lifetime of work to both advance minority representation professionally and strive for better care for underrepresented patient populations.

At the San Antonio Breast Cancer Symposium taking place in December, a special session titled "Trust in Science and Healthcare" will explore how investigators can extend the reach of patient care the underserved populations with key thought leaders, such as Eric P. Winer, MD, of Dana-Farber Cancer Institute, taking the helm for certain parts of the discussion.

Witnessing the resiliency of the oncology community in the face of challenges to both patients and their providers builds momentum in the community and is sure to lead to better outcomes going forward. As always, oncology providers across multidisciplinary specialties can stay up-to-date on the latest in this and other oncology news at CancerNetwork.com, home of the journal ONCOLOGY ${ }^{\circledR}$.

Mike Hennessy Sr Chairman and Founder of ONCOLOGY's parent company, MJH Life Sciences ${ }^{\text {mox }}$ 


\title{
LEADing the Way: Leadership, Empowerment, and Development Conference
}

\author{
Julie M. Vose, MD, MBA \\ Chief, Division of Hematology and Oncology \\ University of Nebraska Medical Center
}

$\mathrm{T}$ he LEAD 2021 conference recently brought together leaders in hematology-oncology for a daylong virtual event focusing on essential career development, networking, oral abstract presentations, and awards. What makes this conference different than all the other hematology and oncology conferences? LEAD stands for Leadership, Empowerment, and Development, Enriching and Supporting Women in Hematology and Oncology. This conference does not focus on the science or medicine of hematology-oncology, but instead focuses on presenting statistics on women in hematologyoncology leadership, the perceived barriers to advancement, and methods for overcoming these barriers.

LEAD had several unique aspects such as professional vignettes from hematology-oncology physicians, oral abstract presentations on diversity and inclusion, and an all-male panel discussing the male perspective on closing the gender gap in hematology-oncology. During the professional vignettes female physicians from academia, the pharmaceutical industry, and community practice discussed their stories and how they came to be the strong leaders they are today. These stories showed the remarkable resilience of the women who are subject to difficult circumstances in their personal or work environments and how they overcame these barriers. Abstracts were submitted for presentation on topics such as overcoming barriers, increasing diversity, and looking to the future of women in the hematology/oncology world. There was an excellent panel on resiliency and techniques to use for "treating" yourself and how to push the "reset button." This conference, of which I severed as a co-chair, is a testament to how many outstanding and capable women are working in hematology-oncology.

Julie Silver, MD, who is affiliated with Spaulding Rehabilitation, Massachusetts General Hospital, and Brigham and Women's Hospitals, gave the keynote address "Leadership Skills: How to Lead in a Man's World." Silver, who is associate professor and associate chair, Department of Physical Medicine and Rehabilitation at Harvard Medical School, has focused her research on improving gaps in the delivery of health care as well as workforce diversity and inclusion. She discussed how women are often excluded and looked over for positions of authority and how to overcome some of those barriers-such as education on business and leadership skills, involvement in key committees or teams, and volunteering for appropriate dutiesthat would be helpful in one's career.

My favorite part of the meeting was a panel of male hematology-oncology leaders who talked about the male perspective on closing the gender gap in leadership. The panel (a "man-el") was moderated by Elizabeth Plimack, MD, MS, Fox Chase Cancer Center, and featured Clifford Hudis, MD, FACP, FASCO, CEO of the American Society of Clinical Oncology; Thomas Lynch Jr, MD, president and director of Fred Hutchinson Cancer Research Center; Michael Caligiuri, MD, president of City of Hope National Medical Center; and Marty Whalen, vice president of Hematology at Bristol Meyers Squibb. My key takeaway from the panel was that it is critical for men to advocate for change. If all the committees are male dominated, there must be an advocate's voice to point out the inequities and to bring forward deserving female candidates for positions or awards. If $51 \%$ of the population is excluded from consideration, the position may not be filled by the most capable applicant. In addition, male leaders need to recognize the potential in all hematology-oncology physicians to enhance the infrastructure and be flexible to support their diverse needs.

The conference finished up with some practical tips on wealth wisdom and financial health for busy women professionals as well as 2 awards, Woman Oncologist of the Year, which was awarded to Pamela Kunz, MD, of Yale School of Medicine; and the Rising Star in Hematology-Oncology to Ana Velazquez Mañana, MD, MSc, of University of California, San Francisco Helen Diller Family Comprehensive Cancer Center. Ilook forward to the LEAD Conference next year and continuing education outreach on diversity and equity for female hematologyoncology physicians, hopefully at an in-person meeting. 
TO INFORM TREATMENT DECISIONS

\section{Signatera looks deeper

Is your cancer MRD test...

$>$ Pan-tumor

$>$ Quantitative

$>$ Predictive of treatment benefit ${ }^{1}$

Signatera ${ }^{T \mathrm{M}}$ is a personalized, tumor-informed assay for ultrasensitive detection of molecular residual disease (MRD) ${ }^{2}$

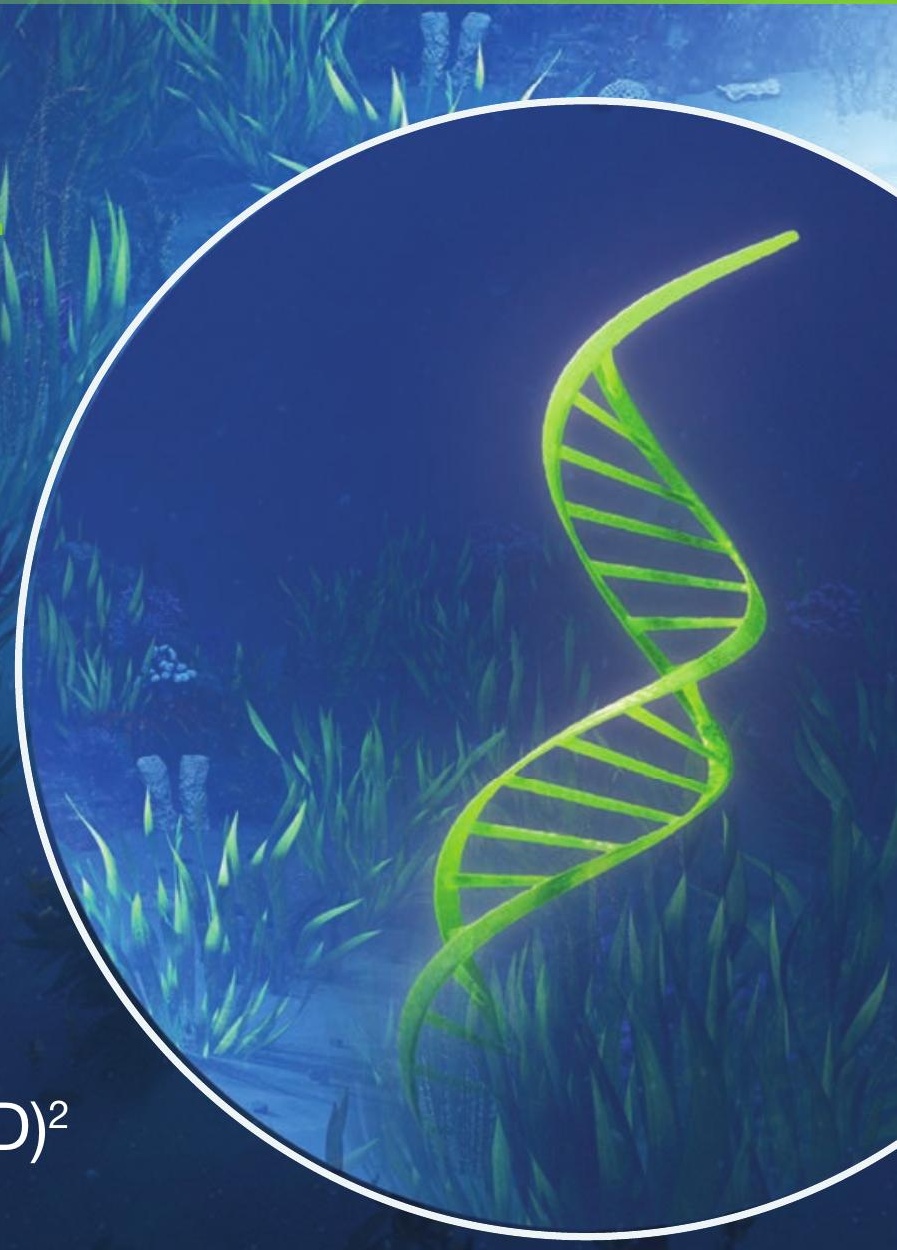

Dive deeper at natera.com/signateratest

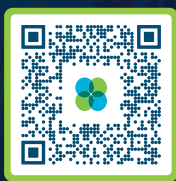

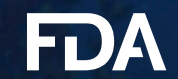

BREAKTHROUGH DESIGNATION

1. Christensen E, Birkenkamp-Demtroder K, Sethi H, et al. Early Detection of Metastatic Relapse and Monitoring of Therapeutic Efficacy by Ultra-Deep Sequencing of Plasma Cell-Free DNA in Patients With Urothelial Bladder Carcinoma. J Clin Oncol. 2019;37(18):1547-1557. 2. Reinert T, Henriksen TV, Christensen E, et al. Analysis of Plasma Cell-Free DNA by Ultradeep Sequencing in Patients With Stages I to III Colorectal Cancer. JAMA Oncol. 2019. 


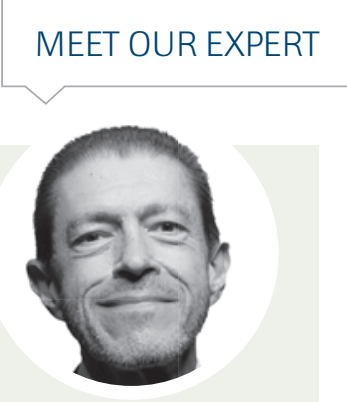

Jorge E. Cortes, MD, is the director of the Georgia Cancer Center and cochair of the 26th Annual International Congress on Hematologic Malignancies, hosted by Physicians' Education Resource, LLC (PER $\left.{ }^{\circledR}\right)$.

\section{How the Study of Leukemias Inspired a Decades-Long Career}

A passion for patient care by key oncology investigators has led to breakthroughs in the field of hematologic malignancies, with novel tyrosine kinase inhibitors (TKIs) and advancements in stem cell transplant administration leading the charge.

In an interview with $O N C O L O G Y^{\circledR}$, Jorge E. Cortes, MD, director of the Georgia Cancer Center as well as co-chair of the 26th Annual International Congress on Hematologic Malignancies, hosted by Physicians’ Education Resource, LLC (PER $\left.{ }^{\circledR}\right)$, discussed his entry into the field and how he led the charge through many important breakthroughs in therapy and approvals of life-saving treatments.

Cortes spoke about his research across different hematologic malignancies using TKIs and about recent clinical trials that have the potential to change the future of the treatment of hematologic malignancies. He also spoke about treating elderly patients and how they are just as determined to beat cancer as their younger counterparts.

\section{Q:} Can you discuss what you believe is the most significant research of your career?

A: [Over the course of my career, I've always worked on] some research in leukemia specifically, and have mostly focused on product development, particularly early product development. I think some of the most important contributions that I've made have been in CML [chronic myeloid leukemia]. I've been working on the development of some of the TKIs, and I've led the research that ended up in the approval of 3 of the drugs that we use today: ponatinib [Iclusig], bosutinib [Bosulif], and omacetaxine [Synribo]. [The latter is a drug] we don't use that much, but it's still a drug that was approved, and it helps a few patients.
I've done a lot of work [not only with] clinical trials, but also understanding the disease, the prognostic factors, the management of adverse effects [AEs]. I've also done a lot of work in AML [acute myeloid leukemia] and multiple trials with PI3K inhibitors. I also led the clinical trial that ended up leading to the approval of gilteritinib [Xospata], a hedgehog inhibitor for AML. ${ }^{1}$ Those are some of the most important contributions that I think I have been a part of.

\section{How did you decide that leukemia Q. was going to be your focus of research?}

A: It was a little bit by chance. I am originally from Mexico, and I had done my training there. However, I came to Houston to repeat 
my training, particularly in hematology. In Mexico, hematology and oncology are separated, so I came to repeat my training in hematology with a focus on thrombosis and hemostasis. [I went] to a sister institution of MD Anderson [Cancer Center], University of Texas Health Science Center across the street, because they had a good thrombosis and coagulation program there. The malignancy part of the rotation of that fellowship was at MD Anderson.

When I started my rotation, I started there in leukemia. I met wonderful mentors, in particular Susan O'Brien, MD. Looking at the research, the care, and the patients made me switch my program and the focus of my career. I had a lot of opportunities working with other departments and with her and Hagop M. Kantarjian, MD, and Moshe Talpaz, $\mathrm{MD}$, and many others. That convinced me to change [my career] and I am very happy I did.

\section{Q: What is it about leukemias that you found particularly} interesting?

A: Remember, we're talking about almost 30 years ago. In those days, it was very challenging [to treat] with very few new therapies available, but there was a good opportunity to study because the access to tissue was readily available. You get the outcomes very quickly. The clinical trials could be conducted rapidly. Again, the city where I was [located] was a very active environment for research with lots of clinical trials, academic discussions, and interaction. I thought it was a field that was ripe for preclinical research. Sure enough, since then a lot of new things have happened. Some of them I have been a part of, some of them I've been witnessing, but it's been a rapid development.

\section{Q: What drew you to research in TKIs?}

A: I was working [on treating] CML already with Talpaz and Kantarjian. It started with the development of what in those days was called CGP-571, which ended up being imatinib [Gleevec].

There was a collaboration with Brian Druker, MD, from Oregon; I was working in the clinic with Talpaz, who was the principal investigator at MD Anderson. I was a witness to those early patients who went into phase 1 trials. It became very impressive to see the response of these patients and the efficacy of the drug, knowing that it was so molecularly targeted. I had the opportunity very early on to meet Druker, and it was the start of the era of targeted therapy with good understanding of the biology and drugs that were specifically developed for that. You may remember the famous cover of Time magazine about "magic bullets." I was there, [and working] with these mentors made it a very attractive field. I started getting involved myself, leading some of these trials, and seeing one drug better than another led to the incredible improvements in something that was, up until then, very difficult to see.

\section{What were the biggest 1. challenges in the development of bosutinib and ponatinib?}

A: It is a very complex endeavor. You have to design trials in such a way that will not only give you the academic and clinical answers that you want, but will also meet the regulatory requirements for getting approval. It's a complex interaction, so you have to work with investigators, sponsors, and regulatory authorities. Most importantly, you have to work with patients to recruit and enroll them.

The drugs [may look] good initially, [but] you have to acknowledge that you know very little and sometimes you learn things that you didn't expect. For example, we had a wonderful drug, a very effective drug, and a great development, but then we learned that it had this risk of arterial occlusive events, [such as] heart attacks and strokes, and these things were completely unexpected. How do you react to that? You have very effective growth, but you have AEs that you didn't expect and don't want. The balance of what to do with that risk-benefit ratio and how you deal with the sponsor, the regulatory authorities, and, of course, the patients [is complex].

\section{Can you discuss challenges of treating older patients? How can we treat them better?}

A: It's a complex scenario because, number 1, leukemias are more frequent in older patients and the older population is complex. Age does make you less able to tolerate treatment. It is more common that older patients will not be able to tolerate treatments and you cannot treat them as aggressively. They take many other medications frequently, so there is the complexity of drug interactions, and they take many other medications frequently, so there is the complexity of drug interactions, and [the doctor or patients have] a tendency to give up.

I remember when I started, there were studies about treatments of AML in the elderly, and the age cutoff was 55 years. We wouldn't do stem cell transplants in patients aged 50 or 55 years or older. Nowadays that sounds ridiculous, but it reflected how toxic the therapy was, how different the perceptions were of age and life expectancy, and how [you should decide] what to do with these patients. Today, we recognize that these patients need special attention and special considerations, but they are as interested in defeating cancer as any other patient of any other age.

\section{REFERENCE}

Perl AE, Martinelli G, Cortes JE, et al. Gilteritinib or chemotherapy for relapsed or refractory FLT3-mutated AML. N Engl J Med. 2019;381(18):1728-1740. doi:10.1056/ NEJMoa 1902688 


\section{Efficacy of PARP Inhibitors as Maintenance Therapy for Metastatic Castration-Resistant Prostate Cancer: A Meta-Analysis of Randomized Controlled Trials}

Muhammad Rafay Khan Niazi, MD1; Abdullah Jahangir, MD1; Syeda Sahra, MD1; Saud Bin Abdul Sattar, MD1; Divya Asti, MD2; and Alexander Bershadskiy, MD22

\section{ABSTRACT}

BACKGROUND: PARP inhibitors have been recently approved by the FDA for the treatment of metastatic castration-resistant prostate cancer (mCRPC). Their effectiveness is seen when used with androgen deprivation therapy in patients with or without deleterious germline and somatic genetic mutations.

OBJECTIVES: To identify all the randomized controlled trials (RCTs) in which PARP inhibitors have been assessed in the treatment of mCRPC, and to compare the efficacy of PARP inhibitors in these patients with standard-of-care (SOC)/antihormonal therapies like abiraterone acetate (Zytiga) or enzalutamide (Xtandi) in terms of progression-free survival (PFS) and overall survival (OS).

SEARCH STRATEGY: A systemic review search was conducted using PubMed, Embase, and Central Cochrane Registry.

SELECTION CRITERIA: Randomized clinical trials with PARP inhibitors, with or without antihormonal therapy, as the intervention arm, with SOC as control.

DATA ANALYSIS: HRs were calculated for PFS and OS. For effect sizes, a confidence interval of $95 \%$ was used, and for statistical significance, a $P$ value of less than .05 was used. Analysis was done using random and fixed effect analysis and both were reported. Heterogeneity was evaluated using $\mathrm{l}^{2}$ statistic.

RESULTS: Three RCTs were included in the analysis. PARP inhibitors showed a statistically significant improvement in OS when calculated using a fixed model (HR, 0.751; 95\% Cl, 0.582-0.968) but the improvement was not significant when calculated using a random model (HR, 0.758; $95 \% \mathrm{Cl}, 0.565-$ $1.017 ; I^{2}=23$ ). Similarly, the improvement in PFS was statistically significant when calculated using a fixed model (HR, 0.626; 95\% Cl, 0.521-0.752), and no statistical significance was noted with a random model (HR, 0.674; 95\% Cl, 0.437-1.039; $\mathrm{I}^{2}=80$ ).

CONCLUSIONS: PARP inhibitors contributed to significant increases in PFS and OS when used with or without antihormonal agents like abiraterone or enzalutamide. This efficacy was pronounced among the patients with deleterious germline or somatic homologous recombination repair gene mutations, although patients without these mutations also showed a better PFS and OS in comparison with SOC therapy.

KEYWORDS: PARP inhibitors, metastatic castrationresistant prostate cancer (mCRPC), overall survival, progression-free survival 


\section{Introduction}

Prostate cancer is the second most common and fifth most aggressive cancer among men worldwide. ${ }^{1}$ According to one estimate, 1 in 7 US men and 1 in 25 men worldwide will be diagnosed with prostate cancer during his lifetime. ${ }^{1}$ Despite the advanced screening methods available, such as measurement of prostate-specific antigen levels, the incidence of metastatic disease remains as high as $20 \% .^{2}$ The best-known risk factors for prostate cancer are race (ie, African American descent), obesity, and genetics (eg, BRCA1/2 mutations). Gleason scoring is commonly used for histopathologic evaluation and for clinical and pathologic staging of disease. Patients with high-risk disease are treated with prostatectomy and/ or external beam radiotherapy followed by androgen deprivation therapy (ADT) as maintenance therapy. If disease progression occurs while the patient is receiving ADT, the disease is noted to be castration-resistant prostate cancer (CRPC). Unfortunately, the majority of patients with prostate cancer progress to castration-resistant disease within 2 to 3 years. ${ }^{3}$

For decades the standard-of-care (SOC) treatment for metastatic CRPC (mCRPC) has been composed of cytotoxic agents, including taxanes (docetaxel or cabazitaxel [Jevtana]), and second-generation antihormonal agents (antihormonal therapy; AHT) such as abiraterone (Zytiga) or enzalutamide (Xtandi). Previously, CRPC was called "androgen-independent prostate cancer" and "hormone-refractory prostate cancer." "Subsequently, results of several studies showed that intratumoral (intracrine and paracrine) androgen production plays a significant role in the development of resistance among prostate cancer cells to testosterone suppression therapy. ${ }^{5}$

Other treatment options include pembrolizumab (Keytruda) for PD-L1-positive and microsatellite instability (MSI)-high disease, and radium-223 (Xofigo) for bone metastasis. PARP1 (or PARP) inhibitors are used in patients with mutations in homologous recombination repair (HRR)

\section{FIGURE 1. PRISMA Flow Diagram for Meta-Analysis}
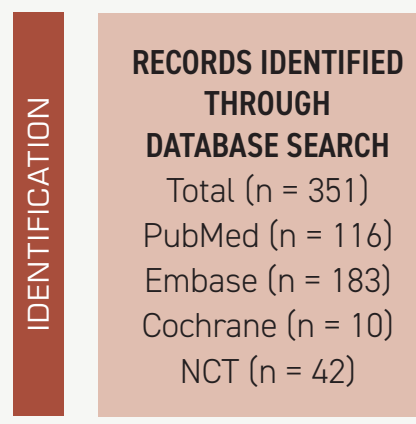

Total $(n=351)$

PubMed $(n=116)$

Embase $(n=183)$

Cochrane $(n=10)$

$\operatorname{NCT}(n=42)$
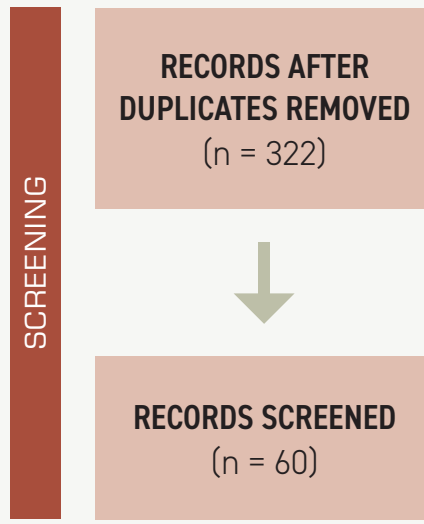

RECORDS SCREENED

$(n=60)$

RECORDS EXCLUDED

$(n=262)$
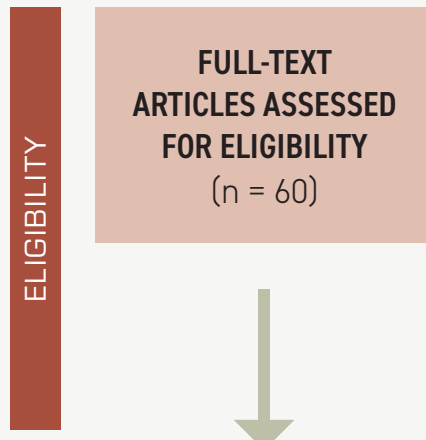

\section{FULL-TEXT ARTICLES EXCLUDED, WITH REASONS}

$$
(n=57)
$$

Review articles $(n=13)$

Incomplete trials ( $n=37$ )

Terminated trials $(n=2)$

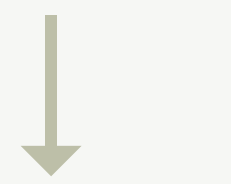

Intervention not related $(n=1)$

Single arm $(n=4)$ 
genes (most commonly, BRCA1/2). Recent study results indicate that the androgen receptor (AR) regulates the DNA repair pathways, and reciprocally, several enzymes involved in DNA repair can moderate AR activity. ${ }^{6-8}$ An example of such an enzyme is PARP1, which is involved in identifying single-stranded DNA breaks and their repair through the base excision method. ${ }^{9}$ Several cancers, including prostate cancer, exhibit increased PARP1 activity or expression. ${ }^{9-11}$ The mechanism of action of PARP inhibitors includes physical obstruction of the replication fork (PARP trapping), which affects HRR, resulting in DNA double-strand breaks. ${ }^{12}$ Previous study results have shown that these PARP inhibitors are synergistic when used with agents affecting the AR pathway regardless of HRR mutation status. ${ }^{9,13}$ In 2020, for the first time, the FDA approved PARP inhibitors for use in mCRPC.

The aim of this meta-analysis is to analyze the efficacy of these drugs in the treatment of mCRPC in terms of progression-free survival (PFS) and overall survival (OS), using the results of completed trials.

\section{Methodology}

The authors followed PRISMA guidelines.

\section{Search Strategy}

The databases accessed were Cochrane Central Registry of Clinical Trials, Embase, and PubMed. Search terms used were PARP inhibitors, prostate cancer, prostate neoplasm, olaparib (Lynparza), veliparib.

\section{Inclusion and Exclusion Criteria}

Papers had no restrictions in terms of date or status of publications. To be included, however, the papers had to report on RCTs that:

1. compared PARP inhibitors against SOC in patients with MCRPC;

2. reported PFS and OS;

3. included only patients 18 years or older; and

4. were available in the English language.

Papers that did not meet the above criteria were excluded.

\section{Trial Selection and Evaluation}

Three authors independently reviewed all articles and abstracts and excluded the irrelevant trials. Risk of bias for selected papers was assessed using the Cochrane Collaboration tool and then classified as high, uncertain, or low.

\section{Data Extraction}

Information was extracted using a prespecified extraction table. Information was extracted from the papers by reading through the main texts and tables, and a second author reviewed the information collected to ensure its accuracy. The extracted data included HRs for PFS and OS.

\section{Statistical Analysis}

The meta-analysis was performed using Comprehensive Meta-analysis software version 3. HRs were calculated for PFS and OS . For effect sizes, a 95\% CI was used, and a $P$ value of less than .05 indicated statistical significance. Analysis was done using random and fixed models and both were reported. Heterogeneity was evaluated using $I^{2}$ statistic and categorized as low (<40), moderate (40-60), and high (>60). Where a median was used, it was assumed to be equivalent to the mean, and SDs were estimated by dividing interquartile differences by 1.35 . Fixed effect analysis is usually adapted in cases where $\mathrm{I}^{2}$ value is $\leq 50 \%$; otherwise, random effect model is used.

\section{Literature Search}

The initial search identified 351 articles; removal of duplicates left 322 . The first screening excluded 262 articles. The full texts of the remaining 60 articles were analyzed. Thirty-seven articles were excluded because the trials described were incomplete; 13 were review articles; 2 described trials that were terminated; 4 were about single-arm studies; and 1 article's study did not have relevant intervention. Ultimately, articles describing 3 RCTs were included, and these trials had a total of 682 patients. The PRISMA flow diagram is shown in Figure 1, and main characteristics of RCTs are listed in the Table.

\section{Results}

\section{Risk of bias}

The results of risk of bias are shown in Figure 2 and Figure 3.

\section{Results of quantitative analysis \\ Overall survival}

Two studies reported OS when patients used PARP inhibitors compared with SOC. ${ }^{14,15}$ The difference was statistically significant when calculated using the fixed model (HR, 0.751; 95\% CI, 5.82-0.968; $P=.027$ ), and $\mathrm{I}^{2}=23.23$. When calculated using the random model, there was a strong deviation favoring PARP inhibitors, but it did not reach statistical significance (HR, 0.758; 95\% CI, 0.565-1.017; $P=.064)$ (Figure 4).

\section{Progression-free survival}

Three studies reported PFS when patients used PARP inhibitors compared with SOC. ${ }^{14-16}$ The difference was 


\section{TABLE. Characteristics of Randomized Control Trials}

\begin{tabular}{|c|c|c|c|c|c|}
\hline Study name & $\begin{array}{l}\text { Treatment } \\
\text { drugs }\end{array}$ & $\begin{array}{c}\text { Study } \\
\text { characteristic }\end{array}$ & Inclusion & Exclusion & $\begin{array}{c}\text { Primary } \\
\text { outcome(s) }\end{array}$ \\
\hline $\begin{array}{l}\text { Clarke et al } \\
\text { (NCT01972217) }\end{array}$ & $\begin{array}{l}\text { Olaparib (300 } \\
\text { mg BID) + } \\
\text { abiraterone } \\
(1000 \mathrm{mg} \text { OD) } \\
(\mathrm{n}=71) \mathrm{vs} \\
\text { abiraterone } \\
(1000 \mathrm{mg} \text { od }) \\
\text { alone }(\mathrm{n}=71)\end{array}$ & $\begin{array}{l}\text { Patients with } \\
\text { mCRPC who had } \\
\text { previously received } \\
\text { docetaxel and } \\
\text { were candidates } \\
\text { for abiraterone } \\
\text { treatment }\end{array}$ & $\begin{array}{l}\text { Male, aged >18, } \\
\text { with mCRPC; } \\
<2 \text { prior lines of } \\
\text { chemotherapy; } \\
\text { testosterone < } 50 \\
\text { ng/dL; no previous } \\
\text { exposure to } \\
\text { second-generation } \\
\text { antihormonal } \\
\text { agents; candidate } \\
\text { for abiraterone } \\
\text { treatment; ECOG } \\
\text { performance } \\
\text { status of } 0-2 ; \text { life } \\
\text { expectancy } \geq 12 \\
\text { weeks }\end{array}$ & $\begin{array}{l}\text { Any previous } \\
\text { treatment with } \\
\text { PARPi; previous } \\
\text { treatment with DNA- } \\
\text { damaging cytotoxic } \\
\text { chemotherapy; } \\
\text { other malignancies } \\
\text { (including MDS and } \\
\text { MGUS) within the } \\
\text { past } 5 \text { years }\end{array}$ & $\begin{array}{l}\text { Percentage } \\
\text { of patients } \\
\text { experiencing } \\
\text { adverse events; } \\
\text { number of patients } \\
\text { with dose-limiting } \\
\text { toxicities; median } \\
\text { (rPFS) time; } \\
\text { percentage of } \\
\text { patients with } \\
\text { progression events } \\
\text { or death }\end{array}$ \\
\hline $\begin{array}{l}\text { De Bono et } \\
\text { al (PROfound } \\
\text { study; NCT029 } \\
\text { 87543) }\end{array}$ & $\begin{array}{l}\text { Olaparib ( } 300 \\
\text { mg BID) vs } \\
\text { enzalutamide } \\
\text { ( } 160 \text { mg OD) } \\
\text { or abiraterone } \\
\text { (1000 mg OD) } \\
+ \text { prednisone } \\
\text { ( } 5 \text { mg BID) }\end{array}$ & $\begin{array}{l}\text { Men with mCRPC } \\
\text { whose disease } \\
\text { had progressed } \\
\text { during treatment } \\
\text { with enzalutamide } \\
\text { or abiraterone. } \\
\text { Cohort } A= \\
\text { patients with at } \\
\text { least } 1 \text { alteration } \\
\text { in } B R C A 1, B R C A 2 \text {, } \\
\text { or ATM. Cohort } \\
B=\text { patients with } \\
\text { alteration in any of } \\
12 \text { other genes }\end{array}$ & $\begin{array}{l}\text { Men } \geq 18 \text { years of } \\
\text { age with mCRPC; } \\
<2 \text { prior lines of } \\
\text { chemotherapy; } \\
\text { no previous } \\
\text { exposure to } \\
\text { second-generation } \\
\text { antihormonal } \\
\text { agents; candidate } \\
\text { for abiraterone } \\
\text { treatment; ECOG } \\
\text { performance } \\
\text { status of } 0-2 ; \text { life } \\
\text { expectancy } \geq 12 \\
\text { weeks }\end{array}$ & $\begin{array}{l}\text { Any previous } \\
\text { treatment with } \\
\text { PARPi; previous } \\
\text { treatment with DNA- } \\
\text { damaging cytotoxic } \\
\text { chemotherapy; } \\
\text { other malignancies } \\
\text { (including MDS and } \\
\text { MGUS) within the } \\
\text { past } 5 \text { years }\end{array}$ & $\begin{array}{l}\text { PFS via RECIST v1.1 } \\
\text { for soft tissue, as } \\
20 \% \text { increase in the } \\
\text { sum of diameters of } \\
\text { target lesions }\end{array}$ \\
\hline $\begin{array}{l}\text { Hussain et al } \\
\text { (NCT01576172) }\end{array}$ & $\begin{array}{l}\text { Arm } A= \\
\text { abiraterone } \\
(1000 \text { mg })+ \\
\text { prednisone (5 } \\
\text { mg BID). Arm } \\
B=\text { veliparib } \\
\text { (300 mg BID) } \\
+ \text { abiraterone } \\
\text { (1000 mg) + } \\
\text { prednisone (5 } \\
\text { mg BID) }\end{array}$ & $\begin{array}{l}\text { Patients } \\
\text { stratified by prior } \\
\text { ketoconazole } \\
\text { and ETS fusion } \\
\text { status (positive } \\
\text { or negative). } \\
\text { Randomly } \\
\text { assigned to Arm A } \\
\text { or Arm B }\end{array}$ & $\begin{array}{l}\text { Men with mCRPC; } \\
\text { ECOG status, } \\
0-2 ; \text { testosterone } \\
<50 \text { ng/dL; no } \\
\text { prior exposure } \\
\text { to abiraterone; } \\
2 \text { or fewer prior } \\
\text { chemotherapy } \\
\text { regimens }\end{array}$ & $\begin{array}{l}\text { Chemotherapy, } \\
\text { radiotherapy, or oral } \\
\text { antifungal agents } \\
\text { (within } 3 \text { weeks } \\
\text { prior to entering } \\
\text { the study); history } \\
\text { of active seizures; } \\
\text { pituitary or adrenal } \\
\text { dysfunction; active } \\
\text { or symptomatic viral } \\
\text { hepatitis; chronic } \\
\text { liver disease; brain } \\
\text { metastases }\end{array}$ & $\begin{array}{l}\text { Confirmed PSA } \\
\text { response rate time } \\
\text { frame: up to } 3 \text { years }\end{array}$ \\
\hline
\end{tabular}

BID, twice daily; mCRPC, metastatic castration resistant prostate cancer; MDS, myelodysplastic syndrome; MGUS, monoclonal gammopathy of undetermined significance; OD, once daily; PARPi, PARP inhibitors; PFS, progression-free survival; PSA, prostate specific antigen; rPFS, radiologic PFS. 
statistically significant when calculated using the fixed model (HR, 0.626; 95\% CI, 0.521-0.752; $P<.001$ ), and $\mathrm{I}^{2}=80.240$. When calculated using the random model, there was a strong deviation favoring PARP inhibitors, but it did not reach statistical significance (HR, 0.674; 95\% CI, 0.437-1.039; $P=$.074) (Figure 5).

\section{Discussion}

Overall results of this meta-analysis indicate that patients with mCRPC experience survival benefits when treated with PARP inhibitors as compared with placebo or SOC chemotherapy. OS was better in the PARP inhibitor group under fixed effect (HR, 0.751; 95\% CI,0.582-0.968; $P=.027$ ) and under random effect (HR, 0.758; 95\% CI, 0.565-1.017;

\section{FIGURE 2. Risk of Bias Graph: Review Authors' Judgements About Each Risk of Bias Item Presented as Percentages Across All Included Studies}

LOW RISK OF BIAS

Random sequence generation (selection bias)

Allocation concealment (selection bias)

Blinding of participants and personnel (performance bias)

Blinding of outcome assessment (detection bias)

Incomplete outcome (attrition bias)

Selective reporting (reporting bias)

Other bias

(1)
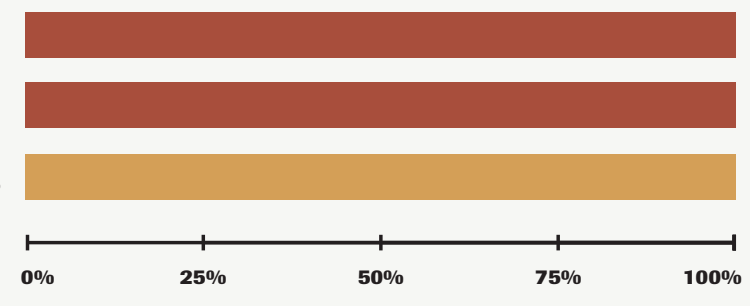

\section{FIGURE 3. Risk Of Bias Summary: Review Authors' Judgements About Each Risk of Bias Item} for Each Included Study

$\begin{array}{rccc} & \text { Clarke et al } & \text { de Bono et al } & \text { Hussain et al } \\ \text { Random sequence generation (selection bias) } & + & 2020\end{array}$ ?


$P=.064)$. PFS was improved in the PARP inhibitor group (HR, 0.626; 95\% CI, 0.521-0.752; $P<.001$ ) compared with the chemotherapy group when analyzed under fixed effect.

In 2020, the FDA approved 2 PARP inhibitorsrucaparib (Rubraca) and olaparib-to treat $\mathrm{mCRPC}$ in patients harboring somatic and/or germline mutations in BRCA1 or BRCA2 as well as in ATM genes. This decision was based upon the data from the multicenter, single-arm TRITON2 clinical trial (NCT02952534), in which rucaparib was used in patients with $\mathrm{MCRPC}$ positive for $B R C A$ mutations. Currently, numerous clinical trials are ongoing to determine the efficacy of PARP inhibitors in mCRPC. Ongoing clinical trials with olaparib, veliparib, rucaparib, niraparib (Zejula), and talazoparib (Talzenna) in $\mathrm{MCRPC}$ were searched on the clinicaltrials.gov website. Currently, 37 trials are ongoing, 2 have been terminated, and 3 trials have been completed.

In 2 trials, olaparib was the study drug. ${ }^{14,15}$ In Clarke et al, patients were randomized into the treatment group (abiraterone plus olaparib) or the control group (abiraterone alone) irrespective of any genetic mutations or biomarker criteria. The study showed statistically significant improvement in both PFS and OS in the treatment group, indicating that a broader population, regardless of HRR mutation status, can benefit from the synergy of PARP inhibitors and AR inhibitors. However, men with HRR mutations derive the greatest benefit from these medications.

Our literature review also shows that PARP inhibitors are much more effective in patients with HRR or ATM mutations. In the PROfound study (NCT02987543; de Bono et al), patients were divided into 2 cohorts: Cohort $\mathrm{A}$ included patients with 1 or more of 3 mutations (BRCA1/2; $A T M)$, and Cohort $\mathrm{B}$ included patients with a mutation in any of 12 other prespecified genes. Each cohort was divided into a treatment arm (olaparib) and a control arm (enzalutamide or abiraterone). OS was prolonged when measured together for cohorts A and B: 17.5 months with PARP inhibitor vs 14.4 months with chemotherapy (HR for death, 0.67; 95\% CI, 0.49-0.93). The PFS for cohort A vs cohort B was 7.4 months vs 3.6 months, respectively; HR for progression or death, $0.34 ; 95 \% \mathrm{CI}, 0.25-0.47 ; P<.001$. The results for Cohort A and B combined showed median PFS to be

\section{FIGURE 4. Forest Plot on Overall Survival When Assessed Under Fixed Effect (above) and Random Effect Analysis (below)}

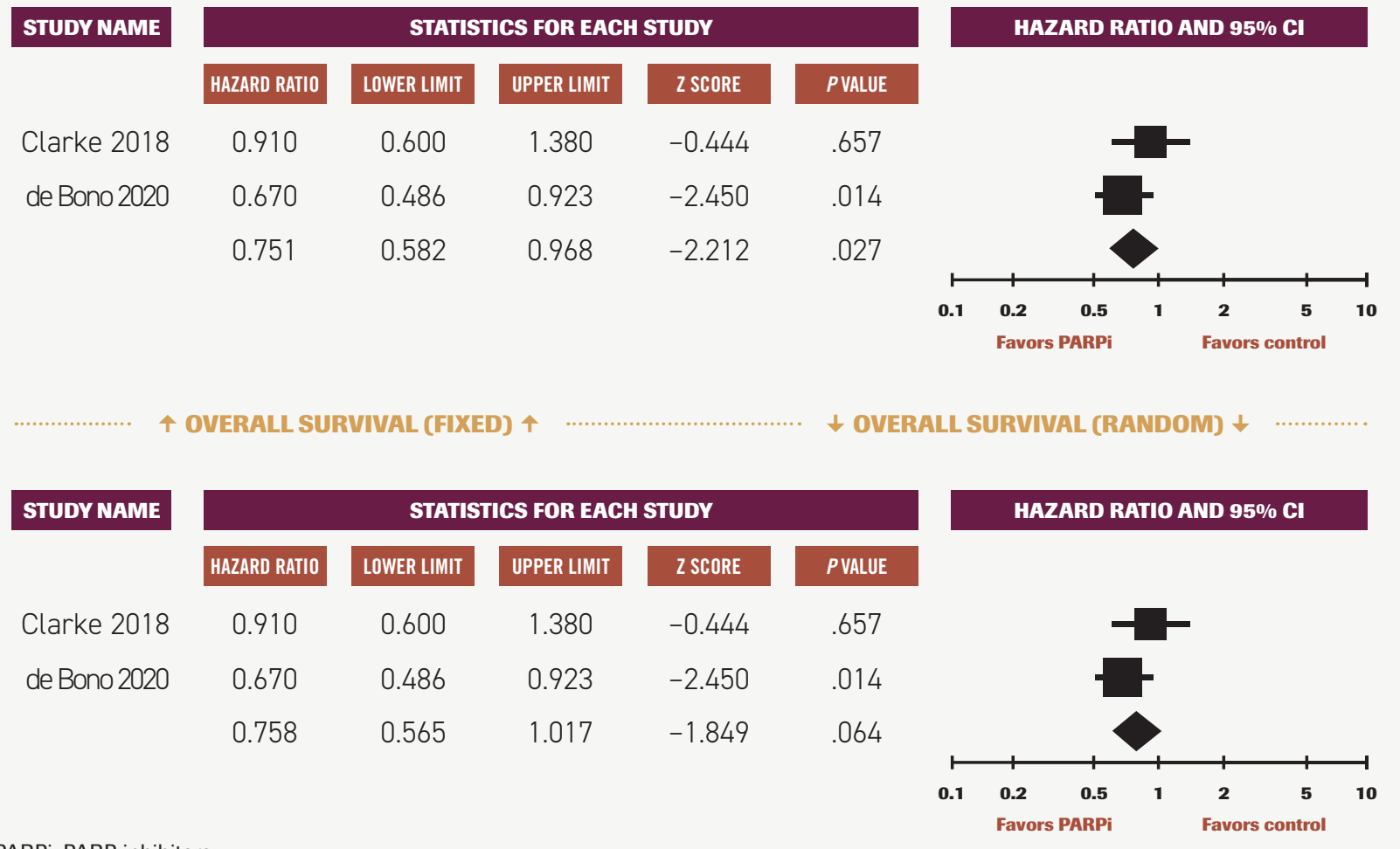

PARPi, PARP inhibitors 
5.8 months vs 3.5 months (HR, 0.49; 95\% CI, 0.38-0.63; $P<.001)$. Once again, these results indicate that PARP inhibitors are effective in patients with $\mathrm{mCRPC}$ regardless of genetic mutation status, although responses are much more evident in the population with BRCA and ATM alterations.

In the third trial (NCT01576172; Hussain et al), veliparib was compared with a control regimen of abiraterone plus prednisone. ${ }^{16}$ The investigators' primary objective was to see if ETS fusion status (related to a family of transcription factors) has a role in the tumor response to the treatment. Patients were first divided according to ETS fusion status (positive or negative) and then equally distributed in the case and control cohorts. Surprisingly, there was no difference in PFS between the treatment arms, regardless of ETS status, with overall PFS of 11 months (95\% CI, 8.1-13.6) in the treatment group vs 10.1 months (95\% CI, 8.2-13.8) in the control group $(P=.99)$. However, a significant finding was that DNA repair status (ie, DRD gene mutation) was associated with statistically significant improvement in PFS regardless of treatment status: 14.5 months (abnormal DRD gene) vs 8 months (normal DRD gene) (HR, 0.52; 95\% CI, $0.29-0.93 ; P=.02$ ). This study was not included in the forest plot for OS because OS was not calculated in this group.

\section{Strengths and limitations}

This study, as a meta-analysis, remains a retrospective chart review; the possibility for biases exists. Fewer trials and smaller study populations lead to publication bias. We made our best effort to locate all relevant published studies, randomize them, and complete data extraction and analysis. Another major limitation of this trial is the difficulty in performing stratified pool analysis for each PARP inhibitor drug; only a very limited number of completed phase 2/3 RCTs have currently available results. Other potential contributors to bias for this meta-analysis include heterogeneous population and inclusion criteria (with different first-line therapy patients

\section{FIGURE 5. Forest Plot on Progression-Free Survival When Assessed Under Fixed Effect (above) and Random Effect Analysis (below)}

\begin{tabular}{r|cccccc} 
STUdY NAME & \multicolumn{5}{c}{ STATISTICS FOR EACH STUDY } \\
& HAZARD RATI0 & LOWER LIMIT & UPPER LIMIT & Z SCORE & PVALUE \\
Clarke 2018 & 0.650 & 0.438 & 0.965 & -2.136 & 0.033 \\
de Bono 2020 & 0.490 & 0.381 & 0.631 & -5.531 & 0.000 \\
Hussain 2017 & 1.000 & 0.697 & 1.434 & 0.000 & 1.000 \\
& 0.626 & 0.521 & 0.752 & -5.004 & 0.000
\end{tabular}

HAZARD RATIO AND 95\% CI

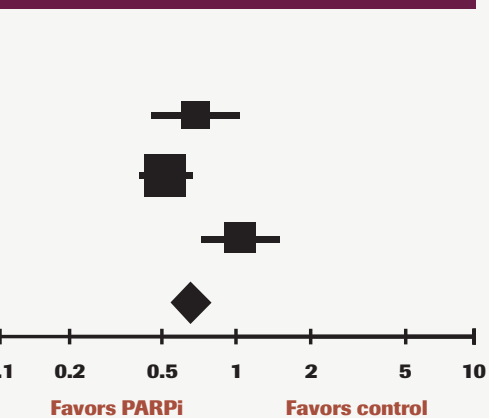

\section{STUDY NAME}

HAZARD RATIO

Clarke 2018

0.650

de Bono 2020

0.490

Hussain 2017

1.000

0.674
STATISTICS FOR EACH STUDY

LOWER LIMIT

0.438

0.381

0.697

0.437

UPPER LIMIT

0.965

0.631

1.434

1.039

\section{Z SCORE}

$-2.136$

$-5.531$

0.000

$-1.787$
PVALUE

.033

.000

1.000

.074
HAZARD RATIO AND 95\% CI

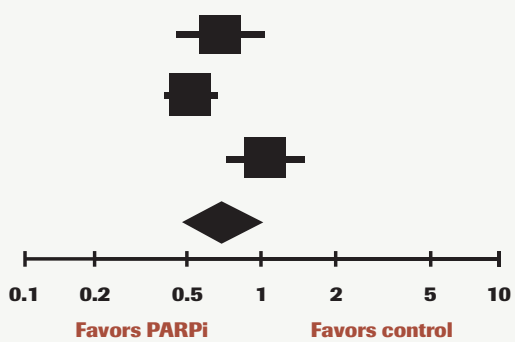


and BRCA or other gene mutations). Another limitation is the inability to compare the adverse effect profiles between the PARP inhibitor and chemotherapy groups.

Conversely, a strength of this analysis is that it includes all phase 2/3 RCTs evaluating the efficacy of PARP inhibitors in mCRPC that have been completed and published, to date.

\section{Conclusions}

This meta-analysis shows that PARP inhibitors can prolong PFS or OS compared to SOC treatment in patients with mCRPC irrespective of HRR or other genetic mutation status. Longer PFS and OS were seen when PARP inhibitors were used alone or in combination with AHT therapies like abiraterone or enzalutamide. The effect was more significant when examined with a fixed model analysis. Although there was a significant deviation towards an increase in PFS and OS in the random model analysis, the effect was not statistically significant, and it was likely secondary to a relatively small patient population in the meta-analysis. Although, at baseline, there was heterogeneity among the populations participating in these trials, in terms of genetic alterations, the results of all the trials showed better outcomes in their intervention arms. This heterogeneity can be dealt with by incorporating more RCTs into meta-analyses going forward. More studies can further magnify these results once they are published.

\section{DECLARATIONS}

ETHICS APPROVAL AND CONSENT TO PARTICIPATE: The data

extracted and manuscript were reviewed with the Research Department and Ethics Committee of Department of Medicine, Staten Island University Hospital/Northwell. No experimental intervention was performed, and no specifications of guidelines, legislations, or permissions were required.

AVAILABILITY OF DATA AND MATERIALS: Data are available in Excel files. Patient identifying information was removed at all stages in all the studies included.

COMPETING INTERESTS: No competing financial or personal interests are involved for all the authors.

FUNDING: No funding was obtained from any organization or personnel during any stage of manuscript writing or submission.

AUTHOR'S CONTRIBUTIONS: Manuscript written and data obtained by M.R.K.N, A.J, S.S, S.B.S. Proofreading and literature review done by D.A and A.B.

\section{AUTHOR AFFILIATIONS:}

1. Department of Internal Medicine, Zucker School of Medicine at Hofstra/Northwell at Staten Island University Hospital, Staten Island, NY, USA.

2. Division of Hematology and Medical Oncology, Zucker School of Medicine at Hofstra/Northwell at Staten Island University Hospital, Staten Island, NY, USA.

\section{REFERENCES}

1. Barsouk A, Padala SA, Vakiti A, et al. Epidemiology, staging and management of prostate cancer. Med Sci (Basel). 2020;8(3):28. doi:10.3390/medsci8030028

2. Studer UE, Hauri D, Hanselmann S, et al. Immediate versus deferred hormonal treatment for patients with prostate cancer who are not suitable for curative local treatment: results of the randomized trial SAKK 08/88. J Clin Oncol. 2004;22(20):4109-4118. doi:10.1200/ jco.2004.11.514

3. Harris WP, Mostaghel EA, Nelson PS, Montgomery B. Androgen deprivation therapy: progress in understanding mechanisms of resistance and optimizing androgen depletion. Nat Clin Pract Urol. 2009;6(2):76-85. doi:10.1038/ncpuro1296

4. Ahmad K. New progress in treatment of hormone-refractory prostate cancer. Lancet Oncol. 2004;5(12):706. doi:10.1016/s14702045(04)01641-9

5. Montgomery RB, Mostaghel EA, Vessella R, et al. Maintenance of intratumoral androgens in metastatic prostate cancer: a mechanism for castration-resistant tumor growth. Cancer Res. 2008;68(11):44474454. doi:10.1158/0008-5472.Can-08-0249

6. Haffner MC, Aryee MJ, Toubaji A, et al. Androgen-induced TOP2B-mediated double-strand breaks and prostate cancer gene rearrangements. Nat Genet. 2010;42(8):668-675. doi:10.1038/ng.613

7. Schiewer MJ, Knudsen KE. Linking DNA damage and hormone signaling pathways in cancer. Trends Endocrinol Metab. 2016;27(4):216-225 .doi:10.1016/j.tem.2016.02.004

8. Ta HQ, Gioeli D. The convergence of DNA damage checkpoint pathways and androgen receptor signaling in prostate cancer. Endocr Relat Cancer. 2014;21(5):R395-R407. doi:10.1530/erc-14-0217

9. Schiewer MJ, Goodwin JF, Han S, et al. Dual roles of PARP1 promote cancer growth and progression. Cancer Discov. 2012;2(12):1134-1149. doi:10.1158/2159-8290.Cd-12-0120

10. Hirai K, Ueda K, Hayaishi O. Aberration of poly(adenosine diphosphate-ribose) metabolism in human colon adenomatous polyps and cancers. Cancer Res. 1983;43(7):3441-3446.

11. Fukushima M, Kuzuya K, Ota K, Ikai K. Poly(ADP-ribose) synthesis in human cervical cancer cell -diagnostic cytological usefulness. Cancer Lett. 1981;14(3):227-236. doi:10.1016/0304-3835(81)90148-8

12. O'Connor MJ. Targeting the DNA damage response in cancer. Mol Cell. 2015;60(4):547-560. doi:10.1016/j.molcel.2015.10.040

13. Asim M, Tarish F, Zecchini HI, et al. Synthetic lethality between androgen receptor signalling and the PARP pathway in prostate cancer. Nat Commun. 2017;8(1):374. doi:10.1038/s41467-017-00393-y

14. de Bono J, Mateo J, Fizazi $\mathrm{K}$, et al. Olaparib for metastatic castration-resistant prostate cancer. N Engl J Med. 2020;382(22):20912102. doi:10.1056/NEJMoa1911440

15. Clarke N, Wiechno P, Alekseev B, et al. Olaparib combined with abiraterone in patients with metastatic castration-resistant prostate cancer: a randomised, double-blind, placebo-controlled, phase 2 trial. Lancet Oncol. 2018;19(7):975-986. doi:10.1016/s14702045(18)30365-6

16. Hussain M, Daignault-Newton $S$, Twardowski PW, et al. Targeting androgen receptor and DNA repair in metastatic castration-resistant prostate cancer: results from NCI 9012. J Clin Oncol. 2018;36(10):991999. doi:10.1200/jco.2017.75.7310

For references visit cancernetwork.com/Niazi_11.21 


\section{Powerful efficacy to start the treatment journey ${ }^{1,4}$}

After a median $\sim 30$ months* of follow-up, mPFS was not reached with DARZALEX ${ }^{\circledR}$ Rd vs 31.9 months with Rd alone. ${ }^{1.4}$

- $70.6 \%$ of patients had not progressed with DRd vs $55.6 \%$ of patients in the Rd group (DRd: $95 \% \mathrm{Cl}, 65.0-75.4 ; \mathrm{Rd}: 95 \% \mathrm{Cl}$, $49.5-61.3)^{+}$

$\mathbf{4 4 \%}$ reduction in the risk of disease progression or death with $\mathrm{DRd}$ vs $\mathrm{Rd}$ alone $(\mathrm{HR}=0.56 ; 95 \% \mathrm{Cl}$, $0.43-0.73 ; P<0.0001)$

\section{Demonstrated safety profile}

(median treatment duration of 25.3 months)'

- The most common adverse reactions ( $\geq 20 \%$ ) were upper respiratory infection, neutropenia, IRRs, thrombocytopenia, diarrhea, constipation, anemia, peripheral sensory neuropathy, fatigue, peripheral edema, nausea, cough, pyrexia, dyspnea, and asthenia

- Serious adverse reactions with a $2 \%$ greater incidence in the DRd arm compared with the Rd arm were pneumonia (DRd $15 \%$ vs Rd $8 \%$ ), bronchitis (DRd $4 \%$ vs Rd $2 \%$ ), and dehydration (DRd $2 \%$ vs Rd $<1 \%$ )

MAIA Study Design: A phase 3 global, randomized, open-label study, compared treatment with DRd $(n=368)$ to $R d(n=369)$ in adult patients with newly diagnosed, transplant-ineligible multiple myeloma. Treatment was continued until disease progression or unacceptable toxicity. The primary efficacy endpoint was PFS.

$\mathrm{Cl}=$ confidence interval; DRd=DARZALEX ${ }^{\boxplus}(\mathrm{D})$ + lenalidomide $(\mathrm{R})$ + dexamethasone (d); $H R=$ hazard ratio; IRR=injection-related reaction; $\mathrm{mPFS}=$ median progression-free survival; $P F S=$ progression-free survival; $R d=$ =enalidomide $(R)+$ dexamethasone (d); TEAE=treatment-emergent adverse event.

*Range: 0.0-41.4 months. ${ }^{4}$

tKaplan-Meier estimate.

‡Range: 0.03-69.52 months. ${ }^{3}$

\$TEAEs are defined as any adverse event (AE) that occurs after start of the first study treatment through 30 days after the last study treatment: or the day prior to start of subsequent antimyeloma therapy, whichever is earlier: or any AE that is considered subsequent antimyeloma therapy, whichever is earlier; or any AE that is considere of the event; or any AE that is present at baseline but worsens in toxicity grade or is of the event; or any AE that is present at baseline but worsens
subsequently considered drug related by the investigator.

" 3 to 5 minutes refers to the time it takes to administer DARZALEX FASPRO ${ }^{\star}$ and does not account for all aspects of treatment. For intravenous daratumumab, median durations of $16 \mathrm{mg} / \mathrm{kg}$ infusions for the first, second, and subsequent infusions were approximately 7,4 , and 3 hours, respectively. ${ }^{1.5}$

\section{Efficacy results in long-term follow-up ${ }^{2,3}$}

At median $\sim 5$ years ( 56 months) $)^{\ddagger}$ of follow-up, mPFS was not reached with DRd vs 34.4 months with Rd alone. ${ }^{2}$

- $\mathbf{5 3 \%}$ of patients had not progressed after $\sim 5$ years of treatment with DRd vs $29 \%$ with Rd alone (DRd: $95 \%$ Cl, $47-58$; $\mathrm{Rd}: 95 \% \mathrm{Cl}, 23-35)^{\dagger}$

$47 \%$ reduction in the risk of disease progression or death $47 \%$ with DRd vs Rd alone (HR=0.53; 95\% Cl, 0.43-0.66)

These $\sim 5$-year analyses were not adjusted for multiplicity and are not included in the current Prescribing Information.

\section{Safety results in long-term follow-up} (median treatment duration of 47.5 months) ${ }^{2}$

At median $\sim 5$ years of follow-up ${ }^{2,3}$ :

- Most frequent TEAEs $\$ \geq 30 \%$ were diarrhea, neutropenia, fatigue, constipation, peripheral edema, anemia, back pain, asthenia, nausea, bronchitis, cough, dyspnea, insomnia, weight decreased, peripheral sensory neuropathy, pneumonia, and muscle spasms

- Grade 3/4 infections were $41 \%$ for DRd vs $29 \%$ for Rd

- Grade $3 / 4$ TEAEs $\geq 10 \%$ were neutropenia $(54 \%$ for DRd vs $37 \%$ for Rd), pneumonia ( $19 \%$ vs $11 \%$ ), anemia ( $17 \%$ vs $22 \%$ ), lymphopenia (16\% vs $11 \%$ ), hypokalemia (13\% vs $10 \%)$, leukopenia ( $12 \%$ vs $6 \%$ ), and cataract ( $11 \%$ vs $11 \%$ )

These $\sim 5$-year analyses are not included in the current Prescribing Information.

With an $\sim 3$ to 5 minute subcutaneous injection

DARZALEX FASPRO ${ }^{\circledR}$ can be administered substantially faster than intravenous daratumumab ${ }^{1,51}$

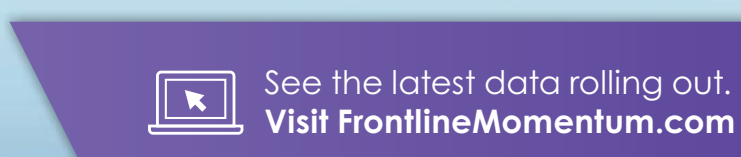

life-threatening (Grade 4) reaction occurs and institute appropriate emergency care. For patients with Grade 1, 2, or 3 reactions, reduce the infusion rate when re-starting the infusion. To reduce the risk of delayed infusion-related reactions, administer oral corticosteroids to all patients following DARZALEX ${ }^{\circledR}$ infusions. Patients with a history of chronic obstructive pulmonary disease may require additional post-infusion medications to manage respiratory complications. Consider prescribing short- and longacting bronchodilators and inhaled corticosteroids for patients with chronic obstructive pulmonary disease.

\section{DARZALEX FASPRO ${ }^{\circledR}:$ Hypersensitivity and Other Administration Reactions}

Both systemic administration-related reactions, including severe or life-threatening reactions, and local injection-site reactions can occur with DARZALEX FASPRO ${ }^{\circledR}$. Fatal reactions have been reported with daratumumab-containing products, including DARZALEX FASPRO ${ }^{\circledR}$.

Systemic Reactions

In a pooled safety population of 832 patients with multiple myeloma ( $N=639)$ or light chain $(A L)$ amyloidosis $(N=193)$ who received DARZALEX FASPRO ${ }^{\circledR}$ as monotherapy or in combination, $9 \%$ of patients experienced a systemic administration-related reaction (Grade 2: 3.5\%, Grade 3: 0.8\%). Systemic administrationrelated reactions occurred in $8 \%$ of patients with the first injection, $0.4 \%$ with the second injection, and cumulatively $1 \%$ with subsequent injections. The median time to onset was 3.2 hours (range: 9 minutes to 3.5 days). Of the 129 systemic administrationrelated reactions that occurred in 74 patients, 110 (85\%) occurred on the day of DARZALEX FASPRO ${ }^{\circledR}$ administration. Delayed systemic administration-related reactions have occurred in $1 \%$ of the patients.

Severe reactions included hypoxia, dyspnea, hypertension, and tachycardia. Other signs and symptoms of systemic administrationrelated reactions may include respiratory symptoms, such as bronchospasm, nasal congestion, cough, throat irritation, allergic rhinitis, and wheezing, as well as anaphylactic reaction, pyrexia, chest pain, pruritus, chills, vomiting, nausea, and hypotension. Pre-medicate patients with histamine-1 receptor antagonist, acetaminophen, and corticosteroids. Monitor patients for systemic administration-related reactions, especially following the first and second injections. For anaphylactic reaction or life-threatening (Grade 4) administration-related reactions, immediately and permanently discontinue DARZALEX FASPRO ${ }^{\circledR}$. 
Consider administering corticosteroids and other medications after the administration of DARZALEX FASPRO ${ }^{\circledR}$ depending on dosing regimen and medical history to minimize the risk of delayed (defined as occurring the day after administration) systemic administrationrelated reactions.

Local Reactions

In this pooled safety population, injection-site reactions occurred in $8 \%$ of patients, including Grade 2 reactions in $0.6 \%$. The most frequent $(>1 \%)$ injection-site reaction was injection-site erythema. These local reactions occurred a median of 5.5 minutes (range: 0 minutes to 6.5 days) after starting administration of DARZALEX FASPRO ${ }^{\oplus}$. Monitor for local reactions and consider symptomatic management.

\section{DARZALEX $^{\circledR}$ and DARZALEX FASPRO ${ }^{\circledR}$ : Neutropenia and} Thrombocytopenia

DARZALEX ${ }^{\circledR}$ and DARZALEX FASPRO ${ }^{\circledast}$ may increase neutropenia and thrombocytopenia induced by background therapy. Monitor complete blood cell counts periodically during treatment according to manufacturer's prescribing information for background therapies. Monitor patients with neutropenia for signs of infection. Consider withholding DARZALEX ${ }^{\circledR}$ or DARZALEX FASPRO ${ }^{\circledR}$ until recovery of neutrophils or for recovery of platelets.

In lower body weight patients receiving DARZALEX FASPRO ${ }^{\circledR}$, higher rates of Grade 3-4 neutropenia were observed.

\section{DARZALEX $^{\circledR}$ and DARZALEX FASPRO ${ }^{\circledR}$ : Interference With Serological Testing}

Daratumumab binds to CD38 on red blood cells (RBCs) and results in a positive indirect antiglobulin test (indirect Coombs test). Daratumumab-mediated positive indirect antiglobulin test may persist for up to 6 months after the last daratumumab administration. Daratumumab bound to RBCs masks detection of antibodies to minor antigens in the patient's serum. The determination of a patient's $A B O$ and Rh blood type are not impacted. Notify blood transfusion centers of this interference with serological testing and inform blood banks that a patient has received DARZALEX ${ }^{\circledR}$ and DARZALEX FASPRO ${ }^{\circledR}$. Type and screen patients prior to starting DARZALEX ${ }^{\circledR}$ and DARZALEX FASPRO ${ }^{\circledR}$

\section{DARZALEX $^{\circledR}$ and DARZALEX FASPRO ${ }^{\circledR}$ : Interference With Determination} of Complete Response

\section{Daratumumab is a human immunoglobulin $G$ (IgG) kappa} monoclonal antibody that can be detected on both the serum protein electrophoresis (SPE) and immunofixation (IFE) assays used for the clinical monitoring of endogenous M-protein. This interference can impact the determination of complete response and of disease progression in some patients with IgG kappa myeloma protein.

\section{DARZALEX ${ }^{\circledR}$ and DARZALEX FASPRO ${ }^{\circledR}$ : Embryo-Fetal Toxicity}

Based on the mechanism of action, DARZALEX ${ }^{\circledR}$ and

DARZALEX FASPRO ${ }^{\circledR}$ can cause fetal harm when administered to a pregnant woman. DARZALEX ${ }^{\circledR}$ and DARZALEX FASPRO ${ }^{\circledR}$ may cause depletion of fetal immune cells and decreased bone density. Advise pregnant women of the potential risk to a fetus. Advise females with reproductive potential to use effective contraception during treatment with DARZALEX ${ }^{\circledR}$ or DARZALEX FASPRO ${ }^{\circledR}$ and for 3 months after the last dose.

The combination of DARZALEX ${ }^{\circledR}$ or DARZALEX FASPRO ${ }^{\circledR}$ with lenalidomide, pomalidomide, or thalidomide is contraindicated in pregnant women because lenalidomide, pomalidomide, and thalidomide may cause birth defects and death of the unborn child. Refer to the lenalidomide, pomalidomide, or thalidomide prescribing information on use during pregnancy.

\section{DARZALEX ${ }^{\circledR}$ : ADVERSE REACTIONS}

The most frequently reported adverse reactions (incidence $\geq 20 \%$ ) were: upper respiratory infection, neutropenia, infusion-related reactions, thrombocyłopenia, diarrhea, constipation, anemia, peripheral sensory neuropathy, fatigue, peripheral edema, nausea, cough, pyrexia, dyspnea, and asthenia. The most common hematologic laboratory abnormalities $(\geq 40 \%)$ with DARZALEX ${ }^{\circledR}$ are: neutropenia, lymphopenia, thrombocytopenia, leukopenia, and anemia.

\section{DARZALEX FASPRO ${ }^{\circledR}:$ ADVERSE REACTIONS}

In multiple myeloma, the most common adverse reaction ( $\geq 20 \%$ ) with DARZALEX FASPRO ${ }^{\circledR}$ monotherapy is upper respiratory tract infection. The most common adverse reactions with combination therapy ( $\geq 20 \%$ for any combination) include fatigue, nausea,

diarrhea, dyspnea, insomnia, pyrexia, cough, muscle spasms, back pain, vomiting, upper respiratory tract infection, peripheral sensory neuropathy, constipation, and pneumonia. The most common hematologic laboratory abnormalities $\left(\geq 40 \%\right.$ ) with DARZALEX FASPRO ${ }^{\circledR}$ are decreased leukocytes, decreased lymphocytes, decreased neutrophils, decreased platelets, and decreased hemoglobin.

\section{INDICATIONS}

DARZALEX ${ }^{\circledR}$ (daratumumab) is indicated for the treatment of adult patients with multiple myeloma:

- In combination with lenalidomide and dexamethasone in newly diagnosed patients who are ineligible for autologous stem cell transplant and in patients with relapsed or refractory multiple myeloma who have received at least one prior therapy

- In combination with bortezomib, melphalan, and prednisone in newly diagnosed patients who are ineligible for autologous stem cell transplant

- In combination with bortezomib, thalidomide, and dexamethasone in newly diagnosed patients who are eligible for autologous stem cell transplant

- In combination with bortezomib and dexamethasone in patients who have received at least one prior therapy

- In combination with carfilzomib and dexamethasone in patients with relapsed or refractory multiple myeloma who have received one to three prior lines of therapy

- In combination with pomalidomide and dexamethasone in patients who have received at least two prior therapies including lenalidomide and a proteasome inhibitor (PI)

- As monotherapy in patients who have received at least three prior lines of therapy including a PI and an immunomodulatory agent or who are double-refractory to a PI and an immunomodulatory agent DARZALEX FASPRO ${ }^{\circledR}$ (daratumumab and hyaluronidase-fihj) is indicated for the treatment of adult patients with multiple myeloma:

- In combination with bortezomib, melphalan, and prednisone in newly diagnosed patients who are ineligible for autologous stem cell transplant

- In combination with lenalidomide and dexamethasone in newly diagnosed patients who are ineligible for autologous stem cell transplant and in patients with relapsed or refractory multiple myeloma who have received at least one prior therapy

- In combination with bortezomib, thalidomide, and dexamethasone in newly diagnosed patients who are eligible for autologous stem cell transplant

- In combination with pomalidomide and dexamethasone in patients who have received at least one prior line of therapy including lenalidomide and a proteasome inhibitor (PI)

- In combination with bortezomib and dexamethasone in patients who have received at least one prior therapy

- As monotherapy in patients who have received at least three prior lines of therapy including a PI and an immunomodulatory agent or who are double-refractory to a PI and an immunomodulatory agent

Please see Brief Summary of full Prescribing Information for DARZALEX ${ }^{\circledR}$ and DARZALEX FASPRO ${ }^{\circledR}$ on adjacent pages.

cp-248517v1

References: 1. DARZALEX ${ }^{\circledR}$ [Prescribing Information]. Horsham, PA: Janssen Biotech, Inc. 2. Facon T, Kumar SK, Plesner T, et al. Overall survival results with daratumumab, lenalidomide, and dexamethasone versus lenalidomide and dexamethasone in transplant-ineligible newly diagnosed multiple myeloma: phase 3 MAIA study. Poster presented at: Virtual 26th European Hematology Association (EHA) Annual Congress; June 9-17, 2021. 3. Data on file. Janssen Biotech, Inc. 4. Facon T, Kumar S, Plesner T, et al; the MAIA Trial Investigators. Daratumumab plus lenalidomide and dexamethasone for untreated myeloma. N Engl J Med. 2019;380(22):2104-2115. 5. DARZALEX FASPRO ${ }^{\oplus}$ [Prescribing Information]. Horsham, PA: Janssen Biotech, Inc.

(๑) Janssen Biotech, Inc. 2021 All rights reserved. $08 / 21 \mathrm{cp}-233641 \mathrm{v} 2$

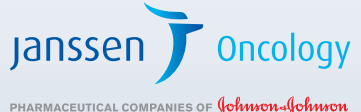
Gohnonefohnon 
DARZALEX ${ }^{\circledR}$ (daratumumab) injection, for intravenous use

\section{Brief Summary of Full Prescribing Information}

\section{INDICATIONS AND USAGE}

DARZALEX is indicated for the treatment of adult patients with multiple myeloma:

- in combination with lenalidomide and dexamethasone in newly diagnosed patients who are ineligible for autologous stem cell transplant and in patients with relapsed or refractory multiple myeloma who have received at least one prior therapy.

- in combination with bortezomib, melphalan and prednisone in newly diagnosed patients who are ineligible for autologous stem cell transplant.

- in combination with bortezomib, thalidomide, and dexamethasone in newly diagnosed patients who are eligible for autologous stem cell transplant

- in combination with bortezomib and dexamethasone in patients who have received at least one prior therapy.

- in combination with carfilzomib and dexamethasone in patients with relapsed or refractory multiple myeloma who have received one to three prior lines of therapy.

- in combination with pomalidomide and dexamethasone in patients who have received at least two prior therapies including lenalidomide and a proteasome inhibitor

- as monotherapy, in patients who have received at least three prior lines of therapy including a proteasome inhibitor (PI) and an immunomodulatory agent or who are double-refractory to a PI and an immunomodulatory agent.

\section{CONTRAINDICATIONS}

DARZALEX is contraindicated in patients with a history of severe hypersensitivity (e.g. anaphylactic reactions) to daratumumab or any of the components of the formulation [see Warnings and Precautions].

\section{WARNINGS AND PRECAUTIONS}

\section{Infusion-Related Reactions}

DARZALEX can cause severe and/or serious infusion-related reactions including anaphylactic reactions. These reactions can be life-threatening and fatal outcomes have been reported [see Adverse Reactions].

In clinical trials (monotherapy and combination: $\mathrm{N}=2,066$ ), infusionrelated reactions occurred in $37 \%$ of patients with the Week $1(16 \mathrm{mg} / \mathrm{kg})$ infusion, $2 \%$ with the Week 2 infusion, and cumulatively $6 \%$ with subsequent infusions. Less than $1 \%$ of patients had a Grade 3/4 infusionrelated reaction at Week 2 or subsequent infusions. The median time to onset was 1.5 hours (range: 0 to 73 hours). The incidence of infusion modification due to reactions was $36 \%$. Median durations of $16 \mathrm{mg} / \mathrm{kg}$ infusions for the Week 1, Week 2, and subsequent infusions were approximately 7, 4, and 3 hours respectively. Nearly all reactions occurred during infusion or within 4 hours of completing DARZALEX. Prior to the introduction of post-infusion medication in clinical trials, infusion-related reactions occurred up to 48 hours after infusion.

Severe reactions have occurred, including bronchospasm, hypoxia, dyspnea, hypertension, tachycardia, headache, laryngeal edema and pulmonary edema. Signs and symptoms may include respiratory symptoms, such as nasal congestion, cough, throat irritation, as well as chills, vomiting and nausea. Less common symptoms were wheezing, allergic rhinitis, pyrexia, chest discomfort, pruritus, and hypotension [see Adverse Reactions].

When DARZALEX dosing was interrupted in the setting of ASCT (CASSIOPEIA) for a median of 3.75 months (range: 2.4 to 6.9 months), upon re-initiation of DARZALEX, the incidence of infusion-related reactions was $11 \%$ for the first infusion following ASCT. Infusion rate/dilution volume used upon re-initiation was that used for the last DARZALEX infusion prior to interruption for ASCT. Infusion-related reactions occurring at re-initiation of DARZALEX following ASCT were consistent in terms of symptoms and severity (Grade 3 or $4:<1 \%$ ) with those reported in previous studies at Week 2 or subsequent infusions.

In EQUULEUS, patients receiving combination treatment $(n=97)$ were administered the first $16 \mathrm{mg} / \mathrm{kg}$ dose at Week 1 split over two days i.e. $8 \mathrm{mg} / \mathrm{kg}$ on Day 1 and Day 2, respectively. The incidence of any grade infusionrelated reactions was $42 \%$, with $36 \%$ of patients experiencing infusion-related reactions on Day 1 of Week 1, 4\% on Day 2 of Week 1, and $8 \%$ with subsequent infusions. The median time to onset of a reaction was 1.8 hours (range: 0.1 to 5.4 hours). The incidence of infusion interruptions due to reactions was $30 \%$. Median durations of infusions were 4.2 hours for Week 1-Day 1, 4.2 hours for Week 1-Day 2, and 3.4 hours for the subsequent infusions.

Pre-medicate patients with antihistamines, antipyretics and corticosteroids. Frequently monitor patients during the entire infusion [see Dosage and Administration (2.3) in Full Prescribing Information]. Interrupt DARZALEX infusion for reactions of any severity and institute medical management as needed. Permanently discontinue DARZALEX therapy if an anaphylactic reaction or life-threatening (Grade 4) reaction occurs and institute appropriate emergency care. For patients with Grade 1, 2, or 3 reactions, reduce the
DARZALEX $^{\circledR}$ (daratumumab) injection

infusion rate when re-starting the infusion [see Dosage and Administration (2.4) in Full Prescribing Information].

To reduce the risk of delayed infusion-related reactions, administer oral corticosteroids to all patients following DARZALEX infusions [see Dosage and Administration (2.3) in Full Prescribing Information]. Patients with a history of chronic obstructive pulmonary disease may require additional post-infusion medications to manage respiratory complications. Consider prescribing shortand long-acting bronchodilators and inhaled corticosteroids for patients with chronic obstructive pulmonary disease [see Dosage and Administration (2.3) in Full Prescribing Information].

\section{Interference with Serological Testing}

Daratumumab binds to CD38 on red blood cells (RBCs) and results in a positive Indirect Antiglobulin Test (Indirect Coombs test). Daratumumab-mediated positive indirect antiglobulin test may persist for up to 6 months after the last daratumumab infusion. Daratumumab bound to RBCs masks detection of antibodies to minor antigens in the patient's serum [see References]. The determination of a patient's ABO and Rh blood type are not impacted [see Drug Interactions].

Notify blood transfusion centers of this interference with serological testing and inform blood banks that a patient has received DARZALEX. Type and screen patients prior to starting DARZALEX [see Dosage and Administration (2.1) in Full Prescribing Information].

\section{Neutropenia}

DARZALEX may increase neutropenia induced by background therapy [see Adverse Reactions].

Monitor complete blood cell counts periodically during treatment according to manufacturer's prescribing information for background therapies. Monitor patients with neutropenia for signs of infection. Consider withholding DARZALEX until recovery of neutrophils.

\section{Thrombocytopenia}

DARZALEX may increase thrombocytopenia induced by background therapy [see Adverse Reactions].

Monitor complete blood cell counts periodically during treatment according to manufacturer's prescribing information for background therapies. Consider withholding DARZALEX until recovery of platelets.

\section{Interference with Determination of Complete Response}

Daratumumab is a human IgG kappa monoclonal antibody that can be detected on both, the serum protein electrophoresis (SPE) and immunofixation (IFE) assays used for the clinical monitoring of endogenous M-protein [see Drug Interactions]. This interference can impact the determination of complete response and of disease progression in some patients with $\lg \mathrm{G}$ kappa myeloma protein.

\section{Embryo-Fetal Toxicity}

Based on the mechanism of action, DARZALEX can cause fetal harm when administered to a pregnant woman. DARZALEX may cause depletion of fetal immune cells and decreased bone density. Advise pregnant women of the potential risk to a fetus. Advise females with reproductive potential to use effective contraception during treatment with DARZALEX and for 3 months after the last dose [see Use in Specific Populations].

The combination of DARZALEX with lenalidomide, pomalidomide, or thalidomide is contraindicated in pregnant women, because lenalidomide, pomalidomide, and thalidomide may cause birth defects and death of the unborn child. Refer to the lenalidomide, pomalidomide, or thalidomide prescribing information on use during pregnancy.

\section{ADVERSE REACTIONS}

The following clinically significant adverse reactions are described elsewhere in the labeling:

- Infusion-related reactions [see Warning and Precautions].

- Neutropenia [see Warning and Precautions].

- Thrombocytopenia [see Warning and Precautions].

\section{Clinical Trials Experience}

Because clinical trials are conducted under widely varying conditions, adverse reaction rates observed in the clinical trials of a drug cannot be directly compared to rates in the clinical trials of another drug and may not reflect the rates observed in practice.

The safety data described below reflects exposure to DARZALEX (16 mg/kg) in 2,459 patients with multiple myeloma including 2,303 patients who received DARZALEX in combination with background regimens and 156 patients who received DARZALEX as monotherapy. In this pooled safety population, the most common adverse reactions $(\geq 20 \%)$ were upper respiratory infection, neutropenia, infusion-related reactions, thrombocytopenia, diarrhea, constipation, anemia, peripheral sensory neuropathy, fatigue, peripheral edema, nausea, cough, pyrexia, dyspnea, and asthenia. 
Newly Diagnosed Multiple Myeloma Ineligible for Autologous Stem Cell Transplant

Combination Treatment with Lenalidomide and Dexamethasone (DRd)

The safety of DARZALEX in combination with lenalidomide and dexamethasone was evaluated in MAIA [see Clinical Studies (14.1) in Full Prescribing Information]. Adverse reactions described in Table 1 reflect exposure to DARZALEX for a median treatment duration of 25.3 months (range: 0.1 to 40.44 months) for daratumumab-lenalidomide-dexamethasone (DRd) and of 21.3 months (range: 0.03 to 40.64 months) for lenalidomide-dexamethasone (Rd).

Serious adverse reactions with a $2 \%$ greater incidence in the DRd arm compared to the Rd arm were pneumonia (DRd $15 \%$ vs Rd $8 \%$ ), bronchitis (DRd $4 \%$ vs Rd $2 \%$ ) and dehydration (DRd $2 \%$ vs $R d<1 \%$ ).

Table 1: Adverse Reactions Reported in $\geq 10 \%$ of Patients and With at Least a $5 \%$ Greater Frequency in the DRd Arm in MAIA

\begin{tabular}{|c|c|c|c|c|c|c|}
\hline \multirow{2}{*}{$\begin{array}{l}\text { Body System } \\
\text { Adverse Reaction }\end{array}$} & \multicolumn{3}{|c|}{ DRd (N=364) } & \multicolumn{3}{|c|}{$\operatorname{Rd}(\mathrm{N}=365)$} \\
\hline & $\begin{array}{l}\text { All } \\
\text { Grades } \\
\text { (\%) }\end{array}$ & $\begin{array}{l}\text { Grade } 3 \\
(\%)\end{array}$ & $\begin{array}{l}\text { Grade } 4 \\
(\%)\end{array}$ & \begin{tabular}{|l|} 
All \\
Grades \\
(\%)
\end{tabular} & $\begin{array}{l}\text { Grade } 3 \\
(\%)\end{array}$ & $\begin{array}{l}\text { Grade } 4 \\
(\%)\end{array}$ \\
\hline
\end{tabular}

Gastrointestinal disorders

\begin{tabular}{|l|l|l|l|l|l|l|}
\hline Diarrhea & 57 & 7 & 0 & 46 & 4 & 0 \\
\hline Constipation & 41 & 1 & $<1$ & 36 & $<1$ & 0 \\
\hline Nausea & 32 & 1 & 0 & 23 & 1 & 0 \\
\hline Vomiting & 17 & 1 & 0 & 12 & $<1$ & 0 \\
\hline
\end{tabular}

\section{Infections}

\begin{tabular}{|l|l|l|l|l|l|l|}
\hline $\begin{array}{l}\text { Upper respiratory } \\
\text { tract infection }^{\mathrm{a}}\end{array}$ & 52 & 2 & $<1$ & 36 & 2 & $<1$ \\
\hline Bronchitis $^{\mathrm{b}}$ & 29 & 3 & 0 & 21 & 1 & 0 \\
\hline Pneumoniac & 26 & 14 & 1 & 14 & 7 & 1 \\
\hline $\begin{array}{l}\text { Urinary tract } \\
\text { infection }\end{array}$ & 18 & 2 & 0 & 10 & 2 & 0 \\
\hline
\end{tabular}

\section{General disorders and administration site conditions}

\begin{tabular}{|c|c|c|c|c|c|c|}
\hline $\begin{array}{l}\text { Infusion-related } \\
\text { reactions }^{d}\end{array}$ & 41 & 2 & $<1$ & 0 & 0 & 0 \\
\hline Peripheral edemae & 41 & 2 & 0 & 33 & 1 & 0 \\
\hline Fatigue & 40 & 8 & 0 & 28 & 4 & 0 \\
\hline Asthenia & 32 & 4 & 0 & 25 & 3 & $<1$ \\
\hline Pyrexia & 23 & 2 & 0 & 18 & 2 & 0 \\
\hline Chills & 13 & 0 & 0 & 2 & 0 & 0 \\
\hline
\end{tabular}

\section{Musculoskeletal and connective tissue disorders}

\begin{tabular}{|l|l|l|l|l|l|l|}
\hline Back pain & 34 & 3 & $<1$ & 26 & 3 & $<1$ \\
\hline Muscle spasms & 29 & 1 & 0 & 22 & 1 & 0 \\
\hline
\end{tabular}

\section{Respiratory, thoracic and mediastinal disorders}

\begin{tabular}{|l|l|l|l|l|l|l|}
\hline Dyspnea $^{f}$ & 32 & 3 & $<1$ & 20 & 1 & 0 \\
\hline Coughg & 30 & $<1$ & 0 & 18 & 0 & 0 \\
\hline
\end{tabular}

\section{Nervous system disorders}

\begin{tabular}{|l|l|l|l|l|l|l|}
\hline $\begin{array}{l}\text { Peripheral sensory } \\
\text { neuropathy }\end{array}$ & 24 & 1 & 0 & 15 & 0 & 0 \\
\hline Headache & 19 & 1 & 0 & 11 & 0 & 0 \\
\hline Paresthesia & 16 & 0 & 0 & 8 & 0 & 0 \\
\hline
\end{tabular}

\section{Metabolism and nutrition disorders}

\begin{tabular}{|l|l|l|l|l|l|l|}
\hline $\begin{array}{l}\text { Decreased } \\
\text { appetite }\end{array}$ & 22 & 1 & 0 & 15 & $<1$ & $<1$ \\
\hline Hyperglycemia & 14 & 6 & 1 & 8 & 3 & 1 \\
\hline Hypocalcemia & 14 & 1 & $<1$ & 9 & 1 & 1 \\
\hline Vascular disorders \\
\hline Hypertension ${ }^{\mathrm{h}}$ & 13 & 6 & $<1$ & 7 & 4 & 0 \\
\hline
\end{tabular}

\section{Key: $\mathrm{D}=$ daratumumab, $\mathrm{Rd}=$ =lenalidomide-dexamethasone.}

a Acute sinusitis, Bacterial rhinitis, Laryngitis, Metapneumovirus infection, Nasopharyngitis, Oropharyngeal candidiasis, Pharyngitis, Respiratory syncytial virus infection, Respiratory tract infection, Respiratory tract infection viral, Rhinitis, Rhinovirus infection, Sinusitis, Tonsillitis, Tracheitis, Upper respiratory tract infection, Viral pharyngitis, Viral rhinitis, Viral upper respiratory tract infection b Bronchiolitis, Bronchitis, Bronchitis viral, Respiratory syncytial virus bronchiolitis, Tracheobronchitis

C Atypical pneumonia, Bronchopulmonary aspergillosis, Lung infection, Pneumocystis jirovecii infection, Pneumocystis jirovecii pneumonia, Pneumonia, Pneumonia aspiration, Pneumonia pneumococcal, Pneumonia viral, Pulmonary mycosis

d Infusion-related reaction includes terms determined by investigators to be related to infusion

e Generalized edema, Gravitational edema, Edema, Peripheral edema, Peripheral swelling

f Dyspnea, Dyspnea exertional

g Cough, Productive cough

h Blood pressure increased, Hypertension

Laboratory abnormalities worsening during treatment from baseline listed in Table 2.

Table 2: Treatment-Emergent Hematology Laboratory Abnormalities in MAIA

\begin{tabular}{|l|l|l|l|l|l|l|}
\hline & \multicolumn{3}{|l|}{ DRd (N=364) } & \multicolumn{2}{l|}{ Rd (N=365) } \\
\cline { 2 - 7 } & $\begin{array}{l}\text { All } \\
\text { Grades } \\
\end{array}$ & $\begin{array}{l}\text { Grade 3) } \\
(\%)\end{array}$ & $\begin{array}{l}\text { Grade 4 } \\
(\%)\end{array}$ & $\begin{array}{l}\text { All } \\
\text { Grades } \\
(\%)\end{array}$ & $\begin{array}{l}\text { Grade 3 } \\
(\%)\end{array}$ & $\begin{array}{l}\text { Grade 4 } \\
(\%)\end{array}$ \\
\hline Leukopenia & 90 & 30 & 5 & 82 & 20 & 4 \\
\hline Neutropenia & 91 & 39 & 17 & 77 & 28 & 11 \\
\hline Lymphopenia & 84 & 41 & 11 & 75 & 36 & 6 \\
\hline Thrombocytopenia & 67 & 6 & 3 & 58 & 7 & 4 \\
\hline Anemia & 47 & 13 & 0 & 57 & 24 & 0 \\
\hline
\end{tabular}

Key: $\mathrm{D}=$ daratumumab, $\mathrm{Rd}=$ =enalidomide-dexamethasone.

Combination Treatment with Bortezomib, Melphalan and Prednisone

The safety of DARZALEX in combination with bortezomib, melphalan and prednisone was evaluated in ALCYONE [see Clinical Studies (14.1) in Full Prescribing Information]. Adverse reactions described in Table 3 reflect exposure to DARZALEX for a median treatment duration of 14.7 months (range: 0 to 25.8 months) for daratumumab, bortezomib, melphalan and prednisone (D-VMP) and of 12 months (range: 0.1 to 14.9 months) for VMP.

Serious adverse reactions with at least a $2 \%$ greater incidence in the $D$-VMP arm compared to the VMP arm were pneumonia (D-VMP $11 \%$ vs VMP $4 \%$ ), upper respiratory tract infection (D-VMP $5 \%$ vs VMP $1 \%$ ), and pulmonary edema (D-VMP $2 \%$ vs VMP $0 \%$ ).

Table 3: Adverse Reactions Reported in $\geq 10 \%$ of Patients and With at Least a $5 \%$ Greater Frequency in the D-VMP Arm in ALCYONE

\begin{tabular}{|l|l|l|l|l|l|l|}
\hline \multirow{3}{*}{$\begin{array}{l}\text { Body System } \\
\text { Adverse Reaction }\end{array}$} & \multicolumn{2}{|l|}{ D-VMP (N=346) } & \multicolumn{2}{l|}{ VMP (N=354) } \\
\cline { 2 - 7 } & $\begin{array}{l}\text { All } \\
\text { Grades } \\
(\%)\end{array}$ & $\begin{array}{l}\text { Grade 3 } \\
(\%)\end{array}$ & $\begin{array}{l}\text { Grade 4 } \\
(\%)\end{array}$ & $\begin{array}{l}\text { All } \\
\text { Grades } \\
(\%)\end{array}$ & $\begin{array}{l}\text { Grade 3 } \\
(\%)\end{array}$ & $\begin{array}{l}\text { Grade 4 } \\
(\%)\end{array}$ \\
\hline
\end{tabular}

\section{Infections}

\begin{tabular}{l|l|l|l|l|l|l}
\hline $\begin{array}{l}\text { Upper } \\
\text { respiratory tract } \\
\text { infection }^{\mathrm{a}}\end{array}$ & 48 & 5 & 0 & 28 & 3 & 0 \\
\hline Pneumoniab $^{\mathrm{b}}$ & 16 & 12 & $<1$ & 6 & 5 & $<1$ \\
\hline
\end{tabular}

\section{General disorders and administration site conditions}

\begin{tabular}{|l|l|l|l|l|l|l|}
\hline $\begin{array}{l}\text { Infusion-related } \\
\text { reactions }^{c}\end{array}$ & \multicolumn{1}{|c|}{28} & 4 & 1 & 0 & 0 & 0 \\
\hline $\begin{array}{l}\text { Peripheral } \\
\text { edemad }^{d}\end{array}$ & 21 & 1 & $<1$ & 14 & 1 & 0 \\
\hline
\end{tabular}

Respiratory, thoracic and mediastinal disorders

\begin{tabular}{|l|l|l|l|l|l|l|}
\hline Coughe & 16 & $<1$ & 0 & 8 & $<1$ & 0 \\
\hline Dyspnea $^{f}$ & 13 & 2 & 1 & 5 & 1 & 0 \\
\hline Vascular disorders \\
\hline Hypertensiong & 10 & 4 & $<1$ & 3 & 2 & 0 \\
\hline
\end{tabular}

Key: $D=$ daratumumab, VMP=bortezomib-melphalan-prednisone

a upper respiratory tract infection, bronchitis, bronchitis bacterial, epiglottitis, laryngitis, laryngitis bacterial, metapneumovirus infection, nasopharyngitis, oropharyngeal candidiasis, pharyngitis, pharyngitis streptococcal, respiratory syncytial virus infection, respiratory tract infection, respiratory tract infection viral, rhinitis, sinusitis, tonsillitis, tracheitis, tracheobronchitis, viral pharyngitis, viral rhinitis, viral upper respiratory tract infection 
b pneumonia, lung infection, pneumonia aspiration, pneumonia bacterial, pneumonia pneumococcal, pneumonia streptococcal, pneumonia viral, and pulmonary sepsis

c Infusion-related reaction includes terms determined by investigators to be related to infusion

d edema peripheral, generalized edema, peripheral swelling

e cough, productive cough

f dyspnea, dyspnea exertional

g hypertension, blood pressure increased

Laboratory abnormalities worsening during treatment from baseline listed in Table 4.

Table 4: Treatment-Emergent Hematology Laboratory Abnormalities in ALCYONE

\begin{tabular}{|l|l|l|l|l|l|l|}
\hline & \multicolumn{3}{|l|}{ D-VMP (N=346) } & \multicolumn{2}{l|}{ VMP (N=354) } \\
\cline { 2 - 7 } & $\begin{array}{l}\text { All } \\
\text { Grades } \\
(\%)\end{array}$ & $\begin{array}{l}\text { Grade 3 } \\
(\%)\end{array}$ & $\begin{array}{l}\text { Grade 4 } \\
(\%)\end{array}$ & $\begin{array}{l}\text { All } \\
\text { Grades } \\
(\%)\end{array}$ & $\begin{array}{l}\text { Grade 3 } \\
(\%)\end{array}$ & $\begin{array}{l}\text { Grade 4 } \\
(\%)\end{array}$ \\
\hline Thrombocytopenia & 88 & 27 & 11 & 88 & 26 & 16 \\
\hline Neutropenia & 86 & 34 & 10 & 87 & 32 & 11 \\
\hline Lymphopenia & 85 & 46 & 12 & 83 & 44 & 9 \\
\hline Anemia & 47 & 18 & 0 & 50 & 21 & 0 \\
\hline
\end{tabular}

Key: $\mathrm{D}=$ daratumumab, VMP=bortezomib-melphalan-prednisone

Newly Diagnosed Multiple Myeloma Eligible for Autologous Stem Cell Transplant Combination Treatment with Bortezomib, Thalidomide and Dexamethasone (DVTd)

The safety of DARZALEX in combination with bortezomib, thalidomide and dexamethasone was evaluated in CASSIOPEIA [see Clinical Studies (14.1) in Full Prescribing Information]. Adverse reactions described in Table 5 reflect exposure to DARZALEX up to day 100 post-transplant. The median duration of induction/ASCT/consolidation treatment was 8.9 months (range: 7.0 to 12.0 months) for DVTd and 8.7 months (range: 6.4 to 11.5 months) for VTd.

Serious adverse reactions with a $2 \%$ greater incidence in the DVTd arm compared to the VTd arm were bronchitis (DVTd $2 \%$ vs VTd $<1 \%$ ) and pneumonia (DVTd 6\% vs VTd 4\%)

Table 5: Adverse Reactions Reported in $\geq 10 \%$ of Patients and With at Least a $5 \%$ Greater Frequency in the DVTd Arm in CASSIOPEIA

\begin{tabular}{|c|c|c|c|c|c|c|}
\hline \multirow{2}{*}{$\begin{array}{l}\text { Body System } \\
\text { Adverse Reaction }\end{array}$} & \multicolumn{3}{|c|}{ DVTd (N=536) } & \multicolumn{3}{|c|}{ VTd (N=538) } \\
\hline & $\begin{array}{l}\text { All } \\
\text { Grades } \\
(\%)\end{array}$ & $\begin{array}{l}\text { Grade } 3 \\
(\%)\end{array}$ & $\begin{array}{l}\text { Grade } 4 \\
(\%)\end{array}$ & $\begin{array}{l}\text { All } \\
\text { Grades } \\
(\%)\end{array}$ & $\begin{array}{l}\text { Grade } 3 \\
(\%)\end{array}$ & $\begin{array}{l}\text { Grade } \\
(\%)\end{array}$ \\
\hline
\end{tabular}

\begin{tabular}{|c|c|c|c|c|c|c|}
\hline \multicolumn{7}{|c|}{ General disorders and administration site conditions } \\
\hline $\begin{array}{l}\text { Infusion-related } \\
\text { reactions }\end{array}$ & 35 & 3 & $<1$ & 0 & 0 & 0 \\
\hline Pyrexia & 26 & 2 & $<1$ & 21 & 2 & 0 \\
\hline \multicolumn{7}{|c|}{ Gastrointestinal disorders } \\
\hline Nausea & 30 & 4 & 0 & 24 & 2 & $<$ \\
\hline Vomiting & 16 & 2 & 0 & 10 & 2 & 0 \\
\hline \multicolumn{7}{|l|}{ Infections } \\
\hline $\begin{array}{l}\text { Upper } \\
\text { respiratory tract } \\
\text { infection }^{\mathrm{b}}\end{array}$ & 27 & 1 & 0 & 17 & 1 & 0 \\
\hline Bronchitis $^{\mathrm{C}}$ & 20 & 1 & 0 & 13 & 1 & 0 \\
\hline \multicolumn{7}{|c|}{ Respiratory, thoracic and mediastinal disorders } \\
\hline Coughd $^{d}$ & 17 & 0 & 0 & 9 & 0 & 0 \\
\hline \multicolumn{7}{|l|}{ Vascular disorders } \\
\hline Hypertension & 10 & 4 & 0 & 5 & 2 & 0 \\
\hline
\end{tabular}

Key: D=daratumumab, VTd=bortezomib-thalidomide -dexamethasone.

a Infusion-related reaction includes terms determined by investigators to be related to infusion

b Laryngitis, Laryngitis viral, Metapneumovirus infection, Nasopharyngitis, Oropharyngeal candidiasis, Pharyngitis, Respiratory syncytial virus infection, Respiratory tract infection, Respiratory tract infection viral, Rhinitis, Rhinovirus infection, Sinusitis, Tonsillitis, Tracheitis, Upper respiratory tract infection, Viral pharyngitis, Viral rhinitis, Viral upper respiratory tract infection

c Bronchiolitis, Bronchitis, Bronchitis chronic, Respiratory syncytial virus bronchitis, Tracheobronchitis

d Cough, Productive cough

Note: Hematology laboratory related toxicities were excluded and reported separately in the table below
Table 6: Treatment-Emergent Hematology Laboratory Abnormalities in CASSIOPEIA

\begin{tabular}{|l|l|l|l|l|l|l|}
\hline & \multicolumn{2}{|l|}{ DVTd (N=536) } & \multicolumn{2}{l|}{ VTd (N=538) } \\
\cline { 2 - 7 } & $\begin{array}{l}\text { All } \\
\text { Grades } \\
(\%)\end{array}$ & $\begin{array}{l}\text { Grade 3 } \\
(\%)\end{array}$ & $\begin{array}{l}\text { Grade 4 } \\
(\%)\end{array}$ & $\begin{array}{l}\text { All } \\
\text { Grades } \\
(\%)\end{array}$ & $\begin{array}{l}\text { Grade 3 } \\
(\%)\end{array}$ & $\begin{array}{l}\text { Grade 4 } \\
(\%)\end{array}$ \\
\hline Lymphopenia & 95 & 44 & 15 & 91 & 37 & 10 \\
\hline Leukopenia & 82 & 14 & 10 & 57 & 6 & 9 \\
\hline Thrombocytopenia & 81 & 9 & 5 & 58 & 8 & 3 \\
\hline Neutropenia & 63 & 19 & 14 & 41 & 10 & 9 \\
\hline Anemia & 36 & 4 & 0 & 35 & 5 & 0 \\
\hline
\end{tabular}

Key: D=daratumumab, VTd=bortezomib-thalidomide -dexamethasone.

Relapsed/Refractory Multiple Myeloma

Combination Treatment with Lenalidomide and Dexamethasone

The safety of DARZALEX in combination with lenalidomide and dexamethasone was evaluated in POLLUX [see Clinical Studies (14.2) in Full Prescribing Information]. Adverse reactions described in Table 7 reflect exposure to DARZALEX for a median treatment duration of 13.1 months (range: 0 to 20.7 months) for daratumumab-lenalidomide-dexamethasone (DRd) and of 12.3 months (range: 0.2 to 20.1 months) for lenalidomide-dexamethasone (Rd). Serious adverse reactions occurred in $49 \%$ of patients in the DRd arm compared with $42 \%$ in the $\mathrm{Rd}$ arm. Serious adverse reactions with at least a $2 \%$ greater incidence in the DRd arm compared to the Rd arm were pneumonia (DRd $12 \%$ vs Rd 10\%), upper respiratory tract infection (DRd $7 \%$ vs $\mathrm{Rd} 4 \%$ ), influenza and pyrexia (DRd $3 \%$ vs Rd $1 \%$ for each).

Adverse reactions resulted in discontinuations for $7 \%(n=19)$ of patients in the DRd arm versus $8 \%(n=22)$ in the $R d$ arm.

Table 7: Adverse Reactions Reported in $\geq 10 \%$ of Patients and With at Least a 5\% Greater Frequency in the DRd Arm in POLLUX

\begin{tabular}{|l|l|l|l|l|l|l|}
\hline Adverse Reaction & \multicolumn{2}{|l|}{ DRd (N=283) } & \multicolumn{2}{l|}{ Rd (N=281) } \\
\cline { 2 - 6 } & $\begin{array}{l}\text { All } \\
\text { Grades } \\
(\%)\end{array}$ & $\begin{array}{l}\text { Grade 3 } \\
(\%)\end{array}$ & $\begin{array}{l}\text { Grade 4 } \\
(\%)\end{array}$ & $\begin{array}{l}\text { All } \\
\text { Grades } \\
(\%)\end{array}$ & $\begin{array}{l}\text { Grade 3 } \\
(\%)\end{array}$ & $\begin{array}{l}\text { Grade 4 } \\
(\%)\end{array}$ \\
\hline
\end{tabular}

\section{Infections}

\begin{tabular}{|l|l|l|l|l|l|l|}
$\begin{array}{l}\text { Upper } \\
\text { respiratory tract } \\
\text { infectiona }^{\mathrm{n}}\end{array}$ & 65 & 6 & $<1$ & 51 & 4 & 0 \\
\hline
\end{tabular}

General disorders and administration site conditions

\begin{tabular}{|l|l|l|l|l|l|l|}
\hline $\begin{array}{l}\text { Infusion-related } \\
\text { reactions }^{b}\end{array}$ & 48 & 5 & 0 & 0 & 0 & 0 \\
\hline Fatigue & 35 & 6 & $<1$ & 28 & 2 & 0 \\
\hline Pyrexia & 20 & 2 & 0 & 11 & 1 & 0 \\
\hline
\end{tabular}

Gastrointestinal disorders

\begin{tabular}{|l|l|l|l|l|l|l|}
\hline Diarrhea & 43 & 5 & 0 & 25 & 3 & 0 \\
\hline Nausea & 24 & 1 & 0 & 14 & 0 & 0 \\
\hline Vomiting & 17 & 1 & 0 & 5 & 1 & 0
\end{tabular}

Respiratory, thoracic and mediastinal disorders

\begin{tabular}{|l|l|l|l|l|l|l|}
\hline Coughc $^{\text {Dyspnea }}$ & 30 & 0 & 0 & 15 & 0 & 0 \\
\hline Dys $^{\text {Dy }}$ & 21 & 3 & $<1$ & 12 & 1 & 0 \\
\hline
\end{tabular}

Musculoskeletal and connective tissue disorders

\begin{tabular}{|l|l|l|l|l|l|l} 
Muscle spasms & 26 & 1 & 0 & 19 & 2 \\
\hline
\end{tabular}

Nervous system disorders

\begin{tabular}{|l|l|l|l|l|l|l|} 
Headache & 13 & 0 & 0 & 7 & 0 & 0 \\
\hline
\end{tabular}

Key: $\mathrm{D}=$ daratumumab, $\mathrm{Rd}$ =lenalidomide-dexamethasone.

a upper respiratory tract infection, bronchitis, sinusitis, respiratory tract infection viral, rhinitis, pharyngitis, respiratory tract infection, metapneumovirus infection, tracheobronchitis, viral upper respiratory tract infection, laryngitis, respiratory syncytial virus infection, staphylococcal pharyngitis, tonsillitis, viral pharyngitis, acute sinusitis, nasopharyngitis, bronchiolitis, bronchitis viral, pharyngitis streptococcal, tracheitis, upper respiratory tract infection bacterial, bronchitis bacterial, epiglottitis, laryngitis viral, oropharyngeal candidiasis, respiratory moniliasis, viral rhinitis, acute tonsillitis, rhinovirus infection

b Infusion-related reaction includes terms determined by investigators to be related to infusion

c cough, productive cough, allergic cough

d dyspnea, dyspnea exertional 
Laboratory abnormalities worsening during treatment from baseline listed in Table 8.

Table 8: Treatment-Emergent Hematology Laboratory Abnormalities in POLLUX

\begin{tabular}{|l|l|l|l|l|l|l|}
\hline & \multicolumn{2}{|l|}{ DRd (N=283) } & \multicolumn{2}{l|}{ Rd (N=281) } \\
\cline { 2 - 7 } & $\begin{array}{l}\text { All } \\
\text { Grades } \\
(\%)\end{array}$ & $\begin{array}{l}\text { Grade 3 } \\
(\%)\end{array}$ & $\begin{array}{l}\text { Grade 4 } \\
(\%)\end{array}$ & $\begin{array}{l}\text { All } \\
\text { Grades } \\
(\%)\end{array}$ & $\begin{array}{l}\text { Grade 3 } \\
(\%)\end{array}$ & $\begin{array}{l}\text { Grade 4 } \\
(\%)\end{array}$ \\
\hline Lymphopenia & 95 & 42 & 10 & 87 & 32 & 6 \\
\hline Neutropenia & 92 & 36 & 17 & 87 & 32 & 8 \\
\hline Thrombocytopenia & 73 & 7 & 6 & 67 & 10 & 5 \\
\hline Anemia & 52 & 13 & 0 & 57 & 19 & 0 \\
\hline
\end{tabular}

Key: D=daratumumab, $\mathrm{Rd}=$ =lenalidomide-dexamethasone.

Combination Treatment with Bortezomib and Dexamethasone

The safety of DARZALEX in combination with lenalidomide and dexamethasone was evaluated in CASTOR (see Clinical Studies (14.2) in Full Prescribing Information]. Adverse reactions described in Table 9 reflect exposure to DARZALEX for a median treatment duration of 6.5 months (range: 0 to 14.8 months) for daratumumab-bortezomib-dexamethasone (DVd) and of 5.2 months (range: 0.2 to 8.0 months) for bortezomib-dexamethasone (Vd) arm. Serious adverse reactions occurred in $42 \%$ of patients in the DVd arm compared with $34 \%$ in the Vd arm. Serious adverse reactions with at least a $2 \%$ greater incidence in the DVd arm compared to the $\mathrm{Vd}$ arm were upper respiratory tract infection (DVd $5 \%$ vs Vd $2 \%$ ), diarrhea and atrial fibrillation (DVd $2 \%$ vs Vd $0 \%$ for each).

Adverse reactions resulted in discontinuations for $7 \%(n=18)$ of patients in the DVd arm versus $9 \%(n=22)$ in the $V d$ arm.

Table 9: Adverse Reactions Reported in $\geq 10 \%$ of Patients and With at Least a 5\% Greater Frequency in the DVd Arm CASTOR

\begin{tabular}{|l|l|l|l|l|l|l|}
\hline Adverse Reaction & \multicolumn{2}{|l|}{ DVd (N=243) } & \multicolumn{2}{l|}{ Vd (N=237) } \\
\cline { 2 - 6 } & $\begin{array}{l}\text { All } \\
\text { Grades } \\
(\%)\end{array}$ & $\begin{array}{l}\text { Grade 3 } \\
(\%)\end{array}$ & $\begin{array}{l}\text { Grade 4 } \\
(\%)\end{array}$ & $\begin{array}{l}\text { All } \\
\text { Grades } \\
(\%)\end{array}$ & $\begin{array}{l}\text { Grade 3 } \\
(\%)\end{array}$ & $\begin{array}{l}\text { Grade } \\
(\%)\end{array}$ \\
\hline
\end{tabular}

\section{Nervous system disorders}

\begin{tabular}{l|l|l|l|l|l|l}
$\begin{array}{l}\text { Peripheral } \\
\text { sensory } \\
\text { neuropathy }\end{array}$ & 47 & 5 & 0 & 38 & 6 & $<1$ \\
\hline
\end{tabular}

\section{General disorders and administration site conditions}

\begin{tabular}{|l|l|l|l|l|l|l|}
\hline $\begin{array}{l}\text { Infusion-related } \\
\text { reactions }^{a}\end{array}$ & 45 & 9 & 0 & 0 & 0 & 0 \\
\hline $\begin{array}{l}\text { Peripheral } \\
\text { edema }^{b}\end{array}$ & 22 & 1 & 0 & 13 & 0 & 0 \\
\hline Pyrexia & 16 & 1 & 0 & 11 & 1 & 0 \\
\hline
\end{tabular}

\section{Infections}

Upper

respiratory

\begin{tabular}{l|l|l|l|l|l|l|} 
tract infectionc $^{c}$ & 44 & 6 & 0 & 30 & 3 & $<1$ \\
\hline
\end{tabular}

\section{Gastrointestinal disorders}

\begin{tabular}{|l|l|l|l|l|l|l|}
\hline Diarrhea & 32 & 3 & $<1$ & 22 & 1 & 0 \\
\hline Vomiting & 11 & 0 & 0 & 4 & 0 & 0 \\
\hline
\end{tabular}

\section{Respiratory, thoracic and mediastinal disorders}

\begin{tabular}{|l|l|l|l|l|l|l|} 
Cough $^{d}$ & 27 & 0 & 0 & 14 & 0 & 0 \\
\hline Dyspnea & 21 & 4 & 0 & 11 & 1 & 0 \\
\hline
\end{tabular}

Key: $D=$ daratumumab, Vd=bortezomib-dexamethasone.

a Infusion-related reaction includes terms determined by investigators to be related to infusion

b edema peripheral, edema, generalized edema, peripheral swelling

c upper respiratory tract infection, bronchitis, sinusitis, respiratory tract infection viral, rhinitis, pharyngitis, respiratory tract infection, metapneumovirus infection, tracheobronchitis, viral upper respiratory tract infection, laryngitis, respiratory syncytial virus infection, staphylococcal pharyngitis, tonsillitis, viral pharyngitis, acute sinusitis, nasopharyngitis, bronchiolitis, bronchitis viral, pharyngitis streptococcal, tracheitis, upper respiratory tract infection bacterial, bronchitis bacterial, epiglottitis, laryngitis viral, oropharyngeal candidiasis, respiratory moniliasis, viral rhinitis, acute tonsillitis, rhinovirus infection

d cough, productive cough, allergic cough

e dyspnea, dyspnea exertional

Laboratory abnormalities worsening during treatment are listed in Table 10.
Table 10: Treatment-Emergent Hematology Laboratory Abnormalities in CASTOR

\begin{tabular}{|l|l|l|l|l|l|l|}
\hline & \multicolumn{2}{|l|}{ DVd (N=243) } & \multicolumn{2}{l|}{ Vd (N=237) } \\
\cline { 2 - 7 } & $\begin{array}{l}\text { All } \\
\text { Grades } \\
(\%)\end{array}$ & $\begin{array}{l}\text { Grade 3 } \\
(\%)\end{array}$ & $\begin{array}{l}\text { Grade 4 } \\
(\%)\end{array}$ & $\begin{array}{l}\text { All } \\
\text { Grades } \\
(\%)\end{array}$ & $\begin{array}{l}\text { Grade 3 } \\
(\%)\end{array}$ & $\begin{array}{l}\text { Grade 4 } \\
(\%)\end{array}$ \\
\hline Thrombocytopenia & 90 & 28 & 19 & 85 & 22 & 13 \\
\hline Lymphopenia & 89 & 41 & 7 & 81 & 24 & 3 \\
\hline Neutropenia & 58 & 12 & 3 & 40 & 5 & $<1$ \\
\hline Anemia & 48 & 13 & 0 & 56 & 14 & 0 \\
\hline
\end{tabular}

Key: $\mathrm{D}=$ daratumumab, $\mathrm{Vd}=$ bortezomib-dexamethasone.

Combination Treatment with Twice-Weekly (20/56 mg/m²) Carfilzomib and Dexamethasone

The safety of DARZALEX in combination with twice weekly carfilzomib and dexamethasone was evaluated in CANDOR [see Clinical Studies (14.2) in Full Prescribing Information]. Adverse reactions described in Table 11 reflect exposure to DARZALEX for a median treatment duration of 16.1 months (range: 0.1 to 23.7 months) for the daratumumab-carfilzomib-dexamethasone (DKd) group and median treatment duration of 9.3 months (range: 0.1 to 22.4 months) for the carfilzomib-dexamethasone group $(\mathrm{Kd})$.

Serious adverse reactions occurred in $56 \%$ of patients who received DARZALEX in combination with $\mathrm{Kd}$ and $46 \%$ of patients who received $\mathrm{Kd}$. The most frequent serious adverse reactions reported in the DKd arm as compared with the Kd arm were pneumonia (DKd 14\% vs Kd 9\%), pyrexia (DKd 4.2\% vs Kd $2.0 \%$ ), influenza (DKd $3.9 \%$ vs Kd 1.3\%), sepsis (DKd 3.9\% vs Kd 1.3\%), anemia (DKd $2.3 \%$ vs Kd $0.7 \%$ ), bronchitis (DKd $1.9 \%$ vs Kd $0 \%$ ), and diarrhea (DKd $1.6 \%$ vs $\mathrm{Kd} 0 \%$ ). Fatal adverse reactions within 30 days of the last dose of any study treatment occurred in $10 \%$ of 308 patients who received DARZALEX in combination with $\mathrm{Kd}$ versus $5 \%$ of 153 patients who received $\mathrm{Kd}$. The most frequent fatal adverse reaction was infection (4.5\% vs $2.6 \%)$.

Permanent discontinuation of DARZALEX due to an adverse reaction occurred in $9 \%$ of patients. Adverse reactions $(>1 \%)$ which resulted in permanent discontinuation of DARZALEX included pneumonia.

Infusion-related reactions that occurred on the day of administration of any DARZALEX dose or on the next day occurred in $18 \%$ of patients and that occurred on the day of administration of the first DARZALEX dose or the next day occurred in $12 \%$.

Table 11: Adverse Reactions ( $\geq 15 \%)$ in Patients Who Received DARZALEX in Combination with Carfilzomib and Dexamethasone (DKd) in CANDOR

\begin{tabular}{|c|c|c|c|c|}
\hline Adverse Reaction & \multicolumn{2}{|c|}{ DKd (N=308) } & \multicolumn{2}{c|}{ Kd (N=153) } \\
\cline { 2 - 5 } & $\begin{array}{c}\text { All Grades } \\
(\%)\end{array}$ & $\begin{array}{c}\text { Grades } 3 \text { or } 4 \\
(\%)\end{array}$ & $\begin{array}{c}\text { All Grades } \\
(\%)\end{array}$ & $\begin{array}{c}\text { Grades } 3 \text { or } 4 \\
(\%)\end{array}$ \\
\hline
\end{tabular}

General Disorders and Administration Site Conditions

\begin{tabular}{|c|c|c|c|c|}
\hline $\begin{array}{l}\text { Infusion-related } \\
\text { reactions }^{a}\end{array}$ & 41 & 12 & 28 & 5 \\
\hline Fatigueb $^{b}$ & 32 & 11 & 28 & 8 \\
\hline Pyrexia & 20 & 1.9 & 15 & 0.7 \\
\hline \multicolumn{5}{|l|}{ Infections } \\
\hline $\begin{array}{l}\text { Respiratory tract } \\
\text { infectionc }\end{array}$ & $40 \mathrm{~g}$ & 7 & 29 & 3.3 \\
\hline Pneumonia & $18^{g}$ & 13 & 12 & 9 \\
\hline Bronchitis & 17 & 2.6 & 12 & 1.3 \\
\hline
\end{tabular}

Blood and lymphatic system disorders

\begin{tabular}{|l|l|l|l|l|} 
Thrombocytopenia $^{\mathrm{d}}$ & 37 & 25 & 30 & 16 \\
\hline Anemia $^{\mathrm{e}}$ & 33 & 17 & 31 & 14 \\
\hline
\end{tabular}

Gastrointestinal disorders

\begin{tabular}{|l|c|c|c|c|}
\hline Diarrhea & 32 & 3.9 & 14 & 0.7 \\
\hline Nausea & 18 & 0 & 13 & 0.7 \\
\hline
\end{tabular}

Vascular Disorders

\begin{tabular}{|l|l|l|l|l} 
Hypertension & 31 & 18 & 28 & 13
\end{tabular}

Respiratory, Thoracic and Mediastinal Disorders

\begin{tabular}{|l|c|c|c|c|}
\hline Cough $^{f}$ & 21 & 0 & 21 & 0 \\
\hline Dyspnea & 20 & 3.9 & 22 & 2.6 \\
\hline
\end{tabular}

Psychiatric disorders

\begin{tabular}{|c|c|c|c|c|}
\hline Insomnia & 18 & 3.9 & 11 & 2 \\
\hline \multicolumn{5}{|c|}{ Musculoskeletal and connective tissue disorders } \\
\hline Back pain & 16 & 1.9 & 10 & 1.3 \\
\hline
\end{tabular}


Key: $\mathrm{D}=$ daratumumab; $\mathrm{Kd}$ =carfilzomib-dexamethasone

a The incidence of infusion related reactions is based on a group of symptoms (including hypertension, pyrexia, rash, myalgia, hypotension, blood pressure increased, urticaria, acute kidney injury, bronchospasm, face edema, hypersensitivity, rash, syncope, wheezing, eye pruritus, eyelid edema, renal failure, swelling face) related to infusion reactions which occurred within 1 day after DKd or Kd administration.

b Fatigue includes fatigue and asthenia.

c Respiratory tract infection includes respiratory tract infection, lower respiratory tract infection, upper respiratory tract infection and viral upper respiratory tract infection.

d Thrombocytopenia includes platelet count decreased and thrombocytopenia.

e Anemia includes anemia, hematocrit decreased and hemoglobin decreased.

$f$ Cough includes productive cough and cough.

$\mathrm{g}$ Includes fatal adverse reactions.

Adverse Reactions Occurring at a Frequency of $<15 \%$

- Blood and lymphatic system disorders: neutropenia, Iymphopenia, leukopenia, febrile neutropenia

- Cardiac disorders: atrial fibrillation

- Gastrointestinal disorders: vomiting, constipation

- General disorders and administration site conditions: peripheral edema, asthenia, chills

- Infections: influenza, urinary tract infection, sepsis, septic shock

- Metabolism and nutrition disorders: decreased appetite, hyperglycemia, hypocalcemia, dehydration

- Musculoskeletal and connective tissue disorders: muscle spasms, arthralgia, musculoskeletal chest pain

- Nervous system disorders: headache, dizziness, peripheral sensory neuropathy, paraesthesia, posterior reversible encephalopathy syndrome

- Respiratory, thoracic and mediastinal disorders: pulmonary edema

- Skin and subcutaneous tissue disorders: rash, pruritus

Combination Treatment with Once-Weekly (20/70 mg/m²) Carfilzomib and Dexamethasone

The safety of DARZALEX in combination with once-weekly carfilzomib and dexamethasone was evaluated in EQUULEUS [see Clinical Studies (14.2) in Full Prescribing Information]. Adverse reactions described in Table 12 reflect exposure to DARZALEX for a median treatment duration of 19.8 months (range: 0.3 to 34.5 months).

Serious adverse reactions were reported in $48 \%$ of patients. The most frequent serious adverse reactions reported were pneumonia (4.7\%), upper respiratory tract infection $(4.7 \%)$, basal cell carcinoma $(4.7 \%)$, influenza $(3.5 \%)$, general physical health deterioration $(3.5 \%)$, and hypercalcemia $(3.5 \%)$. Fatal adverse reactions within 30 days of the last dose of any study treatment occurred in $3.5 \%$ of patients who died of general physical health deterioration, multi-organ failure secondary to pulmonary aspergillosis, and disease progression.

Permanent discontinuation of DARZALEX due to an adverse reaction occurred in $8 \%$ of patients. No adverse reactions which resulted in permanent discontinuation of DARZALEX occurred in more than one patient.

Infusion-related reactions that occurred on the day of administration of any DARZALEX dose or on the next day occurred in $44 \%$ of patients. For patients who received the split first dose of DARZALEX, infusion-related reactions that occurred in $36 \%$ and $4 \%$ on the first and second day of administration of DARZALEX, respectively.

Table 12: Adverse Reactions ( $\geq 15 \%$ ) of Patients Who Received DARZALEX in Combination with Carfilzomib and Dexamethasone in EQUULEUS

\begin{tabular}{|c|c|c|}
\hline \multirow[b]{2}{*}{ Adverse Reaction } & \multicolumn{2}{|c|}{ DKd ( $N=85)$} \\
\hline & All Grades (\%) & Grades 3 or $4(\%)$ \\
\hline \multicolumn{3}{|c|}{ Blood and lymphatic system disorders } \\
\hline Thrombocytopeniaa & 68 & 32 \\
\hline Anemiab & 52 & 21 \\
\hline Neutropenia $^{c}$ & 31 & 21 \\
\hline Lymphopeniad $^{d}$ & 29 & 25 \\
\hline \multicolumn{3}{|c|}{ General disorder and administration site conditions } \\
\hline Fatigue $^{\mathrm{e}}$ & 54 & 18 \\
\hline Infusion-related reactions ${ }^{f}$ & 53 & 12 \\
\hline Pyrexia & 37 & 1.2 \\
\hline \multicolumn{3}{|l|}{ Infections } \\
\hline $\begin{array}{l}\text { Respiratory tract } \\
\text { infectiong }\end{array}$ & 53 & 3.5 \\
\hline Bronchitis & 19 & 0 \\
\hline Nasopharyngitis & 18 & 0 \\
\hline Influenza & 17 & 3.5 \\
\hline
\end{tabular}

Table 12: Adverse Reactions ( $\geq 15 \%$ ) of Patients Who Received DARZALEX in Combination with Carfilzomib and Dexamethasone in EQUULEUS (continued)

\begin{tabular}{|l|c|c|}
\hline \multirow{2}{*}{ Adverse Reaction } & \multicolumn{2}{|c|}{ DKd (N=85) } \\
\cline { 2 - 3 } & All Grades (\%) & Grades 3 or 4 (\%) \\
\hline Gastrointestinal disorders & 42 & 1.2 \\
\hline Nausea & 40 & 1.2 \\
\hline Vomiting & 38 & 2.4 \\
\hline Diarrhea & 17 & 0 \\
\hline Constipation & 35 & 3.5 \\
\hline Respiratory, thoracic and mediastinal disorders \\
\hline Dyspnea & 33 & 0 \\
\hline Cough & \\
\hline Vascular disorders & 33 & 20 \\
\hline Hypertension & 33 & 4.7 \\
\hline Psychiatric disorders & 27 \\
\hline Insomnia & 25 & 1.2 \\
\hline Nervous system disorders & 15 & 0 \\
\hline Headache & \\
\hline Musculoskeletal and connective tissue disorders \\
\hline Back pain & \multicolumn{2}{|c|}{} \\
\hline Pain in extremity &
\end{tabular}

Key: $\mathrm{D}=$ daratumumab; $\mathrm{Kd}$ =carfilzomib-dexamethasone

a Thrombocytopenia includes platelet count decreased and thrombocytopenia.

b Anemia includes anemia, hematocrit decreased and hemoglobin decreased.

c Neutropenia includes neutrophil count decreased and neutropenia

d Lymphopenia includes lymphocyte count decreased and lymphopenia

e Fatigue includes fatigue and asthenia.

$f$ The incidence of infusion related reactions is based on a group of symptoms (including hypertension, pyrexia, rash, myalgia, hypotension, blood pressure increased, urticaria, acute kidney injury, bronchospasm, face edema, hypersensitivity, rash, syncope, wheezing, eye pruritus, eyelid edema, renal failure, swelling face) related to infusion reactions which occurred within 1 day after DKd administration.

$g$ Respiratory tract infection includes respiratory tract infection, lower respiratory tract infection, upper respiratory tract infection and viral upper respiratory tract infection.

h Cough includes productive cough and cough.

Adverse Reactions Occurring at a Frequency of $<15 \%$

- Blood and lymphatic system disorders: leukopenia, febrile neutropenia

- Cardiac disorders: atrial fibrillation

- Gastrointestinal disorders: pancreatitis

- General disorders and administration site conditions: peripheral edema, chills

- Infections: pneumonia, urinary tract infection, sepsis, septic shock

- Metabolism and nutrition disorders: decreased appetite, hyperglycemia, dehydration, hypocalcemia

- Musculoskeletal and connective tissue disorders: muscle spasms, musculoskeletal chest pain, arthralgia

- Nervous system disorders: dizziness, paraesthesia, peripheral sensory neuropathy

- Skin and subcutaneous tissue disorders: pruritus, rash Combination Treatment with Pomalidomide and Dexamethasone

The safety of DARZALEX in combination with pomalidomide and dexamethasone was evaluated in EQUULEUS [see Clinical Studies (14.2) in Full Prescribing Information]. Adverse reactions described in Table 13 reflect exposure to DARZALEX, pomalidomide and dexamethasone (DPd) for a median treatment duration of 6 months (range: 0.03 to 16.9 months).

The overall incidence of serious adverse reactions was $49 \%$. Serious adverse reactions reported in $\geq 5 \%$ patients included pneumonia $(7 \%)$. Adverse reactions resulted in discontinuations for $13 \%$ of patients. 
Table 13: Adverse Reactions With Incidence $\geq \mathbf{1 0} \%$ Reported in EQUULEUS Adverse Reaction $\mathrm{DPd}(\mathrm{N}=\mathbf{1 0 3})$ \begin{tabular}{|l|l|l|}
\hline All Grades (\%) & Grade $3(\%)$ & Grade $4(\%)$ \\
\hline
\end{tabular}

\section{General disorders and administration site conditions}

\begin{tabular}{|l|c|c|c|}
\hline Fatigue & 50 & 10 & 0 \\
\hline $\begin{array}{l}\text { Infusion-related } \\
\text { reactions }\end{array}$ & 50 & 4 & 0 \\
\hline Pyrexia & 25 & 1 & 0 \\
\hline Chills & 20 & 0 & 0 \\
\hline Edema peripheral & 17 & 4 & 0 \\
\hline Asthenia & 15 & 0 & 0 \\
\hline Non-cardiac chest pain & 15 & 0 & 0 \\
\hline Pain & 11 & 0 & 0 \\
\hline
\end{tabular}

\section{Infections}

\begin{tabular}{l|l|l|l}
$\begin{array}{l}\text { Upper respiratory tract } \\
\text { infectionc }\end{array}$ & 50 & 4 & 1 \\
\hline
\end{tabular}

Pneumonia $^{\mathrm{d}}$

15

Respiratory, thoracic and mediastinal disorders

\begin{tabular}{|l|l|l|l}
\hline Coughe & 43 & 1 & 0 \\
\hline Dyspnea $^{f}$ & 33 & 6 & 1 \\
\hline Nasal congestion & 16 & 0 & 0 \\
\hline
\end{tabular}

\section{Gastrointestinal disorders}

\begin{tabular}{|l|l|l|l|}
\hline Diarrhea & 38 & 3 & 0 \\
\hline Constipation & 33 & 0 & 0 \\
\hline Nausea & 30 & 0 & 0 \\
\hline Vomiting & 21 & 2 & 0 \\
\hline
\end{tabular}

\section{Musculoskeletal and connective tissue disorders}

Muscle spasms

Back pain

Arthralgia

Pain in extremity

Bone pain

Musculoskeletal chest

pain

\begin{tabular}{|l|l|l|l|} 
& 26 & 1 & 0 \\
\hline & 25 & 6 & 0 \\
\hline & 22 & 2 & 0 \\
\hline & 15 & 0 & 0 \\
\hline & 13 & 4 & 0 \\
\hline
\end{tabular}

\section{Psychiatric disorders}

\begin{tabular}{|l|l|l|l}
\hline Insomnia & 23 & 2 & 0 \\
\hline Anxiety & 13 & 0 & 0 \\
\hline
\end{tabular}

\section{Nervous system disorders}

\begin{tabular}{|l|l|l|l|}
\hline Dizziness & 21 & 2 & 0 \\
\hline Tremor & 19 & 3 & 0 \\
\hline Headache & 17 & 0 & 0 \\
\hline Metabolism and nutrion dis
\end{tabular}

\section{Metabolism and nutrition disorders}

\begin{tabular}{|l|c|c|c|}
\hline Hypokalemia & 16 & 3 & 0 \\
\hline Hyperglycemia & 13 & 5 & 1 \\
\hline Decreased appetite & 11 & 0 & 0 \\
\hline
\end{tabular}

Key: $\mathrm{D}=$ daratumumab, $\mathrm{Pd}$ =pomalidomide-dexamethasone.

a Infusion-related reaction includes terms determined by investigators to be related to infusion

b edema, edema peripheral, peripheral swelling.

c acute tonsillitis, bronchitis, laryngitis, nasopharyngitis, pharyngitis, respiratory syncytial virus infection, rhinitis, sinusitis, tonsillitis, upper respiratory tract infection

d lung infection, pneumonia, pneumonia aspiration

e cough, productive cough, allergic cough

f dyspnea, dyspnea exertional

Laboratory abnormalities worsening during treatment are listed in Table 14.

Table 14: Treatment-Emergent Hematology Laboratory Abnormalities in EOUULEUS

\begin{tabular}{|l|c|c|c|}
\hline \multirow{2}{*}{} & \multicolumn{3}{|c|}{ DPd (N=103) } \\
\cline { 2 - 4 } & $\begin{array}{c}\text { All Grades } \\
(\mathbf{\%})\end{array}$ & $\begin{array}{c}\text { Grade 3 } \\
(\mathbf{\%})\end{array}$ & $\begin{array}{c}\text { Grade 4 } \\
(\mathbf{\%})\end{array}$ \\
\hline Neutropenia & 95 & 36 & 46 \\
\hline Lymphopenia & 94 & 45 & 26 \\
\hline Thrombocytopenia & 75 & 10 & 10 \\
\hline Anemia & 57 & 30 & 0 \\
\hline
\end{tabular}

Key: $\mathrm{D}=$ daratumumab, $\mathrm{Pd}$ =pomalidomide-dexamethasone.

\section{Monotherapy}

The safety of DARZALEX was evaluated in 156 adult patients with relapsed and refractory multiple myeloma in three open-label, clinical trials. Patients received DARZALEX $16 \mathrm{mg} / \mathrm{kg}$. The median duration of exposure was 3.3 months (range: 0.03 to 20.04 months).

Serious adverse reactions were reported in $51(33 \%)$ patients. The most frequent serious adverse reactions were pneumonia $(6 \%)$, general physical health deterioration $(3 \%)$, and pyrexia $(3 \%)$.

Adverse reactions resulted in treatment delay for $24(15 \%)$ patients, most frequently for infections. Adverse reactions resulted in discontinuations for $6(4 \%)$ patients.

Adverse reactions occurring in at least $10 \%$ of patients are presented in Table 15. Table 16 describes Grade 3-4 laboratory abnormalities reported at a rate of $\geq 10 \%$.

\section{Table 15: Adverse Reactions With Incidence $\geq 10 \%$ in Patients With} Multiple Myeloma Treated With DARZALEX $16 \mathrm{mg} / \mathrm{kg}$

\begin{tabular}{|c|c|c|c|c|c|}
\hline \multirow[b]{2}{*}{ Adverse Reaction } & & \multicolumn{4}{|c|}{$\begin{array}{l}\text { DARZALEX } \\
(\mathrm{N}=156)\end{array}$} \\
\hline & & \multicolumn{2}{|c|}{$\begin{array}{l}\text { All Grades } \\
(\%)\end{array}$} & $\begin{array}{c}\text { Grade } 3 \\
(\%)\end{array}$ & $\begin{array}{c}\text { Grade } 4 \\
(\%)\end{array}$ \\
\hline \multicolumn{6}{|c|}{ General disorders and administration site conditions } \\
\hline \multicolumn{2}{|c|}{ Infusion-related reaction ${ }^{\mathrm{a}}$} & \multicolumn{2}{|c|}{48} & 3 & 0 \\
\hline \multicolumn{2}{|c|}{ Fatigue } & \multicolumn{2}{|c|}{39} & 2 & 0 \\
\hline \multicolumn{2}{|l|}{ Pyrexia } & \multicolumn{2}{|c|}{21} & 1 & 0 \\
\hline \multicolumn{2}{|l|}{ Chills } & \multicolumn{2}{|c|}{10} & 0 & 0 \\
\hline \multicolumn{6}{|c|}{ Gastrointestinal disorders } \\
\hline \multicolumn{2}{|c|}{ Nausea } & \multicolumn{2}{|c|}{27} & 0 & 0 \\
\hline \multicolumn{2}{|l|}{ Diarrhea } & \multicolumn{2}{|c|}{16} & 1 & 0 \\
\hline \multicolumn{2}{|l|}{ Constipation } & \multicolumn{2}{|c|}{15} & 0 & 0 \\
\hline \multicolumn{2}{|l|}{ Vomiting } & \multicolumn{2}{|c|}{14} & 0 & 0 \\
\hline \multicolumn{6}{|c|}{ Musculoskeletal and connective tissue disorders } \\
\hline \multicolumn{2}{|c|}{ Back pain } & \multicolumn{2}{|c|}{23} & 2 & 0 \\
\hline \multicolumn{2}{|l|}{ Arthralgia } & \multicolumn{2}{|c|}{17} & 0 & 0 \\
\hline \multicolumn{2}{|l|}{ Pain in extremity } & 1 & & 1 & 0 \\
\hline Musculoskeletal cl & st pain & 1 & & 1 & 0 \\
\hline Respiratory, thoraci & and me & istinal & sord & & \\
\hline Cough & & 2 & & 0 & 0 \\
\hline Nasal congestion & & 1 & & 0 & 0 \\
\hline Dyspnea & & 1 & & 1 & 0 \\
\hline Infections & & & & & \\
\hline $\begin{array}{l}\text { Upper respiratory } \\
\text { infection }\end{array}$ & & 2 & & 1 & 0 \\
\hline Nasopharyngitis & & 1 & & 0 & 0 \\
\hline Pneumonia $^{b}$ & & 1 & & 6 & 0 \\
\hline Metabolism and nut & tion dis & lers & & & \\
\hline Decreased appetit & & 1 & & 1 & 0 \\
\hline Nervous system dis & ders & & & & \\
\hline Headache & & 1 & & 1 & 0 \\
\hline Vascular disorders & & & & & \\
\hline Hypertension & & 1 & & 5 & 0 \\
\hline $\begin{array}{l}\text { a Infusion-related } r \\
\text { be related to infus } \\
\text { b Pneumonia also i } \\
\text { pneumonia. }\end{array}$ & $\begin{array}{l}\text { action in } \\
\text { on }\end{array}$ & $\begin{array}{l}\text { udes te } \\
\text { terms }\end{array}$ & is d & $\begin{array}{l}\text { ermined b } \\
\text { occal pne }\end{array}$ & $\begin{array}{l}\text { investigators to } \\
\text { nonia and lobar }\end{array}$ \\
\hline Table 16: Treatment-E & 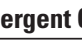 & tae 3-4 & 100 & ory Abnor & lities ( $\geq 10 \%)$ \\
\hline & & Daratur & Imak & $16 \mathrm{mg} / \mathrm{kg}($ & $=156)$ \\
\hline & All Gra & s (\%) & Gra & e $3(\%)$ & Grade $4(\%)$ \\
\hline Lymphopenia & & & & 30 & 10 \\
\hline Neutropenia & & & & 17 & 3 \\
\hline Thrombocytopenia & & & & 10 & 8 \\
\hline Anemia & & & & 19 & 0 \\
\hline
\end{tabular}

\section{Herpes Zoster Virus Reactivation}

Prophylaxis for Herpes Zoster Virus reactivation was recommended for patients in some clinical trials of DARZALEX. In monotherapy studies, herpes zoster was reported in $3 \%$ of patients. In the combination therapy studies, herpes zoster was reported in $2-5 \%$ of patients receiving DARZALEX. 


\section{$\underline{\text { Infections }}$}

Grade 3 or 4 infections were reported as follows:

- Relapsed/refractory patient studies: DVd: $21 \%$ vs. Vd: $19 \%$; DRd: $28 \%$ vs. Rd: 23\%; DPd: 28\%; DKda: 37\%, Kda: 29\%; DKdb: $21 \%$

a where carfilzomib $20 / 56 \mathrm{mg} / \mathrm{m}^{2}$ was administered twice-weekly

b where carfilzomib 20/70 mg/m² was administered once-weekly

- Newly diagnosed patient studies: D-VMP: 23\%, VMP: 15\%; DRd: 32\%, Rd: 23\%; DVTd: $22 \%$; VTd: $20 \%$.

Pneumonia was the most commonly reported severe (Grade 3 or 4 ) infection across studies. In active controlled studies, discontinuations from treatment due to infections occurred in $1-4 \%$ of patients.

Fatal infections (Grade 5) were reported as follows:

- Relapsed/refractory patient studies: DVd: $1 \%$, Vd: $2 \%$; DRd: $2 \%$, Rd: $1 \%$; DPd: $2 \%$; DKda: $5 \%$, Kda: 3\%; DKdb: $0 \%$

a where carfilzomib $20 / 56 \mathrm{mg} / \mathrm{m}^{2}$ was administered twice-weekly

b where carfilzomib $20 / 70 \mathrm{mg} / \mathrm{m}^{2}$ was administered once-weekly

- Newly diagnosed patient studies: D-VMP: $1 \%$, VMP: $1 \%$; DRd: $2 \%$, Rd: $2 \%$; DVTd: $0 \%$, VTd: $0 \%$.

Fatal infections were generally infrequent and balanced between the DARZALEX containing regimens and active control arms. Fatal infections were primarily due to pneumonia and sepsis.

Hepatitis B Virus (HBV) Reactivation

Hepatitis $B$ virus reactivation has been reported in less than $1 \%$ of patients (including fatal cases) treated with DARZALEX in clinical trials.

\section{Other Clinical Trials Experience}

The following adverse reactions have been reported following administration of daratumumab and hyaluronidase for subcutaneous injection:

\section{Nervous System disorders: Syncope}

\section{Immunogenicity}

As with all therapeutic proteins, there is the potential for immunogenicity. The detection of antibody formation is highly dependent on the sensitivity and specificity of the assay. Additionally, the observed incidence of antibody (including neutralizing antibody) positivity in an assay may be influenced by several factors including assay methodology, sample handling, timing of sample collection, concomitant medications, and underlying disease. For these reasons, comparison of the incidence of antibodies in the studies described below with the incidence of antibodies in other studies or to other daratumumab products may be misleading.

In clinical trials of patients with multiple myeloma treated with DARZALEX as monotherapy or as combination therapies, none of the 111 evaluable monotherapy patients, and 2 of the 1,383 evaluable combination therapy patients, tested positive for anti-daratumumab antibodies. One patient administered DARZALEX as combination therapy, developed transient neutralizing antibodies against daratumumab. However, this assay has limitations in detecting anti-daratumumab antibodies in the presence of high concentrations of daratumumab; therefore, the incidence of antibody development might not have been reliably determined.

\section{Postmarketing Experience}

The following adverse reactions have been identified during post-approval use of daratumumab. Because these reactions are reported voluntarily from a population of uncertain size, it is not always possible to reliably estimate their frequency or establish a causal relationship to drug exposure.

Immune System disorders: Anaphylactic reaction; IRR (including deaths)

Gastrointestinal disorders: Pancreatitis

Infections: Cytomegalovirus, Listeriosis

\section{DRUG INTERACTIONS}

\section{Effects of Daratumumab on Laboratory Tests}

\section{Interference with Indirect Antiglobulin Tests (Indirect Coombs Test)}

Daratumumab binds to CD38 on RBCs and interferes with compatibility testing, including antibody screening and cross matching. Daratumumab interference mitigation methods include treating reagent RBCs with dithiothreitol (DTT) to disrupt daratumumab binding [see References] or genotyping. Since the Kell blood group system is also sensitive to DTT treatment, supply K-negative units after ruling out or identifying alloantibodies using DTT-treated RBCs.

If an emergency transfusion is required, administer non-cross-matched $A B O /$ RhD-compatible RBCs per local blood bank practices.

\section{Interference with Serum Protein Electrophoresis and Immunofixation Tests}

Daratumumab may be detected on serum protein electrophoresis (SPE) and immunofixation (IFE) assays used for monitoring disease monoclonal immunoglobulins (M protein). False positive SPE and IFE assay results may occur for patients with IgG kappa myeloma protein impacting initial assessment of complete responses by International Myeloma Working
Group (IMWG) criteria. In patients with persistent very good partial response, where daratumumab interference is suspected, consider using a FDAapproved daratumumab-specific IFE assay to distinguish daratumumab from any remaining endogenous $M$ protein in the patient's serum, to facilitate determination of a complete response.

\section{USE IN SPECIFIC POPULATIONS}

\section{Pregnancy}

Risk Summary

DARZALEX can cause fetal harm when administered to a pregnant woman. The assessment of associated risks with daratumumab products is based on the mechanism of action and data from target antigen CD38 knockout animal models (see Data). There are no available data on the use of DARZALEX in pregnant women to evaluate drug-associated risk of major birth defects, miscarriage or adverse maternal or fetal outcomes. Animal reproduction studies have not been conducted.

The estimated background risk of major birth defects and miscarriage for the indicated population is unknown. All pregnancies have a background risk of birth defect, loss, or other adverse outcomes. In the U.S. general population, the estimated background risk of major birth defects and miscarriage in clinically recognized pregnancies is $2 \%$ to $4 \%$ and $15 \%$ to $20 \%$, respectively. The combination of DARZALEX and lenalidomide, pomalidomide, or thalidomide is contraindicated in pregnant women, because lenalidomide, pomalidomide, and thalidomide may cause birth defects and death of the unborn child. Lenalidomide, pomalidomide, and thalidomide are only available through a REMS program. Refer to the lenalidomide, pomalidomide, or thalidomide prescribing information on use during pregnancy.

\section{Clinical Considerations}

\section{Fetal/Neonatal Adverse Reactions}

Immunoglobulin G1 (IgG1) monoclonal antibodies are transferred across the placenta. Based on its mechanism of action, DARZALEX may cause depletion of fetal CD38 positive immune cells and decreased bone density. Defer administering live vaccines to neonates and infants exposed to DARZALEX in utero until a hematology evaluation is completed.

\section{Data}

\section{Animal Data}

Mice that were genetically modified to eliminate all CD38 expression (CD38 knockout mice) had reduced bone density at birth that recovered by 5 months of age. Data from studies using CD38 knockout animal models also suggest the involvement of CD38 in regulating humoral immune responses (mice), fetomaternal immune tolerance (mice), and early embryonic development (frogs).

\section{Lactation}

\section{Risk Summary}

There is no data on the presence of daratumumab in human milk, the effects on the breastfed child, or the effects on milk production. Maternal immunoglobulin $\mathrm{G}$ is known to be present in human milk. Published data suggest that antibodies in breast milk do not enter the neonatal and infant circulations in substantial amounts. Because of the potential for serious adverse reactions in the breastfed child when DARZALEX is administered with lenalidomide, pomalidomide, or thalidomide, advise women not to breastfeed during treatment with DARZALEX. Refer to lenalidomide, pomalidomide, or thalidomide prescribing information for additional information.

\section{Females and Males of Reproductive Potential}

DARZALEX can cause fetal harm when administered to a pregnant woman [see Use in Specific Populations].

\section{Pregnancy Testing}

With the combination of DARZALEX with Ienalidomide, pomalidomide, or thalidomide, refer to the lenalidomide, pomalidomide, or thalidomide labeling for pregnancy testing requirements prior to initiating treatment in females of reproductive potential.

\section{Contraception}

Advise females of reproductive potential to use effective contraception during treatment with DARZALEX and for 3 months after the last dose. Additionally, refer to the lenalidomide, pomalidomide, or thalidomide labeling for additional recommendations for contraception.

\section{Pediatric Use}

Safety and effectiveness of DARZALEX in pediatric patients have not been established.

\section{Geriatric Use}

Of the 2,459 patients who received DARZALEX at the recommended dose, $38 \%$ were 65 to 74 years of age, and $15 \%$ were 75 years of age or older. No overall differences in effectiveness were observed between these patients and younger patients. The incidence of serious adverse reactions was higher 
in older than in younger patients [see Adverse Reactions]. Among patients with relapsed and refractory multiple myeloma $(n=1,213)$, the serious adverse reactions that occurred more frequently in patients 65 years and older were pneumonia and sepsis. Within the DKd group in CANDOR, fatal adverse reactions occurred in $14 \%$ of patients 65 years and older compared to $6 \%$ of patients less than 65 years. Among patients with newly diagnosed multiple myeloma who are ineligible for autologous stem cell transplant $(n=710)$, the serious adverse reaction that occurred more frequently in patients 75 years and older was pneumonia.

\section{REFERENCES}

1. Chapuy, Cl, RT Nicholson, MD Aguad, et al., 2015, Resolving the daratumumab interference with blood compatibility testing, Transfusion, 55:1545-1554 (accessible at http://onlinelibrary.wiley.com/doi/10.1111/ trf.13069/epdf).

\section{PATIENT COUNSELING INFORMATION}

Advise the patient to read the FDA-approved patient labeling (Patient Information).

Infusion-Related Reactions

Advise patients to seek immediate medical attention for any of the following signs and symptoms of infusion-related reactions: itchy, runny or blocked nose; fever, chills, nausea, vomiting, throat irritation, cough, headache, dizziness or lightheadedness, tachycardia, chest discomfort, wheezing, shortness of breath or difficulty breathing, itching [see Warnings and Precautions].

Neutropenia

Advise patients to contact their healthcare provider if they have a fever [see Warnings and Precautions].

Thrombocytopenia

Advise patients to contact their healthcare provider if they notice signs of bruising or bleeding [see Warnings and Precautions].

Interference with Laboratory Tests

Advise patients to inform their healthcare providers, including personnel at blood transfusion centers that they are taking DARZALEX, in the event of a planned transfusion [see Warnings and Precautions].

Advise patients that DARZALEX can affect the results of some tests used to determine complete response in some patients and additional tests may be needed to evaluate response [see Warnings and Precautions].

\section{Hepatitis B Virus (HBV) Reactivation}

Advise patients to inform healthcare providers if they have ever had or might have a hepatitis B infection and that DARZALEX could cause hepatitis $B$ virus to become active again [see Adverse Reactions].

\section{Embryo-Fetal Toxicity}

Advise pregnant women of the potential hazard to a fetus. Advise females of reproductive potential to inform their healthcare provider of a known or suspected pregnancy [see Warnings and Precautions, Use in Specific Populations].

Advise females of reproductive potential to avoid becoming pregnant during treatment with DARZALEX and for 3 months after the last dose [see Use in Specific Populations].

Advise patients that lenalidomide, pomalidomide, or thalidomide has the potential to cause fetal harm and has specific requirements regarding contraception, pregnancy testing, blood and sperm donation, and transmission in sperm. Lenalidomide, pomalidomide, and thalidomide are only available through a REMS program [see Use in Specific Populations].

Manufactured by:

Janssen Biotech, Inc.

Horsham, PA 19044

U.S. License Number 1864

(C) 2015-2021 Janssen Pharmaceutical Companies

cp-60865v6 
DARZALEX FASPR0 ${ }^{\circledR}$ (daratumumab and hyaluronidase-fihj) injection, for subcutaneous use

\section{Brief Summary of Full Prescribing Information \\ INDICATIONS AND USAGE \\ Multiple Myeloma}

DARZALEX FASPRO is indicated for the treatment of adult patients with

multiple myeloma:

- in combination with bortezomib, melphalan and prednisone in newly diagnosed patients who are ineligible for autologous stem cell transplant.

- in combination with lenalidomide and dexamethasone in newly diagnosed patients who are ineligible for autologous stem cell transplant and in patients with relapsed or refractory multiple myeloma who have received at least one prior therapy.

- in combination with bortezomib, thalidomide, and dexamethasone in newly diagnosed patients who are eligible for autologous stem cell transplant.

- in combination with bortezomib and dexamethasone in patients who have received at least one prior therapy.

- in combination with pomalidomide and dexamethasone in patients who have received at least one prior line of therapy including lenalidomide and a proteasome inhibitor.

- as monotherapy, in patients who have received at least three prior lines of therapy including a proteasome inhibitor (PI) and an immunomodulatory agent or who are double-refractory to a PI and an immunomodulatory agent.

\section{Light Chain Amyloidosis}

DARZALEX FASPRO in combination with bortezomib, cyclophosphamide and dexamethasone is indicated for the treatment of adult patients with newly diagnosed light chain (AL) amyloidosis.

This indication is approved under accelerated approval based on response rate [see Clinical Studies (14.1) in Full Prescribing Information]. Continued approval for this indication may be contingent upon verification and description of clinical benefit in a confirmatory trial(s).

\section{Limitations of Use}

DARZALEX FASPRO is not indicated and is not recommended for the treatment of patients with light chain (AL) amyloidosis who have NYHA Class IIIB or Class IV cardiac disease or Mayo Stage IIIB outside of controlled clinical trials [see Warnings and Precautions].

\section{CONTRAINDICATIONS}

DARZALEX FASPRO is contraindicated in patients with a history of severe hypersensitivity to daratumumab, hyaluronidase or any of the components of the formulation [see Warnings and Precautions and Adverse Reactions].

\section{WARNINGS AND PRECAUTIONS}

\section{Hypersensitivity and Other Administration Reactions}

Both systemic administration-related reactions, including severe or life-threatening reactions, and local injection-site reactions can occur with DARZALEX FASPRO. Fatal reactions have been reported with daratumumab-containing products, including DARZALEX FASPRO [see Adverse Reactions].

\section{Systemic Reactions}

In a pooled safety population of 832 patients with multiple myeloma ( $\mathrm{N}=639$ ) or light chain (AL) amyloidosis ( $\mathrm{N}=193$ ) who received DARZALEX FASPRO as monotherapy or as part of a combination therapy, $9 \%$ of patients experienced a systemic administration-related reaction (Grade 2: $3.5 \%$, Grade 3: $0.8 \%$ ). Systemic administration-related reactions occurred in $8 \%$ of patients with the first injection, $0.4 \%$ with the second injection, and cumulatively $1 \%$ with subsequent injections. The median time to onset was 3.2 hours (range: 9 minutes to 3.5 days). Of the 129 systemic administration-related reactions that occurred in 74 patients, $110(85 \%)$ occurred on the day of DARZALEX FASPRO administration. Delayed systemic administration-related reactions have occurred in $1 \%$ of the patients.

Severe reactions included hypoxia, dyspnea, hypertension and tachycardia. Other signs and symptoms of systemic administration-related reactions may include respiratory symptoms, such as bronchospasm, nasal congestion, cough, throat irritation, allergic rhinitis, and wheezing, as well as anaphylactic reaction, pyrexia, chest pain, pruritus, chills, vomiting, nausea, and hypotension.

Pre-medicate patients with histamine-1 receptor antagonist, acetaminophen and corticosteroids [see Dosage and Administration (2.5) in Full Prescribing Information]. Monitor patients for systemic administration-related reactions, especially following the first and second injections. For anaphylactic reaction or life-threatening (Grade 4) administration-related reactions, immediately and permanently discontinue DARZALEX FASPRO. Consider administering corticosteroids and other medications after the administration of DARZALEX FASPRO depending on dosing regimen and medical history to minimize the risk of delayed (defined as occurring the day after administration) systemic administration-related reactions [see Dosage and Administration (2.5) in Full Prescribing Information].

\section{Local Reactions}

In this pooled safety population, injection-site reactions occurred in $8 \%$ of patients, including Grade 2 reactions in $0.6 \%$. The most frequent $(>1 \%)$ injection-site reaction was injection site erythema. These local reactions occurred a median of 5.5 minutes (range: 0 minutes to 6.5 days) after starting administration of DARZALEX FASPRO. Monitor for local reactions and consider symptomatic management.

\section{Cardiac Toxicity in Patients with Light Chain (AL) Amyloidosis}

Serious or fatal cardiac adverse reactions occurred in patients with light chain (AL) amyloidosis who received DARZALEX FASPRO in combination with bortezomib, cyclophosphamide and dexamethasone [see Adverse Reactions]. Serious cardiac disorders occurred in $16 \%$ and fatal cardiac disorders occurred in $10 \%$ of patients. Patients with NYHA Class IIIA or Mayo Stage IIIA disease may be at greater risk. Patients with NYHA Class IIIB or IV disease were not studied.

Monitor patients with cardiac involvement of light chain (AL) amyloidosis more frequently for cardiac adverse reactions and administer supportive care as appropriate.

\section{Neutropenia}

Daratumumab may increase neutropenia induced by background therapy [see Adverse Reactions].

Monitor complete blood cell counts periodically during treatment according to manufacturer's prescribing information for background therapies. Monitor patients with neutropenia for signs of infection. Consider withholding DARZALEX FASPRO until recovery of neutrophils. In lower body weight patients receiving DARZALEX FASPRO, higher rates of Grade 3-4 neutropenia were observed.

\section{Thrombocytopenia}

Daratumumab may increase thrombocytopenia induced by background therapy [see Adverse Reactions].

Monitor complete blood cell counts periodically during treatment according to manufacturer's prescribing information for background therapies. Consider withholding DARZALEX FASPRO until recovery of platelets.

\section{Embryo-Fetal Toxicity}

Based on the mechanism of action, DARZALEX FASPRO can cause fetal harm when administered to a pregnant woman. DARZALEX FASPRO may cause depletion of fetal immune cells and decreased bone density. Advise pregnant women of the potential risk to a fetus. Advise females with reproductive potential to use effective contraception during treatment with DARZALEX FASPRO and for 3 months after the last dose [see Use in Specific Populations].

The combination of DARZALEX FASPRO with lenalidomide, thalidomide or pomalidomide is contraindicated in pregnant women, because lenalidomide, thalidomide or pomalidomide may cause birth defects and death of the unborn child. Refer to the lenalidomide, thalidomide or pomalidomide prescribing information on use during pregnancy.

\section{Interference with Serological Testing}

Daratumumab binds to CD38 on red blood cells (RBCs) and results in a positive Indirect Antiglobulin Test (Indirect Coombs test). Daratumumab-mediated positive indirect antiglobulin test may persist for up to 6 months after the last daratumumab administration. Daratumumab bound to RBCs masks detection of antibodies to minor antigens in the patient's serum [see References (15)]. The determination of a patient's $\mathrm{ABO}$ and $\mathrm{Rh}$ blood type are not impacted [see Drug Interactions].

Notify blood transfusion centers of this interference with serological testing and inform blood banks that a patient has received DARZALEX FASPRO. Type and screen patients prior to starting DARZALEX FASPRO [see Dosage and Administration (2.1) in Full Prescribing Information].

\section{Interference with Determination of Complete Response}

Daratumumab is a human IgG kappa monoclonal antibody that can be detected on both the serum protein electrophoresis (SPE) and immunofixation (IFE) assays used for the clinical monitoring of endogenous M-protein [see Drug Interactions]. This interference can impact the determination of complete response and of disease progression in some DARZALEX FASPRO-treated patients with IgG kappa myeloma protein.

\section{ADVERSE REACTIONS}

The following clinically significant adverse reactions are described elsewhere in the labeling:

- Hypersensitivity and Other Administration Reactions [see Warning and Precautions].

- Cardiac Toxicity in Patients with Light Chain (AL) Amyloidosis [see Warning and Precautions].

- Neutropenia [see Warning and Precautions].

- Thrombocytopenia [see Warning and Precautions].

\section{Clinical Trials Experience}

Because clinical trials are conducted under widely varying conditions, adverse reaction rates observed in the clinical trials of a drug cannot be directly compared to rates in the clinical trials of another drug and may not reflect the rates observed in practice.

\section{Newly Diagnosed Multiple Myeloma}

\section{In Combination with Bortezomib, Melphalan and Prednisone}

The safety of DARZALEX FASPRO with bortezomib, melphalan and prednisone was evaluated in a single-arm cohort of PLEIADES [see Clinical Studies (14.1) in Full Prescribing Information]. Patients received DARZALEX FASPRO $1,800 \mathrm{mg} / 30,000$ units administered subcutaneously once weekly from weeks 1 to 6 , once every 3 weeks from weeks 7 to 54 and once every 4 weeks starting with week 55 until disease progression or unacceptable toxicity $(N=67)$ in combination with bortezomib, melphalan and prednisone. Among these patients, 93\% were exposed for 6 months or longer and 19\% were exposed for greater than one year. 
Serious adverse reactions occurred in $39 \%$ of patients who received DARZALEX FASPRO. Serious adverse reactions in $>5 \%$ of patients included pneumonia and pyrexia. Fatal adverse reactions occurred in $3 \%$ of patients. Permanent discontinuation of DARZALEX FASPRO due to an adverse reaction occurred in $4.5 \%$ of patients. The adverse reaction resulting in permanent discontinuation of DARZALEX FASPRO in more than 1 patient was neutropenic sepsis.

Dosage interruptions (defined as dose delays or skipped doses) due to an adverse reaction occurred in $51 \%$ of patients who received DARZALEX FASPRO. Adverse reactions requiring dosage interruptions in $>5 \%$ of patients included thrombocytopenia, neutropenia, anemia, and pneumonia.

The most common adverse reactions $(\geq 20 \%)$ were upper respiratory tract infection, constipation, nausea, fatigue, pyrexia, peripheral sensory neuropathy, diarrhea, cough, insomnia, vomiting, and back pain.

Table 1 summarizes the adverse reactions in patients who received DARZALEX FASPRO in PLEIADES.

Table 1: Adverse Reactions ( $\geq 10 \%$ ) in Patients Who Received DARZALEX FASPRO with Bortezomib, Melphalan and Prednisone (DARZALEX FASPRO-VMP) in PLEIADES

\begin{tabular}{|c|c|c|}
\hline \multirow[b]{2}{*}{ Adverse Reaction } & \multicolumn{2}{|c|}{$\begin{array}{c}\text { DARZALEX FASPRO } \\
\text { with Bortezomib, Melphalan } \\
\text { and Prednisone } \\
(\mathrm{N}=67)\end{array}$} \\
\hline & All Grades (\%) & Grades $\geq 3(\%)$ \\
\hline \multicolumn{3}{|l|}{ Infections } \\
\hline Upper respiratory tract infection ${ }^{\mathrm{a}}$ & 39 & 0 \\
\hline Bronchitis & 16 & 0 \\
\hline Pneumoniab $^{b}$ & 15 & $7 \#$ \\
\hline \multicolumn{3}{|l|}{ Gastrointestinal disorders } \\
\hline Constipation & 37 & 0 \\
\hline Nausea & 36 & 0 \\
\hline Diarrhea & 33 & $3^{\#}$ \\
\hline Vomiting & 21 & 0 \\
\hline Abdominal pain ${ }^{\mathrm{C}}$ & 13 & 0 \\
\hline \multicolumn{3}{|c|}{ General disorders and administration site conditions } \\
\hline Fatigue $^{d}$ & 36 & 3 \\
\hline Pyrexia & 34 & 0 \\
\hline Edema peripherale & 13 & $1^{\#}$ \\
\hline \multicolumn{3}{|l|}{ Nervous system disorders } \\
\hline Peripheral sensory neuropathy & 34 & $1^{\#}$ \\
\hline Dizziness & 10 & 0 \\
\hline \multicolumn{3}{|c|}{ Respiratory, thoracic and mediastinal disorders } \\
\hline Cough $^{f}$ & 24 & 0 \\
\hline \multicolumn{3}{|l|}{ Psychiatric disorders } \\
\hline Insomnia & 22 & $3^{\#}$ \\
\hline \multicolumn{3}{|c|}{ Musculoskeletal and connective tissue disorders } \\
\hline Back pain & 21 & $3^{\#}$ \\
\hline Musculoskeletal chest pain & 12 & 0 \\
\hline \multicolumn{3}{|l|}{ Metabolism and nutrition disorders } \\
\hline Decreased appetite & 15 & $1^{\#}$ \\
\hline \multicolumn{3}{|c|}{ Skin and subcutaneous tissue disorders } \\
\hline Rash & 13 & 0 \\
\hline Pruritus & 12 & 0 \\
\hline \multicolumn{3}{|l|}{ Vascular disorders } \\
\hline Hypertension & 13 & $6^{\#}$ \\
\hline Hypotension & 10 & $3^{\#}$ \\
\hline
\end{tabular}

a Upper respiratory tract infection includes nasopharyngitis, respiratory syncytial virus infection, respiratory tract infection, rhinitis, tonsillitis, upper respiratory tract infection, and viral pharyngitis.

b Pneumonia includes lower respiratory tract infection, lung infection, pneumocystis jirovecii pneumonia, pneumonia, and pneumonia bacterial.

Abdominal pain includes abdominal pain, and abdominal pain upper.

d Fatigue includes asthenia, and fatigue.

e Edema peripheral includes edema, edema peripheral, and peripheral swelling.

$f$ Cough includes cough, and productive cough.

\# Only grade 3 adverse reactions occurred.

Clinically relevant adverse reactions in $<10 \%$ of patients who received DARZALEX FASPRO with bortezomib, melphalan and prednisone included:

- General disorders and administration site conditions: infusion reaction, injection site reaction, chills

- Infections: herpes zoster, urinary tract infection, influenza, sepsis

- Musculoskeletal and connective tissue disorders: arthralgia, muscle spasms

- Nervous system disorders: headache, paresthesia

- Metabolism and nutrition disorders: hypocalcemia, hyperglycemia

- Respiratory, thoracic and mediastinal disorders: dyspnea, pulmonary edema

- Cardiac disorders: atrial fibrillation

Table 2 summarizes the laboratory abnormalities in patients who received DARZALEX FASPRO in PLEIADES.

Table 2: Select Hematology Laboratory Abnormalities Worsening from Baseline in Patients Who Received DARZALEX FASPRO with Bortezomib, Melphalan and Prednisone (DARZALEX FASPRO-VMP) in PLEIADES

\begin{tabular}{|c|c|c|}
\hline \multirow[b]{2}{*}{ Laboratory Abnormality } & \multicolumn{2}{|c|}{$\begin{array}{c}\text { DARZALEX FASPRO } \\
\text { with Bortezomib, Melphalan } \\
\text { and Prednisone }\end{array}$} \\
\hline & All Grades (\%) & Grades 3-4 (\%) \\
\hline Decreased leukocytes & 96 & 52 \\
\hline Decreased lymphocytes & 93 & 84 \\
\hline Decreased platelets & 93 & 42 \\
\hline Decreased neutrophils & 88 & 49 \\
\hline Decreased hemoglobin & 48 & 19 \\
\hline
\end{tabular}

a Denominator is based on the safety population treated with DARZALEX FASPRO-VMP ( $\mathrm{N}=67)$.

\section{Relapsed/Refractory Multiple Myeloma}

In Combination with Lenalidomide and Dexamethasone

The safety of DARZALEX FASPRO with lenalidomide and dexamethasone was evaluated in a single-arm cohort of PLEIADES [see Clinical Studies (14.2) in Full Prescribing Information]. Patients received DARZALEX FASPRO $1,800 \mathrm{mg} / 30,000$ units administered subcutaneously once weekly from weeks 1 to 8 , once every 2 weeks from weeks 9 to 24 and once every 4 weeks starting with week 25 until disease progression or unacceptable toxicity $(N=65)$ in combination with lenalidomide and dexamethasone. Among these patients, $92 \%$ were exposed for 6 months or longer and $20 \%$ were exposed for greater than one year.

Serious adverse reactions occurred in $48 \%$ of patients who received DARZALEX FASPRO. Serious adverse reactions in $>5 \%$ of patients included pneumonia, influenza and diarrhea. Fatal adverse reactions occurred in $3.1 \%$ of patients.

Permanent discontinuation of DARZALEX FASPRO due to an adverse reaction occurred in $11 \%$ of patients who received DARZALEX FASPRO. Adverse reactions resulting in permanent discontinuation of DARZALEX FASPRO in more than 1 patient were pneumonia and anemia.

Dosage interruptions due to an adverse reaction occurred in $63 \%$ of patients who received DARZALEX FASPRO. Adverse reactions requiring dosage interruptions in $>5 \%$ of patients included neutropenia, pneumonia, upper respiratory tract infection, influenza, dyspnea, and blood creatinine increased. The most common adverse reactions $(\geq 20 \%)$ were fatigue, diarrhea, upper respiratory tract infection, muscle spasms, constipation, pyrexia, pneumonia, and dyspnea.

Table 3 summarizes the adverse reactions in patients who received DARZALEX FASPRO in PLEIADES.

Table 3: Adverse Reactions ( $\geq 10 \%$ ) in Patients Who Received DARZALEX FASPRO with Lenalidomide and Dexamethasone (DARZALEX FASPRO-Rd) in PLEIADES

\begin{tabular}{|c|c|}
\hline & $\begin{array}{c}\text { DARZALEX FASPRO with } \\
\text { Lenalidomide and Dexamethasone } \\
(\mathrm{N}=65)\end{array}$
\end{tabular}

Adverse Reaction

All Grades (\%)

Grades $\geq 3(\%)$

General disorders and administration site conditions

\begin{tabular}{|l|l|l|}
\hline Fatigue $^{a}$ & 52 & $5^{\#}$ \\
\hline Pyrexia & 23 & $2^{\#}$ \\
\hline Edema peripheral & 18 & $3^{\#}$ \\
\hline
\end{tabular}

Gastrointestinal disorders

\begin{tabular}{|l|l|l}
\hline Diarrhea & 45 & 5 \\
\hline Constipation & 26 & 2 \\
\hline Nausea & 12 & \\
\hline Vomiting & 11 & \\
\hline Infections & & \\
\hline
\end{tabular}

\begin{tabular}{|c|c|c|}
\hline Upper respiratory tract infection ${ }^{b}$ & 43 & $3^{\#}$ \\
\hline Pneumoniac & 23 & 17 \\
\hline Bronchitis $^{d}$ & 14 & $2^{\#}$ \\
\hline Urinary tract infection & 11 & 0 \\
\hline \multicolumn{3}{|c|}{ Musculoskeletal and connective tissue disorders } \\
\hline Muscle spasms & 31 & $2^{\#}$ \\
\hline Back pain & 14 & 0 \\
\hline \multicolumn{3}{|c|}{ Respiratory, thoracic and mediastinal disorders } \\
\hline Dyspnea & 22 & 3 \\
\hline Cough & 14 & 0 \\
\hline \multicolumn{3}{|l|}{ Nervous system disorders } \\
\hline Peripheral sensory neuropathy & 17 & $2^{\#}$ \\
\hline \multicolumn{3}{|l|}{ Psychiatric disorders } \\
\hline Insomnia & 17 & $5^{\#}$ \\
\hline
\end{tabular}


Table 3: Adverse Reactions ( $\geq 10 \%)$ in Patients Who Received DARZALEX FASPRO with Lenalidomide and Dexamethasone (DARZALEX FASPRO-Rd) in PLEIADES (continued)

\begin{tabular}{|c|c|c|}
\hline \multirow[b]{2}{*}{ Adverse Reaction } & \multicolumn{2}{|c|}{$\begin{array}{l}\text { DARZALEX FASPRO with } \\
\text { Lenalidomide and Dexamethasone } \\
\text { ( } N=65)\end{array}$} \\
\hline & All Grades (\%) & Grades $\geq 3$ (\%) \\
\hline Hyperglycemia & 12 & $9^{\#}$ \\
\hline Hypocalcemia & 11 & 0 \\
\hline
\end{tabular}

a Fatigue includes asthenia, and fatigue.

b Upper respiratory tract infection includes nasopharyngitis, pharyngitis, respiratory tract infection viral, rhinitis, sinusitis, upper respiratory tract infection, and upper respiratory tract infection bacterial.

c Pneumonia includes lower respiratory tract infection, lung infection, and pneumonia.

d Bronchitis includes bronchitis, and bronchitis viral.

e Dyspnea includes dyspnea, and dyspnea exertional.

$f$ Cough includes cough, and productive cough.

\# Only grade 3 adverse reactions occurred.

Clinically relevant adverse reactions in $<10 \%$ of patients who received DARZALEX FASPRO with lenalidomide and dexamethasone included:

- Musculoskeletal and connective tissue disorders: arthralgia, musculoskeletal chest pain

- Nervous system disorders: dizziness, headache, paresthesia

- Skin and subcutaneous tissue disorders: rash, pruritus

- Gastrointestinal disorders: abdominal pain

- Infections: influenza, sepsis, herpes zoster

- Metabolism and nutrition disorders: decreased appetite

- Cardiac disorders: atrial fibrillation

- General disorders and administration site conditions: chills, infusion reaction, injection site reaction

- Vascular disorders: hypotension, hypertension

Table 4 summarizes the laboratory abnormalities in patients who received DARZALEX FASPRO in PLEIADES.

Table 4: Select Hematology Laboratory Abnormalities Worsening from Baseline in Patients Who Received DARZALEX FASPRO with Lenalidomide and Dexamethasone (DARZALEX FASPRO-Rd) in PLEIADES

\begin{tabular}{|l|c|c|}
\hline \multirow{2}{*}{ Laboratory Abnormality } & \multicolumn{2}{|c|}{ DARZALEX FASPRO } \\
\cline { 2 - 3 } & $\begin{array}{c}\text { All Grades } \\
(\%)\end{array}$ & $\begin{array}{c}\text { Grades 3-4 } \\
(\%)\end{array}$ \\
\hline Decreased leukocytes & 94 & 34 \\
\hline Decreased lymphocytes & 82 & 58 \\
\hline Decreased platelets & 86 & 9 \\
\hline Decreased neutrophils & 89 & 52 \\
\hline Decreased hemoglobin & 45 & 8 \\
\hline
\end{tabular}

a Denominator is based on the safety population treated with DARZALEX FASPRO-Rd ( $\mathrm{N}=65)$.

In Combination with Pomalidomide and Dexamethasone

The safety of DARZALEX FASPRO with pomalidomide and dexamethasone compared to pomalidomide and dexamethasone $(\mathrm{Pd})$ in patients who had received at least one prior line of therapy with lenalidomide and a proteasome inhibitor (PI) was evaluated in APOLLO [see Clinical Studies (14.2) in Full Prescribing Information]. Patients received DARZALEX FASPRO $1,800 \mathrm{mg} / 30,000$ units administered subcutaneously once weekly from weeks 1 to 8 , once every 2 weeks from weeks 9 to 24 and once every 4 weeks starting with week 25 until disease progression or unacceptable toxicity in combination with pomalidomide and dexamethasone $(n=149)$ or pomalidomide and dexamethasone $(n=150)$. Among patients receiving DARZALEX FASPRO-Pd, $71 \%$ were exposed for 6 months or longer and $50 \%$ were exposed for greater than one year.

Serious adverse reactions occurred in $50 \%$ of patients who received DARZALEX FASPRO-Pd. The most frequent serious adverse reactions in $>5 \%$ of patients who received DARZALEX FASPRO-Pd were pneumonia (15\%) and lower respiratory tract infection (12\%). Fatal adverse reactions occurred in $7 \%$ of patients who received DARZALEX FASPRO-Pd.

Permanent treatment discontinuation due to an adverse reaction occurred in $2 \%$ of patients who received DARZALEX FASPRO-Pd. No adverse reactions resulting in permanent discontinuation occurred in more than 1 patient.

The most common adverse reactions $(\geq 20 \%)$ were fatigue, pneumonia, upper respiratory tract infection, and diarrhea.

Table 5 summarizes the adverse reactions in patients who received DARZALEX FASPRO in APOLLO.
Table 5: Adverse Reactions Reported in $\geq 10 \%$ of Patients and With at Least a 5\% Greater Frequency in the DARZALEX FASPRO-Pd Arm in APOLLO

\begin{tabular}{|c|c|c|c|c|}
\hline \multirow{4}{*}{ Adverse Reaction } & \multicolumn{2}{|c|}{$\begin{array}{c}\text { DARZALEX FASPRO-Pd } \\
\text { (N=149) }\end{array}$} & \multicolumn{2}{c|}{ Pd (N=150) } \\
\cline { 2 - 6 } & $\begin{array}{c}\text { All Grades } \\
(\%)\end{array}$ & $\begin{array}{c}\text { Grades } \geq 3 \\
(\%)\end{array}$ & $\begin{array}{c}\text { All Grades } \\
(\%)\end{array}$ & $\begin{array}{c}\text { Grades } \geq 3 \\
(\%)\end{array}$ \\
\hline
\end{tabular}

General disorders and administration site conditions

\begin{tabular}{|l|c|c|c|c|}
\hline Fatigue & 46 & 13 & 39 & $5^{\#}$ \\
\hline Pyrexia & 19 & 0 & 14 & 0 \\
\hline Edema peripheral ${ }^{b}$ & 15 & 0 & 9 & 0 \\
\hline \multicolumn{5}{|l|}{} \\
\hline Infections \\
\hline Pneumoniac $^{\text {Upper respiratory }}$ & 38 & $23^{@}$ & 27 & $17^{@}$ \\
\hline infection $^{\text {d }}$ & 36 & $1^{\#}$ & 22 & $2^{\#}$ \\
\hline
\end{tabular}

\section{Gastrointestinal disorders}

\begin{tabular}{|l|l|l|l|l|}
\hline Diarrhea & 22 & $5^{\#}$ & 14 & $1^{\#}$
\end{tabular}

Respiratory, thoracic and mediastinal disorders

\begin{tabular}{|l|l|l|l|l|}
\hline Coughe & 13 & 0 & 8 & 0 \\
\hline
\end{tabular}

Key: $\mathrm{Pd}=$ pomalidomide-dexamethasone

a Fatigue includes asthenia, and fatigue.

b Edema peripheral includes edema, edema peripheral and peripheral swelling.

c Pneumonia includes atypical pneumonia, lower respiratory tract infection, pneumonia, pneumonia aspiration, pneumonia bacterial, and pneumonia respiratory syncytial viral.

d Upper respiratory tract infection includes nasopharyngitis, pharyngitis, respiratory syncytial virus infection, respiratory tract infection, respiratory tract infection viral, rhinitis, sinusitis, tonsillitis, upper respiratory tract infection, and viral upper respiratory tract infection.

e Cough includes cough, and productive cough.

\# Only grade 3 adverse reactions occurred.

@ Grade 5 adverse reactions occurred, $\mathrm{n}=3(2.0 \%)$ in the DARZALEX FASPRO-Pd arm and $\mathrm{n}=2(1.3 \%)$ in the Pd arm.

Clinically relevant adverse reactions in $<10 \%$ of patients who received DARZALEX FASPRO with pomalidomide and dexamethasone include:

- Metabolism and nutrition disorders: hypocalcemia, hypokalemia, decreased appetite, dehydration

- Nervous system disorders: peripheral sensory neuropathy, syncope, headache, paresthesia, dizziness

- Musculoskeletal and connective tissue disorders: muscle spasms, musculoskeletal chest pain, arthralgia

- Psychiatric disorders: insomnia

- Gastrointestinal disorders: nausea, abdominal pain, vomiting

- Skin and subcutaneous tissue disorders: rash, pruritus

- Cardiac disorders: atrial fibrillation

- General disorders and administration site conditions: infusion reactions, chills, injection site reaction

- Infections: urinary tract infection, influenza, hepatitis B reactivation, herpes zoster, sepsis

- Vascular disorders: hypertension, hypotension

Table 6 summarizes the laboratory abnormalities in patients who received DARZALEX FASPRO in APOLLO.

Table 6: Select Hematology Laboratory Abnormalities Worsening from Baseline in Patients Who Received DARZALEX FASPRO-Pd or Pd in APOLLO

\begin{tabular}{|l|c|c|c|c|}
\hline & \multicolumn{2}{|c|}{$\begin{array}{c}\text { DARZALEX } \\
\text { FASPRO-Pd }\end{array}$} & \multicolumn{2}{c|}{ Pda $^{\text {Laboratory Abnormality }}$} \\
\cline { 2 - 5 } & $\begin{array}{c}\text { All Grades } \\
(\%)\end{array}$ & $\begin{array}{c}\text { Grades 3-4 } \\
(\%)\end{array}$ & $\begin{array}{c}\text { All Grades } \\
(\%)\end{array}$ & $\begin{array}{c}\text { Grades 3-4 } \\
(\%)\end{array}$ \\
\hline Decreased neutrophils & 97 & 84 & 84 & 63 \\
\hline Decreased leukocytes & 95 & 64 & 82 & 40 \\
\hline Decreased lymphocytes & 93 & 59 & 79 & 33 \\
\hline Decreased platelets & 75 & 19 & 60 & 19 \\
\hline Decreased hemoglobin & 51 & 16 & 57 & 15 \\
\hline
\end{tabular}

Key: Pd=pomalidomide-dexamethasone

a Denominator is based on number of subjects with a baseline and post-baseline laboratory value for each laboratory test: $N=148$ for DARZALEX FASPRO-Pd and $\mathrm{N}=149$ for $\mathrm{Pd}$. 


\section{Monotherapy}

The safety of DARZALEX FASPRO as monotherapy was evaluated in COLUMBA [see Clinical Trials (14.2) in Full Prescribing Information]. Patients received DARZALEX FASPRO $1,800 \mathrm{mg} / 30,000$ units administered subcutaneously or daratumumab $16 \mathrm{mg} / \mathrm{kg}$ administered intravenously; each administered once weekly from weeks 1 to 8 , once every 2 weeks from weeks 9 to 24 and once every 4 weeks starting with week 25 until disease progression or unacceptable toxicity. Among patients receiving DARZALEX FASPR0, 37\% were exposed for 6 months or longer and $1 \%$ were exposed for greater than one year.

Serious adverse reactions occurred in $26 \%$ of patients who received DARZALEX FASPRO. Fatal adverse reactions occurred in $5 \%$ of patients. Fatal adverse reactions occurring in more than 1 patient were general physical health deterioration, septic shock, and respiratory failure.

Permanent discontinuation due to an adverse reaction occurred in $10 \%$ of patients who received DARZALEX FASPRO. Adverse reactions resulting in permanent discontinuation of DARZALEX FASPRO in more than 2 patients were thrombocytopenia and hypercalcemia.

Dosage interruptions due to an adverse reaction occurred in $26 \%$ of patients who received DARZALEX FASPRO. Adverse reactions requiring dosage interruption in $>5 \%$ of patients included thrombocytopenia.

The most common adverse reaction ( $\geq 20 \%$ ) was upper respiratory tract infection. Table 7 summarizes the adverse reactions in COLUMBA.

Table 7: Adverse Reactions ( $\geq 10 \%$ ) in Patients Who Received DARZALEX FASPRO or Intravenous Daratumumab in COLUMBA

\begin{tabular}{|c|c|c|c|c|}
\hline \multirow[b]{2}{*}{ Adverse Reaction } & \multicolumn{2}{|c|}{$\begin{array}{l}\text { DARZALEX FASPRO } \\
(\mathrm{N}=260)\end{array}$} & \multicolumn{2}{|c|}{$\begin{array}{c}\text { Intravenous Daratumumab } \\
(\mathrm{N}=258)\end{array}$} \\
\hline & $\begin{array}{l}\text { All Grades } \\
(\%)\end{array}$ & $\begin{array}{c}\text { Grade } \geq 3 \\
(\%)\end{array}$ & $\begin{array}{c}\text { All Grades } \\
(\%)\end{array}$ & $\begin{array}{c}\text { Grade } \geq 3 \\
(\%)\end{array}$ \\
\hline \multicolumn{5}{|l|}{ Infections } \\
\hline $\begin{array}{l}\text { Upper respiratory } \\
\text { tract infectiona }\end{array}$ & 24 & $1^{\#}$ & 22 & $1^{\#}$ \\
\hline Pneumoniab $^{\mathrm{b}}$ & 8 & 5 & 10 & $6^{\circledR}$ \\
\hline \multicolumn{5}{|c|}{ Gastrointestinal disorders } \\
\hline Diarrhea & 15 & $1^{\#}$ & 11 & $0.4^{\#}$ \\
\hline Nausea & 8 & $0.4^{\#}$ & 11 & $0.4^{\#}$ \\
\hline \multicolumn{5}{|c|}{ General disorders and administration site conditions } \\
\hline Fatigue $^{c}$ & 15 & $1^{\#}$ & 16 & $2^{\#}$ \\
\hline Infusion reactions ${ }^{\mathrm{d}}$ & 13 & $2^{\#}$ & 34 & $5^{\#}$ \\
\hline Pyrexia & 13 & 0 & 13 & $1^{\#}$ \\
\hline Chills & 6 & $0.4^{\#}$ & 12 & $1 \#$ \\
\hline \multicolumn{5}{|c|}{ Musculoskeletal and connective tissue disorders } \\
\hline Back pain & 10 & $2^{\#}$ & 12 & $3^{\#}$ \\
\hline \multicolumn{5}{|c|}{ Respiratory, thoracic and mediastinal disorders } \\
\hline Coughe & 9 & $1^{\#}$ & 14 & 0 \\
\hline Dyspneaf $^{f}$ & 6 & $1^{\#}$ & 11 & $1^{\#}$ \\
\hline
\end{tabular}

a Upper respiratory tract infection includes acute sinusitis, nasopharyngitis, pharyngitis, respiratory syncytial virus infection, respiratory tract infection, rhinitis, rhinovirus infection, sinusitis, and upper respiratory tract infection.

b Pneumonia includes lower respiratory tract infection, lung infection, pneumocystis jirovecii pneumonia, and pneumonia.

c Fatigue includes asthenia, and fatigue.

d Infusion reactions includes terms determined by investigators to be related to infusion.

e Cough includes cough, and productive cough.

Dyspnea includes dyspnea, and dyspnea exertional.

* Only grade 3 adverse reactions occurred.

@ Grade 5 adverse reactions occurred.

Clinically relevant adverse reactions in $<10 \%$ of patients who received DARZALEX FASPRO included:

- General disorders and administration site conditions: injection site reaction, peripheral edema

- Musculoskeletal and connective tissue disorders: arthralgia, musculoskeletal chest pain, muscle spasms

- Gastrointestinal disorders: constipation, vomiting, abdominal pain

- Metabolism and nutrition disorders: decreased appetite, hyperglycemia, hypocalcemia, dehydration

- Psychiatric disorders: insomnia

- Vascular disorders: hypertension, hypotension

- Nervous system disorders: dizziness, peripheral sensory neuropathy, paresthesia

- Infections: bronchitis, influenza, urinary tract infection, herpes zoster, sepsis, hepatitis B virus reactivation

- Skin and subcutaneous tissue disorders: pruritus, rash

- Cardiac disorders: atrial fibrillation

- Respiratory, thoracic and mediastinal disorders: pulmonary edema
Table 8 summarizes the laboratory abnormalities in COLUMBA.

Table 8: Select Hematology Laboratory Abnormalities Worsening from Baseline in Patients Receiving DARZALEX FASPRO or Intravenous Daratumumab in COLUMBA

\begin{tabular}{|l|c|c|c|c|}
\hline \multirow{2}{*}{ Laboratory Abnormality } & \multicolumn{2}{|c|}{$\begin{array}{c}\text { DARZALEX } \\
\text { FASPROa }\end{array}$} & \multicolumn{2}{c|}{$\begin{array}{c}\text { Intravenous } \\
\text { Daratumumaba }\end{array}$} \\
\cline { 2 - 5 } & $\begin{array}{c}\text { All } \\
\text { Grades } \\
(\%)\end{array}$ & $\begin{array}{c}\text { Grades } \\
\mathbf{3 - 4} \\
(\%)\end{array}$ & $\begin{array}{c}\text { All } \\
\text { Grades } \\
(\%)\end{array}$ & $\begin{array}{c}\text { Grades } \\
\mathbf{3 - 4} \\
(\%)\end{array}$ \\
\hline Decreased leukocytes & 65 & 19 & 57 & 14 \\
\hline Decreased lymphocytes & 59 & 36 & 56 & 36 \\
\hline Decreased neutrophils & 55 & 19 & 43 & 11 \\
\hline Decreased platelets & 43 & 16 & 45 & 14 \\
\hline Decreased hemoglobin & 42 & 14 & 39 & 16 \\
\hline
\end{tabular}

Denominator is based on the safety population treated with DARZALEX FASPRO $(\mathrm{N}=260)$ and Intravenous Daratumumab ( $\mathrm{N}=258)$.

\section{Light Chain Amyloidosis}

In Combination with Bortezomib, Cyclophosphamide and Dexamethasone

The safety of DARZALEX FASPRO with bortezomib, cyclophosphamide and dexamethasone (DARZALEX FASPRO-VCd) was evaluated in ANDROMEDA [see Clinical Studies (14.2) in Full Prescribing Information]. Patients received DARZALEX FASPRO $1,800 \mathrm{mg} / 30,000$ units administered subcutaneously once weekly from weeks 1 to 8 , once every 2 weeks from weeks 9 to 24 and once every 4 weeks starting with week 25 until disease progression or unacceptable toxicity or a maximum of 2 years. Among patients who received DARZALEX FASPRO-VCd, 74\% were exposed for 6 months or longer and $32 \%$ were exposed for greater than one year.

Serious adverse reactions occurred in $43 \%$ of patients who received DARZALEX FASPRO in combination with VCd. Serious adverse reactions that occurred in at least $5 \%$ of patients in the DARZALEX FASPRO-VCd arm were pneumonia $(9 \%)$, cardiac failure $(8 \%)$, and sepsis $(5 \%)$. Fatal adverse reactions occurred in $11 \%$ of patients. Fatal adverse reactions that occurred in more than one patient included cardiac arrest $(4 \%)$, sudden death $(3 \%)$, cardiac failure $(3 \%)$, and sepsis $(1 \%)$.

Permanent discontinuation of DARZALEX FASPRO due to an adverse reaction occurred in $5 \%$ of patients. Adverse reactions resulting in permanent discontinuation of DARZALEX FASPRO in more than one patient were pneumonia, sepsis, and cardiac failure.

Dosage interruptions (defined as dose delays or skipped doses) due to an adverse reaction occurred in $36 \%$ of patients who received DARZALEX FASPRO. Adverse reactions which required a dosage interruption in $\geq 3 \%$ of patients included upper respiratory tract infection $(9 \%)$, pneumonia $(6 \%)$, cardiac failure $(4 \%)$, fatigue $(3 \%)$, herpes zoster $(3 \%)$, dyspnea $(3 \%)$, and neutropenia $(3 \%)$.

The most common adverse reactions $(\geq 20 \%)$ were upper respiratory tract infection, diarrhea, peripheral edema, constipation, fatigue, peripheral sensory neuropathy, nausea, insomnia, dyspnea, and cough.

Table 9 below summarizes the adverse reactions in patients who received DARZALEX FASPRO in ANDROMEDA.

Table 9: Adverse Reactions ( $\geq 10 \%$ ) in Patients with AL Amyloidosis Who Received DARZALEX FASPRO with Bortezomib, Cyclophosphamide and Dexamethasone (DARZALEX FASPRO-VCd) with a Difference Between Arms of $>5 \%$ Compared to VCd in ANDROMEDA

\begin{tabular}{|c|c|c|c|c|}
\hline \multirow[b]{2}{*}{ Adverse Reaction } & \multicolumn{2}{|c|}{$\begin{array}{l}\text { DARZALEX FASPRO-VCd } \\
\text { ( } \mathrm{N}=193)\end{array}$} & \multicolumn{2}{|c|}{$\begin{array}{c}\text { VCd } \\
(\mathrm{N}=188)\end{array}$} \\
\hline & $\begin{array}{l}\text { All Grades } \\
(\%)\end{array}$ & $\begin{array}{c}\text { Grades 3-4 } \\
(\%)\end{array}$ & $\begin{array}{c}\text { All Grades } \\
(\%)\end{array}$ & $\begin{array}{c}\text { Grades 3-4 } \\
(\%)\end{array}$ \\
\hline \multicolumn{5}{|l|}{ Infections } \\
\hline $\begin{array}{l}\text { Upper respiratory } \\
\text { tract infectiona }\end{array}$ & 40 & $1^{\#}$ & 21 & $1^{\#}$ \\
\hline Pneumoniab $^{b}$ & 15 & 10 & 9 & 5 \\
\hline \multicolumn{5}{|c|}{ Gastrointestinal disorders } \\
\hline Diarrhea & 36 & $6^{\#}$ & 30 & 4 \\
\hline Constipation & 34 & $2^{\#}$ & 29 & 0 \\
\hline \multicolumn{5}{|c|}{ Nervous system disorders } \\
\hline $\begin{array}{l}\text { Peripheral } \\
\text { sensory } \\
\text { neuropathy }\end{array}$ & 31 & $3^{\#}$ & 20 & $2^{\#}$ \\
\hline \multicolumn{5}{|c|}{ Respiratory, thoracic and mediastinal disorders } \\
\hline Dyspneac & 26 & 4 & 20 & $4^{\#}$ \\
\hline Coughd & 20 & $1^{\#}$ & 11 & 0 \\
\hline
\end{tabular}


Table 9: Adverse Reactions ( $\geq 10 \%$ ) in Patients with AL Amyloidosis Who Received DARZALEX FASPRO with Bortezomib, Cyclophosphamide and Dexamethasone (DARZALEX FASPRO-VCd) with a Difference Between Arms of $>5 \%$ Compared to VCd in ANDROMEDA (continued)

\begin{tabular}{|l|c|c|c|c|}
\hline \multirow{4}{*}{ Adverse Reaction } & $\begin{array}{c}\text { DARZALEX FASPRO-VCd } \\
\text { (N=193) }\end{array}$ & \multicolumn{2}{c|}{$\begin{array}{c}\text { VCd } \\
\text { (N=188) }\end{array}$} \\
\cline { 2 - 5 } & $\begin{array}{c}\text { All Grades } \\
(\%)\end{array}$ & $\begin{array}{c}\text { Grades 3-4 } \\
(\%)\end{array}$ & $\begin{array}{c}\text { All Grades } \\
(\%)\end{array}$ & $\begin{array}{c}\text { Grades 3-4 } \\
(\%)\end{array}$ \\
\hline Musculoskeletal and connective tissue disorders \\
\hline Back pain & 12 & $2^{\#}$ & 6 & 0 \\
\hline Arthralgia & 10 & 0 & 5 & 0 \\
\hline Muscle spasms & 10 & $1^{\#}$ & 5 & 0 \\
\hline Cardiac disorders & 11 & 4 & 5 & 2 \\
\hline Arrhythmiae & 11 & 0 & 0 & 0 \\
\hline General disorders and administration site conditions \\
\hline $\begin{array}{l}\text { Injection site } \\
\text { reactions }\end{array}$ & 11 &
\end{tabular}

\# Only grade 3 adverse reactions occurred.

a Upper respiratory tract infection includes laryngitis, nasopharyngitis, pharyngitis, respiratory syncytial virus infection, respiratory tract infection, respiratory tract infection viral, rhinitis, rhinovirus infection, sinusitis, tonsillitis, tracheitis, upper respiratory tract infection, upper respiratory tract infection bacterial, and viral upper respiratory tract infection.

b Pneumonia includes lower respiratory tract infection, pneumonia, pneumonia aspiration, and pneumonia pneumococcal.

c Dyspnea includes dyspnea, and dyspnea exertional.

d Cough includes cough, and productive cough.

e Arrhythmia includes atrial flutter, atrial fibrillation, supraventricular tachycardia, bradycardia, arrhythmia, bradyarrhythmia, cardiac flutter, extrasystoles, supraventricular extrasystoles, ventricular arrhythmia, ventricular extrasystoles, atrial tachycardia, ventricular tachycardia

$f$ Injection site reactions includes terms determined by investigators to be related to daratumumab injection.

Clinically relevant adverse reactions not included in Table 9 and occurred in patients who received DARZALEX FASPRO with bortezomib, cyclophosphamide and dexamethasone included:

- Skin and subcutaneous tissue disorders: rash, pruritus

- Nervous system disorders: paresthesia

- General disorders and administration site conditions: infusion reaction, chills

- Cardiac disorders: cardiac failure ${ }^{a}$, cardiac arrest

- Metabolism and nutrition disorders: hyperglycemia, hypocalcemia, dehydration

- Infections: bronchitis, herpes zoster, sepsis, urinary tract infection, influenza

- Vascular disorders: hypertension

- Musculoskeletal and connective tissue disorders: musculoskeletal chest pain

- Gastrointestinal disorders: pancreatitis

- Respiratory, thoracic and mediastinal disorders: pulmonary edema

a Cardiac failure includes cardiac dysfunction, cardiac failure, cardiac failure congestive, cardiovascular insufficiency, diastolic dysfunction, pulmonary edema, and left ventricular dysfunction occurred in $11 \%$ of patients.

Table 10 summarizes the laboratory abnormalities in patients who received DARZALEX FASPRO in ANDROMEDA

Table 10: Select Hematology Laboratory Abnormalities Worsening from Baseline in Patients Who Received DARZALEX FASPRO with Bortezomib, Cyclophosphamide and Dexamethasone (DARZALEX FASPRO-VCd) in ANDROMEDA

\begin{tabular}{|l|c|c|c|c|}
\hline & \multicolumn{2}{|c|}{ DARZALEX FASPRO-VCd } & \multicolumn{2}{c|}{ VCd } \\
\cline { 2 - 5 } Laboratory Abnormality & $\begin{array}{c}\text { All Grades } \\
(\%)\end{array}$ & $\begin{array}{c}\text { Grades 3-4 } \\
(\%)\end{array}$ & $\begin{array}{c}\text { All Grades } \\
(\%)\end{array}$ & $\begin{array}{c}\text { Grades 3-4 } \\
(\%)\end{array}$ \\
\hline Decreased lymphocytes & 81 & 54 & 71 & 46 \\
\hline Decreased hemoglobin & 66 & 6 & 70 & 6 \\
\hline Decreased leukocytes & 60 & 7 & 46 & 4 \\
\hline Decreased platelets & 46 & 3 & 40 & 4 \\
\hline Decreased neutrophils & 30 & 6 & 18 & 4 \\
\hline
\end{tabular}

Denominator is based on the number of patients with a baseline and post-baseline laboratory value for each laboratory test, $\mathrm{N}=188$ for DARZALEX FASPRO-VCd and $\mathrm{N}=186$ for VCd.

\section{Cardiac Adverse Reactions in Light Chain (AL) Amyloidosis}

Among patients who received DARZALEX FASPRO in combination with VCd, $72 \%$ of patients had baseline cardiac involvement with Mayo Cardiac Stage I $(3 \%)$, Stage II ( $46 \%)$ and Stage III (51\%). Serious cardiac disorders occurred in $16 \%$ of patients ( $8 \%$ of patients with Mayo Cardiac Stage I and II and $28 \%$ of patients with Stage III). Serious cardiac disorders in $>2 \%$ of patients included cardiac failure $(8 \%)$, cardiac arrest $(4 \%)$ and arrhythmia $(4 \%)$. Fatal cardiac disorders occurred in $10 \%$ of patients ( $5 \%$ of patients with Mayo Cardiac Stage I and II and 19\% of patients with Stage III) who received DARZALEX FASPRO in combination with VCd. Fatal cardiac disorders that occurred in more than one patient in the DARZALEX FASPRO-VCd arm included cardiac arrest $(4 \%)$, sudden death $(3 \%)$, and cardiac failure $(3 \%)$.

\section{Immunogenicity}

As with all therapeutic proteins, there is the potential for immunogenicity. The detection of antibody formation is highly dependent on the sensitivity and specificity of the assay. Additionally, the observed incidence of antibody (including neutralizing antibody) positivity in an assay may be influenced by several factors including assay methodology, sample handling, timing of sample collection, concomitant medications, and underlying disease. For these reasons, comparison of the incidence of antibodies in the studies described below with the incidence of antibodies in other studies or to other daratumumab products or other hyaluronidase products may be misleading. In patients with multiple myeloma and light chain (AL) amyloidosis who received DARZALEX FASPRO as monotherapy or as part of a combination therapy, less than $1 \%$ of 756 patients developed treatment-emergent antidaratumumab antibodies.

In patients with multiple myeloma and light chain (AL) amyloidosis who received DARZALEX FASPRO as monotherapy or as part of a combination therapy, $7 \%$ of 750 patients developed treatment-emergent anti-rHuPH20 antibodies. The anti-rHuPH2O antibodies did not appear to affect daratumumab exposure. None of the patients who tested positive for anti-rHuPH2O antibodies tested positive for neutralizing antibodies.

\section{Postmarketing Experience}

The following adverse reactions have been identified with post-approval use of daratumumab. Because these reactions are reported voluntarily from a population of uncertain size, it is not always possible to reliably estimate their frequency or establish a causal relationship to drug exposure.

Immune System: Anaphylactic reaction; systemic administration reactions (including death)

Gastrointestinal: Pancreatitis

Infections: Cytomegalovirus, Listeriosis

\section{DRUG INTERACTIONS}

\section{Effects of Daratumumab on Laboratory Tests}

Interference with Indirect Antiglobulin Tests (Indirect Coombs Test)

Daratumumab binds to CD38 on RBCs and interferes with compatibility testing, including antibody screening and cross matching. Daratumumab interference mitigation methods include treating reagent RBCs with dithiothreitol (DTT) to disrupt daratumumab binding [see References] or genotyping. Since the Kell blood group system is also sensitive to DTT treatment, supply K-negative units after ruling out or identifying alloantibodies using DTT-treated RBCs.

If an emergency transfusion is required, administer non-cross-matched $A B O$ / $\mathrm{RhD}$-compatible RBCs per local blood bank practices.

Interference with Serum Protein Electrophoresis and Immunofixation Tests Daratumumab may be detected on serum protein electrophoresis (SPE) and immunofixation (IFE) assays used for monitoring disease monoclonal immunoglobulins (M protein). False positive SPE and IFE assay results may occur for patients with IgG kappa myeloma protein impacting initial assessment of complete responses by International Myeloma Working Group (IMWG) criteria. In DARZALEX FASPRO-treated patients with persistent very good partial response, where daratumumab interference is suspected, consider using a FDA-approved daratumumab-specific IFE assay to distinguish daratumumab from any remaining endogenous $M$ protein in the patient's serum, to facilitate determination of a complete response.

\section{USE IN SPECIFIC POPULATIONS}

Pregnancy

\section{Risk Summary}

DARZALEX FASPRO can cause fetal harm when administered to a pregnant woman. The assessment of associated risks with daratumumab products is based on the mechanism of action and data from target antigen CD38 knockout animal models (see Data). There are no available data on the use of DARZALEX FASPRO in pregnant women to evaluate drug-associated risk of major birth defects, miscarriage or adverse maternal or fetal outcomes. Animal reproduction studies have not been conducted. 
The estimated background risk of major birth defects and miscarriage for the indicated population is unknown. All pregnancies have a background risk of birth defect, loss, or other adverse outcomes. In the U.S. general population, the estimated background risk of major birth defects and miscarriage in clinically recognized pregnancies is $2 \%$ to $4 \%$ and $15 \%$ to $20 \%$, respectively. The combination of DARZALEX FASPRO and lenalidomide, thalidomide or pomalidomide is contraindicated in pregnant women, because lenalidomide, thalidomide and pomalidomide may cause birth defects and death of the unborn child. Lenalidomide, thalidomide and pomalidomide are only available through a REMS program. Refer to the lenalidomide, thalidomide or pomalidomide prescribing information on use during pregnancy.

Clinical Considerations

\section{Fetal/Neonatal Adverse Reactions}

Immunoglobulin G1 (lgG1) monoclonal antibodies are transferred across the placenta. Based on its mechanism of action, DARZALEX FASPRO may cause depletion of fetal CD38 positive immune cells and decreased bone density. Defer administering live vaccines to neonates and infants exposed to daratumumab in utero until a hematology evaluation is completed.

Data

\section{Animal Data}

DARZALEX FASPRO for subcutaneous injection contains daratumumab and hyaluronidase. Mice that were genetically modified to eliminate all CD38 expression (CD38 knockout mice) had reduced bone density at birth that recovered by 5 months of age. Data from studies using CD38 knockout animal models also suggest the involvement of CD38 in the regulation of humoral immune responses (mice), feto-maternal immune tolerance (mice), and early embryonic development (frogs).

No systemic exposure of hyaluronidase was detected in monkeys given $22,000 \mathrm{U} / \mathrm{kg}$ subcutaneously (12 times higher than the human dose) and there were no effects on embryo-fetal development in pregnant mice given $330,000 \mathrm{U} / \mathrm{kg}$ hyaluronidase subcutaneously daily during organogenesis, which is 45 times higher than the human dose.

There were no effects on pre- and post-natal development through sexual maturity in offspring of mice treated daily from implantation through lactation with $990,000 \mathrm{U} / \mathrm{kg}$ hyaluronidase subcutaneously, which is 134 times higher than the human doses.

\section{Lactation}

\section{Risk Summary}

There is no data on the presence of daratumumab and hyaluronidase in human milk, the effects on the breastfed child, or the effects on milk production. Maternal immunoglobulin $\mathrm{G}$ is known to be present in human milk. Published data suggest that antibodies in breast milk do not enter the neonatal and infant circulations in substantial amounts. Because of the potential for serious adverse reactions in the breastfed child when DARZALEX FASPRO is administered with lenalidomide, thalidomide or pomalidomide, advise women not to breastfeed during treatment with DARZALEX FASPRO. Refer to lenalidomide, thalidomide or pomalidomide prescribing information for additional information.

Data

\section{Animal Data}

No systemic exposure of hyaluronidase was detected in monkeys given $22,000 \mathrm{U} / \mathrm{kg}$ subcutaneously (12 times higher than the human dose) and there were no effects on post-natal development through sexual maturity in offspring of mice treated daily during lactation with $990,000 \mathrm{U} / \mathrm{kg}$ hyaluronidase subcutaneously, which is 134 times higher than the human doses.

\section{Females and Males of Reproductive Potential}

DARZALEX FASPRO can cause fetal harm when administered to a pregnant woman [see Use in Specific Populations].

\section{Pregnancy Testing}

With the combination of DARZALEXFASPRO with lenalidomide thalidomide or pomalidomide, refer to the lenalidomide, thalidomide or pomalidomide labeling for pregnancy testing requirements prior to initiating treatment in females of reproductive potential.

\section{Contraception}

Advise females of reproductive potential to use effective contraception during treatment with DARZALEX FASPRO and for 3 months after the last dose. Additionally, refer to the lenalidomide, thalidomide or pomalidomide labeling for additional recommendations for contraception.

\section{Pediatric Use}

Safety and effectiveness of DARZALEX FASPRO in pediatric patients have not been established.

\section{Geriatric Use}

Of the 291 patients who received DARZALEX FASPRO as monotherapy for relapsed and refractory multiple myeloma, $37 \%$ were 65 to $<75$ years of age, and $19 \%$ were 75 years of age or older. No overall differences in effectiveness of DARZALEX FASPRO have been observed between patients $\geq 65$ years of age and younger patients. Adverse reactions that occurred at a higher frequency ( $\geq 5 \%$ difference) in patients $\geq 65$ years of age included upper respiratory tract infection, urinary tract infection, dizziness, cough, dyspnea, diarrhea, nausea, fatigue, and peripheral edema. Serious adverse reactions that occurred at a higher frequency ( $\geq 2 \%$ difference) in patients $\geq 65$ years of age included pneumonia.
Of the 214 patients who received DARZALEX FASPRO as combination therapy with pomalidomide and dexamethasone or DARZALEX FASPRO as combination therapy with lenalidomide and low-dose dexamethasone for relapsed and refractory multiple myeloma, $43 \%$ were 65 to $<75$ years of age, and $18 \%$ were 75 years of age or older. No overall differences in effectiveness were observed between patients $\geq 65$ years $(n=131)$ and $<65$ years $(n=85)$. Adverse reactions occurring at a higher frequency ( $\geq 5 \%$ difference) in patients $\geq 65$ years of age included fatigue, pyrexia, peripheral edema, urinary tract infection, diarrhea, constipation, vomiting, dyspnea, cough, and hyperglycemia. Serious adverse reactions occurring at a higher frequency ( $\geq 2 \%$ difference) in patients $\geq 65$ years of age included neutropenia, thrombocytopenia, diarrhea, anemia, COVID-19, ischemic colitis, deep vein thrombosis, general physical health deterioration, pulmonary embolism, and urinary tract infection.

Of the 193 patients who received DARZALEX FASPRO as part of a combination therapy for light chain (AL) amyloidosis, $35 \%$ were 65 to $<75$ years of age, and $10 \%$ were 75 years of age or older. Clinical studies of DARZALEX FASPRO as part of a combination therapy for patients with light chain $(A L)$ amyloidosis did not include sufficient numbers of patients aged 65 and older to determine whether effectiveness differs from that of younger patients. Adverse reactions that occurred at a higher frequency in patients $\geq 65$ years of age were peripheral edema, asthenia, pneumonia and hypotension.

No clinically meaningful differences in the pharmacokinetics of daratumumab were observed in geriatric patients compared to younger adult patients [see Clinical Pharmacology (12.3) in Full Prescribing Information].

\section{REFERENCES}

1. Chapuy, Cl, RT Nicholson, MD Aguad, et al., 2015, Resolving the daratumumab interference with blood compatibility testing, Transfusion, 55:1545-1554 (accessible at http://onlinelibrary.wiley.com/doi/10.1111/trf.13069/epdf).

\section{PATIENT COUNSELING INFORMATION}

Advise the patient to read the FDA-approved patient labeling (Patient Information).

\section{Hypersensitivity and Other Administration Reactions}

Advise patients to seek immediate medical attention for any of the following signs and symptoms of systemic administration-related reactions: itchy, runny or blocked nose; chills, nausea, throat irritation, cough, headache, shortness of breath or difficulty breathing [see Warnings and Precautions].

\section{Cardiac Toxicity in Patients with Light Chain (AL) Amyloidosis}

Advise patients to immediately contact their healthcare provider if they have signs or symptoms of cardiac adverse reactions [see Warnings and Precautions].

\section{Neutropenia}

Advise patients to contact their healthcare provider if they have a fever [see Warnings and Precautions].

\section{Thrombocytopenia}

Advise patients to contact their healthcare provider if they have bruising or bleeding [see Warnings and Precautions].

\section{Embryo-Fetal Toxicity}

Advise pregnant women of the potential hazard to a fetus. Advise females of reproductive potential to inform their healthcare provider of a known or suspected pregnancy [see Warnings and Precautions, Use in Specific Populations].

Advise females of reproductive potential to avoid becoming pregnant during treatment with DARZALEX FASPRO and for 3 months after the last dose [see Use in Specific Populations].

Advise patients that lenalidomide, thalidomide and pomalidomide have the potential to cause fetal harm and have specific requirements regarding contraception, pregnancy testing, blood and sperm donation, and transmission in sperm. Lenalidomide, thalidomide and pomalidomide are only available through a REMS program [see Use in Specific Populations].

\section{Interference with Laboratory Tests}

Advise patients to inform their healthcare provider, including personnel at blood transfusion centers, that they are taking DARZALEX FASPRO, in the event of a planned transfusion [see Warnings and Precautions].

Advise patients that DARZALEX FASPRO can affect the results of some tests used to determine complete response in some patients and additional tests may be needed to evaluate response [see Warnings and Precautions].

Hepatitis B Virus (HBV) Reactivation

Advise patients to inform healthcare providers if they have ever had or might have a hepatitis $B$ infection and that DARZALEX FASPRO could cause hepatitis $B$ virus to become active again [see Adverse Reactions].

\section{Product of Switzerland}

Manufactured by:

Janssen Biotech, Inc.

Horsham, PA 19044

U.S. License Number 1864 


\title{
A Rare Case of Glioblastoma With Extensive Liver Metastases
}

\author{
Ghulam Ghous, MD1; Douglas Miller, MD2; Donald Doll, MD; and Tolga Tuncer, MD \\ Assistant Professor of Clinical Medicine, Ellis Fischel Cancer Center, University of Missouri, Columbia. ggkm5@health.missouri.edu \\ 2Douglas Miller, MD, Chair and Professor of Clinical Pathology and Anatomical Sciences, Ellis Fischel Cancer Center, University of Missouri, Columbia. millerdc@health.missouri.edu \\ 3Donald Doll, MD, Interim Hematology/Oncology Division Director and Professor of Clinical Medicine, Ellis Fischel Cancer Center, University of Missouri, Columbia. dolld@health.missouri.edu \\ ${ }^{4}$ Tolga Tuncer, MD, Assistant Professor, Ellis Fischel Cancer Center, Neuro/Medical Oncologist, University of Missouri, Columbia. tuncert@health.missouri.edu
}

\begin{abstract}
Glioblastoma (GBM), the most common primary brain tumor, is a highly aggressive malignancy for which the median survival is about 13 months, and 5 -year survival is well under $5 \%$. These tumors usually occur in the brain and enlarge and infiltrate through white matter, including crossing through the corpus callosum to the opposite cerebral hemisphere. They may spread to distant parts of the central nervous system (CNS) via cerebrospinal fluid pathways. Extraneural metastases from primary brain tumors are quite rare, for 2 probable reasons: because most patients survive less than 2 years, and because of the absence of true lymphatics in the CNS. Typical sites for distant extraneural metastasis of GBM are lungs and pleura, followed by lymph nodes and bones; spread to the liver is exceptional. Most of the reported cases with liver metastases had either single or only a few such metastatic lesions. We report a probably unique case of GBM with extensive liver metastases along with a review of previous cases of liver metastasis from GBM, and we discuss the possible mechanisms of metastasis.
\end{abstract}

KEYWORDS: Glioblastoma, extraneural metastases, liver metastases, circulating GBM, EGFR amplification

\section{Introduction \\ Glioblastomas (GBM) are the most common and the most aggressive malig- nant brain tumor originating from glial cells. ${ }^{1}$ They arise either de novo (primary glioblastoma) or from lower-grade dif- fuse gliomas (secondary glioblastoma),}

sometimes after many years. It has an annual incidence in the United States of 3 per 100,000 people, with approximately 12,500 cases per year. ${ }^{2}$ The peak age of presentation is in later adult life; median survival is about 13 months and 5-year survival is well under $5 \% .^{1-4}$
Bailey and Cushing initially described leptomeningeal metastases of intracranial gliomas in 1926 and stated that such tumors would not have extracranial metastases..$^{4,5}$ However, Davis provided the first description of extracranial GBM metastasis in $1928 .^{6}$ The recognition and thus apparent incidence of extracranial metastases from GBM has increased from a frequency of only $0.44 \%$ in $1969^{3}$ to $2 \%$ at present; some of this increase may be real, and some of it may be due to longer survivals with modern therapy. ${ }^{7}$ One review article reported that extraneural metastases of GBM included spread to lung and pleura $(60 \%)$, cervical lymph nodes $(51 \%)$, bone (31\%), and only rarely liver $(20 \%) .{ }^{8}$ Yet more unusual examples of metastatic glioblastoma were also reported in heart, adrenal gland, kidney, diaphragm, mediastinum, and pancreas. The median time for detection of such distant spread following diagnosis of the primary brain tumor is reported as 8.5 months, and the median time from that diagnosis to death is 1.5 months. ${ }^{9}$ We report a case of GBM with extensive liver metastases along with a review of previous reports of liver metastasis from GBMs, and we discuss the possible mechanisms of metastasis.

\section{Case Presentation}

A man aged 65 years had a history of a benign lung mass (resected in 1985), 


\section{FIGURE 1. CT Scans of Brain, Chest, and Liver at Initial Presentation}
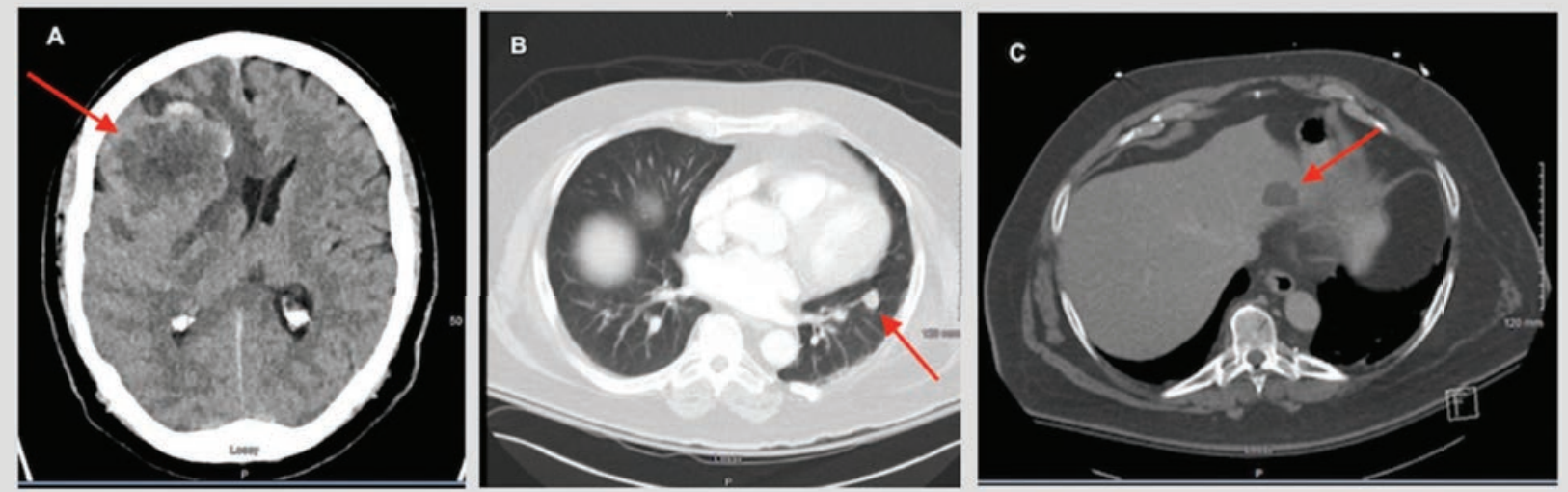

(A) Brain CT shows a right frontal mass with $1 \mathrm{~cm}$ of midline shift.

(B) Chest CT reveals a left lower lobe lung nodule, up to $1.4 \mathrm{~cm}$ greatest dimension, concerning for metastatic disease.

(C) Abdominal CT reveals a lesion in the left lobe of the liver, in segment 7.

\section{FIGURE २. MRI of the Brain}
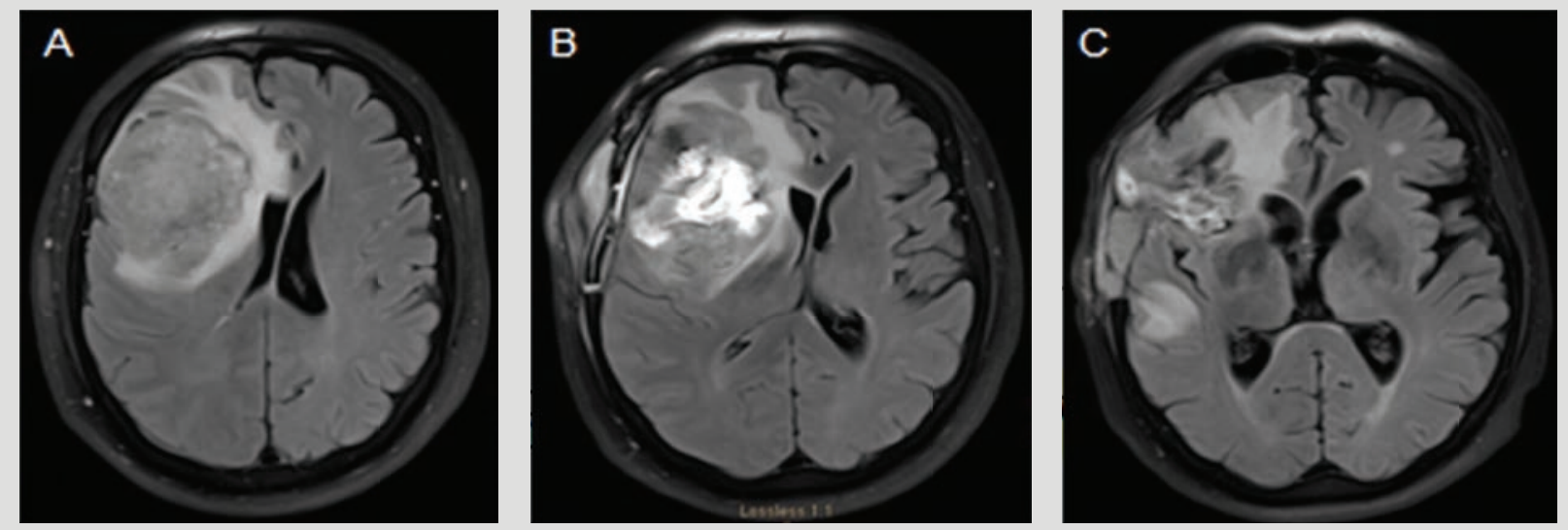

(A) The initial admission MRI reveals an ovoid, lobulated, predominantly peripherally enhancing $5.6-\mathrm{cm} \times 6.5-\mathrm{cm} \times 6.1-\mathrm{cm}$ mass within the right frontal lobe with multifocal hemorrhage.

(B) Recurrent right frontal glioblastoma with significant mass effect on the underlying brain parenchyma and approximately $1.1 \mathrm{~cm}$ of right-to-left midline shift.

(C) Second Readmission, enlarging mass up to at least $4.5 \mathrm{~cm}$ in greatest dimension within the anterior right frontal tumor resection bed, extending through the craniectomy margins, plus an upper left parietal lobe lesion up to $1.5 \mathrm{~cm}$ across.

papillary thyroid cancer (status post thyroidectomy performed in 2016), and a recent diagnosis of prostate cancer (Gleason grade $3+3$; prostate-specific antigen [PSA] $6.25 \mathrm{ng} / \mathrm{mL}$ in 2018); he presented to an outside hospital because of progressive headache and leg weakness over the prior 2 weeks. Physical examination was normal. CT scans showed a right frontal mass with $1 \mathrm{~cm}$ of midline shift (Figure 1A), a 1.4-cm (greatest dimension) left lower lobe lung nodule (Figure 1B), and a $3.3-\mathrm{cm} \times 2.1-\mathrm{cm}$ hypodense lesion in the left hepatic lobe (Figure 1C). He was transferred to our hospital. MRI revealed a $5.6-\mathrm{cm} \times 6.5-\mathrm{cm} \times 6.1-\mathrm{cm}$ ovoid, lobulated, predominantly peripherally enhancing mass within the right frontal lobe, with multiple foci of hemorrhage (Figure 2A). The tumor was gross totally excised and was discovered to be an IDH wild-type glioblastoma that had no MGMT promoter methylation, and no mutation of ATRX. His hospital course 
was complicated by an acute pulmonary embolism requiring placement of an inferior vena cava filter. He was ultimately discharged to a rehabilitation facility. Subsequently, he was seen in our medical oncology clinic and scheduled for concurrent temozolomide (Temodar) and external beam radiation therapy, as per the typical Stupp regimen. ${ }^{10}$

However, prior to initiating the treatment, he was readmitted for dizziness and worsening of left-sided weakness. A repeat MRI revealed a significant recurrent enhancing mass at the prior resection site affecting the underlying brain parenchyma, with approximately $1.1 \mathrm{~cm}$ of midline shift (Figure 2B). The recurrent tumor was resected, along with extensive debridement of subcutaneous, epidural, and intraparenchymal scar tissue. Pathologically, it was recurrent glioblastoma. It is noteworthy that the patient did not need any ventriculoperitoneal shunt (VPS) at any stage. During this surgery, the patient was found to have a stitch abscess with subcutaneous and possible bone flap involvement. Additionally, cultures showed subcutaneous tissue diphtheroids, coagulase-negative Staphylococcus, diphtheroids, Candida parapsilosis, and Cutibacterium. He was discharged on intravenous vancomycin and fluconazole for more than 4 weeks.

Unfortunately, the patient did not receive adjuvant oral temozolomide/radiation therapy in a timely fashion due to infection, and he subsequently presented with altered mental status (AMS), acute kidney injury (AKI), and septic shock. Brain MRI done outside hospital as part of the AMS work-up showed a new lesion in the left parietal region and the patient was then transferred again to our hospital. A new brain MRI confirmed additional new lesions within the right frontotemporal region and in the left parietal lobe (Figure 2C). As part of the AKI work-up, ultrasonography and MRI of his abdomen revealed innumerable

\section{FIGURE 3. MRI Liver}

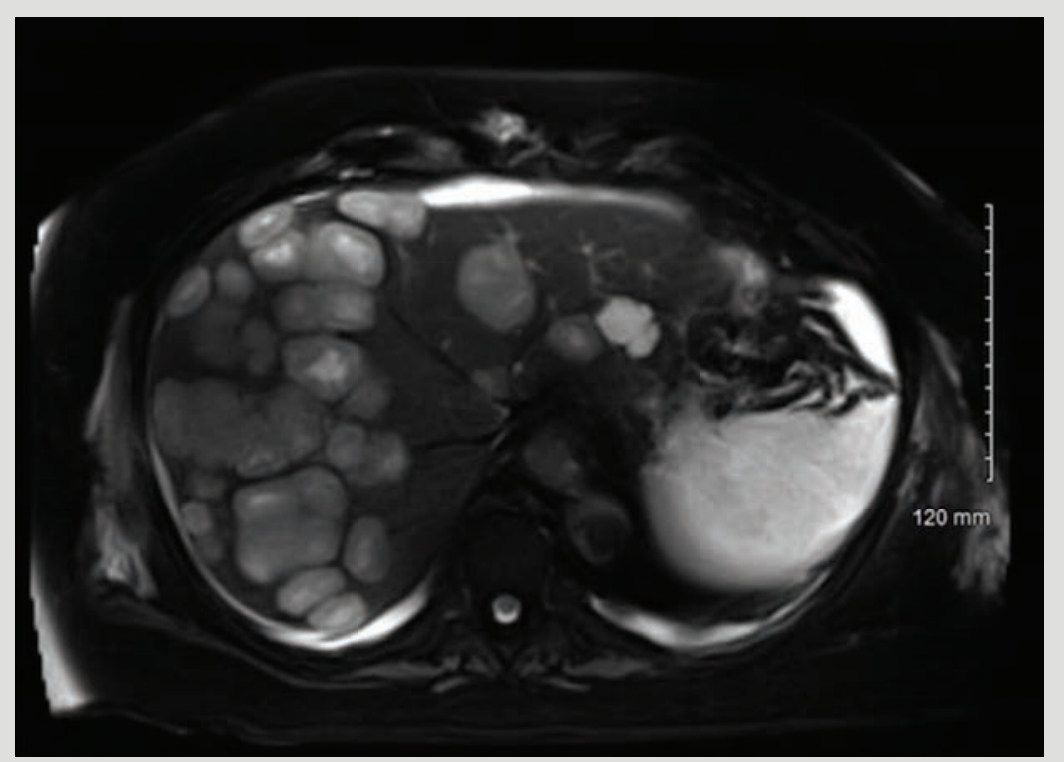

Abdominal MRI demonstrates the interval development of extensive hepatic metastatic disease with innumerable metastatic lesions involving both hepatic lobes and all hepatic segments.

presumed metastatic lesions involving all hepatic segments (Figure 3). Liver biopsy revealed a metastatic epithelioid malignancy that was histologically identical to the intracerebral glioblastoma. He died a little more than a week later.

\section{Tumor Pathology}

The initial resection yielded a piece of cerebral tissue measuring $7.2 \mathrm{~cm} \times 5.1 \mathrm{~cm}$ $\times 1.4 \mathrm{~cm}$ that was mostly replaced by tumor, with extensive necrosis. The tumor had an epithelioid growth pattern with round to polygonal cells with mostly centrally placed pleiomorphic nuclei with substantial mitotic activity (Figure 4A). In a few foci, the necrosis was bordered by a palisade of small tumor cells (Figure 4B). Initially, because there was no edge in the specimen with normal brain to assess infiltrative growth, it was thought the tumor might be metastatic, but a broad panel of immunostains established that it was not carcinoma, germ cell tumor, or melanoma: Specifically, there was no immunoreactivity for cytokeratins (cytokeratin 7, cytokeratin 20, antibody CAM5.2), thyroid transcription factor 1 (TTF1), Napsin, P40, CDX2, PSA, HMB45, or MART-1/Melan-A (antibody A103). These results tended to rule out carcinomas (cytokeratins negative)specifically, carcinomas including pulmonary non-small cell carcinomas (TTF1, Napsin, P40), gastrointestinal primary carcinomas (CDX2), prostatic carcinoma, and melanomas (HMB45, MART1). A germ cell origin was also considered, but immunostains for Oct3/4 and alpha-fetoprotein were both negative.

These results prompted a panel of immunostains appropriate for gliomas, which revealed extensive cytoplasmic immunopositivity for vimentin, rare tumor cells with cytoplasmic glial fibrillary acidic protein (GFAP) immunoreactivity (Figure 4C); no cells were immunopositive for synaptophysin or neurofilament protein (neurofilament protein, antibody RMDO20). There was 
TABLE. Summary of Reported Patients With GBM and Extracranial Liver Metastasis

\begin{tabular}{|c|c|c|c|c|}
\hline Authors & $\begin{array}{l}\text { Patient age } \\
\text { in years }\end{array}$ & Sex & Primary site & Surgery/primary tumor resection \\
\hline Robert et al3 & 45 & $\mathrm{~F}$ & Left temporal & Yes \\
\hline Harrison et al ${ }^{13}$ & 56 & $\mathrm{~F}$ & Right temporal & Yes \\
\hline Fonkem et al ${ }^{14}$ & 69 & M & Left temporal & Yes \\
\hline Greif et $\mathbf{a l}^{15}$ & 51 & M & Left frontal & Yes \\
\hline Undabeitia et $\mathbf{a l}^{4}$ & 20 & $\mathrm{~F}$ & Right temporal & Yes \\
\hline Johansen et al ${ }^{9}$ & 59 & $\mathrm{~F}$ & Occipital & Yes \\
\hline Johansen et $\mathbf{a l}^{9}$ & 60 & M & Frontal & Yes \\
\hline Widjaja et al ${ }^{16}$ & 58 & M & Right temporal & Yes \\
\hline Saad et al' ${ }^{17}$ & 13.5 & M & Left frontal & Yes \\
\hline Tamura et al ${ }^{18}$ & 33 & $\mathrm{~F}$ & Cerebellar & Yes \\
\hline Rosen et al ${ }^{19}$ & 48 & $\mathrm{~F}$ & Left temporal & Yes \\
\hline Shuto et al ${ }^{20}$ & 42 & $\mathrm{~F}$ & Left parieto- occipital & Yes \\
\hline Matsuyama et $\mathbf{a l}^{21}$ & 68 & M & $\begin{array}{l}\text { Right Sylvian fissure or interpeduncular, } \\
\text { quadrigeminal, and ambient cisterns }\end{array}$ & Yes \\
\hline Ogata et $\mathbf{a l}^{22}$ & 68 & M & Left fronto-parietal lobe & Unknown \\
\hline Johnson et $\mathbf{a l}^{23}$ & 46 & M & Right occipito- parietal & Yes \\
\hline Anzil et $\mathbf{a l}^{24}$ & 53 & $\mathrm{~F}$ & Left frontal & No surgery, but had radiation therapy \\
\hline Present report & 65 & M & Right frontal & Yes \\
\hline
\end{tabular}

DX, diagnosis; F, female; GBM, glioblastoma; IV, intravenous; M, male; mo, months; VPS, ventriculoperitoneal shunt.

extensive nuclear immunoreactivity for the neuronal marker Neu-N. These results favored a poorly differentiated (poor GFAP expression), high-grade glioma (glioblastoma) with aberrant neuronal (Neu-N) immunoreactivity. This was further confirmed by the demonstration of an infiltrative pattern of growth, with entrapped axons immunopositive for NFP, some still myelinated as shown with a Luxol fast blue (LFB) stain, as well as single infiltrating tumor cells in adjacent intact LFB-positive white matter. A
Ki67 immunostain marked an estimated $50 \%$ of the tumor cell nuclei (Figure 4D). There was no immunoreactivity for the protein product of the IDH1 R132H mutation, whereas an immunostain for the ATRX protein marked all of the tumor cell nuclei, indicating no mutation or deletion of the ATRX gene. Further assays revealed no methylation of the MGMT promoter and no co-deletion of chromosome arms $1 \mathrm{p}$ and $19 \mathrm{q}$ (thus, with the IDH result, ruling out oligodendroglioma). The fluorescence in situ hybridization assay suggested that the tumor was tetraploid. Given the patient's age and the lack of MGMT methylation, the $I D H$ genes were not sequenced.

The recurrent brain tumor from the second craniotomy was histologically identical to the first (Figure 5A); like the original, it was mostly necrotic. The liver biopsy demonstrated a tumor with an identical histological appearance (Figure 5B). This tumor, like the initially resected brain tumor, had no immunoreactivity for cytokeratins (antibody cocktail 


\begin{tabular}{|c|c|c|c|}
\hline VPS & Sites of metastasis & Timings of metastases after GBM DX & Treatment of metastatic sites \\
\hline No & Liver, spinal cord & $9 \mathrm{mo}$ & Unknown \\
\hline No & Liver, pleural & $15 \mathrm{mo}$ & Temozolomide and bevacizumab \\
\hline Unknown & Liver & Unknown & Unknown \\
\hline No & Liver, lung & Unknown & No treatment \\
\hline No & $\begin{array}{l}\text { Liver, lung, spinal cord, lymph } \\
\text { nodes }\end{array}$ & $5 \mathrm{mo}$ & $\begin{array}{l}\text { Irinotecan } \\
\text { and bevacizumab }\end{array}$ \\
\hline No & Liver, lung, bones, lymph nodes & $5 \mathrm{mo}$ & $\begin{array}{l}\text { Irinotecan } \\
\text { and bevacizumab }\end{array}$ \\
\hline No & Liver & At time of presentation & Died before initiation of treatment \\
\hline No & Liver, spleen & $7 \mathrm{mo}$ & $\begin{array}{l}\text { Oral procarbazine } \\
\text { and IV 5-fluorouracil }\end{array}$ \\
\hline No & Liver, pleural, left temporalis & $9 \mathrm{mo}$ & Procarbazine \\
\hline Unknown & Liver, bone & $2 \mathrm{mo}$ & No treatment \\
\hline No & $\begin{array}{l}\text { Liver, lung, pleura, skull, spinal } \\
\text { cord, rib, pelvis, lymph nodes, } \\
\text { mesentery }\end{array}$ & $6 \mathrm{mo}$ & Lomustine and radiotherapy \\
\hline No & Liver, skull, spinal cord & $1 \mathrm{mo}$ & No treatment \\
\hline Yes & Liver, spleen, spinal cord & $5 \mathrm{mo}$ & No treatment \\
\hline No & $\begin{array}{l}\text { Liver, lung, kidney, heart, spleen, } \\
\text { bronchial lymph nodes }\end{array}$ & $7 \mathrm{mo}$ & No treatment \\
\hline Unknown & Lung, liver, hilar nodes & Unknown & Unknown \\
\hline No & Liver, thoracic spine & $4 \mathrm{mo}$ & No treatment \\
\hline No & Liver (extensive miliary), lungs & $3 \mathrm{mo}$ & No treatment \\
\hline
\end{tabular}

AE1/AE3, cytokeratin 7, cytokeratin 20), TTF1, or CDX2. Unlike the brain lesion, this tumor lacked any GFAP immunoreactivity, but it was vimentin and Neu-N immunoreactive.

\section{Discussion}

GBMs are highly aggressive brain cancers. They usually grow and infiltrate through white matter, and they then spread contiguously by infiltration into the adjacent tissues, including crossing the corpus callosum to the opposite cerebral hemisphere. Distant spread occurs within the central nervous system (CNS) via cerebrospinal fluid (CSF) pathways, ${ }^{11}$ and, in a small minority of cases, to systemic body sites by hematogenous routes. In 1969, an extensive review based on the autopsy findings of 18,000 patients with brain tumors reported only 35 well-documented cases of distant hematogenous metastatic spread that were GBM. ${ }^{12}$ These metastases involved cervical and mediastinal regional lymph nodes, lung, liver, and bone. ${ }^{12}$
Rare metastases were also reported in the heart, adrenal gland, kidney, diaphragm, mediastinum, and pancreas. ${ }^{8}$ Most of the described cases with liver metastases had a single or a few metastatic tumors; only 1 case reported 4 or more metastatic liver lesions ${ }^{3}$ (Table ${ }^{3,4,9,13-24}$ ). To our knowledge, our case is the first GBM case reported to have extensive miliary liver metastases.

Extraneural metastasis of GBM is rare for a number of reasons: The bloodbrain barrier (BBB) probably constitutes 
a significant barrier for the invasion of tumor cells through vessel walls; the intracranial sinuses are enclosed in a dense dural membrane, making penetration by tumor cells difficult; and the intracerebral veins are thin-walled and would probably collapse from compression before they could be penetrated by an expanding tumor. ${ }^{25}$ Additionally, glioma cells do not often express fibronectin, ${ }^{26,27}$ and the lack of collagen and fibronectin within the CNS makes glioma cells have a relatively poor affinity for vascular walls, making direct vascular endothelial invasion and subsequent extracranial seeding more difficult. ${ }^{26,27}$

The dynamics of a well-described molecular mechanism for GBM extracranial metastasis are unclear. However, it has been reported that such metastatic spread is associated with seeding of cells iatrogenically, during stereotactic

\section{FIGURE 4. Tumor Pathology}
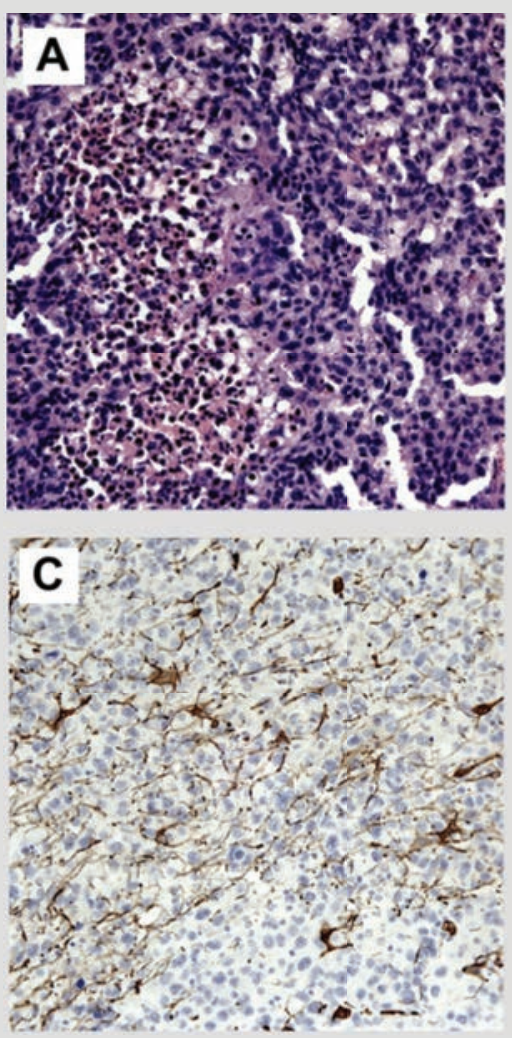
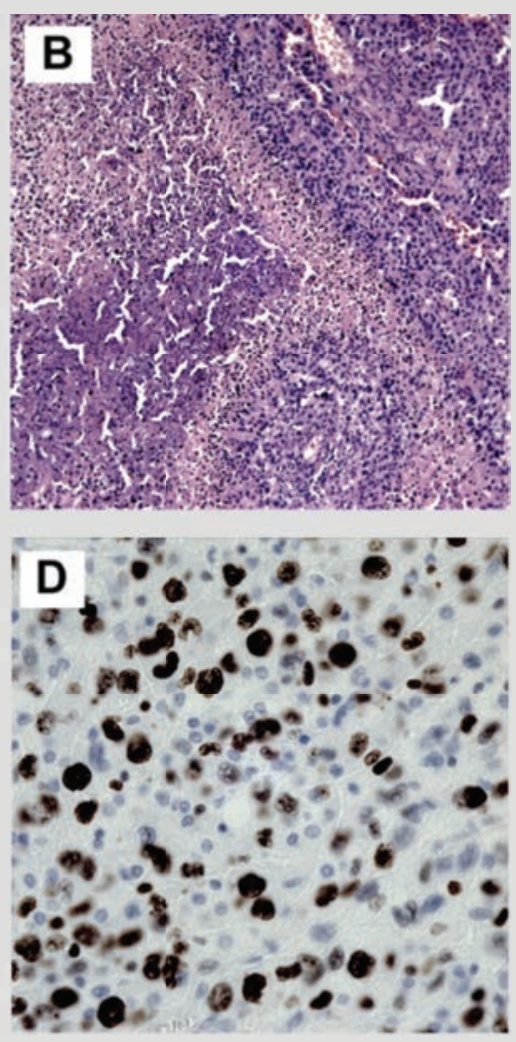

(A) Primary brain tumor resection, demonstrating an epithelioid tumor with pleiomorphic but centrally placed irregularly round nuclei. This could represent melanoma, carcinoma, or even anaplastic oligodendroglioma. Hematoxylin and eosin (H\&E) stain, original magnification 200x.

(B) Focally the tumor had palisades of small tumor cells bordering necrotic zones. H\&E, original magnification 100x.

(C) A minority of the tumor cells had cytoplasmic glial fibrillary acidic protein immunoreactivity; original magnification 200x.

(D) Ki67 labeling index approached an estimated 50\%; original magnification 400x.

biopsy, craniotomy, placement of ventriculoperitoneal shunts, or radiation therapy. ${ }^{28-30}$ According to this hypothesis, medical procedures or radiation therapy (other than VPS, which causes direct seeding) destroy the local BBB, thereby facilitating metastasis.

We reviewed all of the available literature of GBM with liver metastasis from PubMed through March 2021. Based on this review, almost all of the liver metastases occurred after initial neurosurgery to remove the primary GBM. Only 1 patient had not undergone surgery prior to the development of liver tumors; instead, he had undergone radiation therapy, which is also consistent with this hypothesis. In a hypothetical patient who did not undergo any neurosurgical procedures or radiation therapy, the progression of GBM might also destroy and invade into surrounding tissues including the $\mathrm{BBB}$, an artery or vein, CSF, and dural venous spaces, ${ }^{24}$ finally leading to hematogenous distant metastasis. This was the case in our patient, who had liver and lung metastases at presentation. This demonstrates that extraneural metastases can also spontaneously arise from a primary GBM of the brain, and that neither cranial surgery nor radiation therapy are prerequisites for the distal extraneural spread of glioblastomas. Lymphatic metastasis might also exist and lead to GBM extracranial metastasis.

Two recent exciting discoveries in brain physiology and anatomy were the CNS glymphatic system ${ }^{31}$ and the CNS (dural) lymphatic system in 2015.32 Based on these discoveries, it is likely that brain parenchymal CSF permeates into the glymphatic system, which is then connected with the meningeal lymphatic system. The meningeal lymphatic system drains CSF to dural lymphatic vessels. Most importantly, the dural lymphatic vessels are able to carry CSF fluid, CNS antigens, and immune cells to deep cervical lymph nodes. ${ }^{33}$ This suggests an 
opportunity for GBM cells to migrate and metastasize to deep cervical lymph nodes, finally circulating into blood and escaping the CNS.

Once GBM cells circulate into the peripheral blood, the explanation of how these tumor cells metastasize to liver or other extracranial organs remains elusive. The "seed and soil" hypothesis proposed that some tumor cells selectively metastasize to specific regions within a given organ, indicating either a need of the tumor cells to grow only in a similar microenvironment, or that there are surface markers on the tumor cells that specifically bind to receptors on organ- or site-specific endothelial cells. ${ }^{34}$ In a study that screened different cancers for overexpression of tissue-selective genes, it was shown that glioblastoma selectively overexpressed genes that were also overexpressed in lung cancer (26 genes) and liver cancer (18 genes). ${ }^{35}$ The results of this study suggested that tumors might prefer to metastasize to organs that harbor cells with similar overexpressed tissue-selective cancer genes, providing the rationale for organotropism. Additionally, circulating GBM cells have been shown to have a mesenchymal expression profile; some investigators have theorized that this accounts for these cells' ability to obtain access to the bloodstream.

Muller et al first reported that 20\% of patients with GBM have circulating GBM cells in the peripheral blood; such a number obviously represents more frequency than the reported incidence of extracranial metastases of GBM in 2012. ${ }^{33}$ The circulating GBM cells could be used to predict response to treatment and to ascertain the differential diagnosis between CNS GBM recurrence and radiation necrosis. ${ }^{33}$ Gene amplification of the EGFR has been observed in $40 \%$ of glioblastomas, ${ }^{36}$ and it has been observed that some circulating GBM cells have EGFR amplification, indicating that EGFR signaling might support the
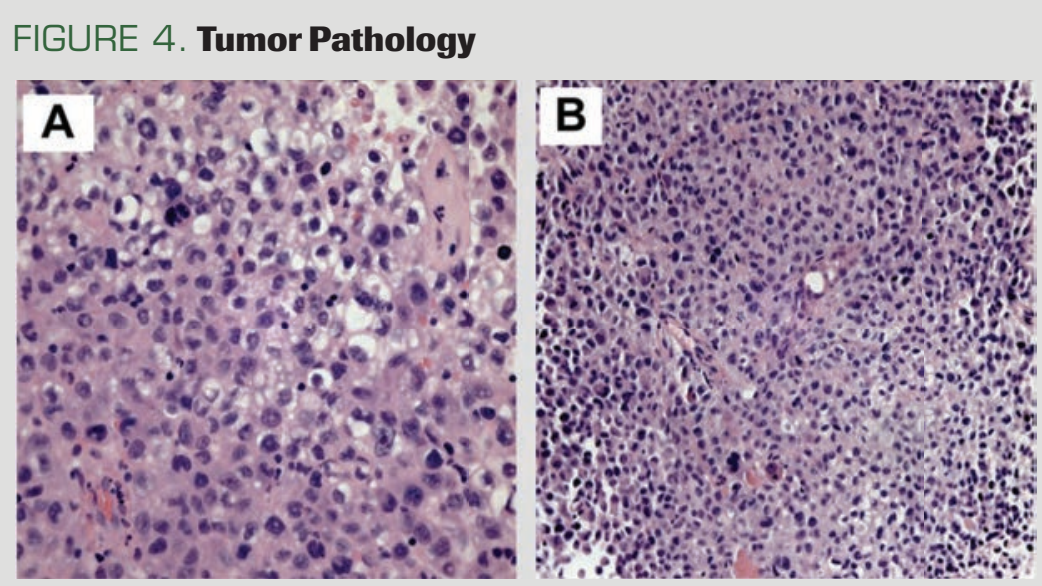

(A) Histological appearance of the recurrent/residual brain tumor was identical to that of the original resection. Most of the tumor was necrotic. H\&E; original magnification 400x.

(B) Liver biopsy showed that the liver needle cores had some liver tissue (not shown) together with sharply demarcated nodules of tumor, histologically identical to the brain lesions. H\&E; original magnification 200x.

extracranial spread of GBM..$^{37,38}$ The TGF-alpha/EGFR signaling pathway plays a key role in colon cancer hepatic metastasis. ${ }^{39}$ Clinically, the combination of the EGFR inhibitor panitumumab (Vectibix) with cetuximab (Erbitux) has been used to treat unresectable metastatic colon cancer. However, the questions of whether GBM hepatic metastasis is also associated with EGFR overexpression, and whether EGFR could be a target for metastatic GBM treatment, have not yet been investigated.

The immune system might also play a role in GBM extracranial metastasis. This notion was supported by the detection of extracranial glioblastomas in the recipients of transplanted organs from glioblastoma donors. About $12.5 \%$ to $25 \%$ of organ donors with glioblastoma might transmit the tumor to the organ recipient. ${ }^{33}$ In a review of 11 patients who received solid organ transplants donated from patients with GBM, all 3 liver transplant patients developed GBM liver metastasis with a mean survival of 7 months; all 3 kidney transplant patients had kidney metastasis, with a mean survival of 17.3 months; and 4 of the 5 lung transplant patients developed lung metastasis. ${ }^{40-43}$ It has also been shown that GBM will grow subcutaneously in an immune-deficient mouse model.

In most patients with GBM, growth and proliferation of these extracranial glioblastomas are probably suppressed by the peripheral immune system. ${ }^{33}$ However, in posttransplant patients, the immune system is iatrogenically suppressed and conceivably could not kill the circulating GBM cells. Additionally, the mTOR inhibitor(s) can also cause an abnormality of glucose metabolism, which may lead to T cell exhaustion. ${ }^{44}$ In contrast, the CNS has traditionally been thought to be immune privileged. Glioblastomas have immunosuppressive microenvironment due to expression of programmed death-ligand 1 (PD-L1) on GBMs, tumor-associated macrophages, and abnormal regulation of cytokines. This immunosuppressive microenvironment helps to evade immune $\operatorname{attack}^{33}$; therefore, checkpoint inhibitors do not work well in the CNS even if GBM cells 
have a moderate-to-high PD-L1 expression. However, once GBM cells circulate into the blood and lose their immunosuppressive microenvironment, whether checkpoint inhibitors would start to work and kill these single GMB cells or cell clusters is unknown.

Extracranial GBM metastasis has no well-established treatment. With limited data, options could include up-front temozolomide, bevacizumab (Avastin) with carboplatin, or docetaxel with carboplatin. Other possibilities are older regimens like cyclophosphamide, doxorubicin (Adriamycin), and etoposide. One obstacle to investigating GBM metastasis and treatment is the lack of ideal animal models. Conventional mouse models would not mimic the human BBB and immune systems. However, inspired by the development of 3-dimensional organoids cultured from patients with colorectal cancer ${ }^{45}$ and co-culturing of intestinal epithelial organoids with local immune response, some investigators have now developed cerebral organoid models. ${ }^{46}$ Recently, BBB organoids have also been developed to investigate the permeability of CNS therapeutics across the BBB. ${ }^{47}$ In the near future, third-generation DNA sequencing could detect the gene expression profile of a single circulating GBM cell in the blood and might predict the response to treatment and the location of metastasis.

\section{Conclusions}

In summary, we report a rare case of GBM with extensive miliary liver metastasis in a patient who had 2 craniotomies and who did not receive chemotherapy and radiation therapy. The mechanism of extracranial metastasis in this particular patient is not known. However, it has been shown that iatrogenic, hematogenous, and lymphatic dissemination may all be possible. Circulating GBM cells have been detected even before surgery in many patients.
These circulating GBM cells are believed to predict early recurrence in the posttreatment setting, and we believe that results of current research will afford the field with a diagnostic tool for differentiation between early recurrence and radionecrosis. The advancement of new cerebral organoids, BBB organoids, and other state-of-the-art biotechnologies will help further explore the pathogenesis of GBM tumorigenesis and metastasis, as well as support the development of novel therapeutics. Comparing molecular abnormalities within matched primary and metastatic tumors will better allow us to understand the mechanisms behind these rare distant metastatic occurrences, as will utilizing matched organoids.

ACKNOWLEDGMENTS: The authors would like to thank all members of the treatment team, the patient and their family, and the University of Missouri - Columbia hematology/oncology department.

CONFLICT OF INTEREST: The authors declare that there is no conflict of interest regarding the publication of this article.

\section{FUNDING: None.}

\section{KEY REFERENCES}

1. Louis DN, Perry A, Reifenberger G, et al. The 2016 World Health Organization Classification of Tumors of the Central Nervous System: a summary. Acta Neuropathol. 2016;131(6):803-820. doi:10.1007/s00401-016-1545-1

2. Ostrom QT, Gittleman $\mathrm{H}$, Liao $\mathrm{P}$, et al. CBTRUS Statistical Report: primary brain and other central nervous system tumors diagnosed in the United States in 20102014. Neuro Oncol. 2017;19(suppl 5):v1v88. doi:10.1093/neuonc/nox158

3. Robert Mc, Wastie MI. Glioblastoma multiforme: a rare manifestation of extensive liver and bone metastases. Biomed Imaging Interv J. 2008;4(1):e3. doi:10.2349/biij.4.1.e3

4. Undabeitia J, Castle M, Arrazola M, Pendleton C, Ruiz I, Úrculo E. Multiple extraneural metastasis of glioblastoma multiforme. An Sist Sanit Navar. 2015;38(1):157-161. doi:10.23938/ ASSN.0061

5. Bailey P, Cushing H. A classification of the tumours of the glioma group on a histogenetic basis, with a correlated study of prognosis. JAMA. 1926;87(4):268. doi:10.1001/jama. 1926.02680040056039

6. Davis L. Spongioblastoma multiforme of the brain. Ann Surg. 1928;87(1):8-14.

7. Piccirilli M, Brunetto GMF, Rocchi G, Giangaspero F, Salvati M. Extra central nervous system metastases from cerebral glioblastoma multiforme in elderly patients. clinico-pathological remarks on our series of seven cases and critical review of the literature. Tumori. 2008;94(1):40-51.

8. Pasquier B, Pasquier D, N'Golet A, Panh MH, Couderc P. Extraneural metastases of astrocytomas and glioblastomas: clinicopathological study of two cases and review of literature. Cancer. 1980;45(1):112-125. doi:10.1002/1097-0142(19800101)45:1<112::aidcncr2820450121>3.0.co;2-9

9. Dinche Johansen M, Rochat P, Law I, Scheie D, Skovgaard Poulsen H, Muhic A. Presentation of two cases with early extracranial metastases from glioblastoma and review of the literature. Case Rep Oncol Med. 2016;2016:8190950. doi:10.1155/2016/8190950

10. Stupp R, Mason WP, van den Bent MJ, et al; European Organisation for Research and Treatment of Cancer Brain Tumor and Radiotherapy Groups; National Cancer Institute of Canada Clinical Trials Group. Radiotherapy plus concomitant and adjuvant temozolomide for glioblastoma. N Engl J Med. 2005;352(10):987-996. doi:10.1056/NEJMoa043330

11. Onda K, Tanaka R, Takahashi H, Takeda N, Ikuta F. Cerebral glioblastoma with cerebrospinal fluid dissemination: a clinicopathological study of 14 cases examined by complete autopsy. Neurosurgery. 1989;25(4):533-540.

12. Smith DR, Hardman JM, Earle KM. Metastasizing neuroectodermal tumors of the central nervous system. J Neurosurg. 1969;31(1):50-58. doi:10.3171/ jns.1969.31.1.0050

13. Harrison WT, Hulette CM, Guy C, Sporn T, Cummings T. Metastatic glioblastoma: a case report and review of the literature. J Med Surg Pathol. 2016;1(2):1000115. doi:10.4172/2472-4971.1000115

14. Fonkem E, Lun M, Wong ET. Rare phenomenon of extracranial metastasis of glioblastoma. J Clin Oncol. 2011;29(34):4594-4595. doi:10.1200/JCO.2011.39.0187 15. Greif J, Horovitz M, Marmor S. Pleuropulmonary metastasis from an intracranial glioblastoma. Lung Cancer. 1998;20(2):135-137. doi:10.1016/s01695002(98)00029-4

16. Widjaja A, Mix H, Gölkel C, et al. Uncommon metastasis of a glioblastoma multiforme in liver and spleen. Digestion. 2000;61(3):219-222. doi:10.1159/000007761

17. Saad AG, Sachs J, Turner CD, et al. Extracranial metastases of glioblastoma in a child: case report and review of the literature. J Pediatr Hematol Oncol. 2007;29(3):190-194. doi:10.1097/ MPH.0b013e31803350a7

18. Tamura M, Kawafuchi J, Wakao T, Kumagai $N$. Cerebellar glioblastoma-report of a case and review of literature (author's transI). Article in Japanese. Neurol Med Chir (Tokyo). 1979;19(6):517-522. doi:10.2176/ nmc. 19.517

19. Rosen J, Blau T, Grau SJ, Barbe MT, Fink GR, Galldiks $\mathrm{N}$. Extracranial metastases of a cerebral glioblastoma: a case report and review of the literature. Case Rep Oncol. 2018;11(2):591-600. doi:10.1159/000492111

20. Shuto T, Fujino H, Inomori S, et al. Glioblastoma multiforme with liver metastasis-case report. Article in Japanese. No To Shinkei. 1995;47(8):772-777.

21. Matsuyama J, Mori T, Hori S, Nakano T, Yamada A. Gliosarcoma with multiple extracranial metastases. case report. Article in Japanese. Neurol Med Chir (Tokyo). 1989;29(10):938-943. doi:10.2176/nmc.29.938

For references visit cancernetwork.com/Ghous_11.21 
SERIES EDITORS

E. David Crawford, MD

Maria T. Bourlon, MD

\section{Treatment of Locally Advanced Cervical Cancer With Kidney Failure and Comorbidities}

Eder A. Arango Bravo, MD 1,2,3 Tatiana Galicia Carmona, MD',2,3; Denisse Castro-Eguiluz, PhD',4;

Dolores Gallardo-Rincón, MD ${ }^{2,5}$; Emilio Conde Flores, $\mathrm{MD}^{6}$; and Lucely del Carmen Cetina-Pérez MD, MSc ${ }^{1,2,3^{*}}$.

\section{THE CASE}

A woman aged 63 years presented at the gynecological oncology outpatient clinic with the following medical history: smoking history (smoking index of 10); systemic arterial hypertension diagnosed 6 years ago; menarche at 16 years; menopause at 52 years; 4 pregnancies, 4 deliveries; beginning of active sexual life at 18 years; 3 sexual partners; and no early cancer detection method in her life. Her performance status per ECOG criteria was 1 . The patient presented with transvaginal bleeding with 5 months of evolution. Upon physical exploration, a $5 \times 5 \mathrm{~cm}$ tumor in the cervix was detected, with the following characteristics: exophytic, friable, bleeding, with invasion to the lower third of the vagina, affection to the cul-de-sac and parametria, and bilaterally fixed to the pelvic wall. A biopsy of the cervix showed moderately differentiated invasive squamous cell carcinoma.

\section{What is the best treatment option for this patient?}
A. Concomitant D. Concomitant CT-RT chemoradiotherapy (CT-RT) with cisplatin with gemcitabine
B. Radiation therapy only E. Neoadjuvant
C. Best supportive care
chemotherapy

TURN TO PAGE 742 FOR THE ANSWER AND A DISCUSSION OF THIS CASE BY EXPERTS.
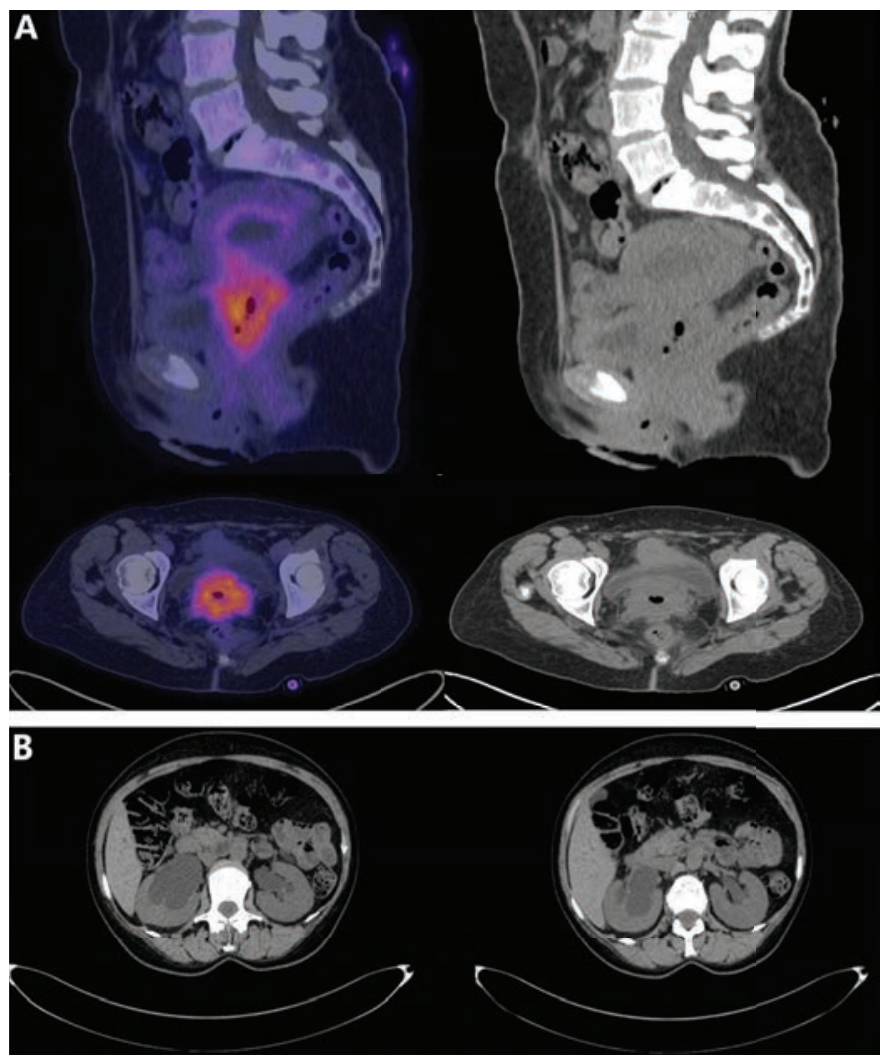

FIGURE 1. Baseline PET-CT Scan (A) Local metabolic activity in the cervix. The lesion measured $48 \times 59 \mathrm{~mm}$, extending to the vagina with SUV max $_{\text {max }}$ of 12.2 and MTV of $36.8 \mathrm{~cm}^{3}$. Lymphadenopathy of the left external iliac chain measured 13 $\mathrm{mm}$ with SUV $\mathrm{Sax}_{\max }$ of 9.4 and MTV of $1.58 \mathrm{~cm}^{3}$. Left common iliac adenopathy measured $10 \mathrm{~mm}$ with SUV max $_{\text {max }}$ of 4.2 and MTV of 2.49 $\mathrm{cm}^{3}$. (B) The presence of bilateral renal ectasia is evidenced. MTV, metabolic tumor volume; SUV $\max _{\text {, }}$ maximum standard unit value. 
Laboratory studies revealed the following: hemoglobin $6.7 \mathrm{~g} / \mathrm{dl}$ (grade 3 anemia); creatinine $5.07 \mathrm{mg} / \mathrm{dl}$; glomerular filtration rate (GFR) $9 \mathrm{ml} / \mathrm{min} / 1.73 \mathrm{~m}^{2}$, estimated by the Chronic Kidney Disease Epidemiology Collaboration formula; and blood urea nitrogen (BUN) $40 \mathrm{mg} / \mathrm{dl}$.

Basal PET-CT scan revealed an irregular, heterogeneous cervix. The lesion measured $48 \times 59 \mathrm{~mm}$ and extended to the vagina, with a maximum standard unit value $\left(\mathrm{SUV}_{\max }\right)$ of 12.2 and metabolic tumor volume (MTV) of $36.8 \mathrm{~cm}^{3}$. The scan also revealed lymphadenopathy of the left external iliac chain with the following dimensions: $13 \mathrm{~mm}, \mathrm{SUV}_{\text {max }}$ of 9.4, and MTV of $1.58 \mathrm{~cm}^{3}$; left common iliac adenopathy of $10 \mathrm{~mm}, \mathrm{SUV}_{\text {max }}$ of 4.2, and MTV of $2.49 \mathrm{~cm}^{3}$; and bilateral hydronephrosis (Figure 1).

MRI scan of the pelvis revealed a neoformation in the cervix of irregular morphology and heterogeneous intensity. It had the following dimensions: $60 \mathrm{~mm}$ (transverse) $\mathrm{x}$ $41 \mathrm{~mm}$ (anteroposterior) x $47 \mathrm{~mm}$ (longitudinal). The lesion infiltrated the lower third of the uterus, conditioning obliteration of the internal cervical orifice. The lesion extended to the lower third of the vagina and presented a loss of interface with the posterior bladder wall and bilateral involvement of the ureterovesical junction; it also presented a loss of the interface with the lower third of the rectum and extended toward the mesorectal fascia. Based on these findings, the patient was diagnosed with cervical cancer (CC) clinical stage IVA.

The patient was hospitalized because of acute kidney injury stage 3 . The urology service performed a cystoscopy without the possibility of placing a double- $J$ catheter and decided to place bilateral nephrostomies instead. The patient also received a transfusion of 3 globular packages. Subsequently, 10 days after the placement of nephrostomies, the laboratory reported the following results: creatinine $1.85 \mathrm{mg} / \mathrm{dl}$, GFR $29 \mathrm{ml} / \mathrm{min} / 1.73 \mathrm{~m}^{2}$, BUN $14 \mathrm{mg} / \mathrm{dl}$, and hemoglobin $9.9 \mathrm{~g} / \mathrm{dl}$.

\title{
CORRECT ANSWER: D. Concomitant CT-RT treatment with gemcitabine has clinical outcomes similar to those of cisplatin but is not as nephrotoxic.
}

\author{
Continued from page 741
}

\section{Discussion}

CC represents a public health problem worldwide; it is the fourth most frequently diagnosed cancer and the fourth leading cause of cancer death in women, with 604,127 new cases per year and 341,831 deaths, according to the Globocan 2020 report. ${ }^{1}$ In the United States, approximately 14,500 new cases of invasive CC and 4300 cancerrelated deaths occur each year. CC is the third most common cancer diagnosis and cause of death among gynecologic cancers in the United States. ${ }^{2}$ In Mexico, it represents the second leading cause of cancer in women, with 9439 cases per year, and it is the second leading cause of death among women, with 4335 deaths. Additionally, in Mexico, more than $70 \%$ of the patients with CC are diagnosed with locally advanced disease (stage IB3 to IVA). ${ }^{1,3}$

Rates of obstructive uropathy and hydronephrosis in CC vary between $14 \%$ and $44.2 \%$. Without therapeutic intervention, obstructive uropathy leads to uremic syndrome and then to renal failure and death. ${ }^{4-6}$ Importantly, FIGO stage is among the main prognostic factors in CC, impacting mortality and overall survival (OS). In locally advanced stages IIIB, IIIC2, and IVA, clinical studies have demonstrated that unilateral and bilateral hydronephrosis are predictors of mortality and poor prognostic factors for survival. Compared with OS in patients without hydronephrosis (68 months), OS in patients with unilateral hydronephrosis is 27 months, and OS in patients with bilateral hydronephrosis is 12 months $(P=.0001){ }^{7,8}$ Rose et al conducted a retrospective analysis of 4 clinical trials that included patients in clinical stage IIIB stratified into 3 subgroups: (1) patients without hydronephrosis, (2) patients with hydronephrosis and urinary tract diversion (retrograde ureteral catheter or nephrostomy catheter), and (3) patients with hydronephrosis without urinary tract diversion. The authors showed that patients in group 1 had the most favorable outcomes, followed by patients in group 2, and patients in group 3 had the worst outcome. Results demonstrated that patients from groups 1, 2, and 3 had an OS of 70 months, 34 months, and 17 months, respectively $(P=.0078)$; their PFS was 48 months, 18 months, and 10 months, respectively, $(P=.019)$. Therefore, Rose et al concluded that hydronephrosis without urinary tract diversion had a negative effect on OS and PFS in this group of patients. ${ }^{6}$

Treatment options for ureteral obstruction are diverse, including the insertion of a retrograde ureteral stent or the performance of an antegrade percutaneous nephrostomy with or without a previous insertion of an antegrade stent. We thoroughly reviewed the management of ureteral obstruction stemming from both benign and 
malignant etiologies. Hsu et al have recommended antegrade percutaneous nephrostomy placement preferably in the following scenarios: when it is impossible to place a retrograde ureteral stent; in the presence of lower urinary tract infection, sepsis, anatomical deformity, or bleeding; when the ureteral compression is associated with malignant neoplasia; or the ureteral obstruction segment is more extensive than $3 \mathrm{~cm} .{ }^{9}$ Antegrade percutaneous nephrostomy is an effective method of diversion in patients with ureteral obstruction secondary to advanced malignant neoplasms involving the urinary bladder. Thus, percutaneous drainage remains an option and is almost always technically satisfactory. It is currently the recommended urinary diversion given its minimal morbidity and mortality. ${ }^{9}$ However, retrograde ureteral stenting is not feasible for more than $70 \%$ of patients with obstructive malignancy. For this reason, the initial attempt to place a retrograde ureteral stent on the patient was unsuccessful, and the derivation of the ureteral obstruction with bilateral nephrostomy catheters was necessary.

On the other hand, in locally advanced disease (stages IB3-IVA) in which renal, hematological, and liver functions are not compromised, we recommend option A, the standard treatment consisting of concomitant CT-RT weekly with cisplatin at a dosage of $40 \mathrm{mg} / \mathrm{m}^{2}$. In the 1990s, 5 randomized clinical trials jointly demonstrated that concomitant CT-RT with cisplatin led to better outcomes in local control of the disease. These reported a $30 \%$ to $50 \%$ reduction of recurrence and $6 \%$ to $15 \%$ improvement in OS compared with radiotherapy (RT) alone (treatment option B) or RT with hydroxyurea, which was the standard treatment at the time. Based on the evidence from the trials mentioned above, the National Cancer Institute of Canada issued an alert in 1999 that

\section{TABLE. Description of Patient's Serum Creatinine Levels and} GFR $^{a}$ Throughout Treatment

\begin{tabular}{l|c|c}
\multicolumn{1}{c|}{ Event } & $\begin{array}{c}\text { Creatinine } \\
\text { (mg/dL) }\end{array}$ & $\begin{array}{c}\text { GFR } \\
\text { (ml/min/1.73 m) })\end{array}$ \\
\hline Day $\mathbf{1}$ hospitalization & 5.03 & 15 \\
\hline Day 3 after nephrostomy & 3.25 & 29 \\
\hline Day 10 after nephrostomy & 1.85 & 50 \\
\hline CT-RT cycle 1 & 1.17 & 61 \\
\hline CT-RT cycle 2 & 1 & 64 \\
\hline CT-RT cycle 3 & 0.96 & 75 \\
\hline CT-RT cycle 4 & 0.84 & 85 \\
\hline CT-RT cycle 5 & 0.76 & 96 \\
\hline Treatment completion & 0.63 & 95 \\
\hline Response to treatment assessment & 0.66 & 9 \\
\hline
\end{tabular}

aGFR estimated by the Chronic Kidney Disease Epidemiology Collaboration formula. ${ }^{\mathrm{b}}$ Assessed 8 weeks after treatment completion.

CT-RT, chemoradiotherapy; GFR glomerular filtration rate.

changed the clinical treatment practice for locally advanced CC worldwide. ${ }^{10-14}$

A meta-analysis published in 2008 aimed to evaluate individual patient data to obtain a time-to-event analysis of OS, locoregional disease-free survival (DFS), and metastasis-free survival, among other outcomes. ${ }^{15}$ This meta-analysis confirmed the benefit of treatment option A, with an HR of 0.81 for OS and 0.78 for DFS. Authors observed a 5-year absolute improvement of $6 \%$ in OS and $8 \%$ in DFS; the benefit was more significant in FIGO stages I-II, up to $10 \%$, compared with $3 \%$ in FIGO stages III/IVA. ${ }^{15}$ More recently, in 2017, another meta-analysis confirmed the same findings, affirming the benefit of concomitant treatment with cisplatin. Hence, treatment option A remains the standard for locally advanced CC. ${ }^{16}$ However, deterioration of renal function limits the use of this drug since nephrotoxicity is the most common adverse effect associated with cisplatin. ${ }^{17}$

In this case, our patient would be categorized in the group with locally advanced disease (stages IIIB, IIIC2, and IVA) who present with bilateral hydronephrosis, acute kidney injury, and a frank contraindication for the use of cisplatin ( $14 \%$ to $44 \%$ of patients). International guidelines for dose adjustment have been created by the Royal College of Radiologists. They suggest a full dose of cisplatin when the GFR is greater than $50 \mathrm{ml} / \mathrm{min} / 1.73 \mathrm{~m}^{2}$, a proportional reduction of the dose if the GFR is between 30 and $50 \mathrm{ml} /$ $\mathrm{min} / 1.73 \mathrm{~m}^{2}$, and the omission of cisplatin if the GFR is lower than $30 \mathrm{ml} /$ $\min / 1.73 \mathrm{~m}^{2}{ }^{18}$ A stricter approach has been proposed by the British Columbia Cancer Agency, suggesting the administration of $75 \%$ of the standard dose of cisplatin if the GFR ranges from 45 to $59 \mathrm{ml} / \mathrm{min} / 1.73 \mathrm{~m}^{2}$ and the omission of the drug when the GFR is lower than 45 $\mathrm{ml} / \mathrm{min} / 1.73 \mathrm{~m}^{2} .{ }^{19}$ The National Comprehensive Cancer Network guideline states that cisplatin should not be used 
in patients with cancer who have a GFR lower than $60 \mathrm{ml} / \mathrm{min} / 1.73 \mathrm{~m}^{2}$ and suggests the use of carboplatin instead of cisplatin. ${ }^{20}$

For years, this group of patients with CC (stages IIIB, IIIC2, or IVA) with hydronephrosis have been treated with RT followed by brachytherapy (treatment option B), with a benefit in DFS at 5 years of $26 \%$ and 10 years of $21 \%,{ }^{21}$ even though the advantage and superiority of concomitant CTRT have been established. ${ }^{15}$ In 2018, a retrospective analysis compared cisplatin with RT (treatment option A) vs RT alone (treatment option B) in a geriatric population of patients with cervi-
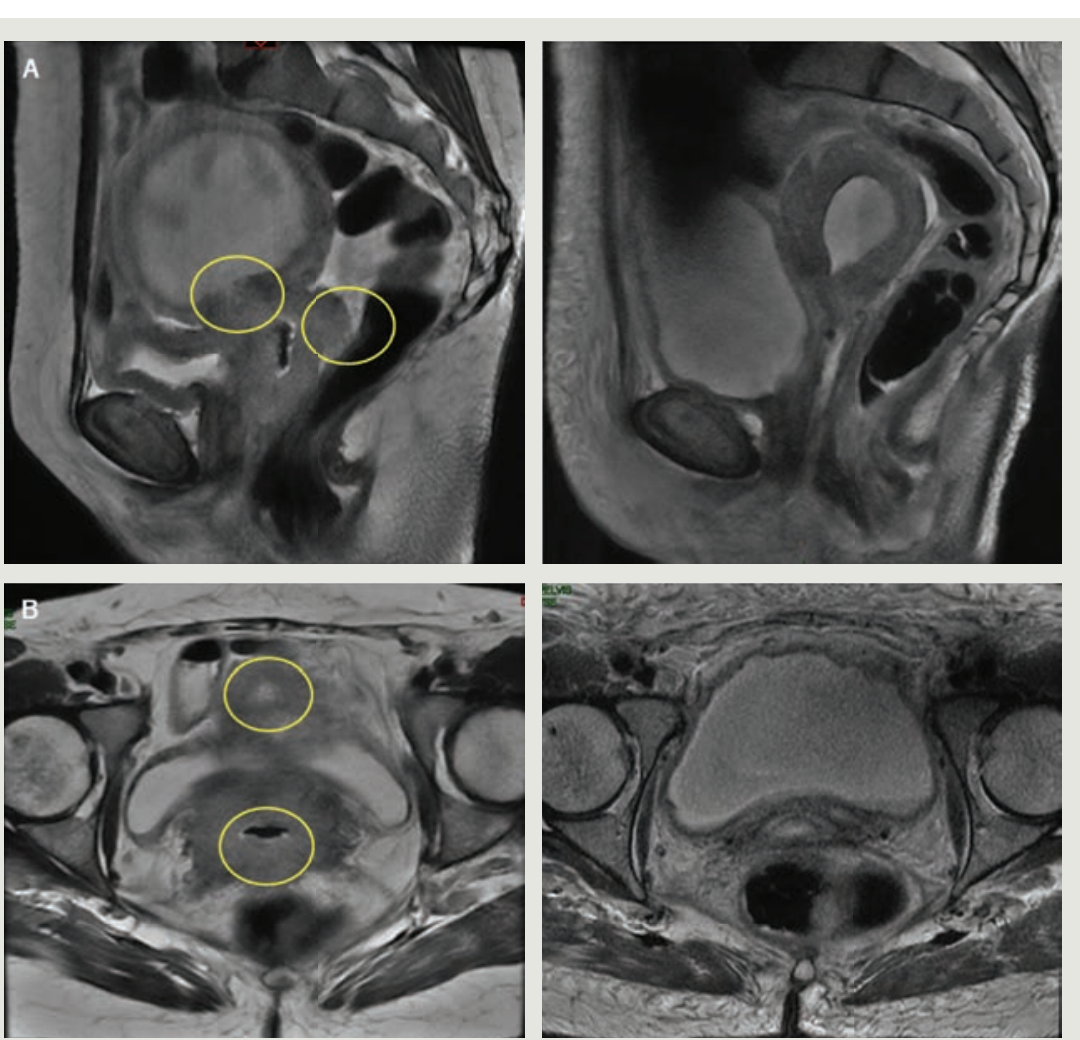

FIGURE 2. Response Assessment Imaging (A) Pelvic MRI image (sagittal section, without contrast). The image on the left corresponds to the baseline diagnosis; the image on the right corresponds to the response assessment 8 weeks after treatment completion. (B) Pelvic MRI image (axial section, without contrast). The image on the left corresponds to the baseline diagnosis; the image on the right corresponds to the response assessment 8 weeks after treatment completion.

cal cancer and comorbidities. Results showed that cancer-specific mortality at 5 years in the group treated with RT was $39 \%$ compared with $31 \%$ in the group treated with concomitant CT-RT; that is, patients treated only with RT, option B, had higher mortality compared with those who received complete treatment, option A. ${ }^{22}$ Therefore, treatment option B, applying only RT to our patient, would not have been a good selection.

On the other hand, treatment option C, best supportive care (palliative care), is an appropriate treatment option for patients with any of the following characteristics: metastatic or advanced dis- 
authors reported a complete clinical response rate of $89 \%$, with a tolerable and manageable toxicity profile. ${ }^{28}$ This evidence led to a pilot study carried out by Cetina et al that included 8 patients with clinical stage IIIB and 1 patient with stage IIIC2 CC restaged according to FIGO 2018. Patients had obstructive uropathy and renal failure, making the use of cisplatin contraindicated. Patients received treatment option $\mathrm{D}, 300 \mathrm{mg} /$ $\mathrm{m}^{2}$ of gemcitabine weekly concomitantly with RT followed by brachytherapy. The study showed that after treatment, all patients had restored creatinine levels. Furthermore, patients reached a complete clinical response rate of $89 \%$, with a tolerable and manageable toxicity profile at hematological and gastrointestinal levels. Essential to note is that the follow-up time was a mean of 11 months in this study. ${ }^{29}$

Kundu et al compared $150 \mathrm{mg} / \mathrm{m}^{2}$ of gemcitabine (option D) vs $40 \mathrm{mg} / \mathrm{m}^{2}$ of cisplatin (option A) in concomitance with RT followed by brachytherapy in a randomized phase 2 study conducted in patients with locally advanced CC who had adequate renal function. Results demonstrated that patients who received cisplatin and patients who received gemcitabine responded similarly $(55 \%$ vs $48.9 \%$, respectively; $P=.67)$. Even so, the study did not compare gemcitabine at a dose of $300 \mathrm{mg} / \mathrm{m}^{2}$, which has shown greater efficacy in locally advanced CC. ${ }^{30}$

Finally, treatment option E was neoadjuvant chemotherapy treatment. $\mathrm{Nu}-$ merous clinical trials have evaluated its efficacy in locally advanced CC with unfavorable results. Recently, Gupta et al demonstrated that concomitant CT-RT (option A) had a more significant benefit in DFS at 5 years compared with neoadjuvant chemotherapy with carboplatin and paclitaxel (option E) followed by surgery, with an absolute difference of $7.4 \%$ between groups. Subgroup analysis suggested that the main benefit of

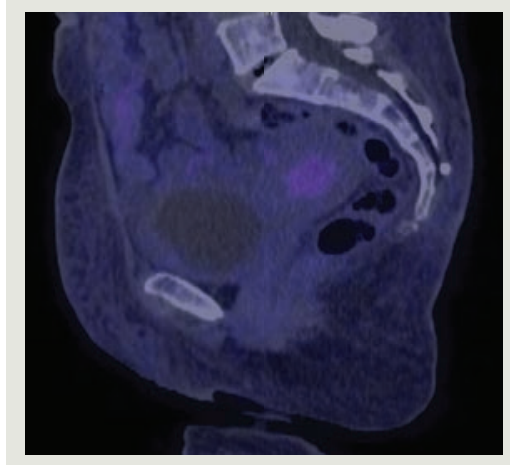

FIGURE 3. Response Assessment PET-CT Scan. The image reveals the absence of metabolic uptake.

concomitant CT-RT was in patients with stage IIB CC; the results showed no difference in OS between the groups. Clinical trials (interLACE, CIRCE) are currently evaluating the efficacy of neoadjuvant chemotherapy, followed by CT-RT with cisplatin, in locally advanced disease. ${ }^{31}$ No conclusive results are available yet, so option $\mathrm{E}$ is not a standard of treatment for patients with locally advanced CC.

\section{Case Outcome}

Based on the evidence presented in this work, we treated the patient with option D, concomitant CT-RT, with $300 \mathrm{mg} / \mathrm{m}^{2}$ of gemcitabine weekly. She received 3-dimensional conformal radiation therapy, which consisted of $50 \mathrm{~Gy}$ in 25 fractions to the pelvis plus a boost of $10 \mathrm{~Gy}$ in 5 fractions to parametria and obturator nodes. Her treatment concluded with high-dose brachytherapy in 4 applications of 6.5 Gy. The patient received 5 weekly chemotherapy cycles; the third cycle dose was reduced by $25 \%$ due to hematological toxicity (grade 2 neutropenia; grade 3 thrombocytopenia). She also presented gastrointestinal toxicity (grade 1 diarrhea; grade 2 abdominal pain) with adequate control. It is important to note that during the weekly chemotherapy cycles, the patient's GFR remained above
$50 \mathrm{ml} / \mathrm{min} / 1.73 \mathrm{~m}^{2}$ since the second application, as shown in the Table.

Eight weeks after the end of brachytherapy, a clinical response assessment demonstrated a complete response; however, both the PET-CT and MRI imaging revealed a partial response, as shown in Figures 2 and 3. In addition, the cervical cytology analysis revealed reactive cell changes associated with RT, and a vaginal dome biopsy evidenced extensive necrosis without viable cells in the sample. The patient is currently in a 24-month disease-free period and under surveillance by the medical oncology department.

DISCLOSURE: Authors declare they have no conflict of interest nor financial interest with the manufacturer of any product mentioned in this article.

\section{AUTHOR AFFILIATIONS:}

1Department of Clinical Research, Instituto Nacional de Cancerología, Mexico City, Mexico.

2Department of Medical Oncology, Instituto Nacional de Cancerología, Mexico City, Mexico.

3Integral Program for the Care of Locally Advanced and Metastatic Cervical Cancer (MICAELA), Instituto Nacional de Cancerología, Mexico City, Mexico.

${ }^{4}$ Investigadores por México, Consejo Nacional de Ciencia y Tecnología (CONACYT), Mexico City, Mexico.

${ }^{5}$ Integral Accessibility Program for the Care of Ovarian and Endometrial Cancer (COE), Instituto Nacional de Cancerología, Mexico City, Mexico. ${ }^{6}$ Department of Oncology, Hospital Médica Sur, Mexico City, Mexico.

\section{ABOUT THE SERIES EDITORS:}

Maria T. Bourlon, MD, is associate professor, head Urologic Oncology Clinic; national researcher, Instituto Nacional de Ciencias Médicas y Nutrición Salvador Zubirán, Mexico City, Mexico. She is also a member of ASCO's IDEA Working Group.

E. David Crawford, MD, is chairman, Prostate Conditions Education Council; editor in chief, Grand Rounds in Urology; and professor of Urology, University of California San Diego, La Jolla.

For references visit cancernetwork.com/Cetina_11.21 


\section{CABOMETYX + QPDIVO (cabozantinib) tablets \\ (nivolumab)}

\section{$1 \mathrm{~L}$ aRCC treatment that OFFERS A BALANCE OF DATA: superior OS, ${ }^{*}$ safety \& tolerability, patient-reported quality of life $e^{1-6 \ddagger}$}

*vs sunitinib in patients with previously untreated aRCC.

'The primary endpoint was PFS (16.6 months with CABOMETYX + OPDIVO vs 8.3 months with sunitinib; $\mathrm{HR}=0.51$; $95 \%$ Cl: 0.41-0.64; $P<0.0001$ ). The secondary endpoints included OS (40\% reduction in risk of death with CABOMETYX + OPDIVO vs Sunitinib; HR=0.60; $98.89 \%$ Cl: 0.40-0.89; $P=0.001$; median OS was not reached in either arm), ORR, and safety.,4

\section{INDICATIONS}

CABOMETYX ${ }^{\otimes}$ (cabozantinib), in combination with nivolumab, is indicated for the first-line treatment of patients with advanced renal cell carcinoma (RCC).

CABOMETYX is indicated for the treatment of patients with advanced RCC.

\section{IMPORTANT SAFETY INFORMATION WARNINGS AND PRECAUTIONS}

Hemorrhage: Severe and fatal hemorrhages occurred with CABOMETYX The incidence of Grade 3 to 5 hemorrhagic events was 5\% in CABOMETYX patients in RCC, HCC, and DTC studies. Discontinue CABOMETYX for Grade 3 or 4 hemorrhage and prior to surgery as recommended. Do not administer CABOMETYX to patients who have a recent history of hemorrhage, including hemoptysis, hematemesis, or melena.

Perforations and Fistulas: Fistulas, including fatal cases, occurred in $1 \%$ of CABOMETYX patients. Gastrointestinal (GI) perforations, including fatal cases, occurred in 1\% of CABOMETYX patients. Monitor patients for signs and symptoms of fistulas and perforations, including abscess and sepsis. Discontinue CABOMETYX in patients who experience a Grade 4 fistula or a Gl perforation.

Thrombotic Events: CABOMETYX increased the risk of thrombotic events. Venous thromboembolism occurred in 7\% (including 4\% pulmonary embolism) and arterial thromboembolism in $2 \%$ of CABOMETYX patients. Fatal thrombotic events occurred in CABOMETYX patients. Discontinue CABOMETYX in patients who develop an acute myocardial infarction or serious arterial or venous thromboembolic events that require medical intervention.

Hypertension and Hypertensive Crisis: CABOMETYX can cause hypertension, including hypertensive crisis. Hypertension was reported in $37 \%$ (16\% Grade 3 and <1\% Grade 4) of CABOMETYX patients. Do not initiate CABOMETYX in patients with uncontrolled hypertension. Monitor blood pressure regularly during CABOMETYX treatment. Withhold CABOMETYX for hypertension that is not adequately controlled with medical management; when controlled, resume at a reduced dose. Permanently discontinue CABOMETYX for severe hypertension that cannot be controlled with antihypertensive therapy or for hypertensive crisis.

Diarrhea: Diarrhea occurred in 62\% of CABOMETYX patients. Grade 3 diarrhea occurred in $10 \%$ of CABOMETYX patients. Monitor and manage patients using antidiarrheals as indicated. Withhold CABOMETYX until improvement to $\leq$ Grade 1, resume at a reduced dose.

Palmar-Plantar Erythrodysesthesia (PPE): PPE occurred in 45\% of CABOMETYX patients. Grade 3 PPE occurred in 13\% of CABOMETYX patients. Withhold CABOMETYX until improvement to Grade 1 and resume at a reduced dose for intolerable Grade 2 PPE or Grade 3 PPE.

Hepatotoxicity: CABOMETYX in combination with nivolumab can cause hepatic toxicity with higher frequencies of Grades 3 and 4 ALT and AST elevations compared to CABOMETYX alone.

Monitor liver enzymes before initiation of and periodically throughout treatment. Consider more frequent monitoring of liver enzymes than when the drugs are administered as single agents. For elevated liver enzymes, interrupt CABOMETYX and nivolumab and consider administering corticosteroids. With the combination of CABOMETYX and nivolumab, Grades 3 and 4 increased ALT or AST were seen in $11 \%$ of patients. ALT or AST $>3$ times ULN (Grade $\geq 2$ ) was reported in 83 patients, of whom 23 (28\%) received systemic corticosteroids; ALT or AST resolved to Grades 0-1 in 74 (89\%). Among the 44 patients with Grade $\geq 2$ increased ALT or AST who were rechallenged with either CABOMETYX ( $n=9)$ or nivolumab $(n=11)$ as a single agent or with both $(n=24)$, recurrence of Grade $\geq 2$ increased ALT or AST was observed in 2 patients receiving CABOMETYX, 2 patients receiving nivolumab, and 7 patients receiving both CABOMETYX and nivolumab. Withhold and resume at a reduced dose based on severity.

Adrenal Insufficiency: CABOMETYX in combination with nivolumab can cause primary or secondary adrenal insufficiency. For Grade 2 or higher adrenal insufficiency, initiate symptomatic treatment, including hormone replacement as clinically indicated. Withhold CABOMETYX and/or nivolumab and resume CABOMETYX at a reduced dose depending on severity.

Adrenal insufficiency occurred in 4.7\% (15/320) of patients with RCC who received CABOMETYX with nivolumab, including Grade 3 (2.2\%), and Grade 2 (1.9\%) adverse reactions. Adrenal insufficiency led to permanent discontinuation of CABOMETYX and nivolumab in $0.9 \%$ and withholding of CABOMETYX and nivolumab in $2.8 \%$ of patients with RCC.

Approximately $80 \%$ (12/15) of patients with adrenal insufficiency received hormone replacement therapy, including systemic corticosteroids. Adrenal insufficiency resolved in $27 \%(n=4)$ of the 15 patients. Of the 9 patients in whom CABOMETYX with nivolumab was withheld for adrenal insufficiency, 6 reinstated treatment after symptom improvement; of these, all $(n=6)$ received hormone replacement therapy and 2 had recurrence of adrenal insufficiency. Proteinuria: Proteinuria was observed in $8 \%$ of CABOMETYX patients. Monitor urine protein regularly during CABOMETYX treatment. For Grade 2 or 3 proteinuria, withhold CABOMETYX until improvement to $\leq$ Grade 1 proteinuria, resume CABOMETYX at a reduced dose. Discontinue CABOMETYX in patients who develop nephrotic syndrome.

Osteonecrosis of the Jaw (ONJ): ONJ occurred in $<1 \%$ of CABOMETYX patients. ONJ can manifest as jaw pain, osteomyelitis, osteitis, bone erosion, tooth or periodontal infection, toothache, gingival ulceration or erosion, persistent jaw pain, or slow healing of the mouth or jaw after dental surgery. Perform an oral examination prior to CABOMETYX initiation and periodically during treatment. Advise patients regarding good oral hygiene practices. Withhold CABOMETYX for at least 3 weeks prior to scheduled dental surgery or invasive dental procedures, if possible. Withhold CABOMETYX for 


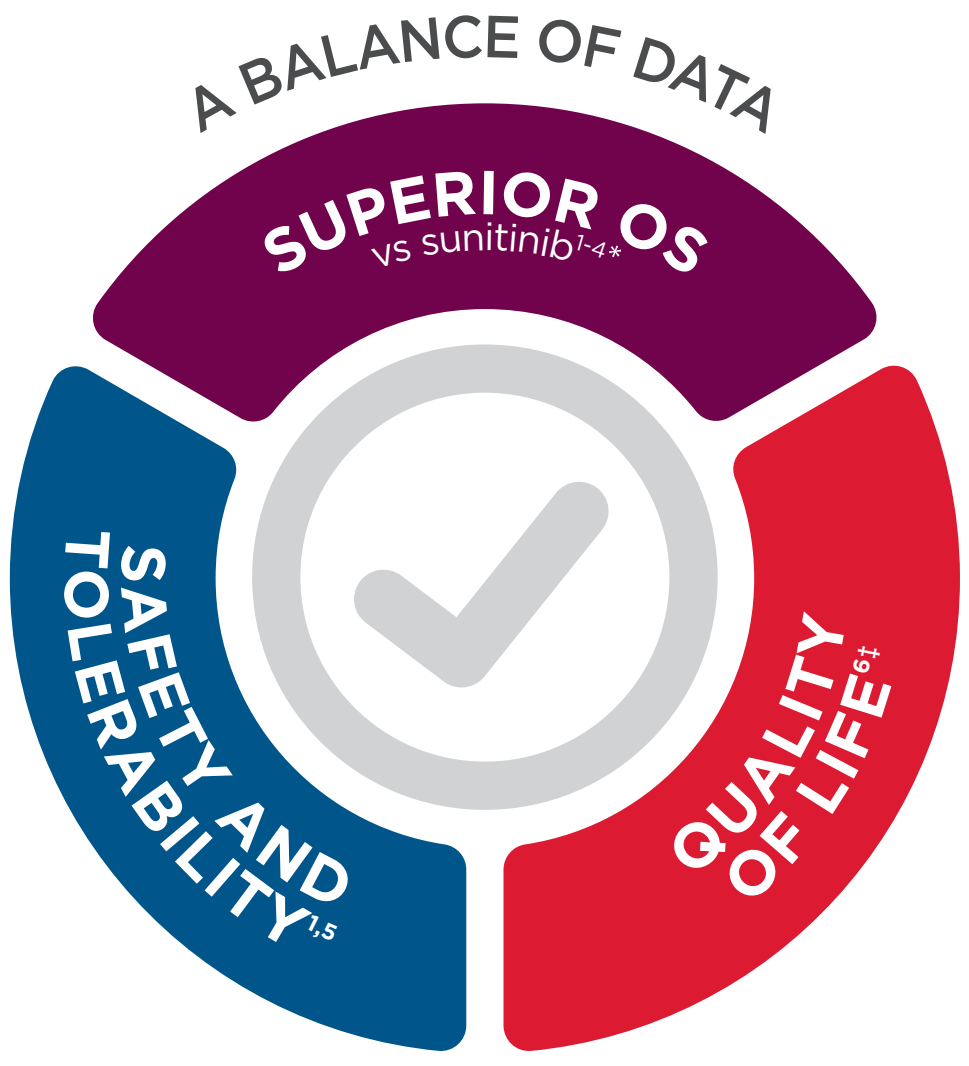

\section{CheckMate-9ER study design}

A randomized (1:1), open-label, Phase 3 trial vs sunitinib in 651 patients with previously untreated $\mathrm{ARCC}$ with a clear-cell component. The trial evaluated CABOMETYX $40 \mathrm{mg}$ (starting dose) $\mathrm{PO}$ once daily in combination with OPDIVO $240 \mathrm{mg}$ flat dose IV every 2 weeks vs sunitinib $50 \mathrm{mg}$ (starting dose) PO once daily for 4 weeks, followed by 2 weeks off, per cycle. The primary endpoint was PFS, and secondary endpoints included OS, ORR, and safety. ${ }^{13,4,47}$

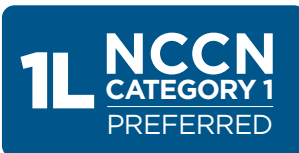

National

Comprehensive Cancer Network (NCCN ${ }^{\circledR}$ )

Cabozantinib (CABOMETYX) + nivolumab (OPDIVO) is a $1 \mathrm{~L}$ combination with a Category 1, preferred designation across all IMDC risk groups in clear-cell aRCC ${ }^{8}$

NCCN makes no warranties of any kind whatsoever regarding their content, use or application and disclaims any responsibility for their application or use in any way.

${ }^{\ddagger}$ Quality of life was evaluated as an exploratory endpoint using the FKSI-19 scale, and the clinical significance is unknown.,

development of ONJ until complete resolution, resume at a reduced dose. Impaired Wound Healing: Wound complications occurred with CABOMETYX. Withhold CABOMETYX for at least 3 weeks prior to elective surgery. Do not administer CABOMETYX for at least 2 weeks after major surgery and until adequate wound healing. The safety of resumption of CABOMETYX after resolution of wound healing complications has not been established.

Reversible Posterior Leukoencephalopathy Syndrome (RPLS): RPLS, a syndrome of subcortical vasogenic edema diagnosed by characteristic findings on MRI, can occur with CABOMETYX. Evaluate for RPLS in patients presenting with seizures, headache, visual disturbances, confusion, or altered mental function. Discontinue CABOMETYX in patients who develop RPLS.

Thyroid Dysfunction: Thyroid dysfunction, primarily hypothyroidism, has been observed with CABOMETYX. Based on the safety population, thyroid dysfunction occurred in $19 \%$ of patients treated with CABOMETYX, including Grade 3 in $0.4 \%$ of patients.

Patients should be assessed for signs of thyroid dysfunction prior to the initiation of CABOMETYX and monitored for signs and symptoms of thyroid dysfunction during CABOMETYX treatment. Thyroid function testing and management of dysfunction should be performed as clinically indicated.

Hypocalcemia: CABOMETYX can cause hypocalcemia. Based on the safety population, hypocalcemia occurred in 13\% of patients treated with CABOMETYX, including Grade 3 in $2 \%$ and Grade 4 in $1 \%$ of patients. Laboratory abnormality data were not collected in CABOSUN.

In COSMIC-311, hypocalcemia occurred in $36 \%$ of patients treated with CABOMETYX, including Grade 3 in $6 \%$ and Grade 4 in 3\% of patients.

Monitor blood calcium levels and replace calcium as necessary during treatment. Withhold and resume at reduced dose upon recovery or permanently discontinue CABOMETYX depending on severity.

Embryo-Fetal Toxicity: CABOMETYX can cause fetal harm. Advise pregnant women and females of reproductive potential of the potential risk to a fetus. Verify the pregnancy status of females of reproductive potential prior to initiating CABOMETYX and advise them to use effective contraception during treatment and for 4 months after the last dose.

\section{ADVERSE REACTIONS}

The most common ( $\geq 20 \%)$ adverse reactions are:

CABOMETYX as a single agent: diarrhea, fatigue, PPE, decreased appetite, hypertension, nausea, vomiting, weight decreased, constipation.

For additional safety information, please see Brief Summary of the Prescribing Information for CABOMETYX on adjacent pages. You are encouraged to report negative side effects of prescription drugs to the FDA. Visit www.FDA.gov/medwatch or call 1-800-FDA-1088.
CABOMETYX in combination with nivolumab: diarrhea, fatigue, hepatotoxicity, PPE, stomatitis, rash, hypertension, hypothyroidism musculoskeletal pain, decreased appetite, nausea, dysgeusia, abdominal pain, cough, and upper respiratory tract infection.

\section{DRUG INTERACTIONS}

Strong CYP3A4 Inhibitors: If coadministration with strong CYP3A4 inhibitors cannot be avoided, reduce the CABOMETYX dosage. Avoid grapefruit or grapefruit juice.

Strong CYP3A4 Inducers: If coadministration with strong CYP3A4 inducers cannot be avoided, increase the CABOMETYX dosage. Avoid St. John's wort.

\section{USE IN SPECIFIC POPULATIONS}

Lactation: Advise women not to breastfeed during CABOMETYX treatment and for 4 months after the final dose.

Hepatic Impairment: In patients with moderate hepatic impairment, reduce the CABOMETYX dosage. Avoid CABOMETYX in patients with severe hepatic impairment.

1L=first-line; aRCC=advanced renal cell carcinoma; $\mathrm{Cl}=$ confidence interval; FKSI-19= Functional Assessment of Cancer Therapy-Kidney Symptom Index 19; HR=hazard ratio; IMDC=International Metastatic RCC Database Consortium; IV=intravenous; ORR=overall response rate; $O S=$ overall survival; $P F S=$ progression-free survival; $P O=$ orally.

References: 1. CABOMETYX (cabozantinib) Prescribing Information. Exelixis, Inc, 2021. 2. Data on file. Topline 9ER. Exelixis, Inc. 3. Motzer RJ, Choueiri TK, Powles T, et al. Nivolumab plus cabozantinib versus sunitinib for advanced renal cell carcinoma: outcomes by sarcomatoid histology and updated trial results with extended follow-up of CheckMate 9ER. Poster presented at: Genitourinary Cancers Symposium; February 11-13, 2021 4. Choueiri TK, Powles T, Burotto M, et al; CheckMate 9ER Investigators. Nivolumab plus cabozantinib versus sunitinib for advanced renal-cell carcinoma. N Engl J Med. 2021;384(9):829-841.5. Choueiri TK, Powles T, Burotto M, et al. Nivolumab plus cabozantinib versus sunitinib in first-line treatment for advanced renal cell carcinoma: first results from the randomized phase 3 CheckMate 9ER trial. Presented at: European Society for Medical Oncology (ESMO) Virtual Congress 2020; September 19-21, 2020. Presentation 6960. 6. Choueiri TK, Powles T, Burotto M, et al; CheckMate 9ER Investigators. Nivolumab plus cabozantinib versus sunitinib for advanced renal-cell carcinoma [supplementary appendix]. N Engl J Med. 2021;384(9):829-841. 7. Apolo AB, Powles T, Burotto M, et al. Nivolumab plus cabozantinib versus sunitinib for advanced renal cell carcinoma: outcomes by baseline disease characteristics in the phase 3 CheckMate 9ER trial. Poster presented at: American Society of Clinical Oncology (ASCO) Annual Meeting; June 4-8, 2021. 8. Referenced with permission from the NCCN Clinical Practice Guidelines in Oncology (NCCN Guidelines ${ }^{\text {) }}$ for Kidney Cancer V1.2022. (c) National Comprehensive Cancer Network, Inc. 2021. All rights reserved. Accessed July 27, 2021. To view the most recent and complete version of the guideline, go online to NCCN.org. 
CABOMETYX ${ }^{\circledR}$ (cabozantinib) TABLETS

BRIEF SUMMARY OF PRESCRIBING INFORMATION.

PLEASE SEE THE CABOMETYX PACKAGE INSERT FOR FULL PRESCRIBING INFORMATION.

INITIAL U.S. APPROVAL: 2012

\section{INDICATIONS AND USAGE}

1.1 Renal Cell Carcinoma

CABOMETYX is indicated for the treatment of patients with advanced renal cell carcinoma (RCC).

CABOMETYX, in combination with nivolumab, is indicated for the first-line treatment of patients with advanced RCC

\subsection{Hepatocellular Carcinoma}

CABOMETYX is indicated for the treatment of patients with hepatocellular carcinoma ( $\mathrm{HCC}$ ) who have been previously treated with sorafenib.

1.3 Differentiated Thyroid Cancer

CABOMETYX is indicated for the treatment of adult and pediatric patients 12 years of age and older with locally advanced or metastatic differentiated thyroid cancer (DTC) that has progressed following prior VEGFR-targeted therapy and who are radioactive iodine-refractory or ineligible.

\section{CONTRAINDICATIONS}

None.

\section{WARNINGS AND PRECAUTIONS}

\subsection{Hemorrhage}

Severe and fatal hemorrhages occurred with CABOMETYX The incidence of Grade 3 to 5 hemorrhagic events was $5 \%$ in CABOMETYX patients in the RCC, HCC, and DTC studies. Discontinue CABOMETYX for Grade 3 or 4 hemorrhage and prior to surgery as recommended. Do not administer CABOMETYX to patients who have a recent history of hemorrhage, including hemoptysis, hematemesis, or melena.

\subsection{Perforations and Fistulas}

Fistulas, including fatal cases, occurred in $1 \%$ of CABOMETYXtreated patients. Gastrointestinal (GI) perforations, including fata cases, occurred in $1 \%$ of CABOMETYX-treated patients.

Monitor patients for signs and symptoms of fistulas and perforations, including abscess and sepsis. Discontinue CABOMETYX in patients who experience a Grade 4 fistula or a $\mathrm{GI}$ perforation.

\subsection{Thrombotic Events}

CABOMETYX increased the risk of thrombotic events. Venous thromboembolism occurred in 7\% (including 4\% pulmonary embolism) and arterial thromboembolism occurred in $2 \%$ of CABOMETYX-treated patients. Fatal thrombotic events occurred in CABOMETYX-treated patients.

Discontinue CABOMETYX in patients who develop an acute myocardial infarction or serious arterial or venous thromboembolic events that require medical intervention.

\subsection{Hypertension and Hypertensive Crisis}

CABOMETYX can cause hypertension, including hypertensive

crisis. Hypertension was reported in $37 \%(16 \%$ Grade 3 and $<1 \%$

Grade 4) of CABOMETYX-treated patients.

Do not initiate CABOMETYX in patients with uncontrolled hypertension. Monitor blood pressure regularly during

CABOMETYX treatment. Withhold CABOMETYX for hypertension that is not adequately controlled with medical management; when controlled, resume CABOMETYX at a reduced dose. Permanently discontinue CABOMETYX for severe hypertension that cannot be controlled with anti-hypertensive therapy or for hypertensive crisis.

\subsection{Diarrhea}

Diarrhea occurred in $62 \%$ of patients treated with CABOMETYX.

Grade 3 diarrhea occurred in $10 \%$ of patients treated with

CABOMETYX.

Monitor and manage patients using antidiarrheals as indicated. Withhold CABOMETYX until improvement to $\leq$ Grade 1, resume CABOMETYX at a reduced dose.

\subsection{Palmar-Plantar Erythrodysesthesia}

Palmar-plantar erythrodysesthesia (PPE) occurred in $45 \%$ of

patients treated with CABOMETYX. Grade 3 PPE occurred in $13 \%$ of patients treated with CABOMETYX.

Withhold CABOMETYX until improvement to Grade 1 and resume CABOMETYX at a reduced dose for intolerable Grade 2 PPE or Grade 3 PPE.

\subsection{Hepatotoxicity}

CABOMETYX in combination with nivolumab can cause hepatic toxicity with higher frequencies of Grades 3 and 4 ALT and AST elevations compared to CABOMETYX alone. Monitor liver enzymes before initiation of and periodically throughout treatment. Consider more frequent monitoring of liver enzymes as compared to when the drugs are administered as single agents. For elevated liver enzymes, interrupt CABOMETYX and nivolumab and consider administering corticosteroids.

With the combination of CABOMETYX and nivolumab, Grades 3 and 4 increased ALT or AST were seen in $11 \%$ of patients. ALT or AST > 3 times ULN (Grade $\geq 2$ ) was reported in 83 patients, of whom $23(28 \%)$ received systemic corticosteroids; ALT or AST resolved to Grades $0-1$ in 74 (89\%). Among the 44 patients with Grade $\geq 2$ increased ALT or AST who were rechallenged with either CABOMETYX $(n=9)$ or nivolumab $(n=11)$ as a single agent or with both ( $n=24)$, recurrence of Grade $\geq 2$ increased ALT or AST was observed in 2 patients receiving CABOMETYX, 2 patients receiving nivolumab, and 7 patients receiving both CABOMETYX and nivolumab. Withhold and resume at a reduced dose based on severity.

\subsection{Adrenal Insufficiency}

CABOMETYX in combination with nivolumab can cause primary or secondary adrenal insufficiency. For Grade 2 or higher adrenal insufficiency, initiate symptomatic treatment, including hormone replacement as clinically indicated. Withhold CABOMETYX and or nivolumab and resume CABOMETYX at a reduced dose depending on severity.

Adrenal insufficiency occurred in 4.7\% (15/320) of patients with RCC who received CABOMETYX with nivolumab, including Grade $3(2.2 \%)$, and Grade $2(1.9 \%)$ adverse reactions. Adrena insufficiency led to permanent discontinuation of CABOMETYX and nivolumab in $0.9 \%$ and withholding of CABOMETYX and nivolumab in $2.8 \%$ of patients with RCC.

Approximately $80 \%$ (12/15) of patients with adrenal insufficiency received hormone replacement therapy, including systemic corticosteroids. Adrenal insufficiency resolved in $27 \%(n=4)$ of the 15 patients. Of the 9 patients in whom CABOMETYX with nivolumab was withheld for adrenal insufficiency, 6 reinstated treatment after symptom improvement; of these, all $(n=6)$ received hormone replacement therapy and 2 had recurrence of adrenal insufficiency.

5.9 Proteinuria

Proteinuria was observed in $8 \%$ of patients receiving CABOMETYX.

Monitor urine protein regularly during CABOMETYX treatment. For Grade 2 or 3 proteinuria, withhold CABOMETYX until improvement to $\leq$ Grade 1 proteinuria, resume CABOMETYX at a reduced dose. Discontinue CABOMETYX in patients who develop nephrotic syndrome.

\subsection{Osteonecrosis of the Jaw}

Osteonecrosis of the jaw (ONJ) occurred in $<1 \%$ of patients reated with CABOMETYX.

ONJ can manifest as jaw pain, osteomyelitis, osteitis, bone erosion, tooth or periodontal infection, toothache, gingival ulceration or erosion, persistent jaw pain or slow healing of the mouth or jaw after dental surgery. Perform an oral examination prior to initiation of CABOMETYX and periodically during CABOMETYX. Advise patients regarding good oral hygiene practices. Withhold CABOMETYX for at least 3 weeks prior to scheduled dental surgery or invasive dental procedures, if possible. Withhold CABOMETYX for development of ONJ until complete resolution, resume at a reduced dose.

\subsection{Impaired Wound Healing}

Wound complications occurred with CABOMETYX. Withhold CABOMETYX for at least 3 weeks prior to elective surgery. Do no administer CABOMETYX for at least 2 weeks after major surgery and until adequate wound healing. The safety of resumption of CABOMETYX after resolution of wound healing complications has not been established.

5.12 Reversible Posterior Leukoencephalopathy Syndrome Reversible Posterior Leukoencephalopathy Syndrome (RPLS), a syndrome of subcortical vasogenic edema diagnosed by characteristic finding on MRI, can occur with CABOMETYX. Perform an evaluation for RPLS in any patient presenting with seizures, headache, visual disturbances, confusion or altered mental function. Discontinue CABOMETYX in patients who develop RPLS

\subsection{Thyroid Dysfunction}

Thyroid dysfunction, primarily hypothyroidism, has been observed with CABOMETYX. Based on the safety population, thyroid dysfunction occurred in $19 \%$ of patients treated with CABOMETYX, including Grade 3 in $0.4 \%$ of patients.

Patients should be assessed for signs of thyroid dysfunction prior to the initiation of CABOMETYX and monitored for signs and symptoms of thyroid dysfunction during CABOMETYX treatment. Thyroid function testing and management of dysfunction should be performed as clinically indicated.

\subsection{Hypocalcemia}

CABOMETYX can cause hypocalcemia. Based on the safety population, hypocalcemia occurred in $13 \%$ of patients treated with CABOMETYX, including Grade 3 in 2\% and Grade 4 in 1\% of patients. Laboratory abnormality data were not collected in CABOSUN

In COSMIC-311, hypocalcemia occurred in $36 \%$ of patients treated with CABOMETYX, including Grade 3 in $6 \%$ and Grade 4 in $3 \%$ of patients.

Monitor blood calcium levels and replace calcium as necessary during treatment. Withhold and resume at reduced dose upon recovery or permanently discontinue CABOMETYX depending on severity.
5.15 Embryo-Fetal Toxicity

Based on data from animal studies and its mechanism of action, CABOMETYX can cause fetal harm when administered to a pregnant woman. Cabozantinib administration to pregnant animals during organogenesis resulted in embryolethality at exposures below those occurring clinically at the recommended dose, and in increased incidences of skeletal variations in rats and visceral variations and malformations in rabbits.

Advise pregnant women of the potential risk to a fetus. Advise females of reproductive potential to use effective contraception during treatment with CABOMETYX and for 4 months after the last dose.

\section{ADVERSE REACTIONS}

The following clinically significant adverse reactions are discussed elsewhere in the labeling: Hemorrhage, Perforations and Fistulas,

Thrombotic Events, Hypertension and Hypertensive Crisis, Diarrhea, Palmar-plantar Erythrodysesthesia, Hepatotoxicity, Adrenal Insufficiency, Proteinuria, Osteonecrosis of the Jaw, Impaired Wound Healing, Reversible Posterior Leukoencephalopathy Syndrome, Thyroid Dysfunction and Hypocalcemia.

\subsection{Clinical Trial Experience}

The data described in the WARNINGS AND PRECAUTIONS section and below reflect exposure to CABOMETYX as a single agent in 409 patients with RCC enrolled in randomized, activecontrolled trials (CABOSUN, METEOR), 467 patients with HCC enrolled in a randomized, placebo-controlled trial (CELESTIAL), in 125 patients with DTC enrolled in a randomized, placebocontrolled trial (COSMIC-311), and in combination with nivolumab $240 \mathrm{mg} / \mathrm{m}^{2}$ every 2 weeks in 320 patients with RCC enrolled in a randomized, active-controlled trial (CHECKMATE-9ER).

Because clinical trials are conducted under widely varying conditions, adverse reaction rates observed in the clinical trials of a drug cannot be directly compared to rates in the clinical trials of another drug and may not reflect the rates observed in practice.

\section{Renal Cell Carcinoma}

METEOR

The safety of CABOMETYX was evaluated in METEOR, a randomized, open-label trial in which 331 patients with advanced renal cell carcinoma received CABOMETYX $60 \mathrm{mg}$ once daily and 322 patients received everolimus $10 \mathrm{mg}$ once daily until disease progression or unacceptable toxicity. Patients on both arms who had disease progression could continue treatment at the discretion of the investigator. The median duration of treatment was 7.6 months (range $0.3-20.5$ ) for patients receiving CABOMETYX and 4.4 months (range $0.21-18.9$ ) for patients receiving everolimus.

Adverse reactions which occurred in $\geq 25 \%$ of CABOMETYXtreated patients, in order of decreasing frequency, were: diarrhea, fatigue, nausea, decreased appetite, palmar-plantar erythrodysesthesia (PPE), hypertension, vomiting, weight decreased, and constipation. Grade 3-4 adverse reactions and laboratory abnormalities which occurred in $\geq 5 \%$ of patients were hypertension, diarrhea, fatigue, PPE, hyponatremia, hypophosphatemia, hypomagnesemia, lymphopenia, anemia hypokalemia, and increased GGT.

The dose was reduced in $60 \%$ of patients receiving CABOMETYX and in $24 \%$ of patients receiving everolimus. Twenty percent (20\%) of patients received CABOMETYX $20 \mathrm{mg}$ once daily as their lowest dose. The most frequent adverse reactions leading to dose reduction in patients treated with CABOMETYX were: diarrhea, PPE, fatigue, and hypertension. Adverse reactions leading to dose interruption occurred in $70 \%$ patients receiving CABOMETYX and in $59 \%$ patients receiving everolimus. Adverse reactions led to study treatment discontinuation in $10 \%$ of patients receiving CABOMETYX and in $10 \%$ of patients receiving everolimus. The most frequent adverse reactions leading to permanent discontinuation in patients treated with CABOMETYX were decreased appetite $(2 \%)$ and fatigue $(1 \%)$

Table 1. Adverse Reactions Occurring in $\geq 10 \%$ Patients Who Received CABOMETYX in METEOR

\begin{tabular}{|c|c|c|c|c|}
\hline \multirow{2}{*}{ Adverse Reaction } & \multicolumn{2}{|c|}{$\underset{(n=331)^{1}}{\text { CABOMETYX }}$} & \multicolumn{2}{|c|}{$\begin{array}{c}\text { Everolimus } \\
(n=322)\end{array}$} \\
\hline & $\begin{array}{c}\text { All } \\
\text { Grades }^{2}\end{array}$ & $\begin{array}{c}\text { Grade } \\
3-4\end{array}$ & \begin{tabular}{c|} 
All \\
Grades $^{2}$
\end{tabular} & $\underset{3-4}{\text { Grade }}$ \\
\hline & \multicolumn{4}{|c|}{ Percentage (\%) of Patients } \\
\hline \multicolumn{5}{|l|}{ Gastrointestinal } \\
\hline Diarrhea & 74 & 11 & 28 & 2 \\
\hline Nausea & 50 & 4 & 28 & $<1$ \\
\hline Vomiting & 32 & 2 & 14 & $<1$ \\
\hline Stomatitis & 22 & 2 & 24 & 2 \\
\hline Constipation & 25 & $<1$ & 19 & $<1$ \\
\hline Abdominal pain ${ }^{3}$ & 23 & 4 & 13 & 2 \\
\hline Dyspepsia & 12 & $<1$ & 5 & 0 \\
\hline \multicolumn{5}{|l|}{ General } \\
\hline Fatigue & 56 & 9 & 47 & 7 \\
\hline Mucosal inflammation & 19 & $<1$ & 23 & 3 \\
\hline Asthenia & 19 & 4 & 16 & 2 \\
\hline \multicolumn{5}{|l|}{ Metabolism and Nutrition } \\
\hline Decreased appetite & 46 & 3 & 34 & $<1$ \\
\hline
\end{tabular}




\begin{tabular}{|c|c|c|c|c|}
\hline \multirow{2}{*}{ Adverse Reaction } & \multicolumn{2}{|c|}{$\begin{array}{l}\text { CABOMETYX } \\
(\mathrm{n}=331)^{1}\end{array}$} & \multicolumn{2}{|c|}{$\underset{(n=322)}{\text { Everolimus }}$} \\
\hline & \begin{tabular}{|c|} 
All \\
Grades
\end{tabular} & $\underset{3-4}{\text { Grade }}$ & \begin{tabular}{|c|} 
All \\
Grades
\end{tabular} & $\begin{array}{c}\text { Grade } \\
3-4\end{array}$ \\
\hline & \multicolumn{4}{|c|}{ Percentage $(\%)$ of Patients } \\
\hline \multicolumn{5}{|l|}{$\begin{array}{l}\text { Skin and Subcutaneous } \\
\text { Tissue }\end{array}$} \\
\hline $\begin{array}{l}\text { Palmar-plantar } \\
\text { erythrodysesthesia }\end{array}$ & 42 & 8 & 6 & $<1$ \\
\hline Rash $^{4}$ & 23 & $<1$ & 43 & $<1$ \\
\hline Dry skin & 11 & 0 & 10 & 0 \\
\hline \multicolumn{5}{|l|}{ Vascular } \\
\hline Hypertension $^{5}$ & 39 & 16 & 8 & 3 \\
\hline \multicolumn{5}{|l|}{ Investigations } \\
\hline Weight decreased & 31 & 2 & 12 & 0 \\
\hline \multicolumn{5}{|l|}{ Nervous System } \\
\hline Dysgeusia & 24 & 0 & 9 & 0 \\
\hline Headache & 11 & $<1$ & 12 & $<1$ \\
\hline Dizziness & 11 & 0 & 7 & 0 \\
\hline \multicolumn{5}{|l|}{ Endocrine } \\
\hline Hypothyroidism & 21 & 0 & $<1$ & $<1$ \\
\hline \multicolumn{5}{|l|}{$\begin{array}{l}\text { Respiratory, Thoracic, } \\
\text { and Mediastinal }\end{array}$} \\
\hline Dysphonia & 20 & $<1$ & 4 & 0 \\
\hline Dyspnea & 19 & 3 & 29 & 4 \\
\hline Cough & 18 & $<1$ & 33 & $<1$ \\
\hline \multicolumn{5}{|l|}{ Blood and Lymphatic } \\
\hline Anemia & 17 & 5 & 38 & 16 \\
\hline \multicolumn{5}{|l|}{$\begin{array}{l}\text { Musculoskeletal and } \\
\text { Connective Tissue }\end{array}$} \\
\hline Pain in extremity & 14 & 1 & 8 & $<1$ \\
\hline Muscle spasms & 13 & 0 & 5 & 0 \\
\hline Arthralgia & 11 & $<1$ & 14 & 1 \\
\hline \multicolumn{5}{|l|}{ Renal and Urinary } \\
\hline Proteinuria & 12 & 2 & 9 & $<1$ \\
\hline \multicolumn{5}{|c|}{ 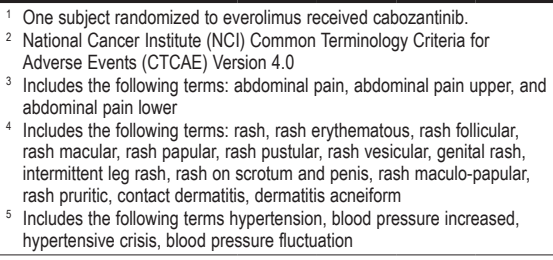 } \\
\hline
\end{tabular}

Other clinically important adverse reactions (all grades) that were reported in $<10 \%$ of patients treated with CABOMETYX included: wound complications $(2 \%)$, convulsion $(<1 \%)$, pancreatitis $(<1 \%)$, osteonecrosis of the jaw $(<1 \%)$, and hepatitis cholestatic $(<1 \%)$.

Table 2. Laboratory Abnormalities Occurring in $\geq 25 \%$ Patients Who Received CABOMETYX in METEOR

\begin{tabular}{|c|c|c|c|c|}
\hline \multirow{2}{*}{ Laboratory Abnormality } & \multicolumn{2}{|c|}{$\begin{array}{c}\text { CABOMETYX } \\
(\mathrm{n}=331)\end{array}$} & \multicolumn{2}{|c|}{$\begin{array}{c}\text { Everolimus } \\
(\mathrm{n}=322)\end{array}$} \\
\hline & $\begin{array}{c}\text { All } \\
\text { Grades }\end{array}$ & $\begin{array}{c}\text { Grade } \\
3-4\end{array}$ & $\begin{array}{c}\text { All } \\
\text { Grades }\end{array}$ & $\begin{array}{c}\text { Grade } \\
3-4\end{array}$ \\
\hline & \multicolumn{4}{|c|}{ Percentage $(\%)$ of Patients } \\
\hline Chemistry & & & & \\
\hline Increased AST & 74 & 3 & 40 & $<1$ \\
\hline Increased ALT & 68 & 3 & 32 & $<1$ \\
\hline Increased creatinine & 58 & $<1$ & 71 & 0 \\
\hline Increased triglycerides & 53 & 4 & 73 & 13 \\
\hline Hypophosphatemia & 48 & 8 & 36 & 5 \\
\hline Hyperglycemia & 37 & 2 & 59 & 8 \\
\hline Hypoalbuminemia & 36 & 2 & 28 & $<1$ \\
\hline Increased ALP & 35 & 2 & 29 & 1 \\
\hline Hypomagnesemia & 31 & 7 & 4 & $<1$ \\
\hline Hyponatremia & 30 & 8 & 26 & 6 \\
\hline Increased GGT & 27 & 5 & 43 & 9 \\
\hline \multicolumn{5}{|l|}{ Hematology } \\
\hline Leukopenia & 35 & $<1$ & 31 & $<1$ \\
\hline Neutropenia & 31 & 2 & 17 & $<1$ \\
\hline Anemia $^{1}$ & 31 & 4 & 71 & 17 \\
\hline Lymphopenia & 25 & 7 & 39 & 12 \\
\hline & 25 & $<1$ & 27 & $<1$ \\
\hline \multicolumn{5}{|c|}{$\begin{array}{l}\text { ALP, alkaline phosphhatase; ALT, alanine aminotransferase; } A S T \text {, aspartate } \\
\text { aminotransferase; } G G T, \text { gammm glutamyl transferase. } \\
\text { NCI CTCAE, Version } 4.0 \\
1 \text { Based on laboratory abnormalities }\end{array}$} \\
\hline
\end{tabular}

\section{CABOSUN}

The safety of CABOMETYX was evaluated in CABOSUN, a randomized, open-label trial in patients with advanced renal cell carcinoma, in which 78 patients received CABOMETYX $60 \mathrm{mg}$ once daily and 72 patients received sunitinib $50 \mathrm{mg}$ once daily ( 4 weeks on treatment followed by 2 weeks off), until disease progression or unacceptable toxicity. The median duration of treatment was 6.5 months (range $0.2-28.7$ ) for patients receiving
CABOMETYX and 3.1 months (range $0.2-25.5$ ) for patients receiving sunitinib.

Within 30 days of treatment, there were 4 deaths in patients treated with CABOMETYX and 6 deaths in patients treated with sunitinib. Of the 4 patients treated with CABOMETYX, 2 patients died due to gastrointestinal perforation, 1 patient had acute renal failure, and 1 patient died due to clinical deterioration. All Grade 3-4 adverse reactions were collected in the entire safety population. The most frequent Grade $3-4$ adverse reactions $(\geq 5 \%)$ in patients treated with CABOMETYX were hypertension, diarrhea, hyponatremia, hypophosphatemia, PPE, fatigue, increased ALT, decreased appetite, stomatitis, pain, hypotension, and syncope. The median average daily dose was $50.3 \mathrm{mg}$ for CABOMETYX and $44.7 \mathrm{mg}$ for sunitinib (excluding scheduled sunitinib nondosing days). The dose was reduced in $46 \%$ of patients receiving CABOMETYX and in $35 \%$ of patients receiving sunitinib. The dose was held in $73 \%$ of patients receiving CABOMETYX and in $71 \%$ of patients receiving sunitinib. Based on patient disposition, 21\% of patients receiving CABOMETYX and $22 \%$ of patients receiving sunitinib discontinued due to an adverse reaction.

Table 3. Grade 3-4 Adverse Reactions Occurring in $\geq 1 \%$ Patients Who Received CABOMETYX in CABOSUN

\begin{tabular}{|c|c|c|}
\hline \multirow[t]{2}{*}{ Adverse Reaction } & $\begin{array}{l}\text { CABOMETYX } \\
(n=78)\end{array}$ & $\begin{array}{l}\text { Sunitinib } \\
(\mathrm{n}=72)\end{array}$ \\
\hline & Grade $3-4^{1}$ & Grade 3-4 \\
\hline & \multicolumn{2}{|c|}{ Percentage $(\%)$ of Patients } \\
\hline $\begin{array}{l}\text { Patients with any Grade } \\
\text { 3-4 Adverse Reaction }\end{array}$ & 68 & 65 \\
\hline \multicolumn{3}{|l|}{ Gastrointestinal } \\
\hline Diarrhea & 10 & 11 \\
\hline Stomatitis & 5 & 6 \\
\hline Nausea & 3 & 4 \\
\hline Vomiting & 1 & 3 \\
\hline Constipation & 1 & 0 \\
\hline \multicolumn{3}{|l|}{ General } \\
\hline Fatigue & 6 & 17 \\
\hline Pain & 5 & 0 \\
\hline \multicolumn{3}{|l|}{ Metabolism and Nutrition } \\
\hline Hyponatremia $^{2}$ & 9 & 8 \\
\hline Hypophosphatemia $^{2}$ & 9 & 7 \\
\hline Decreased appetite & 5 & 1 \\
\hline Dehydration & 4 & 1 \\
\hline Hypocalcemia $^{2}$ & 3 & 0 \\
\hline Hypomagnesemia $^{2}$ & 3 & 0 \\
\hline Hyperkalemia $^{2}$ & 1 & 3 \\
\hline \multicolumn{3}{|l|}{$\begin{array}{l}\text { Skin and Subcutaneous } \\
\text { Tissue }\end{array}$} \\
\hline $\begin{array}{l}\text { Palmar-plantar } \\
\text { erythrodysesthesia }\end{array}$ & 8 & 4 \\
\hline Skin ulcer & 3 & 0 \\
\hline \multicolumn{3}{|l|}{ Vascular } \\
\hline Hypertension $^{3}$ & 28 & 21 \\
\hline Hypotension & 5 & 1 \\
\hline Angiopathy & 1 & 1 \\
\hline \multicolumn{3}{|l|}{ Investigations } \\
\hline Increased $\mathrm{ALT}^{2}$ & 5 & 0 \\
\hline Weight decreased & 4 & 0 \\
\hline Increased $\mathrm{AST}^{2}$ & 3 & 3 \\
\hline $\begin{array}{l}\text { Increased blood } \\
\text { creatinine }^{2}\end{array}$ & 3 & 3 \\
\hline Lymphopenia $^{2}$ & 1 & 6 \\
\hline Thrombocytopenia ${ }^{2}$ & 1 & 11 \\
\hline \multicolumn{3}{|l|}{ Nervous System } \\
\hline Syncope & 5 & 0 \\
\hline \multicolumn{3}{|l|}{$\begin{array}{l}\text { Respiratory, Thoracic, and } \\
\text { Mediastinal }\end{array}$} \\
\hline Dyspnea & 1 & 6 \\
\hline Dysphonia & 1 & 0 \\
\hline \multicolumn{3}{|l|}{ Blood and Lymphatic } \\
\hline Anemia & 1 & 3 \\
\hline \multicolumn{3}{|l|}{ Psychiatric } \\
\hline Depression & 4 & 0 \\
\hline Confusional state & 1 & 1 \\
\hline \multicolumn{3}{|l|}{ Infections } \\
\hline Lung infection & 4 & 0 \\
\hline \multicolumn{3}{|l|}{$\begin{array}{l}\text { Musculoskeletal and } \\
\text { Connective Tissue }\end{array}$} \\
\hline Back pain & 4 & 0 \\
\hline Bone pain & 3 & 1 \\
\hline Pain in extremity & 3 & 0 \\
\hline Arthralgia & 1 & 0 \\
\hline
\end{tabular}

\begin{tabular}{|c|c|c|}
\hline \multirow[t]{2}{*}{ Adverse Reaction } & $\begin{array}{l}\text { CABOMETYX } \\
(n=78)\end{array}$ & $\begin{array}{c}\text { Sunitinib } \\
(\mathrm{n}=72)\end{array}$ \\
\hline & Grade $3-4^{1}$ & Grade $3-4^{1}$ \\
\hline & \multicolumn{2}{|c|}{ Percentage $(\%)$ of Patients } \\
\hline \multicolumn{3}{|l|}{ Renal and Urinary } \\
\hline Renal failure acute & 4 & 1 \\
\hline Proteinuria & 3 & 1 \\
\hline \multicolumn{3}{|c|}{$\begin{array}{l}\text { ALT, alanine aminotransferase; AST, aspartate aminotransferase } \\
\text { }{ }^{2} \mathrm{NCI} \text { CTCAE Version } 4.0 \\
{ }^{2} \text { Laboratory abnormalities are reported as adverse reactions and not } \\
\text { based on shifts in laboratory values } \\
{ }^{3} \text { Includes the following term: hypertension }\end{array}$} \\
\hline
\end{tabular}

CHECKMATE-9ER

The safety of CABOMETYX with nivolumab was evaluated in CHECKMATE-9ER, a randomized, open-label study in patients with previously untreated advanced RCC. Patients received CABOMETYX $40 \mathrm{mg}$ orally once daily with nivolumab $240 \mathrm{mg}$ over 30 minutes every 2 weeks $(n=320)$ or sunitinib $50 \mathrm{mg}$ daily, administered orally for 4 weeks on treatment followed by 2 weeks off $(n=320)$. CABOMETYX could be interrupted or reduced to $20 \mathrm{mg}$ daily or $20 \mathrm{mg}$ every other day. The median duration of treatment was 14 months (range: 0.2 to 27 months) in CABOMETYX and nivolumab-treated patients. In this trial, $82 \%$ of patients in the CABOMETYX and nivolumab arm were exposed to treatment for $>6$ months and $60 \%$ of patients were exposed to treatment for $>1$ year.

Serious adverse reactions occurred in $48 \%$ of patients receiving CABOMETYX and nivolumab.

The most frequent $(\geq 2 \%)$ serious adverse reactions were diarrhea, pneumonia, pneumonitis, pulmonary embolism, urinary tract infection, and hyponatremia. Fatal intestinal perforations occurred in $3(0.9 \%)$ patients.

Adverse reactions leading to discontinuation of either CABOMETYX or nivolumab occurred in $20 \%$ of patients: $8 \%$ CABOMETYX only, $7 \%$ nivolumab only, and $6 \%$ both drugs due to the same adverse reaction at the same time. Adverse reactions leading to dose interruption or reduction of either CABOMETYX or nivolumab occurred in $83 \%$ of patients: $46 \%$ CABOMETYX only, $3 \%$ nivolumab only, and $21 \%$ both drugs due to the same adverse reaction at the same time, and $6 \%$ both drugs sequentially.

The most common adverse reactions reported in $\geq 20 \%$ of patients treated with CABOMETYX and nivolumab were diarrhea, fatigue, hepatotoxicity, PPE, stomatitis, rash, hypertension, hypothyroidism, musculoskeletal pain, decreased appetite, nausea, dysgeusia, abdominal pain, cough, and upper respiratory tract infection.

Table 4. Adverse Reactions in $\geq 15 \%$ of Patients receiving CABOMETYX and Nivolumab-CHECKMATE-9ER

\begin{tabular}{|c|c|c|c|c|}
\hline \multirow[t]{2}{*}{ Adverse Reaction } & \multicolumn{2}{|c|}{$\begin{array}{l}\text { CABOMETYX } \\
\text { and Nivolumab } \\
(\mathrm{n}=320)\end{array}$} & \multicolumn{2}{|c|}{$\begin{array}{c}\text { Sunitinib } \\
(n=320)\end{array}$} \\
\hline & $\begin{array}{c}\text { Grades } \\
1-4\end{array}$ & $\begin{array}{c}\text { Grades } \\
3-4\end{array}$ & $\begin{array}{c}\text { Grades } \\
1-4\end{array}$ & $\begin{array}{c}\text { Grades } \\
3-4\end{array}$ \\
\hline & \multicolumn{4}{|c|}{ Percentage (\%) of Patients } \\
\hline \multicolumn{5}{|l|}{ Gastrointestinal } \\
\hline Diarrhea & 64 & 7 & 47 & 4.4 \\
\hline Nausea & 27 & 0.6 & 31 & 0.3 \\
\hline Abdominal Pain $^{\mathrm{a}}$ & 22 & 1.9 & 15 & 0.3 \\
\hline Vomiting & 17 & 1.9 & 21 & 0.3 \\
\hline Dyspepsiab $^{b}$ & 15 & 0 & 22 & 0.3 \\
\hline \multicolumn{5}{|l|}{ General } \\
\hline Fatigue $^{c}$ & 51 & 8 & 50 & 8 \\
\hline \multicolumn{5}{|l|}{ Hepatobiliary } \\
\hline Hepatotoxicity $^{d}$ & 44 & 11 & 26 & 5 \\
\hline \multicolumn{5}{|c|}{ Skin and Subcutaneous Tissue } \\
\hline $\begin{array}{l}\text { Palmar-plantar } \\
\text { erythrodysesthesia }\end{array}$ & 40 & 8 & 41 & 8 \\
\hline Stomatitis ${ }^{e}$ & 37 & 3.4 & 46 & 4.4 \\
\hline $\operatorname{Rash}^{f}$ & 36 & 3.1 & 14 & 0 \\
\hline Pruritis & 19 & 0.3 & 4.4 & 0 \\
\hline \multicolumn{5}{|l|}{ Vascular } \\
\hline Hypertensiong $^{9}$ & 36 & 13 & 39 & 14 \\
\hline \multicolumn{5}{|l|}{ Endocrine } \\
\hline Hypothyroidism $^{\mathrm{h}}$ & 34 & 0.3 & 30 & 0.3 \\
\hline \multicolumn{5}{|c|}{ Musculoskeletal and Connective Tissue } \\
\hline Musculoskeletal paini & 33 & 3.8 & 29 & 3.1 \\
\hline Arthralgia & 18 & 0.3 & 9 & 0.3 \\
\hline \multicolumn{5}{|c|}{ Metabolism and Nutrition } \\
\hline Decreased appetite & 28 & 1.9 & 20 & 1.3 \\
\hline \multicolumn{5}{|c|}{ Nervous System Disorders } \\
\hline Dysgeusia & 24 & 0 & 22 & 0 \\
\hline Headache & 16 & 0 & 12 & 0.6 \\
\hline \multicolumn{5}{|c|}{ Respiratory, Thoracic, and Mediastinal } \\
\hline Coughi & 20 & 0.3 & 17 & 0 \\
\hline Dysphonia & 17 & 0.3 & 3.4 & 0 \\
\hline
\end{tabular}




\begin{tabular}{|l|c|c|c|c|}
\hline \multirow{2}{*}{ Adverse Reaction } & $\begin{array}{c}\text { CABOMETYX } \\
\text { and Nivolumab } \\
(\mathrm{n}=320)\end{array}$ & \multicolumn{2}{c|}{$\begin{array}{c}\text { Sunitinib } \\
(\mathrm{n}=320)\end{array}$} \\
\cline { 2 - 5 } & $\begin{array}{c}\text { Grades } \\
1-4\end{array}$ & $\begin{array}{c}\text { Grades } \\
3-4\end{array}$ & $\begin{array}{c}\text { Grades } \\
1-4\end{array}$ & $\begin{array}{c}\text { Grades } \\
3-4\end{array}$ \\
\hline \multicolumn{4}{|c|}{ Percentage (\%) of Patients } \\
\hline Infections and Infestations \\
\hline $\begin{array}{l}\text { Upper respiratory tract } \\
\text { infection }\end{array}$ & 20 & 0.3 & 8 & 0.3 \\
\hline
\end{tabular}

Toxicity was graded per NCI CTCAE $v 4$.

a Includes abdominal discomfort, abdominal pain lower, abdominal pain upper.

b Includes gastroesophageal reflux disease.

c Includes asthenia.

d Includes hepatotoxicity, ALT increased, AST increased, blood alkaline phosphatase increased, gamma-glutamyl transferase increased phosphatase increased, gamma-glutamyl transferase increased,
autoimmune hepatitis, blood bilirubin increased, drug induced liver injury, autoimmune hepatitis, blood bilirubin increased, drug induced liver injury,
hepatic enzyme increased, hepatitis, hyperbilirubinemia, liver function test increased, liver function test abnormal, transaminases increased, test increased,

- Includes mucosal inflammation, aphthous ulcer, mouth ulceration.

Includes dermatitis, dermatitis acneiform, dermatitis bullous, exfoliative

rash, rash erythematous, rash follicular, rash macular, rash maculo-

papular, rash papular, rash pruritic.

9 Includes blood pressure increased, blood pressure systolic increased.

${ }^{\mathrm{h}}$ Includes primary hypothyroidism.

Includes back pain, bone pain, musculoskeletal chest pain,

musculoskeletal discomfort, myalgia, neck pain, pain in extremity,

spinal pain.

Includes productive cough.

k Includes nasopharyngitis, pharyngitis, rhinitis

Table 5. Laboratory Values Worsening from Baseline Occurring in $>20 \%$ of Patients receiving CABOMETYX and Nivolumab-CHECKMATE-9ER

\begin{tabular}{|c|c|c|c|c|}
\hline \multirow{2}{*}{$\begin{array}{l}\text { Laboratory } \\
\text { Abnormality }\end{array}$} & \multicolumn{2}{|c|}{$\begin{array}{l}\text { CABOMETYX and } \\
\text { Nivolumab }\end{array}$} & \multicolumn{2}{|c|}{ Sunitinib } \\
\hline & $\begin{array}{c}\text { Grades } \\
1-4 \\
\end{array}$ & $\begin{array}{c}\text { Grades } \\
3-4 \\
\end{array}$ & $\begin{array}{c}\text { Grades } \\
1-4 \\
\end{array}$ & $\begin{array}{c}\text { Grades } \\
1-4\end{array}$ \\
\hline & \multicolumn{4}{|c|}{ Percentage $(\%)$ of Patients } \\
\hline \multicolumn{5}{|l|}{ Chemistry } \\
\hline Increased ALT & 79 & 9.8 & 39 & 3.5 \\
\hline Increased AST & 77 & 7.9 & 57 & 2.6 \\
\hline Hypophosphatemia & 69 & 28 & 48 & 10 \\
\hline Hypocalcemia & 54 & 1.9 & 24 & 0.6 \\
\hline Hypomagnesemia & 47 & 1.3 & 25 & 0.3 \\
\hline Hyperglycemia & 44 & 3.5 & 44 & 1.7 \\
\hline Hyponatremia & 43 & 11 & 36 & 12 \\
\hline Increased lipase & 41 & 14 & 38 & 13 \\
\hline Increased amylase & 41 & 10 & 28 & 6 \\
\hline $\begin{array}{l}\text { Increased alkaline } \\
\text { phosphatase }\end{array}$ & 41 & 2.8 & 37 & 1.6 \\
\hline Increased creatinine & 39 & 1.3 & 42 & 0.6 \\
\hline Hyperkalemia & 35 & 4.7 & 27 & 1 \\
\hline Hypoglycemia & 26 & 0.8 & 14 & 0.4 \\
\hline \multicolumn{5}{|l|}{ Hematology } \\
\hline Lymphopenia & 42 & 6.6 & 45 & 10 \\
\hline Thrombocytopenia & 41 & 0.3 & 70 & 9.7 \\
\hline Anemia & 37 & 2.5 & 61 & 4.8 \\
\hline Leukopenia & 37 & 0.3 & 66 & 5.1 \\
\hline Neutropenia & 35 & 3.2 & 67 & 12 \\
\hline
\end{tabular}

a Each test incidence is based on the number of patients who had both baseline and at least one on-study laboratory measurement available: CABOMETYX and nivolumab group (range: 170 to 317 patients) and sunitinib group (range: 173 to 311 patients).

\section{Hepatocellular Carcinoma}

The safety of CABOMETYX was evaluated in CELESTIAL, a randomized, double-blind, placebo-controlled trial in which 704 patients with advanced hepatocellular carcinoma were randomized to receive CABOMETYX $60 \mathrm{mg}$ orally once daily $(n=467)$ or placebo $(n=237)$ until disease progression or unacceptable toxicity. The median duration of treatment was 3.8 months (range $0.1-37.3$ ) for patients receiving CABOMETYX and 2.0 months (range $0.0-27.2$ ) for patients receiving placebo. The population exposed to CABOMETYX was $81 \%$ male, $56 \%$ White, and had a median age of 64 years.

Adverse reactions occurring in $\geq 25 \%$ of CABOMETYX- treated patients, in order of decreasing frequency were: diarrhea, decreased appetite, PPE, fatigue, nausea, hypertension, and vomiting. Grade $3-4$ adverse reactions which occurred in $\geq 5 \%$ of patients were PPE, hypertension, fatigue, diarrhea, asthenia, and decreased appetite. There were 6 adverse reactions leading to death in patients receiving CABOMETYX (hepatic failure, hepatorenal syndrome, esophagobronchial fistula, porta vein thrombosis, pulmonary embolism, upper gastrointestinal hemorrhage).

The median average daily dose was $35.8 \mathrm{mg}$ for CABOMETYX. The dose was reduced in $62 \%$ of patients receiving CABOMETYX; $33 \%$ of patients required a reduction to $20 \mathrm{mg}$ daily. The most frequent adverse reactions or laboratory abnormalities leading to dose reduction of CABOMETYX were: PPE, diarrhea, fatigue, hypertension, and increased AST. Adverse reactions leading to dose interruption occurred in $84 \%$ patients receiving CABOMETYX Adverse reactions leading to permanent discontinuation of CABOMETYX occurred in $16 \%$ of patients. The most frequent adverse reactions leading to permanent discontinuation of CABOMETYX were PPE $(2 \%)$, fatigue $(2 \%)$, decreased appetite (1\%), diarrhea (1\%), and nausea (1\%).

Table 6. Adverse Reactions Occurring in $\geq 5 \%$ of CABOMETYX-Treated Patients in CELESTIAL ${ }^{1}$

\begin{tabular}{|c|c|c|c|c|}
\hline \multirow{2}{*}{ Adverse Reaction } & \multicolumn{2}{|c|}{$\begin{array}{l}\text { CABOMETYX } \\
(\mathrm{n}=467)\end{array}$} & \multicolumn{2}{|c|}{$\begin{array}{l}\text { Placebo } \\
(n=237)\end{array}$} \\
\hline & \begin{tabular}{|c|} 
All \\
Grades $^{2}$
\end{tabular} & $\begin{array}{c}\text { Grade } \\
3-4\end{array}$ & $\begin{array}{c}\text { All } \\
\text { Grades }^{2}\end{array}$ & $\begin{array}{c}\text { Grade } \\
3-4 \\
\end{array}$ \\
\hline & \multicolumn{4}{|c|}{ Percentage (\%) of Patients } \\
\hline \multicolumn{5}{|l|}{ Gastrointestinal } \\
\hline Diarrhea & 54 & 10 & 19 & 2 \\
\hline Nausea & 31 & 2 & 18 & 2 \\
\hline Vomiting & 26 & $<1$ & 12 & 3 \\
\hline Stomatitis & 13 & 2 & 2 & 0 \\
\hline Dyspepsia & 10 & 0 & 3 & 0 \\
\hline \multicolumn{5}{|l|}{ General } \\
\hline Fatigue & 45 & 10 & 30 & 4 \\
\hline Asthenia & 22 & 7 & 8 & 2 \\
\hline Mucosal inflammation & 14 & 2 & 2 & $<1$ \\
\hline $\begin{array}{l}\text { Metabolism and } \\
\text { Nutrition }\end{array}$ & & & & \\
\hline
\end{tabular}

Nutrition

Decreased appetite

Skin and

Subcutaneous Tissue

Palmar-plantar

erythrodysesthesia

Rash $^{3}$

Vascular

Hypertension $^{4}$

Investigations

Weight decreased

Nervous System

Dysgeusia

Endocrine

Hypothyroidism

Respiratory, Thoracic

and Mediastinal

Dysphonia

Dyspnea

Musculoskeletal and

Connective Tissue

Pain in extremity

Muscle spasms

ncludes terms with a

$\geq 2 \%$ (Grade $3-4)$
NCI CTCAE Version 4.0

Includes the following terms: rash, rash erythematous, rash generalized rash macular, rash maculo-papular, rash papular, rash pruritic, rash pustular, rash vesicular, dermatitis, dermatitis acneiform, dermatitis contact, dermatitis diaper, dermatitis exfoliative, dermatitis infected Includes the following terms: hypertension, blood pressure diastolic increased, blood pressure increased

Table 7. Laboratory Abnormalities Occurring in $\geq 5 \%$ of CABOMETYX-Treated Patients in CELESTIAL

\begin{tabular}{|l|c|c|c|c|}
\hline \multirow{2}{*}{ Laboratory Abnormality } & \multicolumn{2}{|c|}{$\begin{array}{c}\text { CABOMETYX } \\
\text { N=467 }\end{array}$} & \multicolumn{2}{c|}{$\begin{array}{c}\text { Placebo } \\
\text { N=237 }\end{array}$} \\
\cline { 2 - 5 } & $\begin{array}{c}\text { All } \\
\text { Grades }\end{array}$ & $\begin{array}{c}\text { Grade } \\
3-4\end{array}$ & $\begin{array}{c}\text { All } \\
\text { Grades }\end{array}$ & $\begin{array}{c}\text { Grade } \\
3-4\end{array}$ \\
\hline & \multicolumn{3}{|c|}{ Percentage of Patients } \\
\hline Chemistry & & & & \\
\hline Increased LDH & 84 & 9 & 29 & 2 \\
\hline Increased ALT & 73 & 12 & 37 & 6 \\
\hline Increased AST & 73 & 24 & 46 & 19 \\
\hline Hypoalbuminemia & 51 & 1 & 32 & 1 \\
\hline Increased ALP & 43 & 8 & 38 & 6 \\
\hline Hypophosphatemia & 25 & 9 & 8 & 4 \\
\hline Hypokalemia & 23 & 6 & 6 & 1 \\
\hline Hypomagnesemia & 22 & 3 & 3 & 0 \\
\hline Increased amylase & 16 & 2 & 9 & 2 \\
\hline Hypocalcemia & 8 & 2 & 0 & 0 \\
\hline Hematology & & & & \\
\hline Decreased platelets & 54 & 10 & 16 & 1 \\
\hline Neutropenia & 43 & 7 & 8 & 1 \\
\hline Increased hemoglobin & 8 & 0 & 1 & 0 \\
\hline Incyyyy &
\end{tabular}

Includes laboratory abnormalities with a between-arm difference of $\geq 5 \%$ (all grades) or $\geq 2 \%$ (Grade $3-4$ )

ALP, alkaline phosphatase; ALT, alanine aminotransferase; AST, aspartate aminotransferase; LDH, blood lactate dehydrogenase

Differentiated Thyroid Cancer

The safety of CABOMETYX was evaluated in COSMIC-311, a randomized, double-blind, placebo-controlled trial in which 187 patients with advanced differentiated thyroid cancer were randomized to receive CABOMETYX $60 \mathrm{mg}$ orally once daily $(n=125)$ or placebo ( $n=62$ ) with supportive care until disease progression or unacceptable toxicity. At the time of the primary efficacy analysis, the median duration of treatment was 4.4 months (range $0.0-15.7$ ) for patients receiving CABOMETYX and 2.3 months (range $0.3-11.6$ ) for patients receiving placebo. The median age was 66 years (range 32 to 85 years), $55 \%$ were female, $70 \%$ were White, $18 \%$ were Asian, $2 \%$ were Black, $2 \%$ were American Indian or Alaska Native, and $63 \%$ received prior lenvatinib.

Adverse reactions occurring in $\geq 25 \%$ of CABOMETYX-treated patients, in order of decreasing frequency were: diarrhea, PPE, fatigue, hypertension, and stomatitis. Grade 3-4 adverse reactions which occurred in $\geq 5 \%$ of patients were PPE, hypertension, fatigue, diarrhea, and stomatitis. Serious adverse reactions occurred in $34 \%$ of patients who received CABOMETYX. Serious adverse reactions in $\geq 2 \%$ included diarrhea, pleural effusion, pulmonary embolism and dyspnea. Fatal adverse reactions occurred in $1.6 \%$ of patients in the CABOMETYX arm, including arterial hemorrhage $(0.8 \%)$ and pulmonary embolism $(0.8 \%)$. The median average daily dose was $42.0 \mathrm{mg}$ for CABOMETYX. The dose was reduced in $56 \%$ of patients receiving CABOMETYX; $22 \%$ of patients required a second dose reduction. The most frequent adverse reactions $(\geq 5 \%$ ) leading to dose reduction of CABOMETYX were PPE, diarrhea, fatigue, proteinuria, and decreased appetite. Dose interruptions occurred in $72 \%$ patients receiving CABOMETYX. Adverse reactions requiring dosage interruption in $\geq 5 \%$ of patients were PPE, diarrhea, dyspnea, hypertension, decreased appetite and proteinuria. Adverse reactions leading to permanent discontinuation of CABOMETYX occurred in $5 \%$ of patients.

Table 8. Adverse Reactions Occurring in $\geq 5 \%$ of CABOMETYX-Treated Patients in COSMIC-311

\begin{tabular}{|c|c|c|c|c|}
\hline \multirow{2}{*}{ Adverse Reaction } & \multicolumn{2}{|c|}{$\begin{array}{l}\text { CABOMETYX } \\
(\mathrm{N}=125)\end{array}$} & \multicolumn{2}{|c|}{$\begin{array}{c}\text { Placebo } \\
(\mathrm{N}=62)\end{array}$} \\
\hline & $\begin{array}{c}\text { All } \\
\text { Grades }^{2}\end{array}$ & $\begin{array}{c}\text { Grade } \\
3-4\end{array}$ & $\begin{array}{c}\text { All } \\
\text { Grades }^{2}\end{array}$ & $\begin{array}{c}\text { Grade } \\
3-4\end{array}$ \\
\hline & \multicolumn{4}{|c|}{ Percentage $(\%)$ of Patients } \\
\hline \multicolumn{5}{|l|}{ Gastrointestinal } \\
\hline Diarrhea & 51 & 7 & 3 & 0 \\
\hline Nausea & 24 & 3 & 2 & 0 \\
\hline Vomiting & 14 & 1 & 8 & 0 \\
\hline Stomatitis $^{3}$ & 26 & 5 & 3 & 0 \\
\hline Dry mouth & 10 & 1 & 2 & 0 \\
\hline \multicolumn{5}{|l|}{ General } \\
\hline Fatigue $^{4}$ & 42 & 10 & 23 & 0 \\
\hline \multicolumn{5}{|c|}{ Metabolism and Nutrition } \\
\hline Decreased appetite & 23 & 3 & 16 & 0 \\
\hline \multicolumn{5}{|c|}{$\begin{array}{l}\text { Skin and Subcutaneous } \\
\text { Tissue }\end{array}$} \\
\hline $\begin{array}{l}\text { Palmar-plantar } \\
\text { erythrodysesthesia }\end{array}$ & 46 & 10 & 0 & 0 \\
\hline \multicolumn{5}{|l|}{ Vascular } \\
\hline Hypertension $^{5}$ & 30 & 10 & 5 & 3 \\
\hline \multicolumn{5}{|l|}{ Investigations } \\
\hline Weight decreased & 18 & 1 & 5 & 0 \\
\hline \multicolumn{5}{|l|}{ Nervous System } \\
\hline Dysgeusia & 10 & 0 & 0 & 0 \\
\hline Headache & 10 & 2 & 2 & 0 \\
\hline \multicolumn{5}{|l|}{$\begin{array}{l}\text { Respiratory, Thoracic, } \\
\text { and Mediastinal }\end{array}$} \\
\hline Dysphonia & 10 & 0 & 2 & 0 \\
\hline Pulmonary embolism & 5 & 2 & 0 & 0 \\
\hline \multicolumn{5}{|l|}{ Renal and Urinary } \\
\hline Proteinuria & 15 & 1 & 3 & 0 \\
\hline
\end{tabular}

Includes terms that are more frequent in the CABOMETYX arm and

have a between-arm difference of $\geq 5 \%$ (all grades) or $\geq 2 \%$ (Grade $3-4$ ) 2 NCI CTCAE Version 5.0

Includes the following terms: mucosal inflammation, stomatitis

Includes the following terms: fatigue, asthenia

Includes the following terms: hypertension, blood pressure increased, hypertensive crisis

Table 9. Laboratory Abnormalities Occurring in $\geq 10 \%$ of CABOMETYX-Treated Patients in COSMIC-311

\begin{tabular}{|c|c|c|c|c|}
\hline \multirow{2}{*}{$\begin{array}{l}\text { Laboratory } \\
\text { Abnormality }\end{array}$} & \multicolumn{2}{|c|}{$\underset{\substack{\mathrm{N}=125 \\
\text { CABOMETYX }}}{ }$} & \multicolumn{2}{|c|}{$\begin{array}{c}\text { Placebo } \\
N=62\end{array}$} \\
\hline & $\begin{array}{c}\text { All } \\
\text { Grades }\end{array}$ & $\begin{array}{l}\text { Grade } \\
3 \text { or } 4\end{array}$ & $\begin{array}{c}\text { All } \\
\text { Grades }\end{array}$ & $\begin{array}{l}\text { Grade } \\
3 \text { or } 4\end{array}$ \\
\hline & \multicolumn{4}{|c|}{ Percentage (\%) of Patients } \\
\hline Chemistry & & & & \\
\hline $\mathrm{LDH}_{\text {increased }}^{2}$ & 90 & 10 & 32 & 3 \\
\hline AST increased & 77 & 1 & 18 & 0 \\
\hline ALT increased & 66 & 2 & 11 & 0 \\
\hline Hypocalcemia & 36 & 9 & 10 & 2 \\
\hline ALP increased & 34 & 0 & 15 & 0 \\
\hline GGT increased & 26 & 2 & 21 & 2 \\
\hline Hypomagnesemia & 25 & 2 & 5 & 0 \\
\hline Hypoalbuminemia & 19 & 1 & 7 & 0 \\
\hline
\end{tabular}




\begin{tabular}{|l|c|c|c|c|}
\hline \multirow{2}{*}{$\begin{array}{l}\text { Laboratory } \\
\text { Abnormality }\end{array}$} & \multicolumn{2}{|c|}{$\begin{array}{c}\text { CABOMETYX } \\
\mathrm{N}=125\end{array}$} & \multicolumn{2}{c|}{$\begin{array}{c}\text { Placebo } \\
\mathrm{N}=62\end{array}$} \\
\cline { 2 - 5 } & $\begin{array}{c}\text { All } \\
\text { Grades }\end{array}$ & $\begin{array}{c}\text { Grade } \\
\text { 3 or 4 }\end{array}$ & $\begin{array}{c}\text { All } \\
\text { Grades }\end{array}$ & $\begin{array}{c}\text { Grade } \\
\text { 3 or 4 }\end{array}$ \\
\hline & \multicolumn{3}{|c|}{ Percentage (\%) of Patients } \\
\hline Hypokalemia & 18 & 1 & 3 & 0 \\
\hline Hyponatremia & 15 & 0 & 10 & 2 \\
\hline Hyperbilirubinemia & 12 & 0 & 5 & 0 \\
\hline Hematology & & & & \\
\hline $\begin{array}{l}\text { Leukocytes } \\
\text { decreased }\end{array}$ & 38 & 2 & 7 & 2 \\
\hline $\begin{array}{l}\text { Neutrophils } \\
\text { decreased }\end{array}$ & 31 & 2 & 5 & 2 \\
\hline $\begin{array}{l}\text { Platelets } \\
\text { decreased }\end{array}$ & 26 & 0 & 5 & 0 \\
\hline
\end{tabular}

1 Includes laboratory abnormalities that are more frequent in the CABOMETYX arm and have a between-arm difference of $\geq 5 \%$ (all grades) or $\geq 2 \%$ (Grade $3-4$ )

Sponsor-defined grades for LDH were as follows: Grade 1 ( $>$ ULN to $\leq 2 \times$

ULN), Grade $2(>2 \times$ ULN to $\leq 3 \times U L N)$, Grade $3(>3 \times U L N)$.

ALP, alkaline phosphatase; ALT, alanine aminotransferase; AST, aspartate aminotransferase; GGT, gamma glutamyl transferase; LDH, blood lactate dehydrogenase

\section{DRUG INTERACTIONS}

\subsection{Effects of Other Drugs on CABOMETYX} Strong CYP3A4 Inhibitors

Coadministration of a cabozantinib capsule formulation with a strong CYP3A4 inhibitor increased the exposure of cabozantinib, which may increase the risk of exposure-related adverse reactions. Avoid coadministration of CABOMETYX with strong

CYP3A4 inhibitors. Reduce the dosage of CABOMETYX if coadministration with strong CYP3A4 inhibitors cannot be avoided. Avoid grapefruit or grapefruit juice which may also increase exposure of cabozantinib.

Strong CYP3A Inducers

Coadministration of a cabozantinib capsule formulation with a strong CYP3A4 inducer decreased the exposure of cabozantinib, which may reduce efficacy. Avoid coadministration of CABOMETYX with strong CYP3A4 inducers. Increase the dosage of CABOMETYX if coadministration with strong CYP3A4 inducers cannot be avoided. Avoid St. John's wort which may also decrease exposure of cabozantinib.

\section{USE IN SPECIFIC POPULATIONS}

\subsection{Pregnancy}

\section{Risk Summar}

Based on findings from animal studies and its mechanism of action, CABOMETYX can cause fetal harm when administered to a pregnant woman. There are no available data in pregnant women to inform the drug-associated risk. In animal developmental and reproductive toxicology studies administration of cabozantinib to pregnant rats and rabbits during organogenesis resulted in embryofetal lethality and structural anomalies at exposures that were below those occurring clinically at the recommended dose (see Data). Advise pregnant women of the potential risk to a fetus. In the U.S. general population, the estimated background risk of major birth defects and miscarriage in clinically recognized pregnancies is $2-4 \%$ and $15-20 \%$, respectively.

Data

Animal Data

In an embryo-fetal development study in pregnant rats, daily oral administration of cabozantinib throughout organogenesis caused increased embryo-fetal lethality compared to controls at a dose of $0.03 \mathrm{mg} / \mathrm{kg}$ (approximately 0.12 -fold of human area under the curve [AUC] at the recommended dose). Findings included delayed ossification and skeletal variations at a dose of $0.01 \mathrm{mg} / \mathrm{kg} / \mathrm{day}$ (approximately 0.04 -fold of human AUC at the recommended dose)

In pregnant rabbits, daily oral administration of cabozantinib throughout organogenesis resulted in findings of visceral malformations and variations including reduced spleen size and missing lung lobe at $3 \mathrm{mg} / \mathrm{kg}$ (approximately 1.1-fold of the human $\mathrm{AUC}$ at the recommended dose)

In a pre- and postnatal study in rats, cabozantinib was administered orally from gestation day 10 through postnatal day 20. Cabozantinib did not produce adverse maternal toxicity or affect pregnancy, parturition or lactation of female rats, and did not affect the survival, growth or postnatal development of the offspring at doses up to $0.3 \mathrm{mg} / \mathrm{kg} / \mathrm{day}$ (0.05-fold of the maximum recommended clinical dose)

\subsection{Lactation}

\section{Risk Summar}

There is no information regarding the presence of cabozantinib or its metabolites in human milk, or their effects on the breastfed child or milk production. Because of the potential for serious adverse reactions in breastfed children, advise women not to breastfeed during treatment with CABOMETYX and for 4 months after the final dose.
8.3 Females and Males of Reproductive Potential Pregnancy Testing Verify the pregnancy status of females of reproductive potential prior to initiating CABOMETYX.

\section{Contraception}

CABOMETYX can cause fetal harm when administered to a pregnant woman.

Advise females of reproductive potential to use effective contraception during treatment with CABOMETYX and for 4 months after the final dose.

$\underline{\text { Infertility }}$

Females and Males

Based on findings in animals, CABOMETYX may impair fertility in females and males of reproductive potential.

\subsection{Pediatric Use}

The safety and effectiveness of CABOMETYX for the treatment of differentiated thyroid cancer (DTC) have been established in pediatric patients aged 12 years and older.

Use of CABOMETYX in pediatric patients aged 12 years and older with DTC is supported by evidence from adequate and well-controlled studies of CABOMETYX in adults with additional population pharmacokinetic data demonstrating that cabozantinib exposure is within the same range between adults and pediatric patients aged 12 years and older at the recommended dosages. The safety and effectiveness of CABOMETYX in pediatric patients less than 12 years of age have not been established.

Juvenile Animal Toxicity Data

Juvenile rats were administered cabozantinib at doses of 1 or $2 \mathrm{mg} / \mathrm{kg} /$ day from Postnatal Day 12 (comparable to less than 2 years in humans) through Postnatal Day 35 or 70 . Mortalities occurred at doses $\geq 1 \mathrm{mg} / \mathrm{kg} /$ day (approximately 0.16 times the clinical dose of $60 \mathrm{mg} /$ day based on body surface area). Hypoactivity was observed at both doses tested on Postnatal Day 22. Targets were generally similar to those seen in adult animals, occurred at both doses, and included the kidney (nephropathy, glomerulonephritis), reproductive organs, gastrointestinal tract (cystic dilatation and hyperplasia in Brunner's gland and inflammation of duodenum; and epithelial hyperplasia of colon and cecum), bone marrow (hypocellularity and lymphoid depletion), and liver. Tooth abnormalities and whitening as well as effects on bones including reduced bone mineral content and density, physeal hypertrophy, and decreased cortical bone also occurred at all dose levels. Recovery was not assessed at a dose of $2 \mathrm{mg} /$ $\mathrm{kg}$ (approximately 0.32 times the clinical dose of $60 \mathrm{mg}$ based on body surface area) due to high levels of mortality. At the low dose level, effects on bone parameters were partially resolved but effects on the kidney and epididymis/testis persisted after treatment ceased.

\subsection{Geriatric Use}

In CABOSUN and METEOR, $41 \%$ of 409 patients treated with CABOMETYX were age 65 years and older, and $8 \%$ were 75 years and older. In CELESTIAL, $49 \%$ of 467 patients treated with CABOMETYX were age 65 years and older, and $15 \%$ were 75 years and older. In COSMIC-311, $50 \%$ of 125 patients treated with CABOMETYX were age 65 years and older, and $12 \%$ were 75 years and older.

No overall differences in safety or effectiveness were observed between these patients and younger patients.

Of the 320 patients randomized to CABOMETYX administered with nivolumab in CHECKMATE-9ER, $41 \%$ were 65 years or older and $9 \%$ were 75 years or older. No overall difference in safety was reported between elderly patients and younger patients.

\subsection{Hepatic Impairmen}

Increased exposure to cabozantinib has been observed in patients with moderate (Child-Pugh B) hepatic impairment. Reduce the CABOMETYX dose in patients with moderate hepatic impairment. Avoid CABOMETYX in patients with severe hepatic impairment (Child-Pugh C), since it has not been studied in this population.

8.7 Renal Impairment

No dosage adjustment is recommended in patients with mild or moderate renal impairment. There is no experience with CABOMETYX in patients with severe renal impairment.

\section{OVERDOSAGE}

Case of overdosage was reported following administration of another formulation of cabozantinib; a patient inadvertently took twice the intended dose for 9 days. The patient suffered Grade 3 memory impairment, Grade 3 mental status changes, Grade 3 cognitive disturbance, Grade 2 weight loss, and Grade 1 increase in BUN. The extent of recovery was not documented.

\section{PATIENT COUNSELING INFORMATION}

Advise the patient to read the FDA-approved patient labeling (Patient Information)

Hemorrhage: Instruct patients to contact their healthcare provide to seek immediate medical attention for signs or symptoms of unusual severe bleeding or hemorrhage.

Perforations and fistulas: Advise patients that gastrointestinal disorders such as diarrhea, nausea, vomiting, and constipation may develop during CABOMETYX treatment and to seek mmediate medical attention if they experience persistent or severe abdominal pain because cases of gastrointestinal perforation and fistula have been reported in patients taking CABOMETYX

Thrombotic events: Venous and arterial thrombotic events have been reported. Advise patients to report signs or symptoms of an arterial thrombosis. Venous thromboembolic events including pulmonary embolus have been reported. Advise patients to contact their health care provider if new onset of dyspnea, chest pain, or localized limb edema occurs.

Hypertension and hypertensive crisis: Inform patients of the signs and symptoms of hypertension. Advise patients to undergo routine blood pressure monitoring and to contact their health care provider if blood pressure is elevated or if they experience signs or symptoms of hypertension.

Diarrhea: Advise patients to notify their healthcare provider at the first signs of poorly formed or loose stool or an increased frequency of bowel movements.

Palmar-plantar erythrodysesthesia: Advise patients to contact their healthcare provider for progressive or intolerable rash.

Hepatotoxicity: Advise patients to contact their healthcare provider immediately for jaundice, severe nausea or vomiting, or easy bruising or bleeding.

Adrenal insufficiency: Advise patients receiving with nivolumab to contact their healthcare provider immediately for signs or symptoms of adrenal insufficiency.

Proteinuria: Advise patients to contact their healthcare provider for signs or symptoms of proteinuria.

Osteonecrosis of the jaw: Advise patients regarding good oral hygiene practices. Advise patients to immediately contact their healthcare provider for signs or symptoms associated with osteonecrosis of the jaw.

Impaired wound healing: Advise patients that CABOMETYX may impair wound healing. Advise patients to inform their healthcare provider of any planned surgical procedure.

Reversible posterior leukoencephalopathy syndrome: Advise patients to immediately contact their health care provider for new onset or worsening neurological function.

Thyroid dysfunction: Advise patients that CABOMETYX can cause thyroid dysfunction and that their thyroid function should be monitored regularly during treatment. Advise patients to immediately contact their healthcare provider for signs or symptoms of thyroid dysfunction.

Hypocalcemia: Advise patients that CABOMETYX can cause low calcium levels and that their serum calcium levels should be monitored regularly during treatment. Advise patients to immediately contact their healthcare provider for signs or symptoms of hypocalcemia.

Embryo-fetal toxicity:

- Advise females of reproductive potential of the potential risk to a fetus. Advise females to inform their healthcare provider of a known or suspected pregnancy.

- Advise females of reproductive potential to use effective contraception during treatment with CABOMETYX and for 4 months after the final dose.

Lactation: Advise women not to breastfeed during treatment with CABOMETYX and for 4 months following the last dose.

Drug interactions: Advise patients to inform their healthcare provider of all prescription or nonprescription medications, vitamins or herbal products. Inform patients to avoid grapefruit, grapefruit juice, and St. John's wort.

Important administration information Instruct patients to take CABOMETYX at least 1 hour before or at least 2 hours after eating.

This brief summary is based on the CABOMETYX Prescribing Information

Revision 10/2021

Distributed by Exelixis, Inc. Alameda, CA 94502

\section{EXELIXIS}

CABOMETYX is a registered trademark of Exelixis, Inc. (๐) 2021 Exelixis, Inc.

Printed in USA 10/2021 CA-1121-4 


\section{Abstracts From the 18th Annual} Meeting of the International Society of Gastrointestinal Oncology

The 18th Annual Meeting of the International Society of Gastrointestinal Oncology (ISGIO), hosted by Physicians' Education Resource, LLC $\left(P_{E R}{ }^{\circledR}\right)$, was held as a 2-day virtual event on October $1-2,2021$. This multidisciplinary educational conference is dedicated to presenting and discussing some of the latest advances in the field of gastrointestinal cancer research.

Herein, ONCOLOGY ${ }^{\circledR}$ presents abstracts from the meeting, which was led by the journal's Gastrointestinal Cancer Tumor Chair Tanios S. Bekaii-Saab, MD, FACP, along with one of its co-Editors-in-Chief Howard S. Hochster, MD.

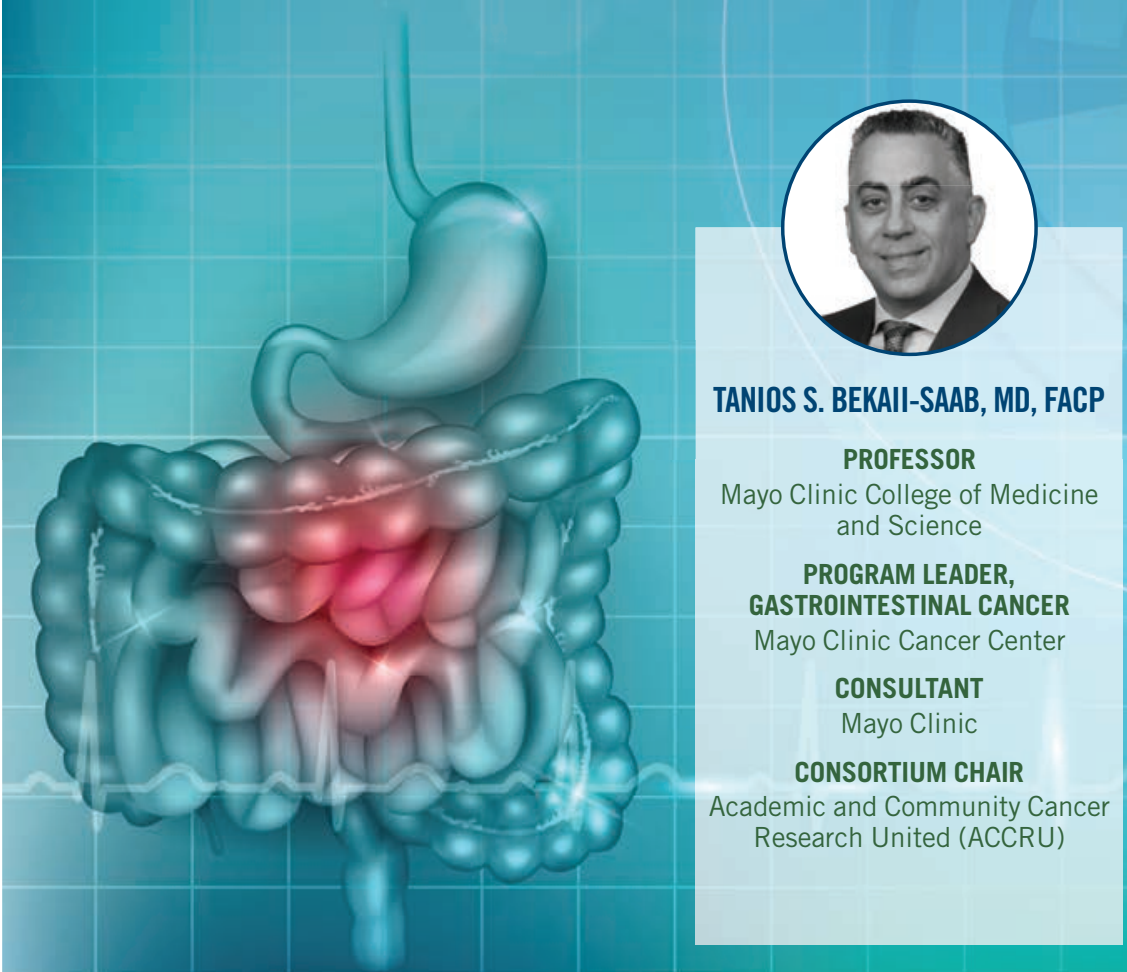




\section{Head-to-head comparison of a risk- adapted screening strategy incorporating different risk-prediction models in detecting advanced colorectal neoplasm}

Ming Lu, MBBS'; Yuhan Zhang, MBBS'; Jie Cai, MPH²; Bin Lu, MBBS'; Chenyu Luo, MBBS'; Hongda Chen, ${ }^{1}{ }^{1}{ }^{1},{ }^{*}$; and Min Dai, $\mathrm{PhD}{ }^{1}$, *

${ }^{1}$ Office of Cancer Screening, National Cancer Center/National Clinical Research Center for Cancer/Cancer Hospital, Chinese Academy of Medical Sciences and Peking Union Medical College, Beijing 100021, China; ${ }^{2}$ Department of General Surgery, Peking Union Medical College Hospital, Chinese Academy of Medical Sciences and Peking Union Medical College, Beijing 100730, China.

*Co-corresponding author

\section{Learning Objective}

To search for potential eligible risk-prediction models using a systematic literature review, and to validate model performance when it was incorporated into a risk-adapted screening strategy in a subset of a large-scale colorectal cancer (CRC) screening cohort in China.

\section{Background}

The risk-adapted screening strategy incorporating the Asia-Pacific Colorectal Screening score and fecal immunochemical test (FIT) showed satisfying CRC screening yield and efficiency. Previous research groups have developed a series of risk-prediction models for advanced colorectal neoplasms. Whether performance of different risk-prediction models would affect the yield of risk-adapted screening has not been evaluated. We further explored the diagnostic performance variation of this strategy using different risk-prediction models.

\section{Methods}

A literature search was conducted to identify studies evaluating risk models for advanced colorectal neoplasm (ACN). The included models were retrospectively validated in a subset sample $(\mathrm{N}=3219)$ from a population-based CRC screening trial in China. The subset sample consisted of 265 patients with ACN (CRC, 24 patients; advanced adenoma, 241 patients) and 2,954 participants with no diagnosis of ACN. Diagnosis-related indicators were compared using different models and the FIT-only strategy. For simulated populations with ACN prevalence of $3 \%$ to $12 \%$, the trade-off of additional false-positives for each additional true-positive was calculated.

\section{Results}

We included 14 eligible risk models (range of areas-underthe-curve, 0.570-0.652) in the validation set. The overall sensitivities of the risk-adapted screening strategy using different risk models for ACN varied from $46.0 \%$ to $69.8 \%$; this was higher than seen with results of the FIT $(21.9 \%)$, but at the expense of specificity (risk-adapted screening strategy, 51.6\%-78.3\%; FIT, 97.1\%). For populations having an ACN prevalence of $3 \%$, risk-adapted screening strategies needed 20.5 to 31.1 additional false-positives for each additional true-positive when compared with FIT results, and a respective number was substantially reduced (from 4.7 to 7.1) as the ACN prevalence increased to $12 \%$.

\section{Conclusions}

A risk-adapted screening strategy using current risk models showed improved sensitivity for ACN as compared with results of FIT at the cost of increased colonoscopy workload. The optimal strategy for screening for CRC should be tailored according to disease burden and availability of health care resources.

\section{Patient and provider factors associated with colorectal cancer screening in a large US claims database}

Nicole M. Engel-Nitz, PhD'; Lesley-Ann Miller-Wilson, MS, PhD, MBA2; Lisa Le, MS'; Paul Limburg, MD, MPH, AGAF3; Deborah Fisher, MD, MHS ${ }^{4}$

${ }^{1}$ Optum, Eden Prairie, MN, USA; ${ }^{2 E x a c t}$ Sciences, Madison, WI, USA; ${ }^{3}$ Mayo Clinic, Rochester, MN, USA; ${ }^{4}$ Eli Lilly and Company, Indianapolis, IN, USA

\section{Learning Objective}

To understand patient and provider factors that could be targeted systematically to improve engagement in average-risk colorectal cancer (CRC) screening.

\section{Background}

Despite the demonstrated effectiveness of average-risk CRC screening, approximately one-third of screeningeligible US adults are not up to date with this important preventive service. 


\section{Methods}

The study included individuals (age, 50-75 years) in a large, deidentified claims database that had continuous enrollment during the year of analysis and 1 year prior. The average-risk population excluded those with high-risk conditions (eg, CRC familial syndromes, adenoma, sessile serrated polyp, history of or current diagnosis of CRC, family history of gastrointestinal cancer, inflammatory bowel disease). Patients were selected if they received screening (ie, colonoscopy, fecal immunochemical test, fecal occult blood test, multitarget stool DNA test, flexible sigmoidoscopy/CT colonography) during their last complete year of analysis. Control patients were randomly selected; they did not have high-risk conditions for CRC and did not claim to have a screening test during the analysis year or any previous year. Cases and controls were compared on baseline demographic and clinical characteristics and screening opportunities as measured by number of baseline health care visits. Logistic regressions modeled the impact of characteristics on screening.

\section{Results}

A total of 664,234 screened and 548,758 unscreened patients were included in the analysis. Screened patients had higher odds of being female (odds ratio [OR], 1.22; 95\% CI, 1.21-1.23), commercially insured, and a resident of both the southern United States and an urban setting. Screened patients also had higher odds of having completed $12^{\text {th }}$ grade or having a bachelor/graduate degree; the odds of being screened increased as net worth increased. Patients who had a primary-care visit (OR, 2.69; 95\% CI, 2.67-2.71), a preventive-care visit, or a main primary-care provider had the greatest odds of being screened.

\section{Conclusions}

The greatest predictors for CRC screening were having a primary-care visit, having a main primary-care provider, and having a recent preventive-care visit. Potential targeted interventions for providers and patients include increasing access to and use of preventive-care visits and interventions not dependent on a clinical visit (eg, mailed CRC screening tests).

DISCLOSURES: Funding for this study was provided by Exact Sciences to Optum. N Engel-Nitz, L Le are employees of Optum and shareholders in UnitedHealth Group. L Miller-Wilson is an employee of Exact Sciences. P Limburg serves as chief medical officer for screening at Exact Sciences through a contracted services agreement with Mayo Clinic. Limburg and Mayo Clinic have contractual rights to receive royalties through this agreement. D Fisher has been a consultant with Exact Sciences and Guardant Health; she is currently employed by Lilly and Co.

\section{The impact of combined DNA repair and oncogene mutations in colorectal cancer survival}

Keeley Barnable, BSc, ${ }^{1}$ Vett Lloyd, BSc, Diplome, PhD, ${ }^{1}$

Gurpreet Singh Ranger, BSc, MSc, MS, MRCS, FCBS, FRCS, FRCSGlasg ${ }^{1,2}$

${ }^{1}$ Mount Allison University, Sackville, NB, Canada; ${ }^{2}$ Upper River Valley Hospital, NB, Canada

\section{Learning Objective}

To determine the impact of selected gene mutations on survival in patients with colorectal cancer (CRC) from a rural population in New Brunswick, Canada.

\section{Background}

Testing for multiple mutations in CRC allows insight into pathways of cancer development and disease outcomes and use for targeted treatment. This study examined the coexistent effect of either KRAS or BRAF gene status with mismatch repair (MMR) gene function on patient outcomes in New Brunswick, Canada.

\section{Methods}

In this retrospective study, mutation status for MMR and other oncogenes was derived from DNA sequencing and immunohistochemistry. Patients with the given genotypes were assessed for overall survival probability using Kaplan-Meier statistics. Significant differences were calculated using the log-rank test (alpha $=.05)$.

\section{Results}

The study involved 117 patients (mean age, $69.6 \pm$ 10.4 years; male:female ratio; $1.34: 1$ ). Analysis of survival outcomes showed significantly poorer survival in patients with mutations of KRAS or MLH1 alleles $(P=.018)$ when compared with patients who did not harbor these genetic mutations. Borderline significant results for poorer survival were noted among patients with the PMS2 mutant phenotype, even with wild-type KRAS $(P=.056)$. No other significant results were noted with $K R A S$ or $B R A F$ mutations paired with MMR mutations or wild-type alleles.

\section{Conclusions}

These results supported previous findings that discovery of mutant oncogenes and altered MMR genes are predictive of survival. As expected, the presence of the mutant MLH1 phenotype confers significantly reduced patient survival. Due to the relatively small sample size, these 
preliminary results should be interpreted cautiously. Based on borderline insignificant pairwise analysis, further analyses using larger sample sizes may reveal more significant associations between known oncogenes and MMR genes and their combined effect on survival.

\section{Gastric cancer with aberrant CLDN6 expression procures reduced cytotoxic activity}

Sanyog Dwivedi, ${ }^{1,2}$ Erika P. Rendón-Huerta, ${ }^{1}$ Vianney OrtizNavarrete, ${ }^{2}$ and Luis F. Montaño ${ }^{1}$

1 Immunobiology Laboratory, Department of Cell and Tissue Biology, Faculty of Medicine, UNAM, Mexico; 2Department of Molecular Biomedicine, Center for Research and Advanced Studies, IPN, Mexico.

\section{Learning Objective}

To understand the association between CLDN6 and immune suppression in gastric cancers.

\section{Background}

CLDN6, a tight junction protein aberrantly expressed in patients diagnosed with gastric cancer (GC), supports epithelial-to-mesenchymal transition, cancer progression, and survival. Immune suppression and exhaustion of cytotoxic natural killer (NK) and T cells is another prominent characteristic of advanced GC. Considering the above, we are interested in seeing if CLDN6 is also associated with the reduced cytotoxic activity of immune cells in GC.

\section{Methods}

CBioPortal was used to access The Cancer Genome Atlas Stomach Adenocarcinoma (TCGA-STAD) Pan-Cancer Analysis Project data of 440 GC samples. These samples were divided into 2 groups according to mRNA expression: z-scores (relative to normal samples, log RNASeq V2 RSEM) of CLDN6 were considered to be high if greater than 5 (71 samples; CLDN6-high) and low if less than 1 (254 samples; CLDN6-neg). The mRNA z-scores were analyzed using MS Excel and GraphPad Prism 8.

\section{Results}

Cytotoxic activity of NK cells depends on synergistic engagement and activation of several activation receptors that downregulate in several cancers, including GC. The mRNA expression of several important receptors and ligands related to the activation of cytotoxic cells were analyzed between groups having CLDN6-high and CLDN6-neg GC samples. NKG2D, one of the key receptors for NK cell activation, was downregulated in GC samples having high CLDN6 expression relative to CLDN6-neg group samples. The NKG2D ligand ULPB1 was significantly upregulated in CLDN6 group samples, although no change in the mRNA levels of MICA, MICB, or other ULBPs were noticed among the groups. The natural cytotoxicity receptors NKp44 and NKp46 were also significantly downregulated in the CLDN6-high group samples. Other important receptors necessary for NK cell activation and IFNY secretion (eg, CD244, DNAM1, CD28, CD69, and CD38) were also downregulated in CLDN6-high group samples. Additionally, high CLDN6 expression was related to the downregulation of important cytokines like IL15 and IFNY, which affected the activation and activity of several immune cells. Cytolytic activity of cytotoxic cells largely depends on cytolytic granule contents (eg, perforin, granzyme, and ligands of death receptors, including FasL and TRAIL). Samples in the CLDN6-high group demonstrated a significant downregulation in FasL, TRAIL, and perforin mRNA levels, indicating reduced cytolytic activity in these samples.

\section{Conclusions}

Collectively, these results indicated that aberrant expression of CLDN6 in GC is associated with the downregulation of cytolytic activity of cytotoxic cells.

ACKNOWLEDGMENTS: This research was supported by CONACYT CVU grant 871712 and PAPIIT grants IN221519 and IN218019. 


\section{Peritoneal carcinomatosis leveraging ctDNA-guided treatment in GI cancer study (PERICLES study)}

Sharon Li, MD; Timothy Kennedy, MD, MBA; Patrick Boland, MD; Kristen Spencer, MD, MPH; Lyudmila Berim, MD; Prateek Gulhati, MD, PhD; H. Richard Alexander, MD*; Howard S. Hochster, MD*.

${ }^{*}$ Co-Principal Investigators.

All affiliated with Rutgers Cancer Institute of New Jersey

\section{Learning Objective}

To follow circulating tumor DNA (ctDNA) as a marker of response to various interventions for peritoneal carcinomatosis (PC) to determine whether it may be used to guide treatment decisions.

\section{Background}

Peritoneal carcinomatosis (PC) is a frequent complication of numerous gastrointestinal (GI) cancers, but crosssectional imaging is notoriously unreliable in detecting extent of disease. Analysis of circulating tumor DNA (ctDNA) is emerging as a noninvasive method to detect cancer-specific molecular alterations in the blood of patients with various tumor types, with applications in cancer surveillance and management. In patients with PC, serial assessments of ctDNA may be a better option than conventional imaging to assess for disease progression.

\section{Methods}

This pilot study will enroll a total of 30 adult patients with PC from any GI malignancy that are candidates for cytoreductive surgery (CRS) at the Rutgers Cancer Institute of New Jersey. This study will be conducted with Natera, Inc, using Signatera, a platform that creates a personalized minimal residual disease (MRD) assay for tracking ctDNA in each patient. Plasma for ctDNA at baseline, presurgery, postsurgery, and every 3 months for 2 years will be obtained in follow-up. Change in ctDNA levels with (1) chemotherapy, (2) CRS, and (3) clinical disease progression will be evaluated and compared with conventional definitions of disease progression (eg, rise in conventional tumor markers, radiographic progression). Participants' ctDNA findings will be followed and used for decisions pertaining to further chemotherapy after surgical debulking.

The primary end point is to determine plasma ctDNA clearance rates with chemotherapy and CRS with or without hyperthermic intraperitoneal chemotherapy, with ctDNA clearance rate defined as the percentage of patients on the protocol with undetectable ctDNA. Any ctDNA changes will be associated with clinical response by RECIST and surgical staging, surgical outcomes, peritoneal cancer index, and completeness of cytoreduction score using standard T-testing, log-rank analysis, or similar nonparametric testing. Multivariate analysis will be used, as appropriate. All results will be reported using descriptive statistics and a $95 \%$ confidence interval.

\section{Status}

The trial is currently screening eligible subjects, with an anticipated completion date around 2024. ClinicalTrials.gov identifier: NCT04929015.

\section{Making Cell and Gene Therapy Practical}

In a recent episode of Deep Dive from the Medical World News ${ }^{\circledR}$ broadcast, CancerNetwork ${ }^{\circledR}$ spoke with Josh Ludwig about how to make cell and gene therapy practical and viable for patients with cancer.

cancernetwork.com/ScaleReady

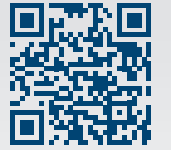

\section{Elizabeth Comen, MD, Discusses How Dance Helps Her Unplug} Plus Connect With Patients

CancerNetwork ${ }^{\circledR}$ sat down with Elizabeth Comen, MD to discuss how she balances her love of dance with both her family and her career as a breast cancer oncologist.

cancernetwork.com/Comen_11.21 


\section{(enzalutamide)}

40 mg tablets | 80 mg tablets

LOOKING FOR

CLINICAL DATA

ON XTANDI

EFFICACY AND

SAFETY?

VISIT

XtandiHCP.com

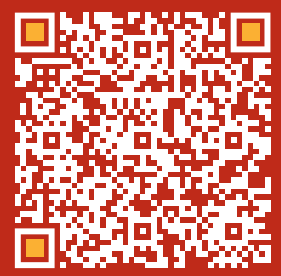

OR SCAN

THIS QR CODE

Wastellas PP/zer

(C) 2021 Astellas Pharma US, Inc. and Pfizer Inc. All rights reserved. 076-7303-PM 10/21 XTANDI, Astellas, and the flying star logo are registered trademarks of Astellas Pharma Inc. 


\section{Physicians Consider Needs of Underinsured Patients}

$\mathrm{T}$ he Affordable Care Act of 2010 was enacted to extend health insurance coverage to many

Americans who were uninsured. A growing portion of the American population are now considered "underinsured," and they present challenges for policy makers, insurance companies, and providers.

Sara R. Collins, PhD, vice president of The Commonwealth Fund, has led studies about the state of health insurance in the United States. Here, she discusses findings of a study regarding implications for the future of health care.

\section{Medical Economics ${ }^{\circledR}$ : How do you define the term "underinsured"?}

COLLINS: Since 2003, through our biennial health insurance survey, we have been tracking the number of adults who are insured all year but have high out-of-pocket costs or deductibles relative to their income. We define someone as underinsured if their out-of-pocket costs are $10 \%$ or more of their income, or their income is under $200 \%$ of the federal poverty level and their out-of-pocket costs are $5 \%$ or more of their income.

\section{Why do $25 \%$ of adults in employer-sponsored} plans fall into the underinsured category?

If we look at the share of people who are underinsured overall, that is largely driven by [those] in employer plans; [this percentage] has climbed from about $17 \%$ in 2010 to about $28 \%$ in 2020 . This growth has been driven by the proliferation of [patients with] deductibles and the size of those deductibles. In 2010 , only $6 \%$ of people with employer plans had deductibles that amounted to about $5 \%$ of their income. By 2018 , that share was $15 \%$.

\section{How does lack of insurance or underinsurance affect an individual's care decisions?}

In our most recent survey, more than half of adults who were uninsured for any time during the prior year reported not getting health care due to cost. This could include not filling a prescription, not getting specialist care, not going to the doctor when they're sick, or not getting a recommended follow-up test or treatment.

\section{How does that also affect a family's or} individual's overall financial situation?

We find that people who report problems paying medical bills [are more likely to] experience longterm financial issues. They're much more likely to say they used up all their savings to pay their bills or that they had a downgrade in their credit rating because of unpaid bills. We even find that about $25 \%$ of people report having to cut back on food, heat, or electricity because of medical bills.

\section{How is the COVID-19 pandemic affecting the problem of underinsurance?}

What we're seeing in our biennial survey, which was in the field from January through June of [2020], is that there's a persistent vulnerability among working-age adults and their ability to afford health care. This could worsen if the pandemic and the economic downturn continue. Aside from many people losing their health benefits because they've lost a job, if incomes aren't growing or business revenue is taking a hit [and] if out-of-pocket costs, deductibles, or premium contributions don't change, health care will take up a larger share of Americans' incomes. 


\section{EXPERT COMMENTARY ON THE PRODUCT PROFILE OF Tepotinib}

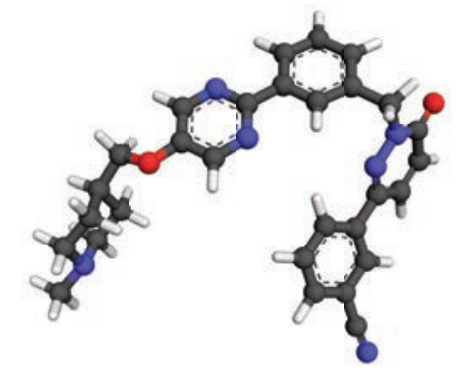

\section{Product Profile}

Drug name: Tepotinib (Tepmetko)

Date of approval: February 3, 2021

Initial indication: Accelerated approval for the treatment of adult patients with metastatic non-small cell lung cancer harboring MET exon 14 skipping alterations $\mathbf{s}^{1,2}$

Dosage and administration: $450 \mathrm{mg}$ orally once daily with food

How supplied: 225-mg tablets

Pivotal clinical trial: VISION $\left(\right.$ NCT02864992) ${ }^{3}$

\section{TRIAL DESIGN OF VISION}

\section{ELIGIBLE PATIENTS}

- Measurable disease per RECIST 1.1 confirmed by IRC

- ECOG performance score of 0 or 1

- Histologically or cytologically confirmed locally advanced or metastatic NSCLC

- Disease that is treatment naïve in the first-line setting or pretreated with no more than 2 lines of prior therapy
Oral tepotinib at 500 mg per day for 21-day cycles until disease progression, death, adverse event leading to discontinuation, or withdrawal of consent

\section{REFERENCES}

1. FDA grants accelerated approval to tepotinib for metastatic non-small cell lung cancer. FDA. February 3,2021 . Accessed October 12, 2021. https://bit.ly/3AAL8NK

2. Tepotinib. Prescribing information. Merck KGaA; 2021. Accessed October 12, 2021. https://bit.ly/3BAWS45

\section{PRIMARY END POINT}

OR per IRC

KEY SECONDARY END POINTS

OR per investigator assessment,

DOR, DCR, PFS, OS, and safety

DCR, disease-control rate; DOR, duration of response; IRC, independent review committee; NSCLC, non-small cell lung cancer; OR, objective response; OS, overall survival; PFS, progressionfree survival. 


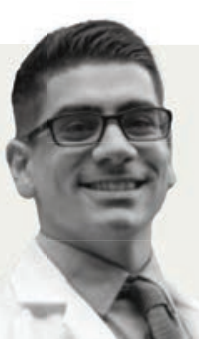

COMMENTARY BY

David Hughes, PharmD, BCOP

Clinical Pharmacy Manager of Oncology and Specialty Programs

Boston Medical Center

Boston, MA

\section{ONCOLOGY: Can you describe the mechanism of action of tepotinib?}

Freydman: [Tepotinib] is a MET kinase inhibitor. The MET kinase has downstream signaling through the RAS and the RAF pathways and the PI3K pathway, and an overexpression of this [MET kinase] leads to cell proliferation and survival. Losing exon 14 in this MET kinase deletes the spot on the juxtamembrane, which leads to decreased ubiquitination, which then leads to increased expression of MET. If you have too much MET [expression], then you have too much cell proliferation and survival. Tepotinib is approved for the $[M E T]$ exon 14 skipping mutation, which then causes the overexpression.

Hughes: Another interesting point is that when we think about MET as a whole, most people think of a biomarker-based or precision-based strategy [where] a patient is diagnosed with metastatic [disease] and then a MET mutation or amplification comes up. To frame it, there are 2 different variants: the $M E T$ exon 14 skipping mutation seen in about $2 \%$ to $3 \%$ of adenocarcinoma lung cancer, and the amplifications that occur within that cohort.

The other interesting piece with MET is that it's been identified as a secondary mutation or acquired resistance to pressure. Several studies have evaluated that when you pressure patients who are on EGFR inhibitors-drugs like osimertinib [Tagrisso] and others-you can see MET amplification as one of the resistance mechanisms to that. It highlights another unique niche area to really focus in on and see how we can incorporate it into the landscape of lung cancer.

\section{What are some of the biggest concerns with the toxicity profile? Have any new safety concerns been made more apparent in the real-world setting?}

Freydman: The adverse events [AEs] that are seen from tepotinib are from the VISION trial [NCT02864992]. In this trial, treatment-related AEs happened in about $90 \%$ of patients, the most common of which was peripheral edema as seen in about $60 \%$. This was followed by nausea and diarrhea, both [of which] were [found] in about a fifth of the patients. It was almost entirely grade 1 and 2 [events of] diarrhea and vomiting. Grade 3 and 4 AEs were present in about $30 \%$ and again, they were mostly [events of] peripheral edema. A few incidences of pleural effusion occurred, in about $3 \%$ of the patients. There wasn't commonly increased lipase, alanine aminotransferase, or aspartate aminotransferase, but [when they did occur, they] were asymptomatic. Mechanistically, this does make sense because one of the ligands for MET is the hepatocyte growth factor, and as tepotinib inhibits the MET, this mechanism would support seeing some [hepatic events].

Hughes: We have 2 different MET inhibitors available, and I'll allude to some
Jessica Freydman, PharmD Pharmacy Resident Boston Medical Center Boston, MA of the differences throughout; we have capmatinib [Tabrecta] $]^{4}$ and tepotinib. Clinically in the real world, edema is a real AE we see with these drugs. It's something that has come up more commonly than not and [can] even require some dosing modifications.

You do you see higher peak [concentration] with tepotinib, so you can see some higher rates of nausea and vomiting comparatively when you look numerically at the 2 [agents] side by side. I'm not necessarily saying one is worse than the other, but when you think about structural differences in pharmacokinetics, I think it makes sense for us, being pharmacists, to recognize the pathogenesis [behind] the hepatotoxicity we see. It's interesting that it's due to the hepatocyte growth factor. These are all very common; we see them in clinical practice [and we saw them] in the VISION trial.

\section{A. Are any dosing modifications common with this agent?}

Freydman: The recommended dose is $450 \mathrm{mg}$ orally once daily. I want to note that the VISION trial, which is the biggest trial, did report on using $500 \mathrm{mg}$ of tepotinib. This was the hydrochloride hydrate formulation, which is equivalent to the $450 \mathrm{mg}$ that we see commercially. The dose reduction as recommended is going down to $225 \mathrm{mg}$, and then patients who can't tolerate the oncedaily $225 \mathrm{mg}$ [dose] should permanently discontinue the medication. Dose reductions occurred in about a third of the patients in the trial, but it was only 
permanently discontinued in $10 \%$ of those patients. The most common reason for a dose reduction was the peripheral edema.

Hughes: When you think about dosing modifications and adherence, I continuously contrast [tepotinib] with capmatinib. We have a once-daily drug [with tepotinib] vs a twice-daily drug [with capmatinib]. So again, I think some of these things are important to think about.

\section{. Should clinicians be aware of any drug interactions?}

Freydman: Tepotinib does have to be taken with food. As far as drug interactions, it does interact with CYP3A [inducers] and PGP [P-glycoprotein]. It should be avoided with inducers of CYP3A such as rifampin, penicillin, or phenobarbital, and with the medications that have dual CYP3A and PGP inhibition, such as azole antifungals or HIV protease inhibitors. Another thing to watch out for is drugs that are PGP substrates with a narrow therapeutic index. For example, digoxin does have a dose reduction that's recommended if you're going to start your patient on tepotinib. Another one to watch out for is dabigatran, because the area under the curve usually does increase by about $50 \%$.

\section{Have any barriers to administrations or receipt} by the patient emerged since this agent's approval, such as common reimbursement issues or logistical challenges?

Hughes: The biggest aspect here is coverage, regardless of the [availability of a] plethora of drugs in the lung cancer space. Most of the targeted therapies are not a $\$ 5$-to-\$6 fill per month an more-they're about $\$ 10,000$-plus a month. As you get more rare mutations that come up like MET, that cost goes up. Obviously, the first challenge is [whether] the patient can afford the drug. Many different assistance programs or commercial co-pay cards exist for patients who may have primary insurance and need co-pay assistance. Then you have the percentage of patients, such as [those with] Medicare, who have very high co-pays; [in those cases, we can] look to resources like chronic disease funds, patient assistance programs, or different manufacturers to find ways to get the patient on the drug.

On top of just the financial piece, certain insurances or payers may have restrictions [regarding] one [MET inhibitor] vs the other. In clinical practice, when asking, 'What am I going to do for my individual patient?', it's really imperative to know what the differences are and to use your knowledge base of pharmacy and payers to know if a provider or a payer will restrict capmatinib over tepotinib or if tepotinib will be the preferred agent, aside from some of the differences that we've seen above. I think reimbursement can become an issue, but I think it's [interesting] because if a patient does have a MET driver mutation, you won't see issues from a prior authorization perspective or financial incentive, at least up front.

\section{Would you like to add
anything else?}

Freydman: I want to stress the importance of doing next-generation sequencing and focusing on that targeted therapy for non-small cell lung cancer. There is utility of doing this both at diagnosis and then if the patient progresses or develops resistance. You may have some resistance patterns that can be targeted with these medications. Again, [let's] go back to the VISION trial: The results were reported based on both liquid biopsy and solid tissue biopsy, which does show that you can utilize both methods for diagnosing patients.
Hughes: We're in an era of precision-based medicine and biomarker-driven approaches in non-small cell lung cancer. Optimally, when testing patients and in retesting progression, you're able to unfold some of these mutations and get a better understanding of tumor biology for utilizing both liquid and tissue biopsies that we know separately have their own advantages and challenges.

Overall, as we learn more and more about these biomarker-based strategies, a lot of [concepts that] we talked about [will remain] very useful in clinical practice to take care of our patients.

FINANCIAL DISCLOSURE: The authors have no significant financial interest in or other relationship with the manufacturer of any product or provider of any service mentioned in this article.

\section{REFERENCES}

1. FDA grants accelerated approval to tepotinib for metastatic non-small cell lung cancer. FDA. February 3, 2021. Accessed October 12, 2021. https://bit. ly/3AAL8NK

2. Tepotinib. Prescribing information. Merck KGaA; 2021. Accessed October 12, 2021. https://bit. ly/3BAWS45

3. Paik PK, Felip E, Veillon R, et al. Tepotinib in nonsmall-cell lung cancer with MET exon 14 skipping mutations. N Engl J Med. 2020;383(10):931-943. doi:10.1056/NEJMoa2004407

4. Capmatinib. Prescribing information. Novartis 2021. Accessed October 13, 2021. https://bit. ly/2X8D09DR-21-1566

David Hughes, PharmD, and Jessica Freydman, PharmD, Discuss the Mechanism of Action of Tepotinib for MET exon 14+ NSCLC

A clinical pharmacy manager and a pharmacy resident detail the unique mechanism of action of tepotinib for metastatic non-small cell lung cancer with mutations in MET exon 14

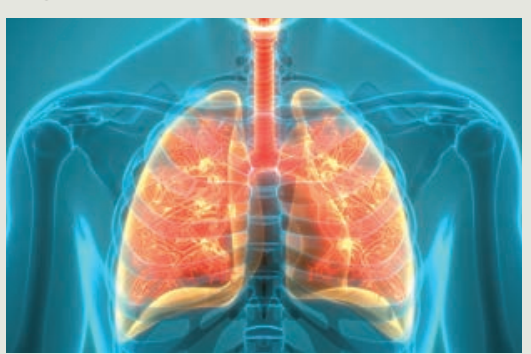

cancernetwork.com/Tepotinib_Hughes_Freydman 

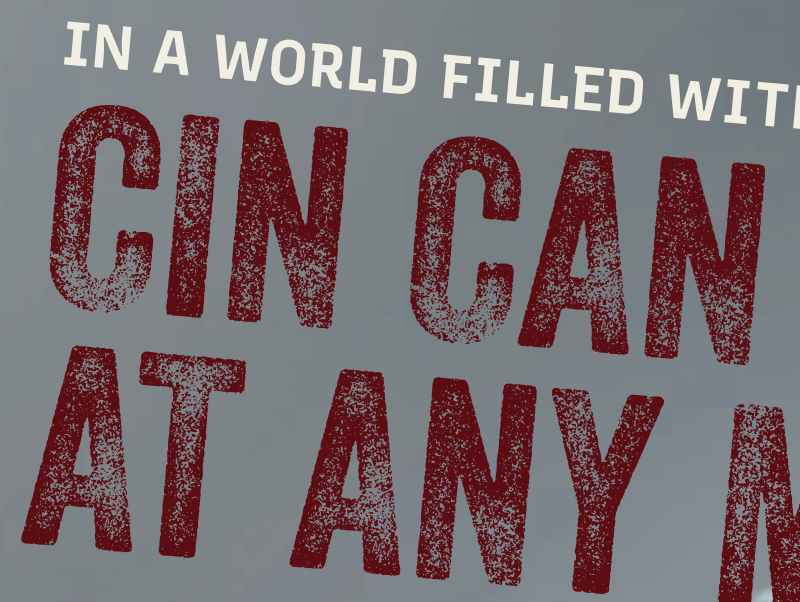

COVID-19..
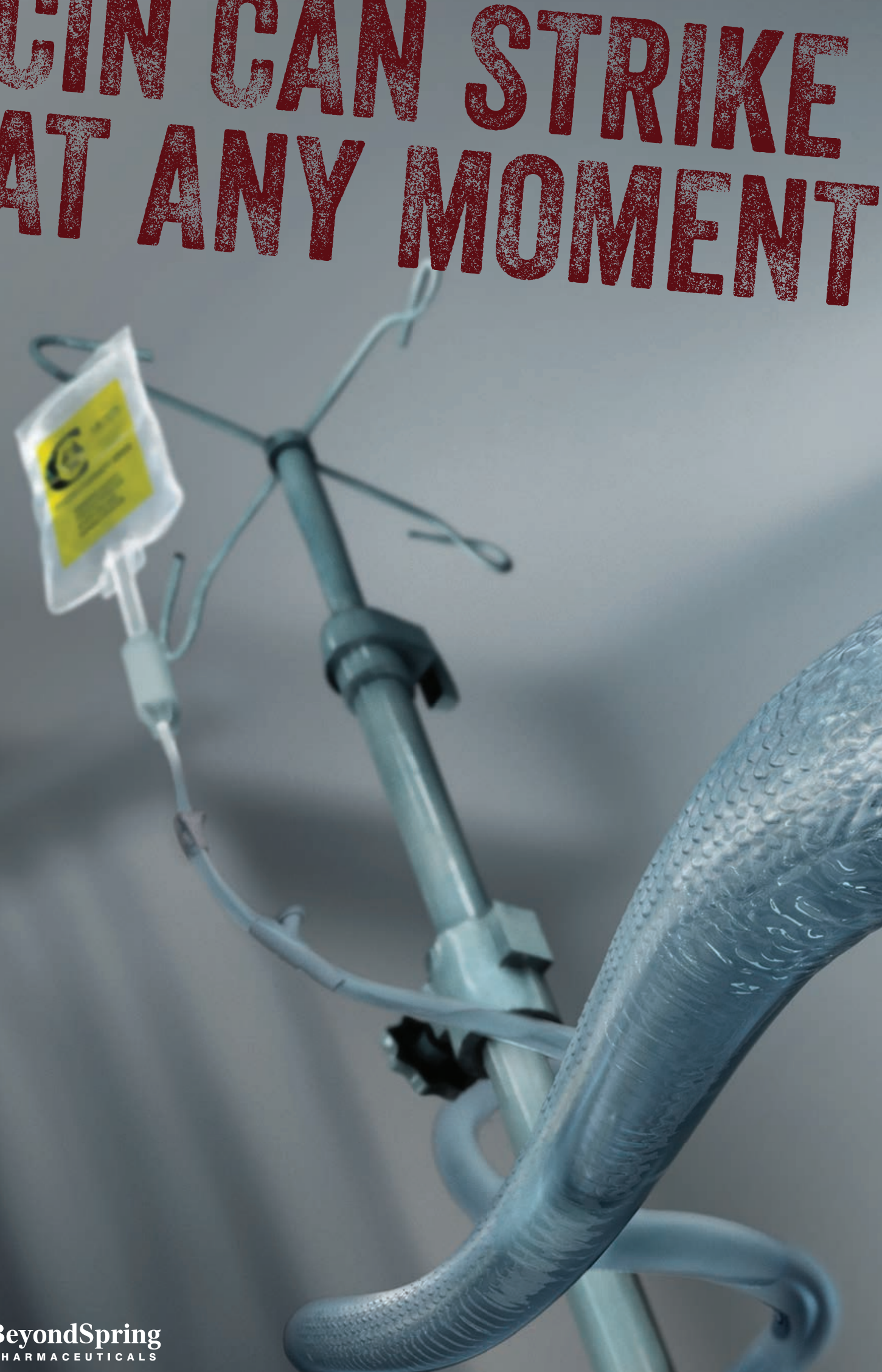

(C)2020 BeyondSpring Pharmaceuticals, Inc. BYSI-2011001A 
With the ongoing threat of chemotherapyinduced neutropenia (CIN), the COVID-19 pandemic is making oncologists and their care teams revisit their approach as they use aggressive regimens to treat their patients with cancer. Along with this, current treatment guidelines are now recommending the expanded prophylactic - use of granulocyte-colony stimulating factors (G-CSFs) to intermediate-risk cancer patients as well. ${ }^{1}$

When your patients are left unprotected, particularly in Cycle $1,{ }^{2}$ CIN may lead to life-threatening events, such as fever, infection, and hospitalization ${ }^{3}$-severely disrupting the predictability of your treatment plan. These chemotherapy delays and decreases can ultimately impact outcomes and decrease overall survival.4-6

It's time to take a crucial new look at CIN, the dire consequences of leaving patients unprotected, and how the COVID-19 pandemic is changing guidelines as well as your approach to providing the best standard of care.

\section{TO LEARN MORE, VISIT} CINRisk.com

References: 1. National Comprehensive Cancer Center. NCCN hematopoietic growth factors. Short-term recommendations specific to issues with COVID-19 (SARS-CoV-2). NCCN.org. Accessed August 20, 2020. 2. Cheng C, Gallagher EM, Yeh, J-Y, et al. Rates of febrile neutropenia with pegfilgrastim on same day versus next day of CHOP with or without rituximab. Anticancer Drugs. 2014;25(8):964-969. 3. Crawford J, Dale DC, Lyman GH. Chemotherapy-induced neutropenia: Risks, consequences, and new directions for its management. Cancer. 2003;100(2):228-237. doi: 10.1002/cncr.11882. 4. Centers for Disease Control and Prevention. Information for health care providers. Preventing infections in cancer patients. Centers for Disease Control and Prevention website. https://www.cdc.gov/cancer/preventinfections/index.htm. Updated December 16, 2019. Accessed June 29, 2020. 5. Lyman GH. Impact of chemotherapy dose intensity on cancer patient outcomes. J Nat/ Compr Canc Netw. 2009;7(1):99108. 6. Crawford J, Denduluri N, Patt D, et al. Relative dose intensity of first-line chemotherapy and overall survival in patients with advanced non-small-cell lung cancer. Support Care Cancer. 2020;28(2):925-932. doi: 10.1007/s00520-019-04815-1. 


\section{RAPID REPORTER $+2$ \\ ONCOLOGY ${ }^{\circledR}$ Recap of Presentations From the 2021 European Society for Medical Oncology Congress}

\section{Gastrointestinal Cancers - ORIENT-15 and ORIENT-16 Trials}

The addition of sintilimab (Tyvyt) to chemotherapy in patients with unresectable, locally advanced, recurrent, or metastatic esophageal squamous cell carcinoma (ESCC) and unresectable, locally advanced, recurrent, or metastatic gastric or gastroesophageal junction (GEJ) adenocarcinoma was able to improve overall survival (OS) vs chemotherapy alone.

First results from the phase 3 ORIENT-15 trial (NCT03748134) in ESCC and the phase 2 ORIENT-16 trial (NCT03745170) in GEJ showed that sintilimab was well tolerated in both groups of patients.

ORIENT-15: Investigators randomized 659 patients in a 1:1 fashion to either sintilimab with cisplatin plus paclitaxel or cisplatin plus 5 -fluorouracil or chemotherapy alone. For the overall population, median OS favored the experimental arm $(\mathrm{n}=327)$ at 16.7 months (95\% CI, 14.8-21.7) vs 12.5 months $(95 \%$ CI, 11.0-14.5) in the 332-patient control arm (HR, 0.628; 95\% CI, 0.508-0.777; $P<.0001)$. In patients with a PD-L1 combined positive score (CPS) of 10 or greater, median OS favored the combination arm $(\mathrm{n}=188)$ at 17.2 months (95\% CI, 15.5 -not calculable [NC]) vs 13.6 months ( $95 \% \mathrm{CI}, 11.3-15.7)$ in the chemotherapy $\operatorname{arm}(\mathrm{n}=193$; HR, 0.638; $95 \%$ CI, 0.480-0.848; $P=.0018)$.

ORIENT-16: Investigators randomized 650 patients in a 1:1 fashion to sintilimab plus oxaliplatin and capecitabine or the chemotherapy doublet alone. At a median follow-up of 18.8 months, the median OS in the total population was 15.2 months (95\% CI, 12.9-18.4) in the 327-patient experimental arm vs 12.3 months (95\% CI, 11.3-13.8) in the 323-patient chemotherapy arm (HR, 0.766; 95\%
CI, 0.626-0.936; $P=.0090)$. In the PD-L1-positive population, the median OS was 18.4 months $(95 \% \mathrm{CI}$, 14.6-NC) in the 197-patient experimental arm vs 12.9 months (95\% CI, 11.1-15.4) in the 200-patient control $\operatorname{arm}(\mathrm{HR}, 0.660 ; 95 \% \mathrm{CI}, 0.505-0.864 ; P=.0023)$. Investigators observed OS benefit at all prespecified CPS cutoffs (CPS $\geq 1,5$, and 10 ).

Sintilimab is an immunoglobulin G4 monoclonal antibody that binds to PD-1 molecules on the surface of T cells and blocks the PD-1/PD-L1 pathway. The agent is designed to reactivate $T$ cells to eliminate cancer cells.

$\rightarrow$ For the full article, visit CancerNetwork.com/ORIENT_11.21

\section{Lung Cancer - ZENITH2O Trial}

The phase 2 ZENITH20 trial (NCT03318939) examining a daily dose of poziotinib (NOV 120101) at $16 \mathrm{mg}$ showed a $35 \%$ median tumor reduction in patients with treatmeantnaïve HER2 exon 20-mutant non-small cell lung cancer.

At a median follow-up of 13.5 months, the objective response rate (ORR) was $43.8 \%$ (95\% CI, 29.5\%-58.8\%) with $1(2.1 \%)$ complete response and $20(41.7 \%)$ partial responses. Fifteen patients $(31.3 \%)$ had stable disease and $7(14.6 \%)$ had progressive disease; 5 patients $(10.4 \%)$ were not evaluable.

The disease control rate was $75 \%$. The ORR, including unconfirmed responses, was $47.9 \%$ (95\% CI, 33.3\%$62.8 \%$ ). The median duration of response was 5.4 months (range, 2.8 to $>19.1$ ). The 6-month and 1-year response duration rates were $42 \%$ and $24 \%$, respectively. 
The median progression-free survival (PFS) was 5.6 months (range, 0 to $>20.2$ ). The 6-month PFS rate was $42 \%$; the 1 -year PFS rate was $26 \%$.

All 48 patients were evaluable for safety and all experienced treatment-related adverse events (TRAEs). Five $(10 \%)$ experienced serious TRAEs. Six $(13 \%)$ left the trial due to AEs, $88 \%$ required dose interruptions, and $77 \%$ required dose reductions.

The most common grade 3 TRAEs were rash $(35 \%)$, stomatitis/mucosal inflammation $(21 \%)$, and diarrhea $(15 \%)$. There were no grade $4 / 5$ AEs observed.

$\rightarrow$ For the full article, visit CancerNetwork.com/ZENITH_11.21

\section{Melanoma - RELATIVITY-047}

The combination of relatlimab and nivolumab (Opdivo) led to longer treatment-free intervals (TFI) as well as reductions in risk of progression or death following the next line of therapy vs nivolumab alone in patients with treatmeant-naïve metastatic or unresectable melanoma, according to findings from the phase 2/3 RELATIVITY-047 trial (NCT03470922).

The new efficacy results demonstrated that those who received the doublet and discontinued treatment $(\mathrm{n}=167)$ experienced a longer TFI vs single-agent nivolumab $(n=151)$, with a median TFI of 3.22 (range, 0.1-30.4) months vs 1.41 months (range, 0.1-25.6), respectively.

Relatlimab plus nivolumab also reduced the risk of progression following the next line of systemic therapy (PFS2), per investigator assessment, or death compared with nivolumab alone. The median PFS2 in the investigative arm was not reached (NR; 95\% CI, 21.75-NR) vs 20.04 months (95\% CI, 15.44-25.13) with nivolumab alone (HR, 0.77; 95\% CI, 0.61-0.97).

To be eligible for enrollment, patients had to have previously untreated metastatic/unresectable melanoma and an ECOG performance status of 0 or 1 . A total of 714 patients were enrolled to the trial; they were randomized 1:1 to receive either the fixed-dose combination of relatlimab at $160 \mathrm{mg}$ plus nivolumab at $480 \mathrm{mg}$ every 4 weeks $(\mathrm{n}=355)$ or nivolumab alone at $480 \mathrm{mg}$ every 4 weeks $(\mathrm{n}=359)$.

The most common reasons for discontinuation on the doublet and monotherapy arms were progressive disease (36.3\% vs $46.0 \%$, respectively), followed by treatmentrelated toxicity $(17.7 \%$ vs $8.9 \%)$, patient request $(5.4 \%$ vs $3.3 \%)$, and an adverse effect that was not related to treatment $(3.4 \%$ vs $3.9 \%)$.
More patients on the nivolumab-alone arm received subsequent therapy compared with the relatlimab/ nivolumab arm, at $37.3 \%$ vs $35.5 \%$, respectively; $29.8 \%$ vs $27.9 \%$ of patients, respectively, received systemic therapy.

Relatlimab is a human LAG-3-blocking antibody that was designed to restore the effector function of $\mathrm{T}$ cells that have been exhausted.

$\rightarrow$ For the full article, visit CancerNetwork.com/RELATIVITY_11.21

\section{Cervical Cancer - KEYNOTE-826}

In the phase 3 KEYNOTE-826 trial (NCT03635567), improved survival and responses were seen in first-line cervical cancer treated with pembrolizumab (Keytruda) plus chemotherapy with or without bevacizumab (Avastin).

In the subset of patients with a PD-L1 combined positive score (CPS) of 1 or higher, the median progression-free survival (PFS) in the investigative and control arms was 10.4 months (95\% CI, 9.7-12.3) vs 8.2 months (95\% CI, 6.38.5 ), respectively (HR, 0.62; 95\% CI, 0.50-0.77; P<.001). In this group, the median overall survival (OS) was not reached (NR) at the time of the data cutoff in the investigative arm (95\% CI, 19.8-NR) vs 16.3 months (95\% CI, 14.5-19.4) in the control arm (HR, 0.64; 95\% CI, 0.50-0.81; $P<.001)$.

In the all-comer population, the median PFS was 10.4 months (95\% CI, 9.1-12.1) in the investigative arm vs 8.2 months $(95 \% \mathrm{CI}, 6.4-8.4)$ in the control arm (HR, $0.65 ; 95 \% \mathrm{CI}, 0.53-0.79 ; P<.001)$. The median OS in this population was 24.4 months (95\% CI, 19.2-NR) with pembrolizumab vs 16.5 months (95\% CI, 14.5-19.4) with placebo (HR, 0.67; 95\% CI, 0.54-0.84; $P<.001$ ).

In the group of patients who had a PD-L1 CPS of 10 or higher, the median PFS with pembrolizumab plus chemotherapy with or without bevacizumab was 10.4 months (95\% CI, 8.9-15.1) vs 8.1 months (95\% CI, 6.2-8.8) with chemotherapy with or without bevacizumab (HR, 0.58; 95\% CI, 0.44-0.77; $P<.001)$. The median OS was also NR (95\% CI, 19.1-NR) in the investigative arm vs 16.4 months (95\% CI, 14.0-25.0) in the control arm (HR, 0.61; 95\% CI, 0.44-0.84; $P=.001$ ).

A total of 617 participants were randomized 1:1 to receive $200 \mathrm{mg}$ intravenous (IV) pembrolizumab every 3 weeks for up to 35 cycles plus paclitaxel/cisplatin or carboplatin every 3 weeks for up to 6 cycles with or without 15 $\mathrm{mg} / \mathrm{kg}$ IV bevacizumab every 3 weeks $(\mathrm{n}=308)$ or matched placebo at the same dose and schedule $(n=309)$. 
The safety profile of the pembrolizumab regimen was manageable. The incidence of all-cause and treatmentrelated grade 3 or higher or serious adverse effects were all numerically greater in the immunotherapy-containing arm, but patients receiving pembrolizumab were generally on treatment longer vs those receiving placebo.

$\rightarrow$ For the full article, visit CancerNetwork.com/KEYNOTE_11.21

\section{Breast Cancer - DESTINY-Breast03}

Data from the DESTINY-Breast03 trial (NCT03529110) exhibited superiority of progression-free survival (PFS) with fam-trastuzumab deruxtecan-nxki (Enhertu) vs trastuzumab emtansine (T-DM1; Kadcyla) in patients with previously treated HER2-positive metastatic breast cancer and is the first trial to compare the 2 options.

Median PFS for patients treated with trastuzumab deruxtecan was not reached (95\% CI, 18.5 to not estimable [NE]) vs 6.8 months (95\% CI, 5.6-8.2) with T-DM1 (HR, 0.28; $95 \%$ CI, $0.22-0.37 ; P=7.8 \times 10^{-22}$ ). Among the 261 patients in the trastuzumab deruxtecan arm, the 12-month PFS rate was $75.8 \%$ (95\% CI, $69.8 \%-80.7 \%$ ) vs $34.1 \%$ (95\% CI, $27.7 \%-40.5 \%$ ) among 263 patients treated in the T-DM1 arm.

The median overall survival (OS) was NE in both arms (HR, 0.56; 95\% CI, 0.36-0.86; $P=.007172$ ). The 12-month OS rates were $94.1 \%(95 \% \mathrm{CI}, 90.3 \%-96.4 \%)$ in the trastuzumab deruxtecan arm vs $85.9 \%$ (95\% CI, $80.9 \%$ $89.7 \%$ ) in the T-DM1 arm.

DESTINY-Breast03 randomized 524 patients with HER2-positive metastatic breast cancer, previously treated with trastuzumab and taxane, to receive either trastuzumab deruxtecan $5.4 \mathrm{mg} / \mathrm{kg}$ every 3 weeks or T-DM1 $3.6 \mathrm{mg} / \mathrm{kg}$ every 3 weeks. Patients with clinically stable, treated brain metastases were eligible for enrollment.

The overall response rate (ORR) and best overall response data also favored trastuzumab deruxtecan. Specifically, the confirmed ORR in the trastuzumab deruxtecan arm was 79.7\% (95\% CI, 74.3\%-84.4\%) vs 34.2\% (95\% CI, $28.5 \%$ $40.3 \%)$ in the T-DM1 $\operatorname{arm}(P<.0001)$.

Of the responders in the trastuzumab deruxtecan arm, $16.1 \%$ had a complete response (CR) and $63.6 \%$ had a partial response (PR). Among responders in the T-DM1 arm, $8.7 \%$ had a CR and $25.5 \%$ had a PR. Stable disease was reported for $16.9 \%$ and $42.6 \%$ of patients, respectively. The disease control rate (CR plus PR plus stable disease) was $96.6 \%$ with trastuzumab deruxtecan vs $76.8 \%$ with T-DM1.
In terms of safety, the incidence of grade 3/4 drugrelated treatment-emergent adverse effects (DRTEAEs) was $45.5 \%$ with trastuzumab deruxtecan vs $39.8 \%$ with T-DM1. This difference extended to incidence of serious DRTEAEs (10.9\% vs $6.1 \%$, respectively), DRTEAEs associated with discontinuation $(21.4 \%$ vs $12.6 \%)$, and DRTEAEs associated with dose reductions $(21.4 \%$ vs $12.6 \%)$.

$\rightarrow$ For the full article, visit CancerNetwork.com/DESTINY_11.21

\section{Prostate Cancer - CheckMate 9KD}

Final data from a cohort analysis of the CheckMate 9KD trial (NCT03338790) indicate that treatment with nivolumab (Opdivo) plus rucaparib (Rubraca) may produce effective results in patients with homologous recombination deficient (HRD)-positive, chemotherapy-naïve metastatic castration-resistant prostate cancer.

Moreover, the study results demonstrated noteworthy activity in individuals whose disease harbored $B R C A$ mutations.

After a median follow-up of 17.5 months, the overall response rate (ORR) among all evaluable patients $(\mathrm{n}=39)$ was $15.4 \%$ (95\% CI, 5.9\%-30.5\%). Confirmed ORR among the 20 patients with HRD-positive tumors was $25 \%(95 \%$ CI, $8.7 \%-49.1 \%$ ). Moreover, the 9 patients whose disease harbored BRCA1/2-positive mutations achieved an ORR of $33.3 \%$ (95\% CI, 7.5\%-70.1\%). However, ORR was unfavorable in the 19 patients who had HRD-negative or nonevaluable tumors $(5.3 \%$; $95 \% \mathrm{CI}, 0.1 \%-26.0 \%)$.

The trend of noteworthy clinical activity in patients with HRD-positive tumors and BRCA1/2-positive mutations continued in confirmed prostate-specific antigen response rates (PSA-RRs). Among 66 evaluable patients, confirmed PSA-RR reached $27.3 \%$ (95\% CI, $17.0 \%-39.6 \%$ ). The confirmed PSA-RR rate among patients with HRD-positive tumors ( $\mathrm{n}=31$ ) was $41.9 \%$ (95\% CI, 24.5\%-60.9\%). And the 13 patients with $B R C A 1 / 2$-positive mutations achieved a confirmed PSA-RR of $84.6 \%$ (95\% CI, 54.6\%-98.1\%).

Nivolumab was administered at $480 \mathrm{mg}$ every 4 weeks and rucaparib was given at a $600 \mathrm{mg}$ dose twice per day. Treatment was given until disease progression or unacceptable toxicity was reached. Of note, nivolumab dosing was limited to a maximum of 2 years.

Among the overall population $(n=71)$, the median radiographic progression-free survival (rPFS) was 8.1 months (95\% CI, 5.6-10.9). The median rPFS in those with HRD-negative tumors $(\mathrm{n}=37)$ was 5.6 months $(95 \%$ 
CI, 3.7-9.1) compared with 10.9 months (95\% CI, 6.7-12.0) in those with HRD-positive tumors $(\mathrm{n}=34)$.

Treatment with the combination was also associated with favorable overall survival (OS) results. The median OS among all patients was 20.2 months (95\% CI, 14.1-22.8). The median OS in the 34 patients with HRD-positive tumors was 22.7 months (95\% CI, 14.1 months to not estimable). Patients in the HRD-negative group $(\mathrm{n}=37)$ had the least favorable median OS at 19.0 months (95\% CI, 8.2-22.1).

Most of the study participants $(n=64)$ experienced a treatment-related adverse event (TRAE) of any grade; approximately half $(\mathrm{n}=36)$ experienced a TRAE that was classified as grade 3 or 4 .

$\rightarrow$ For the full article, visit CancerNetwork.com/CheckMate_11.21

\section{Prostate Cancer - ARCHES}

Treatment with enzalutamide (Xtandi) and androgen deprivation therapy (ADT) yielded a durable overall survival (OS) benefit in men with metastatic hormone-sensitive prostate cancer, according to data from the phase 3 ARCHES study (NCT02677896).

At 24 months, $86 \%$ of patients were alive in the enzalutamide group compared with $82 \%$ in the placebo group. Moreover, at 36 months, $78 \%$ of those in the enzalutamide cohort were alive vs $69 \%$ in the placebo group. Lastly, at 48 months, there were $71 \%$ were alive in the enzalutamide group compared with $57 \%$ in the placebo group. The enzalutamide group achieved a significant improvement in OS, 34\%, compared with the placebo group. The enzalutamide/ADT group had an extended survival compared with the placebo/
ADT group (HR, 0.66; 95\% CI, 0.53-0.81; $P<.0001$ ).

The trial had a median follow-up of 44.6 months. The median treatment duration was 40.2 months in the enzalutamide/ADT cohort, 13.8 months in the placebo/ADT cohort, and 23.9 months for those who crossed over.

The study enrolled 1150 men who were randomized 1:1 to receive either $160 \mathrm{mg}$ of enzalutamide plus ADT $(\mathrm{n}=574)$ or placebo plus ADT $(\mathrm{n}=576)$.

The study was unblinded during final analysis to let those patients who were still enrolled to continue treatment. At the time of unblinding, $31.9 \%(\mathrm{n}=184)$ of patients in the placebo group were progression free and consented to cross over to the enzalutamide group, and almost all $(\mathrm{n}=180)$ received treatment with enzalutamide plus ADT. The median time to crossover was 21.5 months.

Investigators also assessed the time to subsequent antineoplastic therapy and reported that, compared to those receiving placebo, those receiving enzalutamide had a significant delay in the need for subsequent therapy (HR, $0.38 ; 95 \% \mathrm{CI}, 0.31-0.48)$. A total of $8.4 \%$ of patients in the enzalutamide group and $12.3 \%$ of those in the placebo group received treatment with docetaxel. Patients in the enzalutamide and placebo arms, respectively, also received subsequent treatment with abiraterone (Zytiga; $4.5 \%$ vs $7.3 \%)$, enzalutamide $(1.2 \%$ vs $10.6 \%)$, bicalutamide/ flutamide (1.4\% vs $4.0 \%$ ), cabazitaxel (Jevtana; $1.9 \%$ vs $1.0 \%$ ), sipuleucel-T (Provenge; $0.7 \%$ vs $1.0 \%$ ), radium $(1.0 \%$ vs $0.7 \%)$, or another treatment $(4.0 \%$ vs $2.1 \%)$.

Investigators did not find any study- or drug-related treatment-emergent adverse events (TEAEs) leading to death in the enzalutamide arm. However, $13.8 \%(\mathrm{n}=79)$ of TEAEs in the enzalutamide group, $5.6 \%(\mathrm{n}=32)$ in the placebo group, and $7.2(\mathrm{n}=13)$ in the crossover group led to stop or withdrawal from treatment.

$\rightarrow$ For the full article, visit CancerNetwork.com/ARCHES_11.21
Brian Rini, MD, on Expectations for a Trial Examining MK-1308A Plus Lenvatinib and Pembrolizumab With Other Combinations in cCRCC
Brian Rini, MD, spoke with CancerNetwork ${ }^{\circledR}$ at the 2021 European Society for Medical Oncology Congress about his expectations for the results of the upcoming randomized, open-label, phase 3 trial (NCT04736706).

The 3-arm study will compare MK-1308A or belzutifan (Welireg) added to lenvatinib (Lenvima) and pembrolizumab (Keytruda) vs the control arm of pembrolizumab plus lenvatinib to treat advanced clear cell renal cell carcinoma (ccRCC) in the first-line setting.

CancerNetwork.com/ESM021_Rini 


\section{Experts Detail Potential of ${ }^{18}$ F-fluciclovine PET/CT to Guide Prostate Cancer Decision-Making}

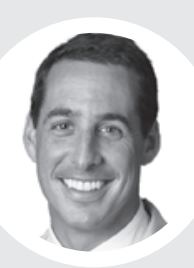

Brian T. Helfand, MD, PhD NorthShore Medical Group Glenview, IL

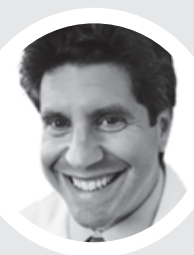

\section{Steven E. Finkelstein, MD} Florida Cancer Affiliates Panama City, Florida

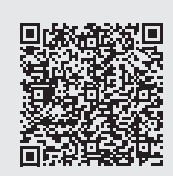

Scan QR code for the complete video series.
1 lthough definitive therapies such as radical prostatectomy and radiation can treat patients with nonmetastatic and localized prostate cancer, $20 \%$ to $40 \%$ of patients may experience disease progression or inadequate treatment responses. ${ }^{1}$

Compared with CT and MRI, evidence for ${ }^{18} \mathrm{~F}$-fluciclovine PET/CT demonstrates its ability to provide better diagnostic capabilities for restaging recurrent prostate cancer, with its use in treatment planning typically resulting in a change to salvage radiotherapy following prostatectomy. The synthetic amino acid radiotracer was developed at Emory University and is FDA approved for prostate cancer recurrence imaging. ${ }^{2}$

In a recent Between the Lines conversation, Brian T. Helfand, MD, PhD, and Steven E. Finkelstein, MD, examined key details from the phase 2/3 randomized EMPIRE-1 trial (NCT01666808) on ${ }^{18} \mathrm{~F}$-fluciclovine PET/CT compared with conventional imaging alone in guiding salvage postprostatectomy radiotherapy for patients with prostate cancer. ${ }^{3}$

Finkelstein, a radiation oncologist with Florida Cancer Affiliates, part of the US Oncology Network, in Panama City, Florida, said, "We have to phrase this in the mindset [that] most imaging modalities are not approved for improvement in demonstrating cancer outcomes. This is the first time that we are using a PET/radiotracer for prostate cancer, specifically in the setting of postprostatectomy salvage."

"I think that this is one of the most important articles that people should be aware of, both for our community and academic-based practices," explained Helfand, a urologist at NorthShore University HealthSystem in Glenview, Illinois. "Most people who are [seeing] this really understand that prostate cancer is a very complex disease and many decisions that we make aren't perfect."

The expectation is that, with the integration of ${ }^{18} \mathrm{~F}$-fluciclovine PET/CT into radiotherapy planning, treatment will be more effective compared with standard imaging sequences.

"If you underwent surgery, waiting until your PSA [prostate-specific antigen] value starts to rise from zero can be used to [determine when to] treat disease recurrence. And molecular imaging is one way to help guide us in these treatment decisions," Helfand explained.

\section{Methods and Results of EMPIRE-1}

The study enrolled 165 patients with prostate cancer and randomly assigned them to either conventional imaging only ( $\mathrm{n}=82$ ) or conventional imaging plus ${ }^{18}$ Ffluciclovine PET/CT $(\mathrm{n}=83)$.

The primary end point was 3-year event-free survival (EFS), with key 
secondary end points including pre and postPET treatment decisions and gastrointestinal and genitourinary adverse effects as reported by providers.

"This technology, ${ }^{18} \mathrm{~F}$-fluciclovine PET/CT imaging, has really been used to help us identify or locate targets that can theoretically make subsequent radiation therapy more accurate and improved," Helfand explained. "We've all accepted this as a paradigm: if we can better localize it and we can treat it, then that should give better oncologic outcomes."

The 3-year EFS analysis found a $12.5 \%$ difference between the 2 groups $(75.5 \%$ vs $63.0 \%)$, favoring ${ }^{18} \mathrm{~F}$-fluciclovine-PET/CT vs conventional imaging $(95 \% \mathrm{CI}, 4.3 \%-20.8 \% ; P=.0028)$.

Variables found to be significant predictors of EFS by univariate analysis included Gleason score greater than 8, absence of extracapsular extension, absence of seminal vesicle invasion, whole pelvic treatment field, and PSA levels of $1.0 \mathrm{ng} / \mathrm{mL}$ or more (TABLE).

"Once we start analyzing significant predictors and putting this all into a model, we can see that EFS showed significantly higher risk in the conventional imaging group compared with the ${ }^{18} \mathrm{~F}$-fluciclovine group," Helfand explained.

Along with EFS, a difference of $24.3 \%$ (95\% CI, $15.6 \%-33.0 \% ; P<.0001$ ) in failure-free survival at 4 years was observed between the 2 groups, with rates of $75.5 \%$ and $51.2 \%$ in the ${ }^{18} \mathrm{~F}$-fluciclovine PET/CT and conventional imaging groups, respectively.

Although the trial expanded the typical radiation field delivered to patients, with 25 and 35 patients receiving treatment to the prostate bed and pelvic nodes in the conventional imaging and ${ }^{18} \mathrm{~F}$-fluciclovine PET/CT groups, respectively, that expansion did not correlate with increased grade 3 or higher adverse effects (AEs).

"[In] this group with PET-driven radiation, [we used] larger fields in

\section{TABLE. Significant Predictors of EFS by Univariate Analysis}

\begin{tabular}{l|l} 
Variables & HR $(95 \% \mathrm{CI})$ \\
\hline Gleason score of 8 or more & $2.15(1.17-3.96)$ \\
\hline Absence of extracapsular extension & $0.44(0.23-0.83)$ \\
\hline Absence of seminal vesicle invasion & $0.49(0.27-0.91)$ \\
\hline Whole pelvis radiotherapy field & $2.77(1.50-5.11)$ \\
\hline PSA of $\mathbf{1 . 0} \mathbf{~ n g / m L ~ o r ~ m o r e ~}$ & $3.18(1.73-5.85)$
\end{tabular}

EFS, event-free survival; PSA, prostate-specific antigen.

many [patients], but the toxicity was not significantly higher," Finkelstein explained. "[I] think urologists will say, 'I'm excited about the fact that we can deliver PET-targeted radiotherapy and keep the toxicity about the same."”

AEs were similar between the groups, with common any-grade AEs including late urinary frequency or urgency $(46 \%$ of patients in the conventional imaging group and $41 \%$ of patients the PET group) and acute diarrhea (14\% and $21 \%$, respectively). Grade 3 AEs were not frequently observed, and no grade 4 or $5 \mathrm{AEs}$ were reported in either group.

\section{Implications and Key Takeaways}

Although many trials have examined the timing of radiotherapy and the roles of androgen deprivation therapy and pelvic lymph node radiation in this setting, this is the first prospective randomized trial to analyze molecular imaging with cancer control as the primary end point.

"[ ${ }^{18} \mathrm{~F}$-fluciclovine PET/CT $]$ imaging has the ability - and this is the first study to prospectively evaluate this-to change our management and improve overall oncologic outcomes over at least a 3.5-year period without adding additional toxicity," Helfand said.

Looking ahead, both Helfand and Finkelstein have their fair share of questions regarding radiotherapy modalities used and about newer therapies that are more stereotactically guided. Also, given that this research was a single-institution study conducted at the Winship Cancer Institute of Emory University in Atlanta,
Georgia-a center known for developing PET agents-the experts were eager to see how this would translate for the community, according to Helfand.

"As we develop next-generation imaging - whether it is [choline] C-11 PET, Axumin scans, or now [prostate-specific membrane antigen] - the idea of actually finding the targets and then radiating them is much more appealing than just going to radiate where the money potentially is, because we're only right about half the time," Finkelstein explained.

Looking ahead, with new next-generation imaging agents on the horizon, Finkelstein hypothesized that the next 10 years will be critical to developing strategies to stratify important variables that may indicate when it is appropriate to accelerate the radiation timeline for patients or to wait to begin the process.

"For the first time, we actually can use a PET-imaging agent, a next-generation agent, and have an improvement using radiation therapy to improve oncologic outcomes," said Finkelstein.

As the modern management of patients via evidence of disease progression and treatment responses continues to evolve, so will the ability to effectively treat patients with prostate cancer, according to the experts.

"Once we have a true system in place to really stratify patients and understand where that disease is coming from, I think it really changes the field," Helfand stressed.

For references visit cancernetwork.com/ProstateBTL_11.21 


\section{Experts Examine Tipifarnib to Treat HNSCC With HRAS Mutations}

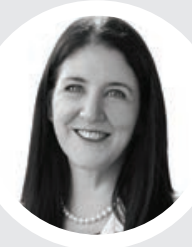

Victoria M. Villafior, MD City of Hope Duarte, CA

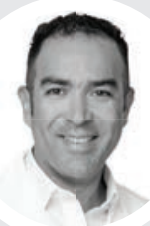

Cesar A. Perez, MD

Sarah Cannon Research Institute at Florida Cancer Specialists Orlando, FL

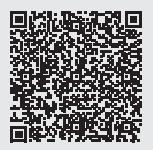

Scan QR code for the complete video series.
1 lthough HRAS mutations occur in $4 \%$ to $8 \%$ of patients with recurrent or metastatic head and neck squamous cell carcinoma (HNSCC), few viable options to effectively target these oncogenic drivers are available. ${ }^{1}$

Results of a recent phase 2 study (NCT02383927) investigating the viability of tipifarnib for patients with recurrent and/or metastatic HNSCC harboring HRAS mutations may provide a rationale for its use in patients whose therapeutic options are limited.

In a Between the Lines ${ }^{\mathrm{TM}}$ conversation between Victoria M. Villaflor, MD, and Cesar A. Perez, MD, the results and key takeaways of the study, and how these may motivate future treatment, were discussed.

"Most of the patients I have seen in my practice with $H R A S$ positivity, as far as mutations, tend to have very poor outcomes," Villaflor, section chief of head and neck oncology and professor, Department of Medical Oncology \& Therapeutics Research, City of Hope, Duarte, California, explained during the program. "They generally are your patients who progress through everything."

Tipifarnib, a farnesyltransferase inhibitor, was developed 20 years ago but has yet to find the right patient population who derive a strong benefit, said Perez, a head and neck medical oncologist and director of drug development at Sarah Cannon Research
Institute at Florida Cancer Specialists.

"It's a drug that is at least 2 decades old and it took all this time for us to find out this specific target," Perez continued.

\section{Methods and Efficacy Results With Tipifarnib}

A total of 22 patients with a high variant allele frequency (VAF; $\geq 20 \%$ ) were enrolled on the trial; 20 were eligible for the efficacy analysis. The patients' median age was 63 years (range, 20-89) and $68.2 \%$ were male.

Oral cavity was the most frequently reported site of the primary tumor in eligible patients (45.5\%). Median prior lines of therapy received was 2 (range, $0-6)$, with all but 2 patients $(90.9 \%$ ) receiving first-line platinum-based therapy for locally advanced or metastatic disease.

Patients with HNSCC initially received oral tipifarnib at a dose of $900 \mathrm{mg} 2$ times a day on days 1 through 7 and 15 through 21 of 28-day cycles, but 9 of 15 patients who received this dosing required dose reductions to $600 \mathrm{mg}$ twice daily in the second cycle to manage toxicities. Thus, the starting dose of tipifarnib was changed to $600 \mathrm{mg}$ twice a day to improve tolerability.

"Many of the patients who had partial responses were treated with the 600-mg dose. It was a good decision from the authors of the study," Perez explained. 
TABLE. Responses by Patient Subgroups

\begin{tabular}{l|c|c} 
VAF level & Objective response rate & $95 \% \mathrm{Cl}$ or range \\
\hline All patients $(\mathbf{n}=\mathbf{2 2})$ & $50.0 \%$ & $95 \% \mathrm{Cl}, 30.7 \%-69.3 \%$ \\
\hline Efficacy-evaluable patients $(\mathbf{n}=\mathbf{2 0})$ & $55.0 \%$ & $95 \% \mathrm{Cl}, 31.5 \%-76.9 \%$ \\
\hline VAF > 35\% (n = 12) & $58.3 \%$ & Range, 37\%-90\% \\
\hline VAF < 35\% (n = 8) & $50.0 \%$ & Range, 23\%-33\% \\
\hline
\end{tabular}

VAF, variant allele frequency.

The primary end point of objective response rate was $55.0 \%(95 \% \mathrm{CI}$, $31.5 \%-76.9 \%$ ) for evaluable patients with high VAF. Partial responses were observed in 11 patients with stable disease occurring in 9 , for a clinical benefit rate of $100 \%$. A slightly higher rate of response was noted in patients with VAF $>35 \%$ vs the rest of the treated patients (TABLE).

"Patients who have higher VAFs, [more than] $20 \%$, have better durations of response to treatment," Villaflor said.

Median progression-free survival (PFS) was higher among patients receiving tipifarnib compared with last prior therapy $(P=.0012)$.

"In a small study, you have a [median] PFS with tipifarnib of 5.6 months [95\% CI, 3.6-16.4 months] in patients who were heavily pretreated," explained Villaflor. "Additionally, patients on their last prior therapy [had a median] PFS of 3.6 months [1.3-5.2 months], which gives you an indication of how [disease in] these patients generally behave."

"These data [regarding] the last prior therapy are very important. As [Dr Villaflor] mentioned, we know that these are patients who were pretreated and were progressing fairly rapidly," Perez explained. "The fact that they had close to a 6-month PFS [with tipifarnib] is very important and significant."

In the safety analysis that featured 30 patients, hematologic adverse effects (AEs) including anemia (37\%), lymphopenia $(13 \%)$, neutropenia $(10 \%)$, and leukopenia (10\%), as well as gastrointestinal disturbances like nausea $(10 \%)$ were the most common grade 3 or higher AEs.

Regarding the safety profile, Perez explained on what was observed with cytopenias. It is common, he explained, for heavily pretreated patients to experience these events even with lower treatment dosages, regardless of chosen therapy.

Treatment-emergent AEs that led to the discontinuation of tipifarnib were laryngeal obstruction in 2 patients and respiratory failure in 1 . At the data cutoff point, no patients with high VAF discontinued treatment with tipifarnib due to AEs.

\section{Future Directions With Tipifarnib in HNSCC}

Given these positive data, Perez and Villaflor looked to the future for tipifarnib use in this population of patients with HNSCC and HRAS mutations.

"It seems that we finally have a target mutation that we can use in patients with HNSCC," Perez said.

"The fact that we do have some data in a small study that show that we might be able to target this gene is very compelling. I look forward to further studies in this area, as well, to see if we can ultimately get this drug approved in this indication," Villaflor explained.

An ongoing pivotal phase 2 study (NCT03719690) is looking at outcomes in HRAS-mutant HNSCC with tipifarnib and how HRAS mutations impact HNSCC therapies.

"Most of the head-and-neck oncology field are waiting for more data about this, and hopefully [the data] will translate into the clinic," Perez explained.

According to Villaflor, the development of targeted therapies for patients with HNSCC has been difficult because of the interrelation of the KRAS, NRAS, and HRAS mutations, adding that the results of this research may support increased genomic testing and ultimately drive further investigation. ${ }^{2}$

"We have been studying HRAS, and all the RAS pathways, in head-andneck cancer for a couple of decades, but it wasn't until now that they caught it. Now that they have these data, we should try to understand [it] a bit better. We have better technology than 20 years ago, we have better sequencing, and once you understand [that], you can develop combination trials that could prolong the duration of response in these patients," Perez explained.

\section{REFERENCES}

1. Ho AL, Brana I, Haddad R, et al. Tipifarnib in head and neck squamous cell carcinoma with HRAS mutations. J Clin Oncol. 2021;39(17):1856-1864. doi:10.1200/ JCO.20.02903

2. Pearson AT, Vokes EE. Is this the dawn of precision oncology in head and neck cancer? J Clin Oncol. 2021;39(17):1839-1841. doi:10.1200/JCO.21.00569

EDITOR'S NOTE: Interview quotes slightly modified for readability. 


\section{CONTINUING MEDICAL EDUCATION (CME)}

\section{Exploring Emerging Immunotherapies in Melanoma}

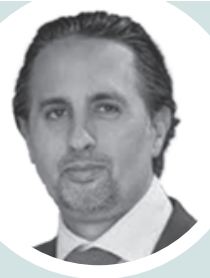

FACULTY

Omid Hamid, MD

Director, Melanoma Center and Phase 1

Immuno-Oncology Program

Chief, Immunotherapy and Translational

Research

The Angeles Clinic and Research Institute

Director, Melanoma Program

Cedars Sinai Samuel Oschin

Comprehensive Cancer Institute

Los Angeles, CA

This activity was written by $P E R^{\circledR}$ editorial staff under faculty guidance and review. The Q\&A portion of the activity was transcribed from a recorded interview with the faculty and edited by faculty and PER ${ }^{\circledR}$ editorial staff for clarity.

\section{CIME PROVIDER CONTACT}

INFORMIATION

Physicians' Education Resource ${ }^{\circledast}$, LLC

2 Clarke Drive, Suite 110

Cranbury, NJ 08512

Toll-Free: 888-949-0045

Local: 609-378-3701

Fax: 609-257-0705

info@gotoper.com

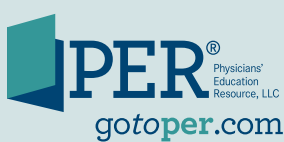

\section{LEARNING OBJECTIVES}

Upon successful completion of this activity, you should be better prepared to:

- Describe the mechanism of actions of novel immune checkpoint inhibitors for the treatment of cancer

- Explain the rationale for using emerging immunotherapies for the management of cancer

- Assess key data from ongoing clinical trials evaluating novel immune checkpoint inhibitors for the treatment of cancer

RELEASE DATE: November 1, 2021

EXPIRATION DATE: November 1, 2022

\section{INSTRUCTIONS FOR PARTICIPATION / HOW TO RECEIVE CREDIT}

1. Read this activity in its entirety.

2. Go to https://www.gotoper.com/go/eeim21 to access and complete the posttest.

3. Answer the evaluation questions.

4. Request credit using the drop-down menu.

You may immediately download your certificate.

\section{FACULTY, STAFF, AND PLANNERS' DISCLOSURES}

In accordance with ACCME Guidelines, PER ${ }^{\circledast}$ has identified and resolved all COI for faculty, staff, and planners prior to the start of this activity by using a multistep process.

Disclosures: Consultant:Aduro, Akeso Biopharma, Amgen, BeiGene, BioAtla, Bristol Myers Squibb, Roche, Genentech, GlaxoSmithKline, Immunocore, Idera Pharmaceuticals, Incyte, Janssen Pharmaceuticals, Merck \& Co., NextCure, Novartis, Pfizer, Sanofi Regeneron, Seagen, Tempus, Zelluna Immunotherapy AS. Speaker's Bureau: Bristol Myers Squibb, Novartis, Pfizer, Sanofi Regeneron. Other Support (please specify): Contracted Research for Institution: Arcus Biosciences, Aduro, Akeso Biopharma, Amgen, BioAtla, Bristol Myers Squibb, CytomX Therapeutics, Exelixis, Roche Genentech, GlaxoSmithKline, Immunocore, Idera Pharmaceuticals, Incyte, lovance Biotherapeutics, Merck \& Co., Moderna, Merck Serono, NextCure, Novartis, Pfizer, Sanofi Regeneron, Seagen, Torque Pharmaceuticals, Zelluna Immunotherapy AS.

The staff of $P E R^{\circledast}$ have no relevant financial relationships with commercial interests to disclose.

\section{OFF-LABEL DISCLOSURE AND DISCLAIMER}

This activity may or may not discuss investigational, unapproved, or off-label use of drugs. Learners are advised to consult prescribing information for any products discussed. The information provided in this activity is for accredited continuing education purposes only and is not meant to substitute for the independent clinical judgment of a healthcare professional relative to diagnostic, treatment, or management options for a specific patient's medical condition. The opinions expressed in the content are solely those of the individual faculty members, and do not reflect those of PER ${ }^{\circledast}$ or any of the companies that provided commercial support for this activity.

This activity is funded by $\mathrm{PER}^{\circledR}$.

\section{ACCREDITATION/CREDIT DESIGNATION}

Physicians' Education Resource ${ }^{\oplus}$, LLC, is accredited by the Accreditation Council for Continuing Medical Education (ACCME) to provide continuing medical education for physicians. Physicians' Education Resource ${ }^{\circledR}$, LLC, designates this enduring material for a maximum of 0.5 AMA PRA Category 1 Credits ${ }^{T}$. Physicians should claim only the credit commensurate with the extent of their participation in the activity. 


\section{ACTIVITY}

Melanoma is a skin malignancy that accounts for approximately $1 \%$ of skin cancers and nearly $73 \%$ of skin cancerrelated deaths in the United States. ${ }^{1}$ The 5-year relative survival rate at the localized stage is $98 \%$; however, this percentage drops significantly to $23 \%$ when patients are diagnosed with advanced or metastatic disease. ${ }^{1}$ The National Comprehensive Cancer Network (NCCN) guidelines recommend anti-PD-1 monotherapy (eg, pembrolizumab, nivolumab) or combined use of anti-CTLA4/PD-1 agents (eg, nivolumab plus ipilimumab) as first-line therapy in patients given a diagnosis of metastatic or unresectable disease. ${ }^{2}$ In malignancies displaying a $B R A F$ V600 activating mutation, treatment options include combination therapy with BRAF and MEK $1 / 2$ inhibitors (eg, dabrafenib plus trametinib, vemurafenib plus cobimetinib, encorafenib plus binimetinib). ${ }^{2}$

The high metastatic potential and poor survival related to melanoma have driven clinical research of novel biomarkers and therapeutics (eg, immunotherapy agents) to improve treatment. ${ }^{3}$ CTLA4 and PD-1 are immune checkpoints expressed on activated T cells; they have emerged as new therapeutic targets in managing metastatic melanoma. ${ }^{4}$ When used alone or in combination, these agents quickly have become the standard of care for patients with stage III or IV melanoma. Recent data has indicated an increase in median survival to 6 years. ${ }^{5}$

In this article, Omid Hamid, MD (@OmidHamidMD), Co-Director of Cutaneous Oncology at The Angeles Clinic and Research Institute, A Cedars Sinai Affiliate, discusses recent data from clinical trials investigating immunotherapeutic approaches for treating melanoma and the potential impact of these emerging therapies on the clinical management of affected patients.

\section{. Broadly speaking, how has immunotherapy impacted the management of melanoma in recent years?}

HAMID: Immunotherapeutic options have changed the prognosis for metastatic melanoma significantly over the course of the last decade. For example, when I began treating patients with unresectable metastatic melanoma, the average survival that we would quote patients was 6 to 8 months. At 6 to 8 months, $50 \%$ of patients would have passed due to their disease. Given the new therapies with checkpoint inhibitors, including anti-PD-1 and anti-CTLA4 therapy and regimens that target patterns of escape and resistance, we have now changed that. The median survival of melanoma now is somewhere around 6 years and [is] improving rapidly. We have begun to understand that immunotherapy is the backbone of all therapy for melanoma and have extended past just checkpoint inhibitors and interleukins (IL-2) into therapy with adoptive T-cell therapy, [chimeric antigen receptor-T cell] therapies, and [bispecific antibodies]. Clearly, we are moving past the standard single-agent checkpoint inhibitors into [combinatorial therapy], paving the way for significant impact in survival for our patients.

\section{What are the current 1. limitations with immune checkpoint inhibitors that we have available?}

HAMID: The current limitations we have with checkpoint inhibitors are multifaceted. First, we do not have great predictive factors to tell us who is going to respond and who is not. Again, these predictive factors would have the additional benefit of telling us who is going to have toxicity and who will not. At this point, we're treating 100\% of the patients initially with checkpoint inhibitor-based therapy. There are patients who will [experience refractory disease] down the line, and there are patients who [have disease that are] initially refractory to these therapies. We have not been able to understand who these patients are, and, at the same time, we have not been able to find a strategy to choose appropriate second-line therapy from the host of therapies available. For example, adoptive T-cell therapy has proven durable response in patients with metastatic melanoma [unresponsive to] standard therapies, including checkpoint inhibitors and targeted agents.

We still do not have an understanding and an agreement [of] where these adoptive T-cell therapies should be placed. Should they be exactly second-line, thirdline, or elsewhere? At the same time, we do not clearly understand how we can move forward with immune therapies for patients who have had significant immune-related adverse events from checkpoint-inhibitor therapy. We know there are some patients restarted on therapy [who] do not have the same toxicity but may have other immune-related toxicities, [whereas] some patients never have a recrudescence of toxicity. The greatest need now is predictive markers, whether they [are] tumor-related [or] whether they [are] related to circulating tumor biomarkers or other factors that we can [use] to tell us who will be responding early [or] have toxicity and which therapies make sense in the future.

We are moving forward with this 
roadmap. All [of] our trials now have circulating-tumor DNA and biopsies on trial to uncover these biomarkers. If you followed the recent [European Society for Medical Oncology (ESMO)] presentations, there was imaging to understand if our $\mathrm{T}$ cells are trafficking to the right area with a [positron emission tomography] tracer that latches onto CD8 ${ }^{+} \mathrm{T}$ cells. ${ }^{6}$ We are continuing to move forward in therapeutics and working hard to have correlative predictive markers to tell us when to stop, who will have toxicity, and who will benefit.

\section{What have been some of the key updates we have seen over the course of 2021 for use of anti-PD-1 and anti- CTLA4 approaches?}

HAMID: [The year] 2021 has seen an increase in the use of checkpoint inhibitors, including anti-PD-1 and anti-CTLA4 [agents] for melanoma. Importantly, most recently at ESMO 2021, Jason Luke, MD, and others presented data from KEYNOTE-716, which was a randomized trial of pembrolizumab versus placebo for patients with stage IIB and IIC melanoma. ${ }^{7}$ This was a double-blind, phase 3 trial [in which] 976 patients [were randomized] in a $1: 1$ fashion to pembrolizumab versus placebo; upon recurrence, [the study was unblinded] to evaluate whether rechallenge or crossover to pembrolizumab therapy was indicated. ${ }^{7}$ At [a median follow-up of] 14.4 months, recurrence-free survival [RFS] in this population was significantly improved with a hazard ratio of 0.65 , which meant, at any time, patients had a $35 \%$ less chance of having recurrence, with a significant $P$ value. ${ }^{7}$ The 12 -month RFS for patients on pembrolizumab was $90.5 \%$ versus $83.1 \%$ [for] patients who had been on placebo. ${ }^{7}$

What we saw here is, hopefully, a change in prognosis for these patients. The number of stage IIB and IIC patients is equivalent to [the number of] stage III

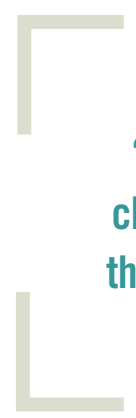

"Clearly, we are moving past the standard single-agent checkpoint inhibitors into [combinatorial therapy], paving the way for significant impact in survival for our patients."

patients seen in the United States yearly. ${ }^{8}$ What we're working on now are predictive markers to try and understand who can benefit. The strongest data that came from this trial was a decrease in distant recurrence from $7.8 \%$ to $4.7 \% .^{7}$ This is wonderful. Unfortunately, there was toxicity, and approximately $20 \%$ of patients received long-term hormonal therapy for management of endocrine toxicities. ${ }^{7}$ We saw an incidence of grade 3 or 4 toxicity similar to our previous experience, and about $15 \%$ of patients had to come off because of toxicity. ${ }^{7}$ The questions remain whether early versus late intervention changes outcome for these patients, what [we can] do with patients who [experience a recurrence] while on pembrolizumab in the adjuvant setting, and whether these patients will be included in future clinical trials.

Updates on the combination of ipilimumab and nivolumab for patients with brain metastases-the final 3-year outcomes on CheckMate-204 were presented by Hussein Tawbi ${ }^{1}$ and Kim Margolin. ${ }^{9}$ [They] showed a significant overall survival [OS] for patients who had response, and intracranial progression-free survival [PFS] was $50 \%$ and plateaued from year 2 to year $3 .^{9}$ The OS rates were $74 \%$ and $72 \%$ from 2 to 3 years. ${ }^{9}$ This is showing significant benefit, disease control, and survival in a subset of patients who were indicated to have the worst prognosis. We also saw data from [using the] intrathecal and intravenous [IV] nivolumab combination for metastatic melanoma with leptomeningeal disease, [which showed] response in patients who had seen IV anti-CTLA4 and anti-PD-1 therapy and had progressed. ${ }^{10}$

We now have also shown the possibility of other checkpoint-checkpoint combinations to affect PFS. RELATIVITY-047 assessed [use of] the combination of anti-PD-1 and anti-LAG3 therapy in first-line unresectable and metastatic [disease] versus single-agent anti-PD-1 alone and showed an improvement of PFS among all subsets and all cohorts. ${ }^{11} \mathrm{We}$ are now moving some of these combinations into the neoadjuvant space and the adjuvant space. We are not standing still. Neoadjuvant combinatorial trials for stage III melanoma, including trials with pegylated IL2 and PD-1, are ongoing. ${ }^{12}$ There is a trial evaluating anti-LAG antibody [in combination with] anti-PD-1 therapy in stage III patients. ${ }^{13}$ There is a lot going on here. There is more to come.

Current clinical trials are also looking to decrease toxicity. Weber and others presented a trial of tocilizumab, an anti-IL-6 antibody, plus [an] anti-PD-1 [agent] plus anti-CTLA4 [therapy, which showed] decreased rates of grade 3 or 4 toxicity. ${ }^{14}$ We are hoping for this to mature andmove on to a randomized trial.

\section{What is the rationale for targeting LAG3 in melanoma?}

HAMID: LAG3 and PD-1 are distinct immune checkpoints often coexpressed on tumor-infiltrating lymphocytes, and they contribute to tumor- 
mediated T-cell exhaustion. LAG3 [expression] is increased in immune resistance and T-cell exhaustion. So, the idea and the ability to target both [of] these checkpoints has been around for an extended period of time. Paolo Ascierto showed data at ASCO previously of the ability to reinvigorate a T-cell response and get [a] response in about $12 \%$ of patients with metastatic melanoma that had progressed on single-agent PD-1 therapies. ${ }^{15}$ Therefore, it made sense to bring these combinations into first-line unresectable and metastatic melanoma.

\section{Where do you see anti-LAG3 inhibitors fitting into the standard of care for melanoma in the future, based on data we have seen in 2021?}

HAMID: The role of LAG3 inhibitors into standard of care in the future for melanoma is great. From early trials, there is evidence of a high response rate. Presented data in ASCO 2021 of fianlimab plus cemiplimab, which is [a combination of an] anti-LAG3 [agent] plus [an] anti-PD-1 [agent], in unresectable and metastatic melanoma showed a $66 \%$ response rate; in patients [with disease refractory to anti-PD-1 therapy,] there was a $13 \%$ response rate. ${ }^{16}$ That response rate held true in neoadjuvant clinical trials, including the one done with relatlimab and nivolumab presented at ASCO 2021 by Dr Amaria and others of [The University of Texas] MD Anderson Cancer Center. ${ }^{17}$ This regimen showed the possibility of greater response in the neoadjuvant setting and the possibility of greater pathologic complete response, which we believe leads to a greater benefit with immunotherapy. ${ }^{17}$ This regimen is also being taken into adjuvant stage III trials, hoping to improve our RFS, and, possibly, OS in the adjuvant setting. ${ }^{13}$

What is most striking is the combinatorial regimen has about an $18 \%$ grade 3 or 4 treatment-related toxicity, which is much less than any anti-CTLA4/ anti-PD-1 regimen. ${ }^{11}$ Where this regimen lacks support is in its [absence] of long-term follow-up data, long-term durability of response, and OS data. And we're hopeful that some of that data will be presented in upcoming meetings.

\section{Are there other immune - checkpoints we should be aware of?}

HAMID: There are other significant immune checkpoints that are coming forward. I'll just key on a couple of them. TIGIT is another checkpoint that has been looked at that has a greater foothold in lung cancer. A first-line trial with [an] antiTIGIT [agent] plus [an] anti-PD-L1 [agent] versus [treatment with an] anti-PD-L1 [agent] alone showed significant benefit in lung cancer, and these targets are being looked at in melanoma in triplet combinations. ${ }^{18}$ There's currently a trial that's ongoing with anti-PD-1, anti-LAG3, and anti-TIM3 checkpoint inhibitors in patients who have failed a firstline anti-PD-1 regimen. ${ }^{19}$ There are combinations of anti-CTLA4, anti-PD-1, and anti-TIM3 [agents] in first-line [therapy] and in refractory patients, so we're looking to figure out where these fit in and, hopefully, have the appropriate biomarkers. We will get to a place where we will have combinations that challenge us to choose the appropriate first-line and second-line therapy for our patients. The answers will come from the correlative work done on trials, such as CheckMate 067, RELATIVITY-047, and also some of the KEYNOTE studies. ${ }^{11,20}$

\section{What other immunotherapy I $=$ approaches are you watching closely?}

HAMID: The role of immunotherapy in melanoma is not just limited to checkpoint inhibitors. Of course, many people are familiar with the recent New England Journal of Medicine publication of tebentafusp, which is a bispecific antibody targeting CD3 and gp100. This has shown a survival benefit in patients with ocular melanoma. ${ }^{21}$ This is a type of melanoma that's been long associated with a lack of immune response and no indication of immune benefit. Clearly this drug is beneficial for patients and is in front of the [United States Food and Drug Administration (FDA)] for approval. This drug is also being looked at in patients with melanoma of the cutaneous and mucosal types. ${ }^{22}$ In standard cutaneous melanoma and mucosal melanoma, the role of adoptive T-cell therapy is being increased.

A trial exploring centrally produced tumor-infiltrating lymphocyte therapy has shown a $38 \%$ response rate in [patients with disease refractory to] anti-PD-1 [therapy] with durable response and manageable toxicity. ${ }^{23}$ We're clearly trying to understand its role in [patients for whom] anti-PD-1 [therapy has failed]. This is also being reviewed by the FDA for approval, and there are multiple similar trials that are upcoming for patients. We look forward to further information as it becomes available.

\section{KEY REFERENCES}

1. Carr S, Smith C, Wernberg J. Epidemiology and risk factors of melanoma. Surg Clin North Am. 2020;100(1):1-12. doi:10.1016/j.suc.2019.09.005

6. Lewis S, Cherk M, Nadebaum DP, Haydon AM. Survival outcomes predicted by irAEs on 18F-FDG-PET in response to PD-1 antibody therapy in metastatic melanoma. Ann Oncol. 2021;32(suppl 5):S867-S905. doi: 10.1016/j.annonc.2021.08.1437

7. Luke JJ, Rutkowski P, Queirolo P, et al. Pembrolizumab versus placebo after complete resection of high-risk stage II melanoma: Efficacy and safety results from the KEYNOTE-716 double-blind phase III trial. Ann Oncol. 2021;32(suppl 5):S1283-S1346. doi:https://doi. org/10.1016/j.annonc.2021.08.2116

11. Hodi FS, Tawbi HA, Lipson EJ, et al. Relatlimab (RELA) + nivolumab (NIVO) vs. NIVO in previously untreated metastatic or unresectable melanoma: Additional efficacy in RELATIVITY-047. Ann Oncol. 2021;32(suppl 5):S867-S905. doi:10.1016/j. annonc.2021.08.1421

21. Nathan P, Hassel JC, Rutkowski P, et al. Overall survival benefit with tebentafusp in metastatic uveal melanoma. N Engl J Med. 2021;385(13):1196-1206. doi:10.1056/NEJMoa2103485

For full reference list, visit https://www.gotoper.com/go/eeim21 
